BMI/OWTD-5

Distribution Category UC-802

BMI/OWTD --5

DE9 1000089

\title{
FRACFLO: Analytical Solutions for Two-Dimensional Transport of a Decaying Species in a Discrete Planar Fracture and Equidistant Multiple Parallel Fractures With Rock Matrix Diffusion
}

Technical Report

July 1990

A. Berge Gureghian

Office of Waste Technology Development

Battelle Energy Systems Group

7000 South Adams Street

Willowbrook, IL 60521

The content of this report was effective as of March 1989. This report was prepared by Battelle Energy Systems Group, Willowbrook, IL, under Contract No. DE-AC02-83CH10139 with the U.S. Department of Energy.

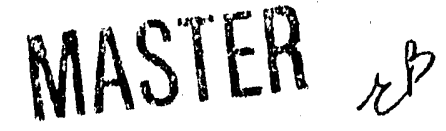




\section{ACKNOWLEDGMENTS}

Several people assisted in the preparation of this report. The authors would like to express their appreciation here for those efforts, which greatly helped the document reach its final form.

In particular, we would like to thank Dr. J. N. Ahn' of the Department of Nuclear Ergineering at the University of California at Berkeley, and Dr. G. Jansen, Jr., Westinghouse Hanford Company, for their review comments. L. Loebel, now with the Fermi Laboratory in Batavia, Illinois, systematically checked the data and enhanced the computer code. Finaliy, M. Steve assisted as Battelle Columbus Division technical editor and coordinated production of the various parts of the document with W. Young in Technical Illustrations and P. Dean and W: Veasey in Text Processing. 
ABSTRACT

Analytical solutions based on the Laplace and Fourier transformation techniques are derived for the transient advective-dispersive transport of a single radionuclide through fractures (twodimensional analysis) and rock (one-dimensional analysis). The longitudinal dispersion-free solution is also reported. The geometry considered consists of either a single planar fracture (infinite diffusion in the rock) or a system of equidistant parallel fracture planes with uniform aperture (finite diffusion in the rock). The solution assumes that the ground-water flow regime is under steady-state and isothermal conditions, and the streamlines along the direction of flow are parallel. The rock matrix is assumed to be homogeneous, isotropic, and saturated with stagnant water. The flow field is assumed to be semi-infinite in the horizontal direction normal to the source, and of either finite or infinite extent in the vertical direction orthogonal to the source. The initial concentration in both the fracture and the rock is assumed to be zero. The upstream boundary conditions exclusive to the fracture correspond to either a finite patch (single or multiple) source or a Gaussian distributed source, subject to a band or step release mode. In addition to the spatial and temporal concentration of the radionuclide in both fracture and rock, this solution also provides the mass flux and curnulative mass flux into the fracture.

The solution related to the single fracture case was verified by comparing its performance with available results from other works. Two sets of solutions were derived for the multiple parallel fracture case; the first, based on a series approximation, and the second, based on contour integration, were designed to cope efficiently with small and large Fourier numbers, respectively. Of interest in the case of the rock matrix, the solution based on contour integration is considerably simplified compared to previously reported or.es. This is achieved by eliminating the infinite scries summation incumbent to a convolution-based approach, which on the one hand limits its range of applicability and on the other hand undermines its computational viability. Numerical tests covering a wide range of Fourier numbers show excellent agreement between the proposed solutions. For the longitudirual dispersion-free solution, criteria are also reported for the applicability of the solution for a single iracture to the case of a multiple parallel fracture system.

The general solution requires, in both cases, the evaluation of a single integral, except in the case of the solution based on contour integration, where an additional one is required. This is performed using a Gauss-Legendre quadrature scheme.

$$
\mathrm{iii} / \mathrm{iv}
$$




\section{FOREWORD}

Following the passage of the Nuclear Waste Policy Act of 1982, the Civilian Radioactive Waste Management Program was organized in September 1983. The purpose of this program, managed by the U:S. Department of Energy (DOE), is to develop technology and provide facilities for safe, environmentally acceptable, permanent disposal of high-level waste (HLW). HLW includes wastes from both commercial and defense sources, such as spent (used) fuel from nuclear power reactuis, accumulations of wastes from production of nuclear weapons, and solidified wastes from fuel reprocessing.

The information in this report pertains to analytical solutions based on Laplace and Fourier transformation techniques used in studying ground-water flow with the FRACFLO code for the Repository Technology Program. This work was sponsored by the DOE Repository Technology and Transportation Division. 


\section{FEDERAL INFORMATION PROCESSING STANDARD SOFTWARE SUMMARY}

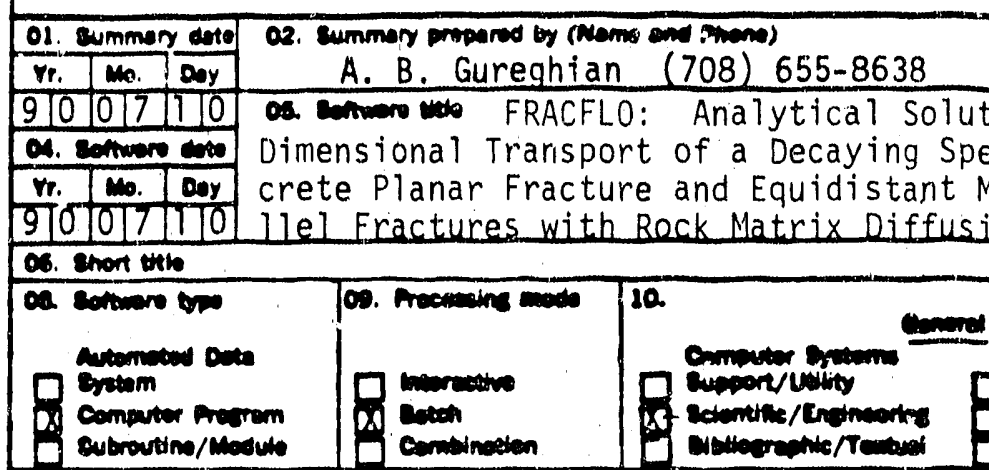

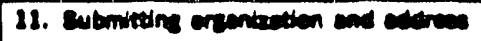

BATTELLE.E

Office of Waste Technology Development

7000 South Adams Street

Willowbrook IL 60521
03. Rumminy cetion

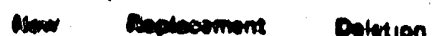

D

Tersion 10 Version 1

07. merned germere to Version 1.1

The FRACFLO code computes the two-dimensional, space-time-dependent, convectivedispersive transport of a single radionuclide in unbounded single or multiple parallel fracture system with constant aperture. It handles the one-dimensional diffusive transport into the rock matrix, as well as the mass flux and cumulative mass flux at any point in the fracture. Steady-state isothermal ground-water flow and parallel streamlines are assumed in the fracture, and the rock matrix is assumed to be fully saturated with immobile water. The model can handle a single or multiple finite patch source or a gaussian distributed source subject to a step or band release mode. The differential equations are solved by Laplace and Fourier transforms and a Gauss-Legendre integration scheme.

14. Konow Laplace and Fourier Transforms, Gauss-Legendre Integration, Radionuclide Transport, Analytical Solution, Convection-Dispersjon Diffusion, Radjoactive Decay, Retardation, Drie and Wo-Dimensions, Cancentration, Sjngle Fracture, Mültiple Fracture, kock Matrix, Máss Flux. Cumulative Mass, Isothermal, Parallel Streamlines, Step ahd Band Release Mode, Patch cr Gaussian Distribution Soursedaplace \& Eourier transfoms Gauss-Legendre jutegratior scheme.

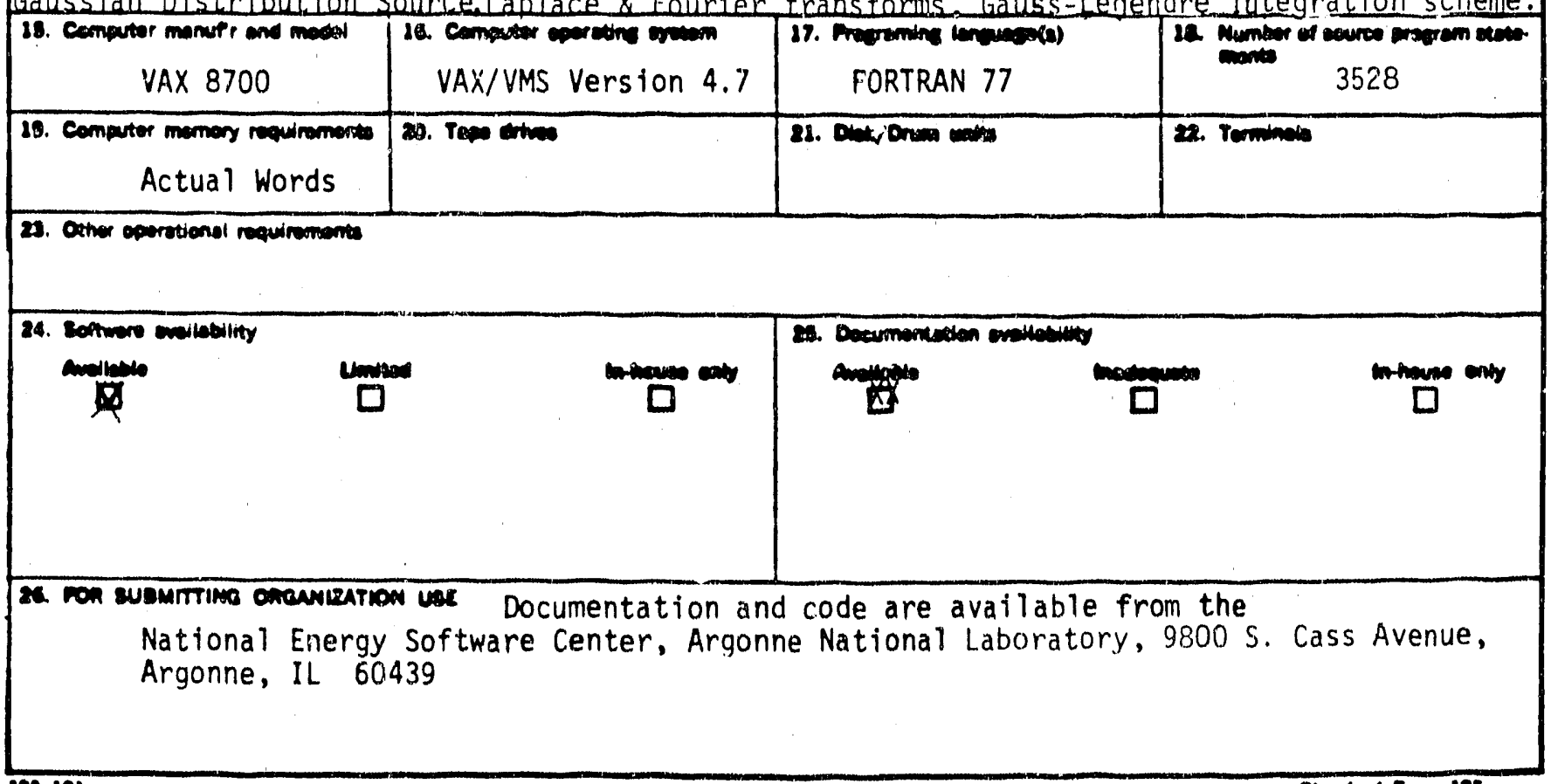




\section{TABLE OF CONTENTS}

Part 1

1.0 INTRODUCTION

1.1 BACKGROUND $\ldots \ldots \ldots \ldots \ldots \ldots \ldots \ldots \ldots \ldots \ldots \ldots \ldots \ldots \ldots \ldots \ldots \ldots$

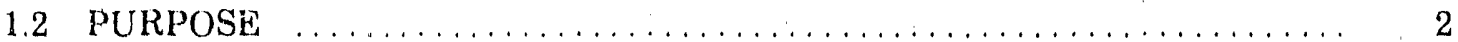

1.3 APPLICATIONS $\ldots \ldots \ldots \ldots \ldots \ldots \ldots \ldots \ldots \ldots \ldots \ldots \ldots \ldots \ldots$

2.0 MASS TRANSPORT EQUA'TIONS FOR FRACTURE AND ROCK MATRIX $\ldots \ldots .5$

2.1 INITIAL AND BOUNDARY CONDITIONS $\ldots \ldots \ldots \ldots \ldots \ldots \ldots \ldots \ldots$

2.1 .1 Fracture $\ldots \ldots \ldots \ldots \ldots \ldots \ldots \ldots \ldots \ldots \ldots \ldots \ldots \ldots \ldots \ldots \ldots \ldots$

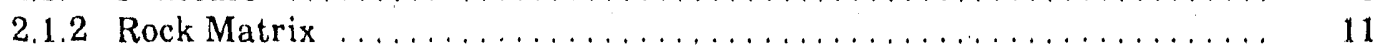

2.1.3 Concentration at the Source and Band Release $\ldots \ldots \ldots \ldots \ldots \ldots \ldots \ldots$

3.0 SINGLE FRACTURE CASE WITH INFINITE DIFFUSION FIELD $\ldots \ldots \ldots \ldots$

3.1 NON-ZERO LONGITUDINAL DISPERSION $\ldots \ldots \ldots \ldots \ldots \ldots \ldots \ldots \ldots \ldots$

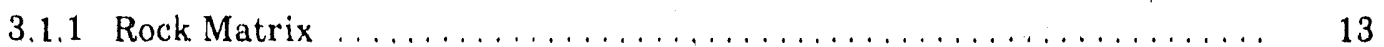

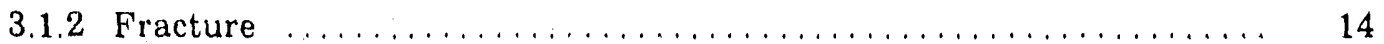

3.2 NO LONGITUDINAL DISPERSION $\ldots \ldots \ldots \ldots \ldots \ldots \ldots \ldots \ldots \ldots \ldots$

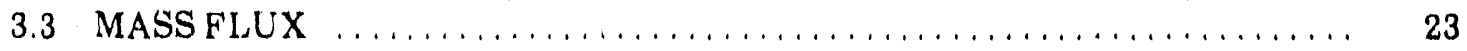

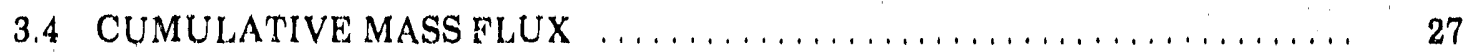

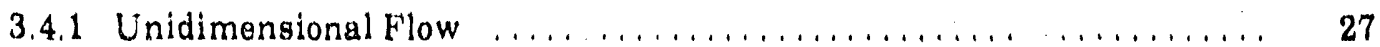

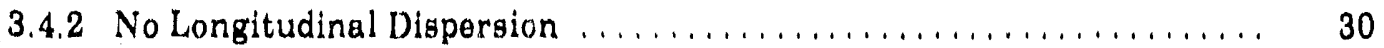

3.5 RESULTSAND DISCUSSIONS $\ldots \ldots \ldots \ldots \ldots \ldots \ldots \ldots \ldots \ldots \ldots \ldots \ldots \ldots$

3.5.1 Case 1: Concentration of Np-237 in a One-Dimensional

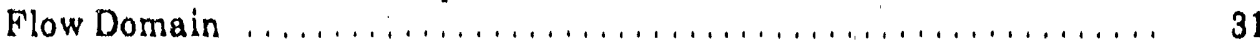

3.5.2 Case 2: Spatial and Time-Dependent Concentrations, Mass Flux, and Cumulative Mass Flux Subject to a Band Release Mode in the Absence of Longitudinal Dispersion $\ldots \ldots \ldots \ldots \ldots \ldots \ldots \ldots . . \ldots 9$

3.5.3 Case 3: Multiple Patch Source Subject to Step Release and Band Release $\ldots \ldots \ldots \ldots \ldots \ldots \ldots \ldots \ldots \ldots \ldots \ldots \ldots \ldots$

3.5.4 Case 4: Two-Dimensional Transport of Tc-99 in Fracture and Rock Matrix 


\section{TABLEOF CONTEN'S}

Part 2

4.0 MULTIPLE PARALLEL FRACTURE CASE WITH FINITE DIFFUSION

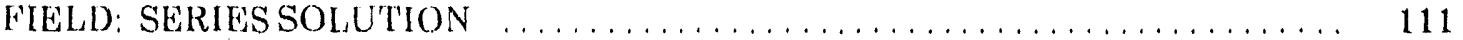

4.1 NON-ZERO LONGITUDINAL DISPERSION $\ldots \ldots \ldots \ldots \ldots \ldots \ldots \ldots \ldots, 111$

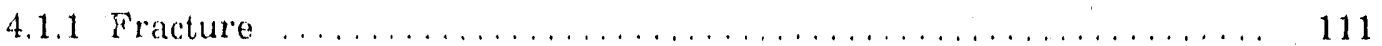

4.1 .2 Rock Matrix .................................... 119

4.1 .3 Mass Flux ........................................ 122

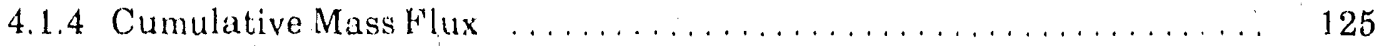

4.2 NOLONGITUDINAL DISPERSION $\ldots \ldots \ldots \ldots \ldots \ldots \ldots \ldots \ldots \ldots \ldots \ldots \ldots$

4.3 SOLUTION FOR BAND RELEASE $\ldots \ldots \ldots \ldots \ldots \ldots \ldots \ldots \ldots \ldots \ldots \ldots$

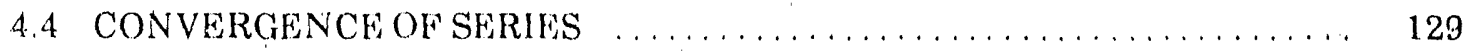

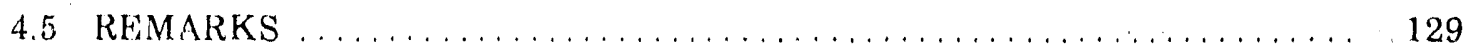

4.5 .1 Fracture ........................................ 130

4.5 .2 Rock ....................................... 131

5.0 MULTIPLE PARAILEL FRACTURE CASE WITH FINITE IDIFFUSION

FIELD: CONTOUR INTEGRATION $\ldots \ldots \ldots \ldots \ldots \ldots \ldots \ldots \ldots \ldots \ldots \ldots$

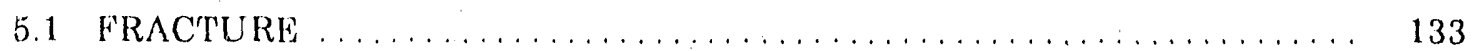

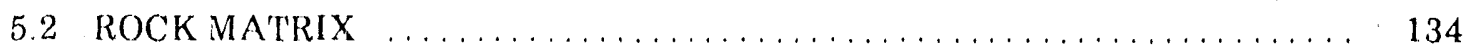

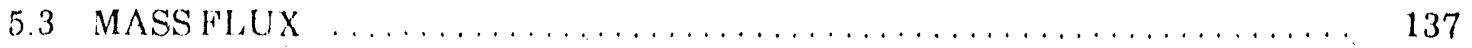

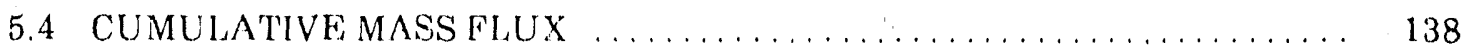

5.5 NO LONGITUDINAL DISPERSION $\ldots \ldots \ldots \ldots \ldots \ldots \ldots \ldots \ldots \ldots \ldots \ldots$

6.0 DISCUSSION AND RESULIS FOR MULTIPIA PARALLEL FRACTURE

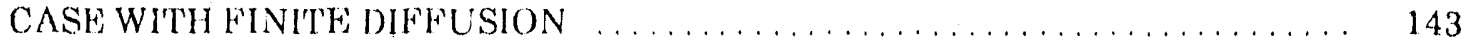

6.1 DISCUSSION OF CASE 5: SPATIAL VARIATION OF

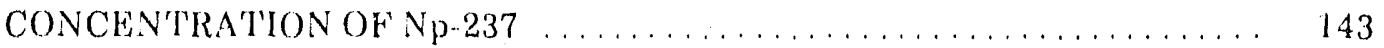

6.1.1 Results for Case 5A: Step Release Mode .................... 143

6.1.2 Results for Case 5B: Band Release Mode ................... 154 


\section{TABLE OF CONTENTS}

(Continued)

Page

6.2 DISCUSSION OF CASE 6: TEMPORAL VARIATION OF CONCENTRATION OF Np-237, INFLUENCE OF

LONGITUDINAL DISPERSION $\ldots \ldots \ldots \ldots \ldots \ldots \ldots \ldots \ldots \ldots \ldots \ldots \ldots \ldots$

\subsection{DISCUSSION OF CASE 7: TWO-DIMENSIONAL TRANSPORT}

OF T' .99 IN FRAC'TURE AND ROCK MATRIX $\ldots \ldots \ldots \ldots \ldots \ldots \ldots, 182$

$7.0 \quad$ SUMMARY AND CONCLUSIONS $\ldots \ldots \ldots \ldots \ldots \ldots \ldots \ldots \ldots \ldots \ldots \ldots \ldots$

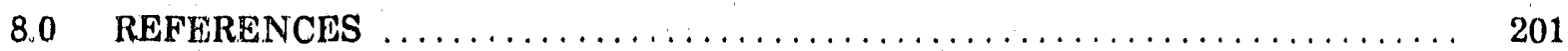

APPENDIX A. THEOREMS, LAPLACE TRANSFORMS, AND
DERIVATIVES $\ldots \ldots \ldots \ldots \ldots \ldots \ldots \ldots \ldots \ldots \ldots \ldots \ldots \ldots \ldots \ldots \ldots$

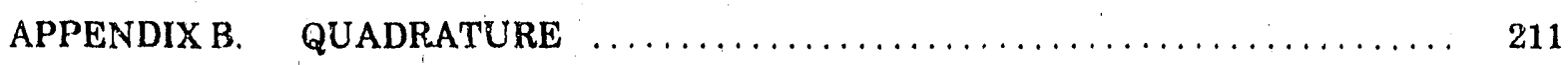

APPENDIX C. Nth DERIVATIVE OF A PRODUCT OF TWO FUNCTIONS . . . . . . 223

APPENDIX D. A COMPLEX DEFINITE INTEGRAL $\ldots \ldots \ldots \ldots \ldots \ldots \ldots \ldots$

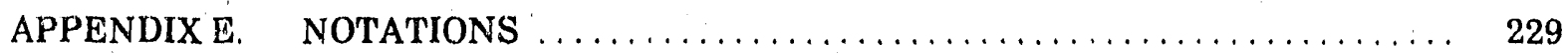

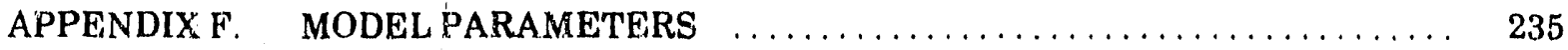




\section{LIST OF TABLES}

Table

Title

$\underline{\text { Page }}$

3-1. Input Parameters for Case 1

3-2a. Case 1A Results: Relative Concentration, Mass Flux, and Cumulative Mass Flux in the Fracture for Np-237 With Infinite Diffusion at Time $t=10^{4} \mathrm{yr}$ and Rock Matrix Retardation Factor $\mathrm{R}^{\prime}=1$

(Step Releuse Mode)

3-2b. Case 1A Results: Relative Concentration, Mass Flux, and Cumulative Mass Flux in the Fracture for Np-237 With Infinite Diffusion at

Time $\mathrm{t}=10^{4} \mathrm{yr}$ and Rock Matrix Retardation Factor $\mathrm{R}^{\prime}=100$

(Step Release Mode)

3-2c. Case 1A Results Relative Concentration, Mass Flux, and Cumulative

Mass Flux in the Fracture for Np-237 With Infinite Diffusion at

Time $t=10^{4}$ yr and Rock Matrix Retardation Factor $R^{\prime}=10,000$

(Step Release Mode)

3-2d. Case 1A Results: Relative Concentration in Rock Matrix $\left(\mathrm{B} / \mathrm{A}^{\circ}\right)$ for $\mathrm{Np}-237$

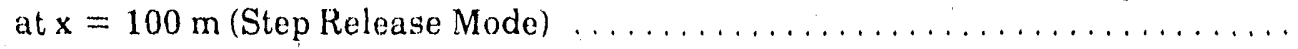

3-2e. Case 1A Results: Relative Concentration, Mass Flux, and Cumulative

Mass Flux in the Fracture for Np-237 Over Time With Rock Matrix

Retardation Factor $R^{\prime}=1$ (Step Release Mode) $\ldots \ldots \ldots \ldots \ldots \ldots \ldots$

3-2f. Case 1A Results: Relative Concentration, Mass Flux, and Cumulative

Mass Flux in the Fracture for $\mathrm{Np}$-237 Over Time With Rock Matrix

Retardation Factor R' $=100$ (Step Release Mode)

3-2g. Case 1A Results: Relative Concentration, Mass Flux, and Cumulative

Mass Flux in the F'racture for Np-237 Over Time With Rock Matrix

Retardation Factor $\mathrm{R}^{\prime}=10,000$ (Step Release Mode)

3-3a. Case 1B Results: Relative Concentration, Mass Flux, and Cumulative

Mass Flux in the Fracture for Np-237 With Infinite Diffusion at

Time $t=10^{4} \mathrm{yr}$ and Rock Matrix Retardation Factor $\mathrm{R}^{\prime}=1$

(Step Release Mode)

3-3b. Case 1B Results: Relative Concentration, Mass Flux, and Cumulative

Mass Flux in the Fracture for $\mathrm{Np}-237$ With Infinite Diffusion at

Time $\mathrm{t}=10^{4} \mathrm{yr}$ and Rock Matrix Retardation Factor $\mathrm{R}^{\prime}=100$

(Step Release Mode)

3-3c. Case 1B Results: Relative Concentration, Mass Flux, and Cumulative

Mass Flux in the Fracture for Np-237 With Infinite Diffusion at

T'ime $\mathrm{t}=10^{4} \mathrm{yr}$ and Rock Matrix Retardation Factor $\mathrm{R}^{\prime}=10,000$

(Step Release Mode) 


\section{LIST OF TABLES}

(Continued)

Table

Title

$\underline{\text { Page }}$

3-3d. Case 1B Results: Relative Concentration in Rock Matrix (B/A $\left.\mathrm{A}^{\circ}\right)$ for Np-237

at $x=100 \mathrm{~m}$ and $\mathrm{D}_{\mathrm{xx}}=0$ (Step Release Mode) $\ldots \ldots \ldots \ldots \ldots \ldots \ldots \ldots \ldots$

3-3e. Case 1B Results: Relative Concentration, Mass Flux, and Cumulative

Mass Flux in the Fracture for Np-237 Over Time With Rock Matrix

Retardation Factor $\mathbf{R}^{\prime}=1$ (Step Release Mode)

3-3f. Case 1B Results: Relative Concentration, Mass Flux, and Cumulative

Mass Flux in the Fracture for Np-237 Over Time With Rock Matrix

Retardation Factor $R^{\prime}=100$ (Step Release Mode) $\ldots \ldots \ldots \ldots \ldots \ldots \ldots \ldots$

3-3g. Case 1B Resulis: Relative Concentration, Mass Flux, and Cumulative

Mass Flux in the Fracture for Np-237 Over Time With Rock Matrix

Retardation Factor $R^{\prime}=10,000$ (Step Release Mode)

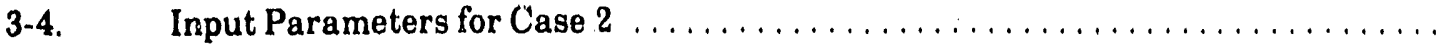

3-5a. Case 2 Results: Relative Concentration, Mass Flux, and Cumulative

Mass Flux in the Fracture for Np-237 with Infinite Diffusion at Time

$t=104 \mathrm{yr}$ and Ruck Mrtrix Retardation Factor $\mathrm{R}^{\prime}=1$ (Band

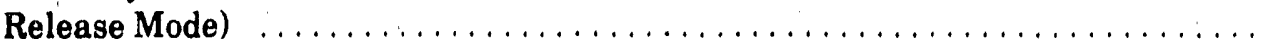

3-5b. Case 2 Results: Relative Concentration, Mass Flux, and Cumulative

Mass Flux in the Fracture for Np-237 at Time $t=10^{4} \mathrm{yr}$ and Rock

Matrix Retardation Factor $R^{\prime}=100$ (Band Release Mode)

3-5c. Case 2 Results: Relative Concentration, Mass Flux, and Cumulative

Mass Flux in the Fracture for Np-237 at Time $t=10^{4}$ yr and Rock

Matrix Retardation Factor $R^{\prime}=10,000$ (Band Release Mode)

3-6a. Case 2 Results: Relative Concentration in the Rock Matrix for

$\mathrm{Np}-237$ at Time $t=104 \mathrm{yr}$ and Rock Matrix Retardation Factor

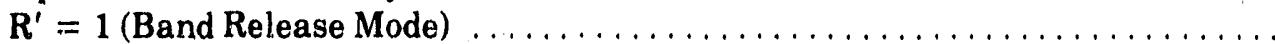

3-6b. Case 2 Results: Relative Concentration in the Rock Matrix for

Np-237 at Time $t=1 \times 10^{4} \mathrm{yr}$ and Rock Matrix Retardation

Factor $R^{\prime}=100$ (Band Release Mode)

3-6c. Case 2 Results: Relative Concentration in the Rock Matrix for

Np-237 at Time $t=10^{4} \mathrm{yr}$ and Rock Matrix Retardation Factor

$R^{\prime}=10,000$ (Band Release Mode)

3-7a. Case 2 Results: Relative Concentration, Mass Flux, and Cumulative Mass Flux in the Fracture for Np-237 Over Time with Rock Matrix

Reürdation Factor $\mathrm{R}^{\prime}=1$ (Band Release Mode) 


\section{LIS'T OF 'I'ABLES}

(Continued)

Table

Title

$\underline{\text { Page }}$

3.7b. Case 2 Results: Relative Concentration, Mass Flux, and Cumulative

Mass Flux in the Fracture for Np-237 Over Time With Rock Matrix

Retardation Factor $R^{\prime}=100$ (Band Release Mode)

3-7c. Case 2 Results: Relative Concentration, Mass Flux, and Cumulative Mass Flux in the Fracture for Np-237 Over Time with Rock Matrix Retardation Factor $\mathrm{R}^{\prime}=10,000$ (Band Release Mode)

3-8. Input Parameters for Case 3

3-9. Case 3 Results: Relative Concentration in Fracture $\left(A / A^{\circ}\right)$ for Cm-245

3-10. Input Parameters Used in Simulation of Tc-99 in Fracture and Rock Matrix for Case 4

3-11a. Case 4A Results: Relative Concentration in the Fracture $\left(A / A^{\circ}\right)$ of Species Tc-99 at Time $t=5 \times 10^{3} \mathrm{yr}$ and $\mathrm{z}=0 \mathrm{~m}$ (Finite Patch Source, Step Release Mode)

3-11b. Case 4A Results: Relative Concentration in the Fracture $\left(\mathrm{A} / \mathrm{A}^{\circ}\right)$ of Species Tc-99 at Time $t=2.2 \times 10^{4} \mathrm{yr}$ and $\mathrm{z}=0 \mathrm{~m}$ (Finite Patch Source, Band Release Mode)

3-11c. Case 4A Results: Relative Concentration in the Rock Matrix $\left(\mathrm{B} / \mathrm{A}^{\circ}\right)$ of Species Tc-99 at T'ime $t=5 \times 10^{3} \mathrm{yr}$ and $\mathrm{z}=1 \mathrm{~m}$ (Finite Patch Source, Step Release Mode)

3-11d. Case 4A Results: Relative Concentration in the Rock Matrix (B/A $)$ of Species Tc-99 at Time $t=2.5 \times 10^{4} \mathrm{yr}$ and $\mathrm{z}=1 \mathrm{~m}$ (Finite Patch Source, Band Release Mode)

3-11e. Case 4A Results: Relative Concentration in the Rock Matrix $\left(B / A^{\circ}\right)$

of Species Tc-99 at 'T'ime $t=5 \times 10^{3} \mathrm{yr}$ and $\mathrm{z}=5 \mathrm{~m}$ (Finite Patch

Source, Step Release Mode)

3-11f. Case 4A Results: Relative Concentration in the Rock Matrix $\left(B / \mathrm{A}^{\circ}\right)$ of Species Tc-99 at Time $t=2.5 \times 10^{4} \mathrm{yr}$ and $\mathrm{z}=5 \mathrm{~m}$ (Finite Patch Source, Band Release Mode)

3-12a. Case 4B Results: Relative Concentration in the Fracture $\left(A / A^{\circ}\right)$ of Species Te-99 at Time $t=5 \times 10^{4}$ yr (Multiple Patch Source,

Step Release.'Mode)

3-12b. Case 4B Results: X-Component of Relative Mass Flux in the Fracture $\left(F_{x} / A^{\circ}\right)(m / y r)$ of Species Tc-99 at Time $t=5 \times 10^{4} \mathrm{yr}$ (Multiple Patch Source, Step Release Mode) 


\section{LIST OF TABLES}

(Continued)

$\underline{\text { Table }}$

Title

$\underline{\text { Page }}$

3-12c. Case 4B Results: Y-Component of Relative Mass Flux in the Fracture

$\left(\mathrm{F}_{\mathrm{y}} / \mathrm{A}^{\circ}\right)(\mathrm{m} / \mathrm{yr})$ of Species Tc-99 at Time $t=5 \times 10^{4} \mathrm{yr}$ (Multiple Patch

Source, Step Release Mode)

3-12d. Case 4B Results: Relative Cumulative Mass. Flux in the Fracture

$\left(\mathrm{N}_{\mathrm{i}} / \mathrm{A}^{\circ}\right)$ of Species Tc-99 at Time $t=5 \times 10^{4} \mathrm{yr}$ (Multiple Patch Source,

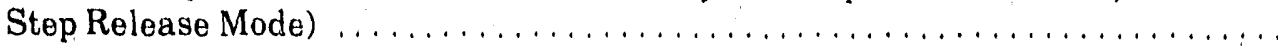

3-12e. Case 4B Results: Relative Concentration in the Rock Matrix (B/ $\left.\mathrm{A}^{\circ}\right)$

of Species Tc-99 at Time $t=5 \times 10^{4} \mathrm{yr}$ and $\mathrm{z}=1 \mathrm{~m}$ (Multiple Patch

Source, Step Release Mode)

3-12f. Case 4B Results: Relative Concentration in the Rock Matrix $\left(B / A^{\circ}\right)$

of Species Tc-99 at Time $t=5 \times 10^{4} \mathrm{yr}$ and $\mathrm{z}=5 \mathrm{~m}$ (Multiple Patch

Source, Step Release Mode)

3-12g. Case 4B Results: Relative Concentration in the Rock Matrix (B/A $)$

of Species Tc-99 at Time $t=5 \times 10^{4} \mathrm{yr}$ and $\mathrm{z}=10 \mathrm{~m}$ (Multiple Patch

Source, Step Release Mode)

101

3-13a. Case 4C Results: Relative Concentration in the Fracture $\left(\mathrm{A} / \mathrm{A}^{\circ}\right)$

of Species Tc-99 at Time $\mathrm{t}=5 \times 10^{3} \mathrm{yr}$ and $\mathrm{z}=0 \mathrm{~m}$ (Gaussian

Distributed Source, Step Release Mode)

3-13b. Case 4C Results: Relative Concentration in the Fracture

$\left(\mathrm{A} / \mathrm{A}^{\circ}\right)$ of Species Tc-99 at Time $\mathrm{t}=2.5 \times 10^{4} \mathrm{yr}$ and $\mathrm{z}=0 \mathrm{~m}$

(Gaussian Distributed Source, Band Release Mode)

3-13c. Case 4C Results: Relative Concentration in the Rock Matrix

$\left(\mathrm{B} / \mathrm{A}^{\circ}\right)$ of Species Tc- 99 at Time $t=5 \times 10^{3} \mathrm{yr}$ and $\mathrm{z}=1 \mathrm{~m}$

(Gaussian Distributed Source, Step Release Mode)

109

3-13d. Case 4C Results: Relative Concentration in the Rock Matrix (B/A $\left.{ }^{\circ}\right)$

of Species Tc-99 at Time $t=2.5 \times 10^{4} \mathrm{yr}$ and $\mathrm{z}=1 \mathrm{~m}$ (Gaussian

Distributed Source, Band Release Mode)

3-13e. Case 4C Results: Relative Concentration in the Rock Matrix $\left(\mathrm{B} / \mathrm{A}^{\circ}\right)$

of Species Tc-99 at Time $t=5 \times 10^{3} \mathrm{yr}$ and $\mathrm{z}=5 \mathrm{~m}$ (Gaussian

Distributed Source, Step Release Mode)

3-13f. Case 4C Results: Relative Concentration in the Rock Matrix (B/A $\left.{ }^{\circ}\right)$

of Species Tc-99 at Time $t=2.5 \times 10^{4} \mathrm{yr}$ and $\mathrm{z}=5 \mathrm{~m}$ (Gaussian

Distributed Source, Band Release Mode)

4-1. Sets of Values for Equations 4-30a Through 4-30e

6-1. Input Parameters for Case 5 


\section{LIST OF TABLES}

(Continued)

Táble

Title

Page

6-2a. Case 5A Results: Cumparison of Relative Concentration, Mass Flux, and Cumulative Mass Fluz: in the Fracture for Np-237 at Time $t=10^{4} \mathrm{yr}$

(Step Release Mode)

6-2b. Case 5A Results: Comparison of Relative Concentration, Mass Flix, and Cumulative Mass Flux in the Fracture for Np-237 at Time $t=6 \times 10^{4} \mathrm{yr}$ (Step Release Mode)

6-2c. Case 5A Results: Comparison of Relative Concentration, Mass Flux, and Cumulative Mass Flux in Fracture for Np-237 at Time $t=2 \times 10^{5} \mathrm{yr}$ (Step Release Mode)

6-2d. Case 5A Results: Comparison of Relative Concentration, Mass Flux, and Cumlative Mass Flux in the Fracture for $\mathrm{Np}-237$ at Time $t=10^{6} \mathrm{yr}$ (S+ep Relcase Mode)

6-2e. Case 5A Results: Comparison of Relative Concentration in the Rock Matrix for $\mathrm{Np}$-237 for Different 'l'imes at Longitudinal Distance $\mathrm{x}=100 \mathrm{~m}$ (Step Release Mode)

6-3a. Case 5B Results: Comparison of Relative Concentration, Mass Flux, and Cumulative Mass Flux in the Fracture for Np-237 at Time $t=6 \times 10^{4} \mathrm{yr}$ (Band Release Mode)

6-3b. Case 5B Results: Cornparison of Relative Concentration, Mass Flux, and Cumulative Mass Flux in the Fracture for Np-237 at Time $t=2 \times 10^{5} \mathrm{yr}$ (Band Release Mode)

6-3c. Case 5B Results: Comparison of Relative Concentration, Mass Flux, and Cumulative Mass Flux in the Frecture for Np-237 at Time $t=10^{6} \mathrm{yr}$ (Band Release Mode)

6-i Case 5B Results: Comparison of Relative Concentration in the Rock Matrix for Np-237 for Different Times at Longitudinal Distance $x=100 \mathrm{~m}$ (Band Release Mode)

6-4. Input Parameters for Case 6

6-5a. Case 6A Results: Comparison of Relative Concentration, Mass Flux, and Cumulative Mass Flux in the Fracture for Np-237 at $x=500 \mathrm{~m}, \mathrm{D}_{\mathrm{xx}}=0$

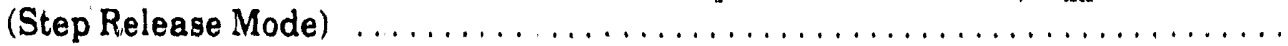

6-5b. Case 6A Results: Comparison of Relative Concentration, Mass Flux, and Cumulative Mass Flux in the Fracture for Np-237 at $x=500 \mathrm{~m}$, $D_{x x}=10 \mathrm{~m}^{2 / y r}$ (Step Release Mode) 


\section{LIST OF TABLES}

(Continued)

$\underline{\text { Table }}$

$\underline{\text { Title }}$

$\underline{\text { Page }}$

6-5c. Case 6A Results: Comparison of Relative Concentration, Mass Flux, and

Cumulative Mass Flux in the Fracture for Np-237 at $x=500 \mathrm{~m}$,

$\mathrm{D}_{\mathrm{xx}}=100 \mathrm{~m}^{2} / \mathrm{yr}$ (Sten Release Mode)

174

6-5d. Case 6A Results: Comparison of Relative Concentration, Mass Flux, and

Cumulative Mass Flux in the Fracture for Np-237 at $x=500 \mathrm{~m}$,

$D_{\mathrm{xx}}=1000 \mathrm{~m}^{2 / y r}$ (Step Release Mode)

6-5e. Case 6A Results: Comparison of Temporal Variation of Relative Concentration in the Rock Matrix for $\mathrm{Np}-237$ for Different $\mathrm{D}_{\mathrm{xx}}$ at Longitudinal Distance

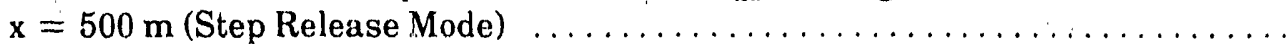

6-óa. Case 6B Results: Comparison of Relative Concentration, Mass Flux, and

Cumulative Mass Flux in the Fracture for Np-237 at $\mathrm{x}=500 \mathrm{~m}$,

$\mathrm{D}_{\mathrm{xx}}=0$ (Band Release Mode)

6-6b. Case 6B Results: Comparison of Relative Concentration, Mass Flux, and

Cumulative Mass Flux in the Fracture for $\mathrm{Np}-237$ at $\mathrm{x}=500 \mathrm{~m}$,

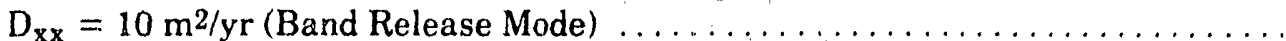

6-6c. Case 6B Results: Comparison of Relative Concentration, Mass Flux, and

Cumulative Mass Flux in the Fracture for Np-237 at $\mathrm{x}=500 \mathrm{~m}$,

$D_{\mathrm{xx}}=100 \mathrm{~m}^{2} / \mathrm{yr}$ (Band he.ease Mode)

6-6d. Case 6B Results: Comparison of Relative Concentration, Mass Flux, and

Cumulative Mass Flux in the Fracture for Np-237 at $x=500 \mathrm{~m}$,

$\mathrm{D}_{\mathrm{xx}}=1,000 \mathrm{~m}^{2 / \mathrm{yr}}$ (Band Release Mode).

6-6e. Case 6B Results: Comparison of Temporal Variation of Relative

Concentration in the Rock Matrix for Np-237 for Different $D_{x x}$ at

Longitudinal Distance $\mathrm{x}=500 \mathrm{~m}$ (Band Release Mode) $\ldots \ldots \ldots \ldots \ldots$

6-7. Input Parameters Used in Simulation of Tc-99 in Fracture and

Rock Matrix for Case?

6-8a. Case 7 Results: Relative Concentration in the Fracture $\left(\mathrm{A} / \mathrm{A}^{\circ}\right)$ of

Species Tc-99 at Time t $=5 \times 10^{4}$ yr (Multiple Patch Source)

6-8b. Case 7 Results: X-Component of Relative Mass Flux in the Fracture $\left(F_{x} / A^{\circ}\right)$

$(\mathrm{m} / \mathrm{yr})$ of Species Tc-99 at Time $t=5 \times 10^{4} \mathrm{yr}$ (Multiple Patch Source) $\ldots \ldots \ldots$

6-8c. Case 7 Results: Y-Component of Relative Mass Flux in the Fracture $\left(F_{y} / A^{\circ}\right)$

$(\mathrm{m} / \mathrm{yr})$ of Species Tc-99 at Time $\mathrm{t}=5 \times 10^{4}$ (Multiple Patch Source) $\ldots \ldots \ldots \ldots$

6-8d. Case 7 Results: Relative Cumulative Mass Flux in the Fracture (M/A $\left.{ }^{\circ}\right)$

of Species Tc-99 at Time $t=5 \times 10^{4} \mathrm{yr}$ (Multiple Patch Source) 


\section{LIST OF TABLES}

(Continued)

Table

Title

Page

6-8e. Case 7 Results: Relative Concentration in the Rock Matrix $\left(\mathrm{B} / \mathrm{A}^{\circ}\right)$ of Species Tc-99 at Time $t=5 \times 10^{4} \mathrm{yr}$ and $\mathrm{z}=0.1 \mathrm{~m}$ (Multiple

Patch Source)

6-8f. Case 7 Results: Relative Concentration in the Rock Matrix $\left(B / A^{\circ}\right)$ of Species Tc-99 at Time $t=5 \times 10^{4} \mathrm{yr}$ and $\mathrm{z}=0.5 \mathrm{~m}$ (Multiple

Patch Source)

6-8g. Case 7 Results: Re'ative Concentration in the Rock Matrix $\left(3 / \mathrm{A}^{\circ}\right)$ of Species Tc-99 at Time $t=5 \times 10^{4} \mathrm{yr}$ and $\mathrm{z}=1.0 \mathrm{~m}$ (Multiple Patch

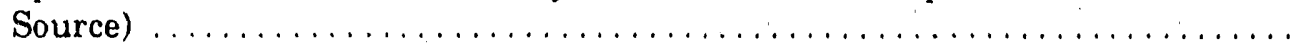

B-1. Parameters Used to Estimate $G(\eta), g_{1}(\eta)$, and $g_{2}(\eta, t) \ldots \ldots \ldots \ldots \ldots \ldots \ldots$

B-2. Quadrature Points Required for Selected Range of Values of $\mathrm{F}_{0}$ and $\varepsilon / 2 \sqrt{t-R_{X}}\left(D_{x}=0\right)$ 


\section{LIST OF FIGURES}

$\underline{\text { Figure }}$

Title

Page

2-1. Schematic of a Single Fracture Rock System $\ldots \ldots \ldots \ldots \ldots \ldots \ldots \ldots \ldots$

2-2. Schematic of Multiple Parallel Fracture Rock System $\ldots \ldots \ldots \ldots \ldots \ldots \ldots \ldots$

3-1a. Relative Concentrations of Np-237 in the Fracture Versus

Longitudinal Distance $x$ at $y=0 \mathrm{~m}$ and $t=10^{4} \mathrm{yr}$ for

Different Rock Matrix Retardation Factors $\left(R^{\prime}=1,10^{2}\right.$,

104)' (Case 1A: Step Release Mode,

3-1b. Relative Concentrations of Np-237 in the Rock Matrix Versus Distance

in the Rock Matrix $\mathrm{z}$ at $\mathrm{x}=100 \mathrm{~m}, \mathrm{y}=0 \mathrm{~m}$, and $\mathrm{t}=10^{4} \mathrm{yr}$ for

Different Rock Matrix Retardation Factors $\left(R^{\prime}=1,10^{2}, 10^{4}\right)$

(Case 1A: Step Release Mode)

3-1c. Relative Mass Flux of Np-237 in the Fracture Versus Distance

$x$ at $y=0 \mathrm{~m}$ and $\mathrm{t}=10^{4} \mathrm{yr}$ for Different Rock Matrix Retardation

Factors $\left(R^{\prime}=1,10^{2}, 10^{4}\right)$ (Case 1A: Step Release Mode) $\ldots \ldots \ldots \ldots \ldots$

3-1d. Relative Cumulative Mass Flux of Np-237 in the Fracture Versus

Longitudinal Distance $\mathrm{x}$ at $\mathrm{y}=0 \mathrm{~m}$ and $\mathrm{t}=10^{4} \mathrm{yr}$ for Different

Rock Matrix Retardation Factors $\left(R^{\prime}=1,10^{2}, 10^{4}\right)$ (Case 1A:

Step Release Mode)

3-1e. Breakthrough Curves Showing Relative Concentrations of

$\mathrm{Np}-237$ in the Fracture Versus Time at $\mathrm{x}=100 \mathrm{~m}$ and

$\mathrm{y}=\mathrm{O} \mathrm{n}$, for Different Rock Matrix Retardation Factors

$\left(R^{\prime}=1,10^{2}, 104\right)($ Case 1A: Step Release Mode) $\ldots \ldots \ldots \ldots \ldots \ldots \ldots \ldots$

3-1f. Relative Mass Flux of Np-237 in the Fracture Versus Time

at $\mathrm{x}=100 \mathrm{~m}$ and $\mathrm{y}=0 \mathrm{~m}$ for Different Rock Matrix

Retardation Factors $\left(R^{\prime}=1,10^{2}, 10^{4}\right)$ (Case 1A: Step

Release Mode)

3-1g. Relative Cumulative Mass Flux of $\mathrm{Np}-237$ in the Fracture

Versus Time at $\mathrm{x}=100 \mathrm{~m}$ and $\mathrm{y}=0 \mathrm{~m}$ for Different Rock

Matrix Retardation Factors $\left(R^{\prime}=1,10^{2}, 10^{4}\right)$ (Case 1A:

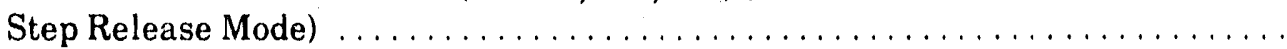

3-2a. Relative Concentrations of Np-237 in the Fracture Versus

Longitudinal Distance $x$ at $y=0 \mathrm{~m}, t=10^{4} \mathrm{yr}$, and

$\mathrm{D}_{\mathrm{xx}}=0$ for Different Rock Matrix Retardation Factors

$\left(R^{\prime}=1,10^{2}, 10^{4}\right)$ (Case 1B: Step Release Mode)

3-2b. Relative Concentrations of Np-237 in the Rock Matrix Versus

Distance in the Rock Matrix at $x=100 \mathrm{~m}, \mathrm{y}=0 \mathrm{~m}$,

$t=10^{4} \mathrm{yr}$, and $D_{\mathrm{xx}}=0$ for Different Rock Matrix Retardation

Factors $\left(R^{\prime}=1,10^{2}, 10^{4}\right)$ (Case 1B: Step Release Mode ) ................ 


\title{
LIST OF FIGURES
}

\author{
(Continued)
}

Figure.

Title

$\underline{\text { Page }}$

3-2c. Relative Mass Flux of Np-237 in the Fracture Versus Distance $x$ at $y=0 \mathrm{~m}, t=10^{4} \mathrm{yr}$, and $\mathrm{D}_{\mathrm{xx}}=0$ for Different Rock Matrix Retardation Factors $\left(R^{\prime}=1,10^{2}, 10^{4}\right)$ (Case 1B: Step Release Mode) $\ldots \ldots \ldots$

3-2d. Relative Cumulative Mass Flux of $\mathrm{Np}-237$ in the Fracture Versus Longitudinal Distance $x$ at $y=0 \mathrm{~m}, t=10^{4} \mathrm{yr}$, and $D_{\mathrm{xx}}=0$ for Different Rock Matrix Retardation Factors $\left(\mathrm{R}^{\prime}=1,10^{2}, 10^{4}\right)$ (Case 1B: Step Release Mode) $\ldots \ldots \ldots \ldots \ldots \ldots \ldots$

3-2e. Breakthrough Curves Showing the Relative Concentration of Np.237 in the Fracture Versus Time at $x=100 \mathrm{~m}, y=0 \mathrm{~m}$, and $\mathrm{D}_{\mathrm{xx}}=0$ for Different Rock Matrix Retardation Factors $\left(R^{\prime}=1,10^{2}, 10^{4}\right)$ (Case 1B: Step Rielease Mode)

3-2f. Relative Mass Flux of Np-237 in the Fracture Versus Time at $x=100 \mathrm{~m}, \mathrm{y}=0 \mathrm{~m}$, and $\mathrm{D}_{\mathrm{xx}}=0$ for Different Rock Matrix Retardation Factors $\left(R^{\prime}=1,10^{2}, 10^{4}\right)$ (Case 1B: Step Release Mode) .......

3-2g. Relative Cumulative Mass Flux of Np-237 in the Fracture Versus Time at $\mathrm{x}=100 \mathrm{~m}, \mathrm{y}=0 \mathrm{~m}$, and $\mathrm{D}_{\mathrm{xx}}=0$ for Different Rock Matrix Retardation Factors $\left(R^{\prime}=1,10^{2}, 10^{4}\right)$ (Case 1B: Step Release Mode) .

3-3a. Relative Concentrations of Np-237 in the Fracture Versus Longitudinal Distance $x$ at $y=0 \mathrm{~m}, t=10^{4} \mathrm{yr}$, and $D_{x x}=0$ for Different Rock Matrix Retardation Factors $\left(R^{\prime}=1,10^{2}, 10^{4}\right)$ (Case 2: Band Release Mode)

3-3b. Relative Mass Flux in the Fracture Versus Distance $x$ at $y=0 \mathrm{~m}, \mathrm{t}=10^{4} \mathrm{yr}$, and $\mathrm{D}_{\mathrm{xx}}=0$ for Different Rock Matrix Retardation Factors $\left(R^{\prime}=1,10^{2}, 10^{4}\right)$ (Case 2: Band Release Mode) . .......

3-3c. Relative Cumulative Mass Flux of $\mathrm{Np}-237$ in the Fracture Versus Longitudinal Distance $x$ at $y=0 \mathrm{~m}, t=10^{4} \mathrm{yr}$, and $D_{x x}=0$ for Different Rock Retardation Matrix Factors $\left(R^{\prime}=1,10^{2}\right.$,

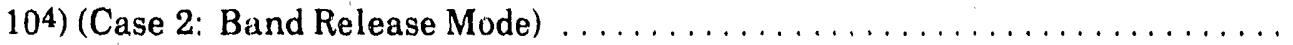

3-3d. Relative Concentrations of Np-237 in the Rock Matrix Versus Distance in the Rock Matrix at $x=100 \mathrm{~m}, \mathrm{y}=0 \mathrm{~m}, \mathrm{t}=10^{4} \mathrm{yr}$, and $D_{x x}=0$ for Different Rock Matrix Retardation Factors $\left(R^{\prime}=1,10^{2}\right.$, 104) (Case 2: Band Release Mode) . . . . . . . . . . . . . . . . . . . . . . .

3-4a. Breakthrough Curves Showing the Relative Concentration of Np-237 in the Fracture Versus Time at $x=100 \mathrm{~m}, \mathrm{y}=0 \mathrm{~m}$, and $D_{\mathrm{xx}}=0$ for Different Rock Matrix Retardation Factors $\left(R^{\prime}=1,10^{2}, 10^{4}\right)$ (Case 2: Band Release Mode) 


\section{LIST' OF FIGURES}

(Continued)

Figure

Title

Page

3-4b. Relative Mass Flux of Np-237 in the Fracture Versus Time at $\mathrm{x}=100 \mathrm{~m}, \mathrm{y}=0 \mathrm{~m}$, and $\mathrm{D}_{\mathrm{xx}}=0$ for Different Rock Matrix Retardation

Factors $\left(R^{\prime}=1,10^{2}, 10^{4}\right)$ (Case 2: Band Release Mode) $\ldots \ldots \ldots \ldots \ldots \ldots$

3-4c. Relative Cumulative Mass Flux of Np-237 in the Fracture

Versus Time at $\mathrm{x}=100 \mathrm{~m}, \mathrm{y}=0 \mathrm{~m}$, and $\mathrm{D}_{\mathrm{xx}}=0$ for

Different Rock Matrix Retardation Factors $\left(\mathrm{R}^{\prime}=1,10^{2}, 10^{4}\right)$

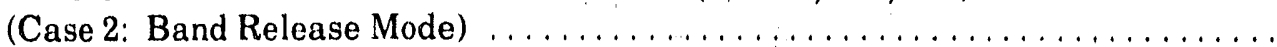

3-5a. Relative Concentration Isopleths for Tc-99 in the Fracture at $\mathrm{z}=0 \mathrm{~m}$

and $t=5 \times 10^{3} \mathrm{yr}$, Step Release Mode (Case 4A: Finite Patch Source) . . . . . .

3-5b. Relative Concentration Isopleths for Tc-99 in the Fracture at $\mathrm{z}=0 \mathrm{~m}$ and

$\mathrm{t}=2.5 \times 10^{4} \mathrm{yr}$, Band Release Mode (Case 4A: Finite Patch Source) ........

3-5c. Relative Concentration Isopleths for Tc-99 in the Rork Matrix at $\mathrm{z}=1 \mathrm{~m}$ and $t=5 \times 10^{3}$ yr, Step Release Mode (Case 4A: Finite Patch Source) .......

3-5d. Relative Concentration Isopleths for Tc-99 in the Rock Matrix at $z=1 \mathrm{~m}$ and $t=2.5 \times 10^{4} \mathrm{yr}$, Band Release Mode (Case 4A: Finite Patch Source) ....

3-5e. Relative Concentration Isopleths for 'Tc-99 in the Rock Matrix at $\mathrm{z}=5 \mathrm{~m}$ and $t=5 \times 10^{3}$ yr, Step Release Mode (Case 4A: Finite Patch Source) . ......

3-5f. Relative Concentration Isopleths for Tc-99 in the Rock Matrix at $\mathrm{z}=5 \mathrm{~m}$ and $t=2.5 \times 10^{4} \mathrm{yr}$, Band Release Mode (Case 4A: Finite Patch Source) ......

3-6a. Relative Concentration Profiles for Tc-99 in the Fracture at $\mathrm{z}=0 \mathrm{~m}$ and $\mathrm{t}=5 \times 10^{4} \mathrm{yr}$ (Case 4B: Multiple Patch Source)

3-6b. Relative Mass Flux Profiles for Tc-99 in the Fracture at $\mathrm{z}=0 \mathrm{~m}$ and $t=5 \times 10^{4}$ yr (Case 4B: Multiple Patch Source)

3-6c. Mass Flux Vector of Tc-99 at Discrete Points in the Fracture at $\mathrm{z}=0 \mathrm{~m}$ and $\mathrm{t}=5 \times 10^{4} \mathrm{yr}$ (Case 4B: Multiple Patch Source) $\ldots \ldots \ldots \ldots \ldots \ldots$

3-6d. Relative Cumulative Mass Flux Profiles for Tc-99 in the Fracture at $\mathrm{z}=0 \mathrm{~m}$ and $\mathrm{t}=5 \times 10^{4} \mathrm{yr}$ (Case $4 \mathrm{~B}:$ Multiple Patch Source) $\ldots \ldots \ldots \ldots$

3-6e. Relative Concentration Profiles for 'Tc-99 in the Rock Matr'ix at $\mathrm{z}=1 \mathrm{~m}$ and $\mathrm{t}=5 \times 10^{4} \mathrm{yr}$ (Case 4B: Multiple Patch Source)

3-6f. Relative Concentration Profiles for Tc-99 in the Rock Matrix at $\mathrm{z}=5 \mathrm{~m}$ and $\mathrm{t}=5 \times 10^{4} \mathrm{yr}$ (Case 4B: Multiple Patch Source)

3-6g. Relative Concentration Profiles for Tc-99 in the Rock Matrix at $\mathrm{z}=10 \mathrm{~m}$ and $\mathrm{t}=5 \times 10^{4} \mathrm{yr}$ (Case 4B: Multiple Patch Source) 


\title{
LIST OF FIGURES
}

\author{
(Continued)
}

Figure

Title

Page

3-7a. Relative Concentration Isopleths for TC-99 in the Fracture at

$\mathrm{z}=0 \mathrm{~m}$ and $\mathrm{t}=5 \times 10^{3} \mathrm{yr}$ (Case $4 \mathrm{C}$ : Gaussian Distributed Source) $\ldots \ldots \ldots$

3-7b. Relative Concentration Isopleths for ' $\mathrm{Tc}-99$ in the Fracture

at $\mathrm{z}=0 \mathrm{~m}$ and $\mathrm{t}=2.5 \times 10^{4} \mathrm{yr}$, Band Release Mode

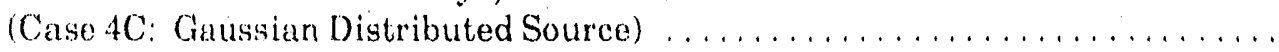

3-7c. Relative Concentration Isopleths for Tc-99 in the Rock Matrix at

$z=1 \mathrm{~m}$ and $\mathrm{t}=5 \times 10^{3} \mathrm{yr}$, Step Release Mode

(Case 4C: Gaussian Distributed Source)

3-7d. Relative Concentration Isopleths for Tc-99 in the Rock Matrix at

$z=1 \mathrm{~m}$ and $\mathrm{t}=2.5 \times 10^{4} \mathrm{yr}$, Band Release Mode

(Case 4C: Gaussian Distributed Source)

3 7. Relative Concentration Isopleths for T'-99 in the Rock Matrix at

$z=5 \mathrm{~m}$ and $t=5 \times 10^{3} \mathrm{yr}$, Step Release Mode

(Case 4C: Gaussian Distributed Source).

3-7f. Relative Concentration Isopleths for Te-99 in the Rock Matrix at

$\mathrm{z}=5 \mathrm{~m}$ and $\mathrm{t}=2.5 \times 10^{4} \mathrm{yr}$, Band Release Mode

(Case 4C: Gaussian Distributed Source) ........................

6.1a. Comparison of Spatial Variation of Relative Concentration of

$\mathrm{Np}-237$ in the Fracture for Different 'Times (Case 5A: Multiple

Parallel Fractures, Step Release Mode, No Longitudinal Dispersion) . . . . . . .

6-1b. Comparison of Spatial Variation of Relative Mass Flux of

$\mathrm{Np} .237$ in the Fracture for Different Times (Case 5A: Multiple

Parallel Fractures, Step Release Mode, No Longitudinal Dispersion)

6-1c. Comparison of Spatial Variation of Relative Cumulative Mass Flux

of Np.237 in the Fracture for Different Times (Case 5A: Multiple

Parallel Fractures, Step Release Mode, No Longitudinal Dispersion) . ........

6-1d. Comparison of Spatial Variation of Relative Concentration of Np-237 in the Ruck Matrix for Different Times (Case 5A: Multiple Parallel Fractures, Step Release Mode, No Longitudinal Dispersion) . . . . . . .

6.2a. Comparison of Spatial Variation of Relative Concentration of $\mathrm{Np} \cdot 237$ in the Fracture for Different Times (Case 5B: Multiple Parallel Fractures, Band Release Mode, No Longitudinal Dispersion) 


\section{LIST OF' FIGURES}

(Continued)

Figure

Title

Page

6-2b. Comparison of Spatial Variation of Relative Mass Flux of

No.237 in the Fracture for Different Times (Case 5B: Multiple

Parallel Fractures, Band Release Mode; No Longitudinal Dispersion) . . . . . . .

6-2c. Comparison of Spatial Variation of Relative Cumulative Mass Flux

of $\mathrm{Np}-237$ in the Fracture for Different Times (Case 5B: Multiple

Parallel Fractures, Band Release Mode, No Longitudinal Dispersion) ........

6-2d. Comparison of Spatial Variation of Relative Concentration of

Np-237 in the Rock Matrix for Different Times (Case 5B: Multiple

Parallel Fractures, Band Release Mode, No Longitudinal Dispersion) . . . . . . .

6-3a. Comparison of Temporal Variation of Relative Concentration of

$\mathrm{Np}-237$ in the Fracture for $D_{x x}=0,10,100,1000 \mathrm{~m}^{2} / \mathrm{yr}$

(Case 6A: Multiple Parallel Fractures, Step Release Mode)

6-3b. Comparison of Temporal Variation of Relative Mass Flux of

$\mathrm{Np}-237$ in the Fracture for $D_{x x}=0,10,100,1000 \mathrm{~m}^{2} / \mathrm{yr}$

(Case 6A: Multiple Parallel Fractures, Step Release Mode)

6-3c. Comparison of Temporal Variation of Relative Cumulative Mass

Flux of Np-237 in the Fracture for $D_{x x}=0,10,100,1000 \mathrm{~m}^{2} / \mathrm{yr}$

(Case 6A: Multiple Parallel Fractures, Step Release Mode)

6-3d. Comparison of Temporal Variation of Relative Concentration of $\mathrm{Np}-237$

in the Rock Matrix at Elevation $z=0.3 \mathrm{~m}$ for $D_{x x}=0,10,100,1000 \mathrm{~m}^{2} / \mathrm{yr}$

(Case 6A: Multiple Parallel Fractures, Step Release Mode)

6-4a. Comparison of Temporal Variation of Relative Concentration of

$\mathrm{Np}-237$ in the Fracture for $\mathrm{D}_{\mathrm{xx}}=0,10,100,1000 \mathrm{~m}^{2} / \mathrm{yr}$

(Case 6B: Multiple Parallel Fractures, Band Release Mode) . . . . . . . . . . . .

6-4b. Comparison of Temporal Variation of Relative Mass Flux of

$\mathrm{Np}$-237 in the Fracture for $\mathrm{D}_{\mathrm{xx}}=0,10,100,1000 \mathrm{~m}^{2} / \mathrm{yr}$

(Case 6B: Multiple Parallel Fractures, Band Release Mode)

6-4c. Comparison of Temporal Variation of Relative Curnulative Mass

Flux of $\mathrm{Np}-237$ in the Fracture for $\mathrm{D}_{\mathrm{xx}}=0,10,100,1000 \mathrm{~m} 2 / \mathrm{yr}$

(Case 6B: Multiple Parallel Fractures, Band Release Mode)

6-4d. Comparison of Temporal Variation of Relative Concentration of $\mathrm{Np}-237$

in the Rock Matrix at Elevation $\mathrm{z}=0.3 \mathrm{~m}$ for $\mathrm{D}_{\mathrm{xx}}=0,10,100,1000 \mathrm{~m}^{2} / \mathrm{yr}$

"(Case 6B: Multiple Parallel Fractures, Band Release Mode) 


\section{LIST OF FIGURES}

(Continued)

Figure

Title

Page

6-5a. Relative Concentration Profiles for Tc-99 in the Fracture at $z=0 \mathrm{~m}$ and $\mathrm{t}=5 \times 10^{4} \mathrm{yr}$ (Case 7: Multiple Patch Source)

6-5b. Relative Mass Flux Profiles for Tc-99 in the Fracture at $\mathrm{z}=0 \mathrm{~m}$ and $t=5 \times 10^{4} \mathrm{yr}$ (Case 7: Multiple Patch Source)

6-5c. Mass Flux Vector of T'-99 at Discrete Points in the Fracture at $z=0 \mathrm{~m}$ and $\mathrm{t}=5 \times 10^{4} \mathrm{yr}$ (Case 7: Multiple Patch Source)

6-5d, Relative Cumulative Mass Flux Profiles for Tc-99 in the Fracture at $\mathrm{z}=0 \mathrm{~m}$ and $\mathrm{t}=5 \times 10^{4} \mathrm{yr}$ (Case 7: Multiple Patch Source)

6-5e. Relative Concentration Profiles for Tc-99 in the Rock Matrix at $z=0.1 \mathrm{~m}$ and $t=5 \times 10^{4} \mathrm{yr}$ (Case 7: Multiple Patch Source)

6-5f. Relative Concentration Profiles for Tc-99 in the Rock Matrix at $\mathrm{z}=0.5 \mathrm{~m}$ and $\mathrm{t}=5 \times 10^{4} \mathrm{yr}$ (Case 7: Multiple Patch Source)

6-5g. Relative Concentration Profiles for Tc-99 in the Rock Matrix at $z=1.0 \mathrm{~m}$ and $t=5 \times 10^{4} \mathrm{yr}$ (Case 7: Multiple Patch Source)

B-1. Variations of Function $G(\eta), g_{1}(\eta)$, and $g_{2}(\eta, t)$ for $x=1 m \ldots \ldots \ldots \ldots$

B-2. Variations of Function $G(\eta), g_{1}(\eta)$, and $g_{2}(\eta, t)$ for $x=100 \mathrm{~m}$

B-3. Variations of Function $G(\eta), g_{1}(\eta)$, and $g_{2}(\eta, t)$ for $x=10,000 \mathrm{~m}$ 


\section{PART 1}

\subsection{INTRODUCTION}

\subsection{BACKGROUND}

In recent years increased interest has been registered in the U.S. and Western Europe for considering rock that may contain fractures as a viable candidate geologic medium for permanent disposal of high-level nuclear waste. The key elements prompting investigations in this area are the low porosity of hard rock coupled with its diffusive (Neretnieks, 1980) and adsorptive properties (Rickert et al., 19'79).

Analytical solutions for solute transport in planar fractures reported to date are for the most part unidimensional; they neglect in some cases the dispersion phenomena as well as decay reaction at the source, and they are based on the Laplace transformation technique. The first recursive onedirnensional solution for dispersion-free transpont of a decay chain of arbitrary length is a single fracture with diffusion into the rock matrix was presented by Kanki et al. (1981) (see also Chambré et al., 1982). Subsequently a nonrecursive solution for a three-member decay chain neglecting dispersion in the fracture and radioactive decay in the rock matrix was reported by the same authors (see Chambre et al, 1982). Neretnieks (1980) reported a solution for the nondispersive transport of a decaying species along a discrete fracture and rock matrix of infinite thickness, and demonstrated the overall impact of the matrix diffusion mechanism on the transport process. Rasmuson and Neretnieks (1980) presented a solution for the radial diffusion problem and longitudinal dispersion in spherical porous particles; their work is an extension of the Rosen (1952) solution, which neglected the dispersion effects, and apparently an improvement of the Babcock et al. (1966) solution of the same problem. Grisak and Pickens (1981), discounting the dispersive effects, presented a solution for a nondecaying solute. Tang et al. (1981) extended the solution presented by Neretnieks (1980) after considering the dispersive component in the governing equation; however in their case the concentration at the source is assumed constant. Chambré et al. (1982) presented a set of analytical solutions $r$ 'ated to radionuclide decay chain transport in fractured media; these solutions neglect for the most part the effects of longitudinal dispersion. Sudicky and Frind (1982) presented the transient and steady-state solution for the dispersive and nondispersive transport of a single decaying solute in a system of parallel fractures where the concentration at the source is held constant. 'This solution was first revised by Davis and Johnston (1984) and the correct form was subsequently given by Ahn et al. (1986). Barker (1982) and Hodgkinson and Maul (1985), utilizing a numerical inversion of the Laplace transform, presented solutions for unidirectional and radial transport of a single decaying species in a system of parallel fractures where the initial concentration was assumed to be a function of position. Van Genuchten 
et al. (1984) presented some exact solutions for transport of a single conservative species through large cylindrical macropores with simultaneous radial diffusion into the rock matrix. Rasmuson (1984) presented a solution for the transport of a radionuclide diffusing into a rock matrix simulated by. spheres where the inlet corcentration is kept constant; this work is an extension of an earlier paper by Rasmuson and Neretnieks (1981).

Sudicky and Frind (1984) presented a solution for the nondispersive transport of a two-member decay chain in a single fracture subjected to a nondecaying boundary condition at the source. An improved form of this solution approach was recently reported by Ahn et al. (1986). Moreno and Rasmuson (1986) examined the impact of two types of inlet boundary conditions on the concentration in the rock matrix for a conservative solute.

Chen (1986) presented solutions for a number of cases dealing with radionuclide transport from an injection well into a fractured porous formation of infinite extent; this approach includes a decaying and a nondecaying source and accounts for the diffusion process in the rock matrix.

\subsection{PURPOSE}

This report presents a set of analytical solutions based on the Laplace and Fourier transforms for the two-dimensional isothermal transport of a radionuclide in an idealized discrete planar fracture of constant aperture and a system of parallel fractures of infinite extent. The approach considers simultaneous infinite or finite diffusion in the rock matrix. The transport phenomena in the fracture include processes such as advection, hydrodynamic dispersion, linear equilibrium adsorption, and radioactive decay (the last two processes and rock matrix diffusion are also applicable to the rock matrix). The rock matrix is assumed to be homogeneous, isotropic, and fully saturated with stagnant water; the flowing water in the fractures, assumed to be under steady-state conditions, has a parallel streamline configuration. The solutions for the mass flux and the cumulative mass flux at any given point in the fracture as well as the longitudinal dispersion-free solution are also presented.

This report is divided into two parts. Part 1 (through Chapter 3 ) focuses on the derivation and verification of the two-dimensional solution for the single fracture case. Part 2 (Chapter 4 to the end) covers a similar endeavor focused on the multiple parallel fracture case where two solutions are reported: the first based on a series approximation and the second on contour integration.

The verification of the associated computer code (i.e., FRACFLO) is performed in the single fracture case by means of available one- and two-dimensional analytical solutions. The onedimensional solution of Ahn et al. (1985) will be used for benchmarking the performance of the reported solutions, restricted however to unidimerisional flow. The two-dimensional solution of Gureghian (1987) will enable a verification of the solution pertaining to the fracture in the absence of rock matrix diffusion. 
In the parallel fracture case the verification will be undertaken by way of a comparison of the performance of one solution against the other.

\subsection{APPLICATIONS}

These solutions are designed to cope with a realistic number of idealized fracture patterns, concentration distributions (i.e., single or multiple patch, or a Gaussian distributed source) decaying with time, and release modes (i.e., step and band release) associated with the geomotry of a high-leval nuclear waste repository in deep geologic rock media with fractures. Applications of these solutions are also reported. The reader should note the limitations of the solutions for the cumulative mass flux, which is restricted to the one-dimensional form of this code, and for the case where the velocity vectur is orthogonal to the inlet or source.

The model FRACFLO was written in VAX FORTRAN Version $4: 8$ using the G floating point option (REAL * 16). Auxiliary graphics programs were written using DISSPLA Version 10.5. 'The computation was executed on a VAX 8700 under VMS Version 4.7. 


\subsection{MASS TRANSPOR'T EQUATIONS FOR FRACTURE AND ROCK MATRIX}

From the mass conservation requirement, the concentration of a nuclide flowing in a discrete fracture plane with uniform aperture while undergoing sorption and diffusion in the surrounding rock matrix under isothermal and laminar flow conditions is given by

$$
\begin{gathered}
\frac{\partial}{\partial t}\left(A+\frac{S}{b}\right)-\nabla \cdot(\bar{D} \cdot \nabla A-A V)-Q+\frac{J}{b}=0 \\
\frac{\partial}{\partial t}\left(\phi B+\Phi_{r} \rho_{r} S^{\prime}\right)+\frac{\partial J}{\partial z}-Q^{\prime}=0
\end{gathered}
$$

where

$\nabla$. is the divergence operator $\partial / \partial x+\partial / \partial y L-1)$

$\nabla \quad$ is the gradient operator $\partial / \partial x, \partial / \partial y(L-1)$

$\mathbf{x}$ and $\mathbf{y}$ are the horizontal cartesian coordinates $(L)$

$z$ is the vertical cartesian coordinate $(L)$

A is the concentration in the fracture $(\mathrm{ML}-3)$

B is the concentration in the rock matrix $(M L-3)$

$\mathrm{V}$ is the average fluid velocity vector (components $v_{x}, v_{y}$ ) in the fracture $(L T-1)$

$\overline{\mathrm{D}} \quad$ is the hydrodynamic dispersion tensor $\left(\mathrm{L}^{2} \mathrm{~T}-1\right)$

$S$ is the concentration of sorbed contaminant on fracture surface $(M L-2)$

$\mathbf{S}^{\prime} \quad$ is the concentration in the adsorbed phase in the rock matrix (MM-1)

$\rho_{r} \quad$ is the rock density (ML-3)

$\phi_{r}$ is the volumetric fraction of the solid phase in the rock matrix $(1-\phi)$

$\phi \quad$ is the rock porosity

$2 \mathrm{~b}$ is the fracture aperture $(\mathrm{L})$

$J$ is the diffusive rate of the nuclide at the qurface of the fracture per unit area of fracture surface $(M L-2 T-1)$

$\mathbf{Q}$ and $\mathbf{Q}^{\prime} \quad$ are the rate of production or removal of solute due to radioactive decay in the fracture and rock matrix, respectively $(M L-3 \mathrm{~T}-1)$

$\mathrm{t}$ is time $(\mathrm{T})$. 
The diffusive rate of a nuclide into the rock matrix is assumed to obey Fick's law of diffusion written as

$$
J=-\left.D_{0} \frac{\partial B}{\partial z}\right|_{z=b}
$$

where $D_{e}$ is the effective diffusivity in the rock matrix (Neretnieks, 1980) defined as

$$
\begin{aligned}
& D_{e}=\phi D_{p} \\
& D_{p}=D_{d} \frac{\delta_{d}}{\tau^{2}}
\end{aligned}
$$

where

$D_{p} \quad$ is the pore diffusivity $\left(L^{2} T^{-1}\right)$

$D_{d} \quad$ is the molecular diffusion of nuclide in water ( $\left.\mathrm{L}^{2} \mathrm{~T}-1\right)$

$\delta_{d} \quad$ is the constrictivity for diffusion $\left(\mathrm{L}^{\circ}\right)$

I is the tortuosity $\left(\mathrm{L}^{0}\right)$.

The hydrodynamic dispersion tensor (Bear, 1972) may be written as

$$
D_{i j}=a_{T} V \delta_{i j}+\left(a_{L}-a_{T}\right) \frac{v_{1} v_{j}}{V}+\tau D_{d}, i, j=x, y
$$

where

$a_{L}$ and $a_{T}$ are the dispersivities in the longitudinal and transverse direction of the flow $(L)$

$\delta_{i j} \quad$ is the Kronecker delta $\left(L^{\circ}\right)$.

When one of the axes of the cartesian coordinate system, say $x$, coincides with the direction of the average velocity vector $\mathrm{V}$, the hydrodynamic dispersion tensor reduces to

$$
\begin{aligned}
& D_{x x}=a_{L} V+r D_{d} \\
& D_{y y}=a_{T} V+\tau D_{d}
\end{aligned}
$$

The following assumptions are made in this work:

(i) Fluid movement in the fracture is assumed under steady-state conditions where the streamlines are parallel.

(ii) The fracture is assumed to be analogous to an isotropic porous medium.

(iii) The rock matrix is assumed to be homogeneous, isotropic, and saturated with stagnant water. 
With the assumption that the dissolved radionuclides are in adsorption equilibr a uis with the fissure wall and the filling material where the prevailing concentration is $A$, the mechanism of adsorption may be adequately described by a linear equilibrium isotherm (Neretnieks, 1982):

$$
\mathrm{S}=\mathrm{K}_{\mathrm{f}} \mathrm{A}
$$

where $\mathrm{K}_{\mathrm{f}}$ is the surface distribution coefficient $(\mathrm{L})$ in the fracture. Similarly, in the rock the adscrption isotherm is given by

$$
S^{\prime}=K_{r} B
$$

where $K_{r}$ is the distribution coefficient in the rock matrix $\left(L^{3} \mathrm{M}-1\right)$.

The instantaneous rate of removal of a nuclide by radioactive decay in the fracture (Q) and the rock matrix $\left(Q^{\prime}\right)$ may then be written as

$$
\begin{aligned}
Q & =-\lambda\left[A+\frac{S}{b}\right] \\
Q^{\prime} & =-\lambda\left[\phi B+\phi_{r} \rho_{r} S^{\prime}\right]
\end{aligned}
$$

where $\lambda$ is the first-order rate constant for decay $(T-1)$ (i.e., $\lambda=\ln 2 / \mathrm{T}_{1 / 2}$ ).

With the above considerations, the set of differential equations describing the movement of a typical nuclide in the fracture and rock matrix, respectively, is given by the following equation in which the parameters $u$ and $v$ replace previously used symbols $v_{x}$ and $v_{y}$.

$$
\begin{gathered}
R \frac{\partial A}{\partial t}-D_{x x} \frac{\partial^{2} A}{\partial x^{2}}-D_{y y} \frac{\partial^{2} \hat{A}}{\partial y^{2}}-2 D_{y x} \frac{\partial^{2} A}{\partial y \partial x}+u \frac{\partial A}{\partial x}+v \frac{\partial A}{\partial y}+\lambda R A+\frac{J}{b}=0 \\
R^{\prime} \frac{\partial B}{\partial t}-D_{p} \frac{\partial^{2} B}{\partial z^{2}}+\lambda R^{\prime} B=0
\end{gathered}
$$

where

$$
R=1+K_{f} / b
$$

and

$$
R^{\prime}=1+\left[(1-\phi j / \phi] \rho_{r} K_{r}\right.
$$


are the retardation factors of a typical nuclide embodying the overall effect of the sorption and desorption reactions in the fissure and rock matrix, respectively.

Two models of idealized fractured rock systems are investigated, namely the single fracture and the multiple parallel fracture cases, where the diffusion field of the rock matrix is assumed infinite in the former case, and finite in the latter case (see Figures 2-1 and 2-2).

\subsection{INITIAL AND BOUNDARY CONDITIONS}

The set of differential equations, Equations 2-10 and 2-11, are subject to the initial conditions:

$$
\begin{gathered}
\mathrm{A}(\mathrm{x}, \mathrm{y}, 0)=0, \mathrm{x}>0,-\infty<\mathrm{y}<+\infty \\
\mathrm{B}(\mathrm{x}, \mathrm{y}, \mathrm{z}, 0)=0, \mathrm{x}>0,-\infty<\mathrm{y}<+\infty,|\mathrm{z}| \geq \mathrm{b}
\end{gathered}
$$

and boundary conditions as follows.

\subsubsection{Fracture}

Finite Patch Source

$$
\begin{gathered}
\widetilde{A}(0, y, t)=A(t) U(t)\left|U\left(y-y_{1}+\frac{d}{2}\right)-U\left(y-y_{1}-\frac{d}{2}\right)\right|, t>0,-\infty<y<+\infty \\
A(\infty, y, t)=0, t>0,-\infty<y<+\infty \\
\frac{\partial A(x, \pm \infty, t)}{\partial y}=0, t>0, x>0
\end{gathered}
$$

where

$y_{1} \quad$ is the location of the source center along the $\mathrm{Y}$-axis

$\widetilde{A}(\mathrm{t})$ is the concentration at the source

$d$ is the width of the finite patch source at the origin along the Y-axis.

\section{Gaussian Source}

In a high-level nuclear waste repository, the concentration at the source depends to a large extent on the release rate of the waste from its canister into the ground water. $A$ boundary condition such as a finite patch source, which implies a uniform concentration across its area ( $2 \mathrm{~b} x \mathrm{~d})$, may not adequately duplicate in situ conditions. Consequently, to circumvent the uncertainty inherent in the 


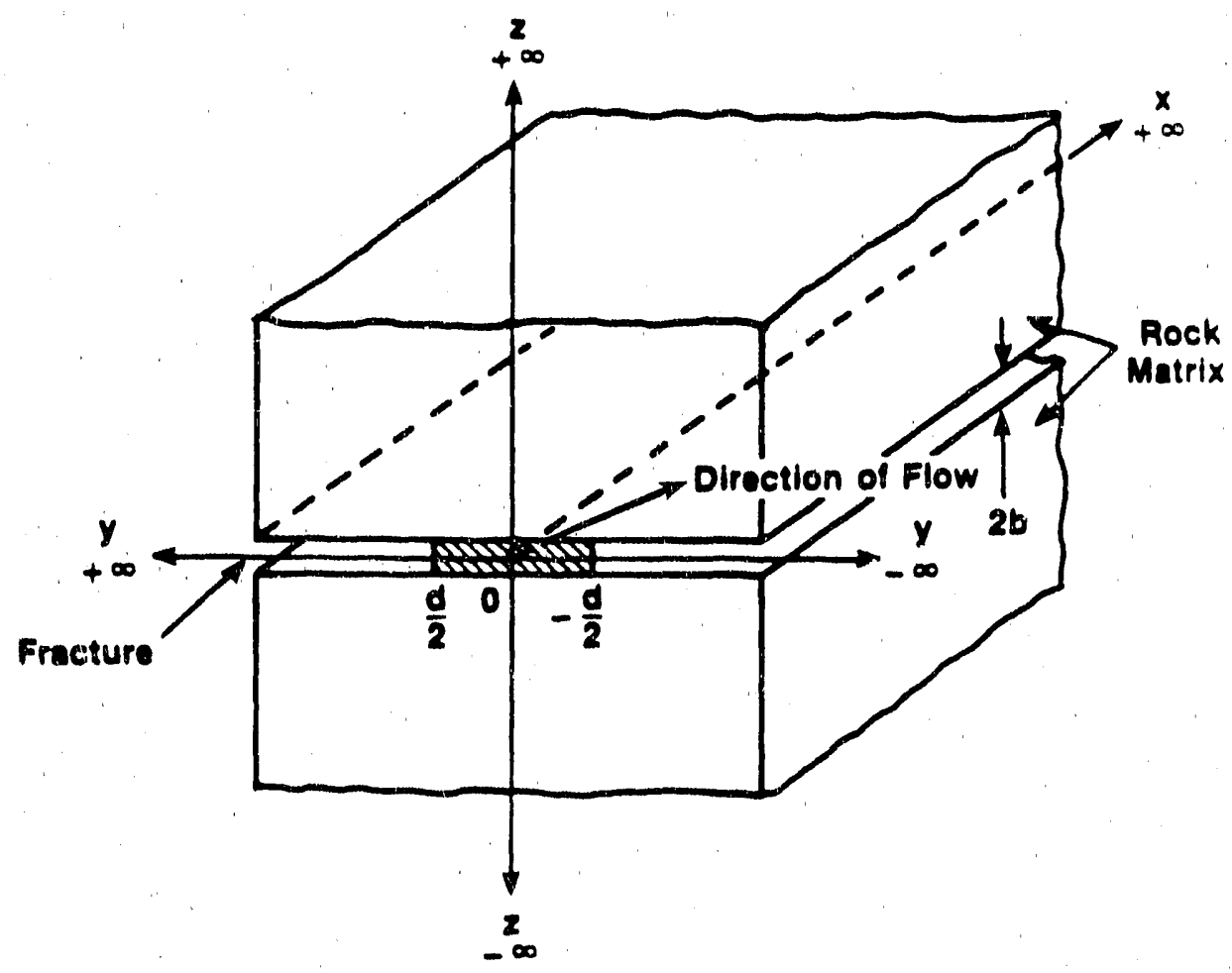

(a)

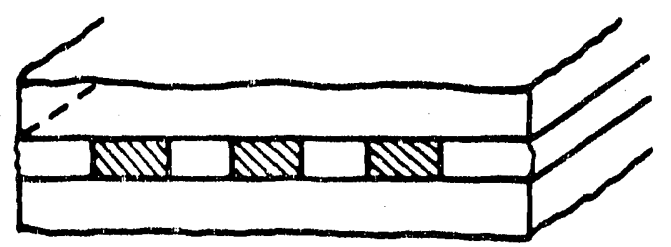

(b)

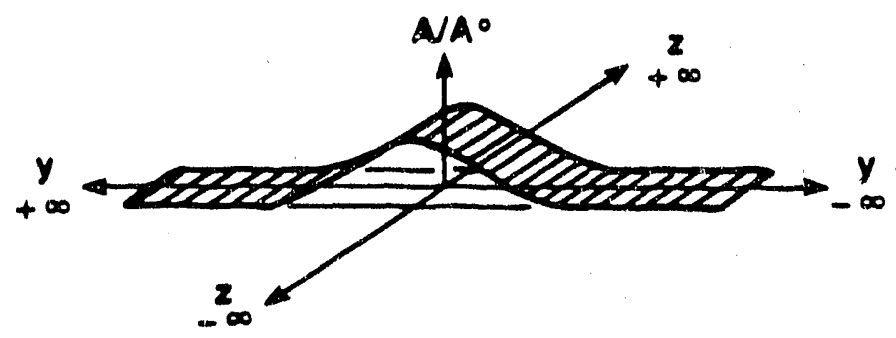

(c)

Figure 2-1. Schematic of a Single Fracture Rock System

(a) Patch Source; (b) Multiple Patch Source;

(c) Gaussian Distribution Source 


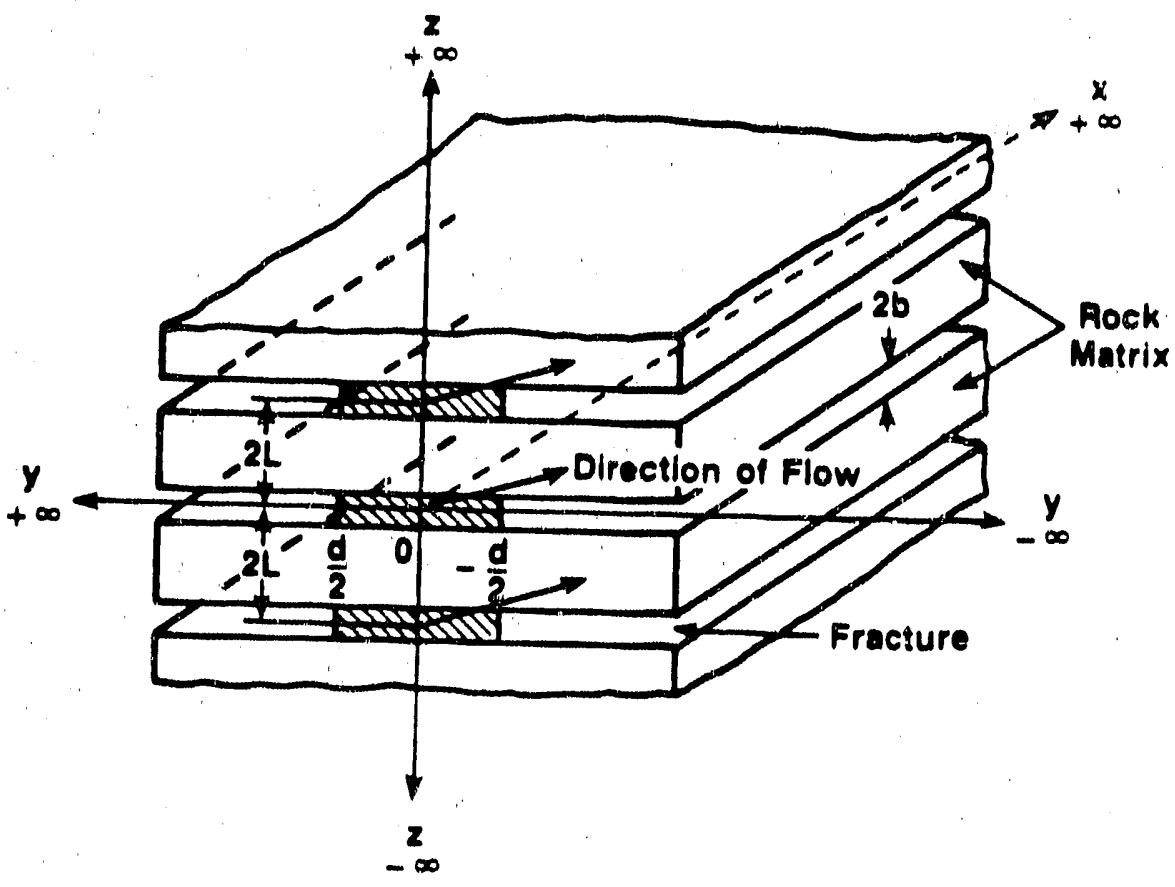

(a)

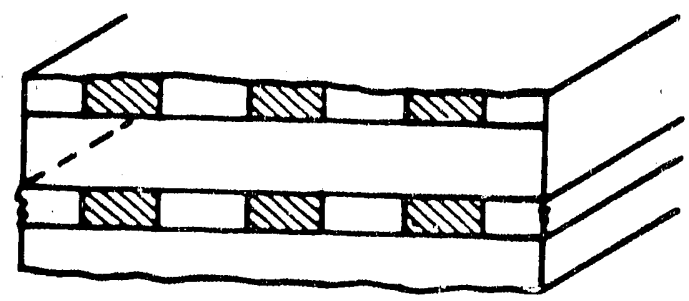

(b)

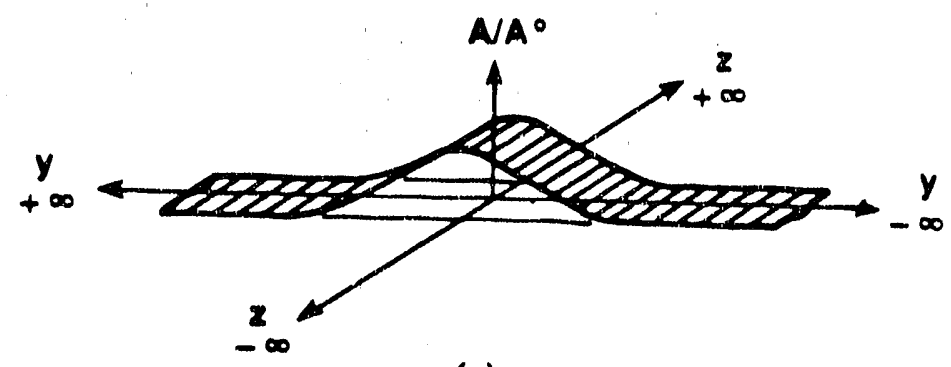

(c)

Figure 2-2. Schematic of Multiple Parallel Fracture Rock System

(a) Patch Source; (b) Multiple Patch Source;

(c) Gaussian Distributed Source 
source term, a probabilistic interpretation of the concentration distribution at the source may be deemed appropriate. In this instance, a source model based on Gaussian distribution is adopted.

The boundary condition for the Gaussian source located at $y_{0}$ with standard deviation $\sigma_{y}$ may be written as

$$
\begin{aligned}
A(0, y, t)= & \widetilde{A}(t) U(t) e^{-\left(y-y_{0}\right)^{2} / 20}{ }_{y}^{2}, t>0,-\infty<y<+\infty \\
& A(\infty, y, t)=0, t>0,-\infty<y<+\infty \\
& \frac{\partial \Lambda(x, \pm \infty, t)}{\partial y}=0, t>0, x>0 .
\end{aligned}
$$

\subsubsection{Rock Matrix}

$$
B(x, y, b, t)=A(x, y, t), x>0,-\infty<y<+\infty
$$

Infinite Diffusion Field

$$
\mathrm{B}(\mathrm{x}, \mathrm{y}, \pm \infty, \mathrm{t})=0, \mathrm{x}>0,-\infty<\mathrm{y}<+\infty, \mathrm{t}>0
$$

Finite Diffusion Field

$$
\frac{\partial B}{\partial z}(x, y, L, t)=0
$$

where $2 \mathrm{~L}$ is the fracture spacing.

\subsubsection{Concentration at the Source and Band Release}

Step Release (Continuous Decaying Source)

The concentration at the source for a typical nuclide may be written as

$$
\widetilde{A}(t)=A^{0} e^{-\lambda t}
$$

where $\mathrm{A}^{0}$ is the concentration of the species at time equals zero. 


\section{Band Release}

The boundary condition for the band release may be written as

$$
A(0, y, t)=A(t)|U(t)-U(t-T)| \phi(y), t>0,-\infty<y<+\infty
$$

where

$$
\begin{aligned}
& \phi(y)=U\left(y-y_{1}+d / 2\right)-U\left(y-y_{1}-d / 2\right) \text { for a finite line source } \\
& \phi(y)=\exp \left[-\left(y-y_{0}\right)^{2} / 2 \sigma_{y}{ }^{2}\right] \text { for a Gaussian source } \\
& T \text { is the leaching time. }
\end{aligned}
$$

$\mathrm{U}(\mathrm{t}-\mathrm{T})$ is the Heaviside unit function defined as

$$
U(t-T)=\left\{\begin{array}{l}
1, t>T \\
\frac{1}{2}, t=T \\
0, t<T
\end{array}\right\}
$$

The general form of the solution for the hand release mode based on a boundary condition given by Equation 2-20 and which uses the superposition technique (see Foglia et al., 1979) may be written as

$$
{ }^{b} A(x, y, t)=\left[A\left(x, y, t ; A^{0}\right)-A\left(x, y, t-T ; A^{0} e^{-\lambda T}\right)\right] U(t-T)
$$

where $\mathrm{T}$ corresponds to the leach duration and superscript $\mathrm{b}$ indicates the band release :olution. 


\subsection{SINGLE WRACTURE CASE WITH INFINITE DIFF'USION FIELD}

\subsection{NON-ZERO LONGITUDINAL DISPERSION}

\subsubsection{Rock Matrix}

The Laplace transformation of Equation 2-11 with its associated boundary condition Equation 2-18a may be written as

$$
\begin{aligned}
& \frac{d^{2} \bar{B}}{d z^{2}}-\frac{R^{\prime}}{D_{p}}(s+\lambda) \bar{B}=0 \\
& \bar{B}(x, y, b, s)=\bar{A}(x, y, s)
\end{aligned}
$$

where

$$
\bar{B}=\int_{0}^{\infty} B e^{-s t} d t
$$

The solution of Equation 3-1 subject to its initial and boundary conditions Equations 2-15, 2-18b, and $3-2$ is given by

$$
\bar{B}(x, y, z, s)=\bar{A} e^{r b^{(z-b)}}
$$

with

$$
r_{b}=-c_{r}(s+\lambda)^{1 / 2}
$$

and

$$
c_{r}=\left(R^{\prime} / D_{p}\right)^{1 / 2}
$$

Note that the inverse Laplace transform of $\bar{B}$ might be sought once $\bar{A}$ is identified as shown in the subsequent section. 
The transformed diffusive flux (Equation 2 -3 ) at the interface of the fracture and rock matrix is given by

$$
\left.\bar{J}=-\phi D_{p} \frac{\partial \bar{B}}{\partial z}(x, y, b, s)=-\phi D_{p} r_{b} \bar{A} ! \quad ; s\right) .
$$

Note that $r_{b}$ in the above equation is given by Equation 3-5a.

\subsubsection{Fracture}

After proper substitution of the transform of the diffusive flux given by Equation 3-6 into the Laplace transformation of Equation 2-10,

$$
D_{x x} \frac{\partial^{2} \bar{A}}{\partial x^{2}}+D_{y y} \frac{\partial^{2} \bar{A}}{\partial y^{2}}+2 D_{y x} \frac{\partial^{2} \bar{A}}{\partial y \partial x}-u \frac{\partial \bar{A}}{\partial x}-v \frac{\partial \bar{A}}{\partial y}-\left|R(s+\lambda)+c_{f}(s+\lambda) 1 / 2\right| \bar{A}=0
$$

with

$$
c_{\mathrm{f}}=\frac{\Phi}{\mathrm{b}}\left(\mathrm{R}^{\prime} \mathrm{D}_{\mathrm{p}}\right)^{1 / 2}
$$

The Laplace transforms of the boundary conditions (Equations 2-16 or 2-17 and 2-19) associated with Equation 2-10 are given by:

Finite Patch Source

$$
\bar{A}(0, y, s)=A^{0} \theta(s)\left[U\left(y-y_{1}+\frac{d}{2}\right)-U\left(y-y_{1}-\frac{d}{2}\right)\right],-\infty<y<\infty
$$

Gaussian Source

$$
\bar{A}(0, y, s)=A^{0} \theta(s) e^{-\left(y-y_{0}\right)^{2} / 2 \sigma_{y}^{2}}
$$

where

$$
\theta(s)=\frac{1}{s+\lambda}
$$


Applying the following Fourier integral transform and inversion formu ? for an infinite region $(-\infty<4$ $y<+\infty)$ (Sneddon, 1951) written as

Integral Transform

$$
\overline{\bar{A}}(x, \beta, s)=\int_{-\infty}^{+\infty} \theta^{i \beta y^{\prime}} \bar{A}\left(x, y^{\prime}, s\right) d y^{\prime}
$$

Inversion Formula

$$
\bar{A}(x, y, s)=\frac{1}{2 \pi} \int_{-\infty}^{+\infty} e^{-i \beta y} \overline{\bar{\Lambda}}(x, \beta, s) d \beta
$$

the y-variation of Equation 3-7 is removed as a result of an integration by parts using Equation 3-10a to get

$$
D_{x x} \frac{d^{2} \overline{\bar{A}}}{d x^{2}}-\left(u+2 D_{y x} i \beta\right) \frac{d \bar{A}}{d x}+\left|i v \beta-D_{y y} \beta^{2}-R(s+\lambda)-c_{f}(s+\lambda)^{1 / 2}\right| \vec{A}=0
$$

The solution of the above equation subject to its initial and boundary conditions given by Equations 2-14 and 2-16 or 2-17 may be written as

$$
\overline{\bar{A}}(x, \beta, s)=\overline{\bar{F}}(\beta, s) e^{a_{n} x}
$$

where

$$
a_{n} x=\frac{1}{2 D_{x x}}\left[\left(u+2 D_{y x} i \beta\right)-\left(\left(u+2 D_{y x} i(\beta)^{2}-4 D_{x x}\left|i v \beta-D_{y y} \beta^{2}-R(s+\lambda)-c_{f}(s+\lambda)^{1 / 2}\right|\right) 1 / 2 \mid x\right.\right.
$$

and $\overline{\bar{F}}(\beta, s)$ is the Fourier transform corresponding to either type of boundary condition considered herein:

$$
\bar{F}(\beta, s)=\int_{-\infty}^{+\infty} \vec{A}\left(0, y^{\prime}, s\right) e^{i \beta y^{\prime}} d y^{\prime}
$$




\section{Finite Patch Source}

Using Equation $3.9 a$, we have

$$
\bar{F}(\beta, s)=\left.A^{0} \theta(s) \frac{e^{i \beta y^{\prime}}}{i \beta}\right|_{y_{1}-\frac{d}{2}} ^{y_{1}+\frac{d}{2}}=A^{\prime \prime} \theta(s) \frac{\theta^{i \beta Y^{\prime}}}{\beta} 2 \sin \left(\beta \frac{d}{2}\right)
$$

\section{Gaussian Source}

Using Equation 3-9b, we have

$$
\overline{\bar{F}}(\beta, \mathrm{s})=\mathrm{A}^{\prime} \theta(\mathrm{s}) \int_{-\infty}^{+\infty} \exp \left|-\frac{\left(y^{\prime}-y_{0}\right)^{2}}{20_{y}^{2}}+i \beta y^{\prime}\right| d y^{\prime} .
$$

Putting

$$
x=y^{\prime}-y_{0}
$$

we have

$$
\overline{\bar{F}}(\beta, s)=e^{i \beta y_{0}} A^{0} \theta(s) \int_{-\infty}^{+\infty} \exp \left(\frac{-y^{2}}{2 o_{y}^{2}}+i \beta y\right) d y
$$

and recognizing the following integral (see Gradshteyn and Ryzhik, 1980, p. 307)

$$
\int_{-\infty}^{+\infty} \exp \left(-p^{2} y^{2}+i q y\right) d y=\frac{\sqrt{\pi}}{p} \exp \left(-q^{2} / 4 p^{2}\right)
$$

Equation 3-14 becomes

$$
\left.\overline{\bar{F}}(\beta, s)=A^{0} \theta(s)\left(2 n \sigma_{y}^{2}\right) 1 / 2 \exp \mid-\beta^{2} \frac{\sigma_{y}^{2}}{2}+1 \beta y_{0}\right] .
$$


Recognizing the following integral (see Appendtx D)

$$
\int_{0}^{\infty} \exp \left(-u^{2}-\frac{y^{2}}{\sigma^{2}}\right) d u=\frac{\sqrt{u}}{2} \exp (-2 \gamma)
$$

Equation 3-12 may now be written in the form

$$
\overline{\bar{A}}(x, \beta, s)=\int_{0}^{\infty} \psi(x, \sigma) \overline{\bar{F}}(\beta, s) \overline{\bar{G}}(\beta, x) e^{r_{a} x} d o
$$

where

$$
\begin{aligned}
& \psi(x, a)=\frac{2}{\sqrt{11}} \exp \left|-\left(0-\frac{u x}{4 D_{x x} \sigma}\right)^{2}\right| \\
& \overrightarrow{\bar{G}}(\beta, x, x)=\exp \left|-\left(D_{y y}-\frac{D_{y x}^{2}}{D_{x x}}\right) x \beta^{2}+\left(\left(v-u \frac{D_{y x}}{D_{x x}}\right) x+\frac{D_{y x}}{D_{x x}} x\right) i \beta\right| \\
& r_{a}=-R(s+\lambda)-c_{f}(s+\lambda)^{1 / 2}
\end{aligned}
$$

and

$$
x=\frac{x^{2}}{41 D_{x x} o^{2}}
$$

Note that $c_{f}$ in Equation 3-22c is given by Equation 3-8. Whence by the inversion formula (Equation 3$10 \mathrm{~b})$, we have

$$
\bar{F}(y, s)=\frac{1}{2 n} \int_{-\infty}^{+\infty} e^{-i \beta y} \overline{\bar{F}}(\beta, s) d \beta .
$$

Finite Patch Source

Referring to Equation 3-15a, this becomes

$$
\bar{F}(y, s)=A^{0} \theta(s)\left|U\left(y-y_{1}+\frac{d}{2}\right)-U\left(y-y_{1}-\frac{d}{2}\right)\right| .
$$


Gaussian Source

Reforring to Equation 3-19, this becomes

$$
\overline{\mathrm{F}}(y, s)=\Lambda^{0} \theta(\mathrm{s})\left(\frac{\sigma_{y}^{2}}{2 \pi}\right)^{1 / 2} \int_{-\infty}^{+\infty} \exp \left|-\frac{\sigma_{y}^{2}}{2} \beta^{2}-i\left(y-y_{0}\right) \beta\right| d \beta .
$$

Hence making use of Equation 3-18, we have

$$
\vec{F}(y, s)=\Lambda^{\prime \prime} \theta(s) \exp \left|-\frac{\left(y-y_{0}\right)^{2}}{2 \sigma_{y}^{2}}\right| .
$$

Similarly, applying Equation 3-18 to the inverse transform of Equation 3-22b, we have

$$
\bar{G}(\beta, x, X)=\frac{1}{2 n} \int_{-\infty}^{+\infty} e^{-i \beta y} \overline{\bar{G}}(\beta, x, x) d \beta=\frac{1}{2 p \sqrt{n}} \exp \left|\frac{-(y-g)^{2}}{4 p^{2}}\right|
$$

where

$$
\begin{gathered}
g=\left(v-u \frac{D_{y x}}{D_{x x}}\right) x+\left(\frac{D_{y x}}{D_{x x}}\right) x \\
p=\left(\left(D_{y y}-\frac{D_{y x}^{2}}{D_{x x}}\right) x\right)^{1 / 2}
\end{gathered}
$$

If we define

$$
\overline{\overline{\mathrm{H}}}(\mathrm{x}, \beta, \mathrm{s})=\overline{\overline{\mathrm{F}}}(\beta, \mathrm{s}) \overline{\overline{\mathrm{C}}}(\beta, x, \mathrm{X})
$$

then the convolution theorem appliod to this equation will yield its inverse fourier transform, which may be writton as

$$
\overline{\mathrm{H}}(x, y, \mathrm{~s})=\int_{-\infty}^{+\infty} \overline{\overline{\mathrm{G}}}(\beta, x, x) \cdot \overline{\overrightarrow{\mathrm{F}}}(\beta, s) \mathrm{e}^{-i \beta y} \mathrm{~d} \beta=\int_{-\infty}^{+\infty} \overline{\mathrm{F}}(\eta, \mathrm{s}) \cdot \overline{\mathrm{G}}(y-\eta, x, x) \mathrm{d} \eta
$$

and with proper substitution, we obtain appropriate equations for the finite source and Gaussian source. 
From Equations 3-24a, 3-26, and 3-29, we obtain

$$
\overline{\mathrm{H}}=\frac{\mathrm{A}^{0} \theta(\mathrm{s})}{2 p \sqrt{\pi}} \int_{-\infty}^{+\infty} \exp \left[\frac{-(y-\eta-g)^{2}}{4 p^{2}}|| U\left(\eta-y_{1}+\frac{d}{2}\right)-U\left(\eta-y_{1}-\frac{d}{2}\right) \mid d \eta\right.
$$

Putting

$$
\Gamma=\frac{y-\eta-g}{2 p}
$$

Equation 3-30 becomes

$$
\bar{H}=A^{0} \theta(s) \frac{1}{\sqrt{\pi}} \int_{-\infty}^{+\infty} e^{-\Gamma^{2}}\left[U\left(y-y_{1}+\frac{d}{2}-g-2 p \Gamma\right)-U\left(y-y_{1}-\frac{d}{2}-g-2 p \Gamma\right) \mid d \Gamma .\right.
$$

Hence,

$$
\bar{H}=A^{0} \theta(s) E_{f}\left[\frac{d}{2} \pm\left(y-y_{1}-g\right), p\right\rceil
$$

where

$$
E_{f}\left[\frac{d}{2}+\left(y-y_{1}-g\right), p\right]=\frac{1}{2}\left[\operatorname{erf}\left(\frac{\frac{d}{2}+y-y_{1}-g}{2 p}\right)+\operatorname{erf}\left(\frac{\frac{d}{2}-y+y_{1}+g}{2 p}\right)\right]
$$

where "erf" represents the error function.

\section{Multiple Patch Source}

Note that when an array of plane sources is encountered at $x=0$ (see Figure 2-1b), radionuclides released from one source will influence the concentration from the remaining ones. In this case, $\mathrm{E}_{\Omega}$ may be written as:

$$
E_{\Omega}=\sum_{k=1}^{n} E_{f}\left[\frac{d}{2}+\left(y-y_{k}-g\right), p\right]
$$


where $\mathrm{n}$ is the number of finite sources. The concentration in this case is said to be obtained after superimposing the solution of all such sources assumed to have the same width and initial concentration.

\section{Gaussian Source}

From Equations 3-25 and 3-26, we obtain

$$
\left.\bar{H}=A^{0} \theta(s) \frac{1}{2 p \sqrt{n}} \int_{-\infty}^{+\infty} \exp \mid \frac{-(y-\eta-g)^{2}}{4 p^{2}}\right\rfloor \exp \left[\frac{-\left(\eta-y_{0}\right)^{2}}{2 \sigma_{y}^{2}}\right\rfloor d \eta
$$

The above equation may also be written as

$$
\bar{H}=A^{0} \theta(s) \frac{1}{2 p \sqrt{n}} \int_{-\infty}^{+\infty} \exp \left|-\left(a_{1} \eta^{2}+2 a_{2} \eta+a_{3}\right)\right| d \eta
$$

where

$$
\begin{aligned}
& a_{1}=\frac{\sigma_{y}^{2}+2 p^{2}}{4 p^{2} \sigma_{y}^{2}} \\
& a_{2}=-\frac{(y-g) \sigma_{y}^{2}+2 y_{0} p^{2}}{4 p^{2} \sigma_{y}^{2}} \\
& a_{3}=\frac{(y-g)^{2} \sigma_{y}^{2}+2 y_{0}^{2} p^{2}}{4 p^{2} \sigma_{y}^{2}} .
\end{aligned}
$$

Note that parameters $g$ and $p$ in Equations 3-36 and 3-38 are given by Equations 3-27a and 3-27b, respectively. Recognizing the following integral (see Abramowitz and Stegun, 1972)

$$
\int_{0}^{\infty} \exp \left[-\left(a t^{2}+2 b t+c\right)\right] d t=\frac{1}{2} \sqrt{\frac{\pi}{a}} \exp \left[\frac{b^{2}-a c}{a}\right] \operatorname{erfc}\left(\frac{b}{\sqrt{a}}\right)
$$


Equation 3-37 becomes

$$
\bar{H}=A^{0} \theta(s) E_{g}\left[g,\left(y-y_{o}\right), \sigma_{y}, p\right]
$$

where, after substitution,

$$
E_{g}=\frac{\sigma_{y}}{\sqrt{\sigma_{y^{\prime}}^{2}+2 p^{2}}} \exp \left|-\frac{\left(y-y_{0}-g\right)^{2}}{2\left(\sigma_{y}^{2}+2 p^{2}\right)}\right| .
$$

With the above results, the inverse Fourier transform of Equation 3-21 may now be written as

$$
\overline{\mathrm{A}}(\mathrm{x}, \mathrm{y}, \mathrm{s})=\mathrm{A}^{0} \int_{0}^{\infty} \Psi(\mathrm{x}, \sigma) \mathrm{E}_{\Omega} \theta(\mathrm{s}) \mathrm{e}^{\mathrm{r} \mathrm{x}} \mathrm{do}
$$

where subscript $\Omega$ set to $f$ would refer to the finite or multiple patch source boundary condition, and when set to $g$ to the Gaussian source. Substitution from Equations 3-9c and 3-22c into the above equation and using the Laplace inversion formulae (Appendix A), the final solution of the concentration in the fracture may be written as

$$
\left.A(x, y, t)=A^{0} e^{-\lambda t} \int_{0}^{\infty} \Psi(x, \sigma) E_{\Omega} \operatorname{erfc} \mid \frac{c_{f} X}{2\left(t-R_{X}\right)^{1 / 2}}\right\rfloor U\left(t-R_{X}\right) d \sigma
$$

Substitution of Equation 3-42 in Equation 3-4 gives

$$
\bar{B}(x, y, z, s)=A^{0} \int_{0}^{\infty} \Psi(x, o) E_{\Omega} \theta(s) \exp \left[r_{b}(z-b)+r_{a} x\right] d o
$$

and the final solution of the concentration in the rock matrix may be written as

$$
\mathrm{B}(\mathrm{x}, \mathrm{y}, \mathrm{z}, \mathrm{t})=\mathrm{A}^{0} \mathrm{e}^{-\lambda t} \int_{0}^{\infty} \Psi(\mathrm{x}, \mathrm{o}) \mathrm{E}_{\Omega} \operatorname{erfc}\left[\frac{\mathrm{c}_{\mathrm{f}} \mathrm{X}+\mathrm{c}_{\mathrm{r}}(\mathrm{z}-\mathrm{b})}{2\left(\mathrm{t}-\mathrm{R}_{\mathrm{X}}\right)^{1 / 2}}\right] \mathrm{U}\left(\mathrm{t}-\mathrm{R}_{\mathrm{X}}\right) \mathrm{do}
$$

Note that $c_{r}, c_{f}, \Psi(x, 0)$, and $x$ in Equations 3-43 and 3-45 are given by Equations 3-5b, 3-8, 3-22a, and 3-22d, respectively.

After setting appropriat: finite integration limits (see Appendix B), the integration of Equations 3-43 and 3-45 is then performed using a Gauss-Legendre quadrature scheme. 


\subsection{NO LONGITUDINAL DISPERSION (Case where $\mathrm{v}=0$ )}

When the direction of the flow is normal to the source (i.e., $v=0$ ) and the longitudinal dispersion effects are neglected, Equation 3-11 becomes

$$
u \frac{d \overline{\bar{A}}}{d x}+\left[D_{y y} \beta^{2}+R(s+\lambda)+c_{f}(s+\lambda)^{1 / 2}\right] \overline{\bar{A}}=0 .
$$

The solution of the above equation subject to its initial and boundary conditions given by Equations 2-14 and 2-16 or 2-17 may be written as

$$
\overline{\bar{A}}(x, \beta, s)=\overline{\bar{F}}(\beta, s) e^{a_{n} x^{\prime}}
$$

where

$$
a_{n}=-D_{y y} \beta^{2}-R(s+\lambda)-c_{f}(s+\lambda)^{1 / 2}
$$

and

$$
x^{\prime}=\frac{x}{u}
$$

The Fourier transforms corresponding to either type of boundary conditions are obtained from Equations 3-14 to 3-21. Hence, Equation 3-21 becomes

$$
\overline{\bar{A}}(x, \beta, s)=\overline{\bar{F}}(\beta, s) \overline{\bar{G}}(\beta, x) e^{r_{a} x^{\prime}}
$$

where $\overline{\overline{\mathrm{F}}}(\beta, \mathrm{s})$ is given either by Equation 3-15a or 3-19 and $\overline{\overline{\mathrm{G}}}(\beta, x)$ is given by Equation 3-22 with $\mathrm{X}^{\prime}$ substituting for $\mathrm{X}$. Note that Equation $3-49$ is equivalent to Equation 3-21 after setting

$$
\int_{0}^{\infty} \Psi(x, \sigma) d \sigma=1
$$


The iriverse Fourier transforms of $\overline{\overline{\mathrm{A}}}(\mathrm{x}, \beta, \mathrm{s})$ may be obtained in the same fashion as outlined by Equations 3-24 through 3-42. Subsequently, the inverse Laplace transforms of the resulting equations yielding the solution in the fracture and the rock matrix are given by

$$
A(x, y, t)=A^{0} E_{\Omega} e^{-\lambda t} \operatorname{erfc}\left[\frac{c_{f} X^{\prime}}{2\left(t-R_{X}\right)^{1 / 2}}\right] U\left(t-R_{X}{ }^{\prime}\right)
$$

and

$$
B(x, y, z, t)=A^{0} E_{\Omega} e^{-\lambda t} \operatorname{erfc}\left[\frac{c_{f} X^{\prime}+c_{r}(z-b)}{2\left(t-R_{X}^{\prime}\right)^{1 / 2}}\right\rceil U\left(t-R_{X}^{\prime}\right)
$$

respectively. Note that $\mathrm{p}$ and $\mathrm{g}$ in $\mathrm{E}_{\mathrm{f}}$ (Equation 3-34) or $\mathrm{E}_{\mathrm{g}}$ (Equation 3-41) should be replaced by $\left(D_{y y} X^{\prime}\right)^{1 / 2}$ and zero; $c_{r}$ and $c_{f}$ are given by Equations $3-5 b$ and $3-8$, respectively.

\subsection{MASS FLUX}

The mass flux at any point in the fracture may be written as

$$
F(t)=\left[F_{x}^{2}+F_{y}^{2}\right]^{1 / 2}
$$

where $F_{x}$ and $F_{y}$ refer to the mass fluxes in the $x$ and $y$ directions, respectively, given by

$$
\begin{aligned}
& F_{x}=u A-D_{x x} \frac{\partial A}{\partial x}-D_{x y} \frac{\partial A}{\partial y} \\
& F_{y}=v A-D_{y x} \frac{\partial A}{\partial x}-D_{y y} \frac{\partial A}{\partial y} .
\end{aligned}
$$

The evaluation of $F_{x}$ and $F_{y}$ is carried out after using the inverse Fourier transform of $A$ (that is, in the Laplace domain) to estimate the spatial derivatives for the two types of source geometry considered here (i.e., finite line source and Gaussian distributed source, respectively). 
Referring to Equation 3-42 the derivatives of $\bar{A}(x, y, s)$ with respect to $x$ and $y$ may be obtained after applying Leibniz's differentiation rule. Using the notation $\mathrm{E}_{\Omega}^{\mathrm{x}}=\partial \mathrm{E}_{\Omega} / \partial \mathrm{x}, \mathrm{E}_{\Omega}^{y}=\partial \mathrm{E}_{\Omega} / \partial \mathrm{y}$,

$$
\begin{gathered}
\frac{\partial \overline{\mathrm{A}}}{\partial \mathrm{x}}=\mathrm{A}^{0} \int_{0}^{\infty} \theta(\mathrm{s})\left\{\left[\Psi^{\prime}(\mathrm{x}, \sigma) \mathrm{E}_{\Omega}+\Psi(\mathrm{x}, \sigma) \mathrm{E}_{\Omega}^{\mathrm{x}}\right] \mathrm{e}^{\mathrm{r}_{\mathrm{a}} \mathrm{x}}+\Psi(\mathrm{x}, \sigma) \mathrm{E}_{\Omega} \frac{\partial}{\partial \mathrm{x}}\left(\mathrm{e}^{\mathrm{r}_{\mathrm{a}} \mathrm{x}}\right)\right\} \mathrm{d} \sigma \\
\frac{\partial \overline{\mathrm{A}}}{\partial \mathrm{y}}=\mathrm{A}^{0} \int_{0}^{\infty} \Psi(\mathrm{x}, \sigma) \mathrm{E}_{\Omega}^{\mathrm{y}} \theta(\mathrm{s}) \mathrm{e}^{\mathrm{r}_{\mathrm{a}} \mathrm{x}} \mathrm{do} .
\end{gathered}
$$

Using Equation 3 22a, we have

$$
\Psi^{\prime}(x, 0)=\Psi(x, 0) 2 a_{1}\left(o-a_{1} x\right)
$$

with

$$
a_{1}=\frac{u}{4 D_{x x} \sigma}
$$

Using Equations 3-22c and 3-22d, we have

$$
\frac{\partial}{\partial x}\left(e^{r_{a} x}\right)=-\bar{\beta}\left[R(s+\lambda)+c_{f}(s+\lambda)^{1 / 2}\right] e^{r_{a} x}
$$

with

$$
\bar{\beta}=\frac{x}{2 D_{x x} o^{2}}
$$

and in the absence of longitudinal dispersion

$$
\bar{\beta}=\frac{1}{u} .
$$

With the error function defined either as

$$
\operatorname{erf}(\alpha)=\frac{2}{\sqrt{\pi}} \int_{0}^{a(x)} e^{-\tau^{2}} d \tau
$$


or the integrand expanded in a power series convergent everywhere and integrated term by term to yield

$$
\left.\operatorname{erf}(\alpha)=\frac{2}{\sqrt{\pi}} \mid \alpha-\frac{a^{3}}{3}+\frac{a^{5}}{5.2 !}-\frac{a^{7}}{7.3 !}+\ldots\right]
$$

its derivative with respect to the variable $\mathrm{x}$ may be then obtained after making use of Leibnitz's differentiation rule. This is written as

$$
\frac{\partial}{\partial x}(\operatorname{erf}(a))=\frac{2}{\sqrt{I I}} \exp \left(-a^{2}\right) \frac{\partial a}{\partial x}
$$

Hence, for the two types of geometry of the source considered here, $\mathrm{E}_{\Omega}^{\mathrm{x}}$ and $\mathrm{E}_{\Omega}^{\mathrm{y}}$ will be handled as follows:

\section{Finite Patch Source}

Applying the above equation to Equation 3-34, we obtain

$$
\begin{aligned}
& E_{f}^{x}=\frac{1}{2 p x \sqrt{\pi}}\left|\exp \left(-\left|\frac{\frac{d}{2}+y-y_{1}-g}{2 p}\right|^{2}\right)\left(-\frac{d}{2}-y+y_{1}-\left(v-u \frac{D_{y x}}{D_{x x}}\right) x\right)\right| \\
& +\exp \left(-\left[\left.\frac{\frac{d}{2}-y+y_{1}+g}{2 p}\right|^{2}\right)\left(-\frac{d}{2}+y-y_{1}+\left(v-u \frac{D_{y x}}{D_{x x}}\right) x\right)\right] \\
& \mathrm{E}_{\mathrm{f}}^{\mathrm{y}}=\frac{1}{2 \mathrm{p} \sqrt{\mathrm{r}}} \mid \exp \left(-\left|\frac{\frac{\mathrm{d}}{2}+\mathrm{y}-\mathrm{y}_{1}-\mathrm{g}}{2 \mathrm{p}}\right|^{2}\right)-\exp \left(-\left[\left.\frac{\frac{\mathrm{d}}{2}-\mathrm{y}^{2}+\mathrm{y}_{1}+\mathrm{g}}{2 \mathrm{p}}\right|^{2}\right) \mid\right.
\end{aligned}
$$

\section{Gaussian Source}

Using Equation 3-41, we obtain

$$
\mathrm{E}_{g}^{\mathrm{x}}=\mathrm{E}_{\mathrm{g}}\left|\frac{2}{x\left(\sigma_{y}^{2}+2 p^{2}\right)}\right|\left\{\left(y-y_{0}-g\right)\left(g-\left(\frac{D_{y x}}{D_{x x}}\right) \frac{x}{2}\right)-p^{2}\left[1-\frac{\left(y-y_{0}-g\right)^{2}}{\left(o_{y}^{2}+2 p^{2}\right)} \mid\right\}\right.
$$




$$
E_{g}^{y}=E_{g}\left[-\frac{\left(y-y_{0}-g\right)}{\left(o_{y}^{2}+2 p^{2}\right)}\right]
$$

Equation 3-55 may now be written as

$$
\frac{\partial \bar{A}}{\partial x}=A^{0} \int_{0}^{\infty} \Psi(x, \sigma) \int\left[\frac{2 a_{1}\left(\sigma-a_{1} x\right)}{s+\Lambda}-\bar{\beta}\left(R+\frac{c_{f}}{(s+\lambda)^{1 / 2}}\right)\right] E_{\Omega}+\frac{E_{\Omega}^{x}}{s+\lambda} \int e^{r_{a^{x}}} d \sigma
$$

Definitions are given now,

$$
\begin{aligned}
{ }_{x} F_{1} & =u E_{\Omega}-D_{x x}\left|2 a_{1}\left(a-a_{1} x\right) E_{\Omega}+E_{\Omega}^{x}\right|-D_{x y} E_{\Omega}^{y} \\
i_{2} F_{2} & =\frac{\bar{\beta} c_{f} D_{i x}}{\sqrt{\pi}} E_{\Omega}, \quad(i=x, y) \\
y_{1} & =v E_{\Omega}-D_{y x}\left|2 a_{1}\left(\sigma-a_{1} x\right) E_{\Omega}+E_{\Omega}^{x}\right|-D_{y y} E_{\Omega}^{y} \\
F_{1}^{*} & =u E_{\Omega} \\
\bar{\varepsilon} & =\frac{c_{f} x}{2} \\
& =\frac{c_{f} X^{\prime}}{2}=\frac{c_{f} x}{2 u} .
\end{aligned}
$$

Substitution of Equation 3-43 and the inverse Laplace transform of Equations 3-56 and3-66 into Equations 3-54a and $3-54 \mathrm{~b}$ gives

$$
\begin{aligned}
F_{i} & =A^{0} e^{-\lambda t} \int_{0}^{\infty} \Psi(x, \sigma) \mid F_{i} \operatorname{erfc}\left(\frac{\bar{\varepsilon}}{\left(t-R_{X}\right)^{1 / 2}}\right) \\
& +{ }_{i} F_{2}\left|\frac{R_{X}}{2\left(t-R_{X}\right)^{3 / 2}}+\frac{1}{\left(t-R_{X}\right)^{1 / 2}}\right| \exp \left|\frac{-\bar{\varepsilon}^{2}}{\left(t-R_{X}\right)}\right| \mid U\left(t-R_{X}\right) d o,(i=x, y)
\end{aligned}
$$


Note that when the streamlines are normal to the source (i.e., $v=0$ ) and with $D_{\mathrm{xx}}=\mathrm{D}_{\mathrm{xy}}=0$, and in view of Equation 3-50, Equation 3-68 becomes

$$
\begin{gathered}
F_{x}=A^{0} e^{-\lambda t} F_{1}^{*} \text { erfc }\left|\frac{\frac{\varepsilon}{\varepsilon}}{\left(t-R_{X}\right)^{1 / 2}}\right| U\left(t,-R X^{\prime}\right) \\
F_{y}=-A^{0} e^{-\lambda t} D_{y y} E_{\Omega}^{y} \operatorname{erfc} \mid \frac{\frac{z}{\left(t-R_{X}\right)^{1 / 2}}}{\left(t-R X^{\prime}\right)}
\end{gathered}
$$

\subsection{CUMULATIVE MASS FLUX}

The cumulative mass flux is given by

$$
M(t)=\int_{0}^{l} F^{\prime}(t) d t
$$

where the integrand given by Equation 3-53 may be written as

$$
F(c)=F_{x}(l)\left|1+\left(\frac{F_{y}(c)}{F_{x}(l)}\right)^{2}\right|^{1 / 2}
$$

Because of the complex nature of Equation 3-70a, a closed form solution of this may be obtained only at the expense of some simplifications of the hydrodynamic dispersion phenomena inherent to the transport process. Two solutions dealing with the case of streamlines parallel to the $\mathrm{x}$ axis will be reported. The first will assume that the source is of uniform strength and extends to infinity (i.e., unidimensional flow, $\mathrm{F}_{\mathrm{y}}=0$ ). The second will assume the type of source considered in this work where the streamlines are normal to the source (i.e., $v=0$ ), which accounts for both $F_{x}$ and $F_{y}$, but which ignores the longitudinal dispersion effects (i.e, $\left.D_{x x}=D_{x y}=0\right)$.

\subsubsection{Unidimensional $\mathrm{Flow}\left(\mathrm{F}_{\mathrm{y}}=0\right)$}

In the case of unidimensional flow, the y component of velocity and transverse dispersion in the fracture are both zero (i.e., $v=0 ; D_{x y}=D_{y y}=0$ ), $p$ in Equation 3-27 becomes zero also. In such a situation, the width of the patch source is said to extend to infinity; hence, functions $\mathrm{E}_{\mathrm{f}}$ and $\mathrm{E}_{\mathrm{f}}$ given by Equations 3-34 and 3-62 will take the value of one and zero, respectively. 
With $\mathrm{F}_{y}(\mathrm{t})$ in Equation 3-70b set to zero, Equation 3-70a becomes

$$
M(t)=\int_{0}^{t}\left|u A(t)-D_{x x} \frac{\partial A(\tau)}{\partial x}\right| d \tau
$$

In the presence of longitudinal dispersion, this integral is of the form

$$
\begin{aligned}
M(t) & =\int_{0}^{t} \int_{0}^{\infty} g(0, t) U\left(\tau-R_{X}\right) d o d \tau \\
& =\int_{0}^{t} \int_{f(t)}^{\infty} g(0, t) d a d t
\end{aligned}
$$

where

$$
f(t)=\frac{x}{2}\left(\frac{R}{D_{x x} \mathrm{l}}\right)^{1 / 2}
$$

We may interchange the order of integration to yield

$$
M(t)=\int_{f^{\prime}(t)}^{\infty} \int_{f^{\prime}(\sigma)}^{t} g(\sigma, t) d t d \sigma
$$

where

$$
f(t)=\frac{x}{2}\left(\frac{R}{D_{x x}}\right)^{1 / 2}, f(\sigma)=R_{X}
$$

In the absence of longitudinal dispersion,

$$
M(t)=\int_{R_{X}}^{t} g(\iota) d \imath
$$

Referring to Equations 3-67a, 3-67b, and 3-67d, these become

$$
\begin{aligned}
& \bar{F}_{1}=u-2 D_{x x} a_{1}\left(o-a_{1} x\right) \\
& \vec{F}_{2}=\frac{\bar{\beta} c_{1} D_{x x}}{\sqrt{I I}} \\
& F_{1}^{*}=u
\end{aligned}
$$


using the definitions

$$
\begin{aligned}
& I_{1}=\int_{R_{X}}^{t} e^{-\lambda t} \operatorname{erfc}\left|\frac{\bar{\varepsilon}}{\sqrt{t-R_{X}}}\right| d t \\
& I_{2}=\int_{R_{X}}^{t} e^{-\lambda t-\frac{\bar{c}^{2}}{1-R_{X}}}\left|\frac{R_{X}}{2 \sqrt{\left(t-R_{X}\right)^{3}}}+\frac{1}{\sqrt{1-R_{X}}}\right| d t
\end{aligned}
$$

where $\bar{\varepsilon}$ is given by Equation 3-67e, we may then expross the cumulative mass flux as

$$
M(t)=\left.A^{0} \int_{f(t)}^{\infty 0} \psi(x, 0)\right|_{x} \overline{I_{1}} \cdot I_{1}+\bar{x}_{2} \cdot \bar{F}_{2} / d o
$$

in the presence of longitudinal dispersion, and as

$$
M(t)=A^{n}\left(w_{1}^{*} \cdot l_{1}\right)
$$

when $D_{x}=0$. Integrating Equation 3-75a by parts gives

$$
I_{1}=-\frac{e^{-\lambda t}}{\lambda} \operatorname{erfc}\left|\frac{\bar{\varepsilon}}{\sqrt{t-R_{X}}}\right|+\frac{\bar{\varepsilon} e^{-\lambda R X}}{\lambda \sqrt{11}} \int_{0}^{1-k x} \frac{1}{\sqrt{t^{3}}} \exp \left|-\lambda \iota-\frac{\varepsilon^{2}}{i}\right| d t
$$

We further define

$$
\begin{aligned}
& K_{0}(a)=-\frac{e^{-\lambda t}}{\lambda} \operatorname{crfc}\left|\frac{a}{\sqrt{t-R_{X}}}\right| \\
& K_{1}(a)=\int_{0}^{t-R x} \frac{1}{\sqrt{t}} \exp \left|-\lambda \iota-\frac{a^{2}}{\imath}\right| d t \\
& K_{2}(a)=\int_{0}^{t-R x} \frac{1}{\sqrt{l^{3}}} \exp \left|-\lambda_{t}-\frac{a^{2}}{\imath}\right| d t
\end{aligned}
$$

Recognizing the following integral (Abramowitz and Stegun, 1972, p. 304)

$$
\int e^{-p^{2} y^{2}-q^{2} / y^{2}} d y=\frac{\sqrt{\pi}}{4 p}\left|e^{2 p x \mid} \operatorname{cor}\left(p y+\frac{q}{y}\right)+e^{-2 p x \mid} \operatorname{err}\left(p y-\frac{q}{y}\right)\right|
$$


we may ovaluate $K_{1}$ and $K_{2}$ after substituting $\gamma=\sqrt{i}$ (for $K_{1}$ ) and $y=1 / \sqrt{i}$ (for $K_{2}$ ). This yiolds

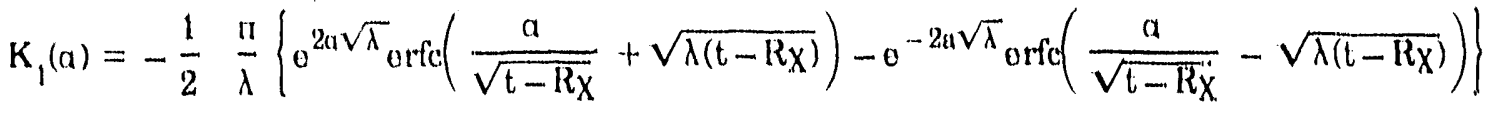

$$
\begin{aligned}
& K_{2}(a)=\frac{\sqrt{11}}{2 a}\left\{e^{2 a \sqrt{\lambda}} \operatorname{orfc}\left(\frac{a}{\sqrt{t-R_{X}}}+\sqrt{\lambda\left(t-R_{X}\right)}\right)+0^{-2 a \sqrt{\lambda}} \operatorname{erfc}\left(\frac{a}{\sqrt{t-R_{X}}}-\sqrt{\lambda\left(t-R_{X}\right)}\right)\right\}
\end{aligned}
$$

so that we may express $I_{1}$ and $I_{2}$ (soo Equations $3-75 a$ and $3-75 b$ ) as

$$
\begin{gathered}
I_{1}=K_{0}(\bar{\varepsilon})+\frac{\bar{\varepsilon} e^{-\lambda R x}}{\lambda \sqrt{n}} K_{2}(\bar{\varepsilon}) \\
I_{2}=e^{-\lambda B \times}\left|\frac{R_{X}}{2} K_{2}(\bar{\varepsilon})+K_{1}(\bar{\varepsilon})\right| .
\end{gathered}
$$

We may then express the cumulative mass flux given by Equation 3.76 as

$M(t)=A^{0} \int_{f(t)}^{\infty} \psi(x, a)\left\{\bar{F}_{1} \cdot\left(K_{0}(\bar{\varepsilon})+\frac{\bar{\varepsilon} e^{-\lambda R x}}{\lambda \sqrt{n}} K_{2}(\bar{\varepsilon})\right)+e^{-\lambda R x} \bar{F}_{2} \cdot\left(\frac{R_{X}}{2} K_{2}(\bar{\varepsilon})+K_{1}(\bar{\varepsilon})\right)\right\} d(j$

in the presence of longitudinal dispersion, and as

$$
M(t)=\Lambda^{0} H_{1}^{\prime \prime}\left(K_{0}\left(\stackrel{\vec{\varepsilon})}{\varepsilon}+\frac{\vec{\varepsilon} e^{-\lambda R X^{\prime}}}{\lambda \sqrt{11}} K_{2}(\dot{\varepsilon})\right) U\left(\ell-R X^{\prime}\right)\right.
$$

when $D_{x x}=0$, where $"$ है is given by Lquation 3-67\%

Note that Equation $3-85$ is equivalent to

$$
M(t)=A^{\prime \prime} \int_{0}^{\infty} \psi(x, 0)\left\{\bar{F}_{1} \cdot I_{1}+e^{-\lambda R x} \bar{F}_{2} \cdot I_{2}\right\} U\left(t-R_{X}\right) d o
$$

where ${ }_{x} \bar{F}_{1}, \bar{F}_{2}, K_{1}, K_{1}$, and $K_{2}$ are given by Lquations 3-74a, 3-74b, 3-79a, 3-81, and 3-82.

\subsubsection{No Longitudinal Disporsion (Cuse whero $\mathrm{v}=0$ )}

After proper substitution of liquations 3-69a and 3-69b in Equations 3-54a and 3-54b and using the following definition

$$
F_{3}=\left|\left(u \mathrm{E}_{\Omega}\right)^{2}+\left(D_{y y} \mathrm{E}_{\Omega}^{y}\right)^{2}\right|^{1 / 2}
$$


Equation 3-70a bacomos

$$
M(t)=\frac{E_{3}}{E_{S \Omega}} \int_{0}^{t} \Lambda(x, y, t) d t .
$$

Basod on the derivations presonted in the provious section, it may bo shown that the cumulative mass flux in this case is givon by an exprossion idontical to Equation 3.86 with $\mathrm{F}_{3}$ substluting fior $\mathrm{F}^{*}$.

\subsection{RESULTS AND DISCUSSIONS}

The analytical solutions presentod in this section of the roport wore vorifiod by comparison with the avallable one- and two-dimensional analytical solutions. 'The one-dimonsional solution of $A \mathrm{hn}$ ot al. (1985) enablod a check of the performance of the reported solutiona rolatod to the concontrations in the fracture and rock matrix, as woll as the mass and cumulative mass fluxes in the fracturo; the two-dimonsional solution of Gureghiun (1987) enabled a check of the prodictive capability of the model with reference to the various boundary conditions at the sourco and in the absence of rock matrix diffusion.

Note that the adequacy of the transformation tochnique of the integral (soo Appendix 13) as well as the quadrature scheme (Gauss-Legendro) adoptod in this work havo boen thoroughly oxamined in a provious report (see Gureghian, 1987). It might be of interest to the reader to note that in practically all the test cases reported in this investigation, 60 quadrature points proved to yiold a convorging quadrature.

\subsubsection{Case 1: Concentration of $\mathrm{Np}-237$ in a One-Dimensional Flow Domuin}

This test case deals with the migration of $\mathrm{Np}$-237 in a one-dimensional flow domain, where the concentration at the source is subjected to a step release modo. The influence of the rotardation factor of the rock matrix on the concentration in the fracture and rock matrix was investigated. 'I'o this offoct the flow field was assumed unidimensional (i.e., $v=0, D_{y y}=0$ ), and the concentration at the source was simulated by means of a plane source of infinite width. 'The input data portaining to this test case are pre:sented in Table 3-1. Results reported for Cases $1 \mathrm{~A}$ and $1 \mathrm{~B}$ are obtained through tho genoral solution and the nondispersive form, respectively. 
Case 1A - Influence of Returdation l'actor In the Rock Matrix

Figures 3-1a and 3-1b show the rolative concentrations of $\mathrm{Np}-237$ in the fracture and rock matrix (i.o., at a distance of $100 \mathrm{~m}$ downstroam from the source) corresponding to threo values of rock matrix rotardation fuctor $\left(R^{\prime}=1,10^{2}\right.$, and 104). Results roported in 'Tables 3-2a through 3-2c and 3-2d) are in excollent agreoment with those roported by Ahn et al. (1985). 'The influence of the retardation factor of the rock matrix on the movement of the solute front in both fracture and rock is quite noticeable. In both cases increasing values of $R^{\prime}$ seem to retard the movement of the solute front in both media. The explanation for these results is that the retardation factor of the rock matrix is reducing the magnitude of the apparent diffusion coefficient; the key parameter gearing the migration process of $\mathrm{Np}-237$ in thly medium exerts In turn a marked influence on the mass transfor process between the rock matrix and the fracture respectivoly (soe tiquation 2-10). For example, a large value of the retardation factor in the rock will incronse the magnitudo of the diffusive flux which may bo interproted as a sink in the equation governing solute transport in the fracture and, conversoly, as a source. Referring to Figure 3- 1 a it may be observed that the concen tration at a given point (say $100 \mathrm{~m}$ ) decreases with incroasing values of $\mathrm{R}^{\prime}$. 'To gain further insight into the diffusion procosses in tho rock matrix and the importance of the retardation phenomenon the reader is referred to the work of Norotnicks (1980).

'Tuble 3-1. Input Parametors for Case 1

\begin{tabular}{|c|c|}
\hline Spocios & $N p-237$ \\
\hline \multicolumn{2}{|l|}{ Initial Concontration $A^{\prime \prime}$} \\
\hline (arbitrary units of activity/l, (3) & 1 \\
\hline 'Typo of Relouse Mode & Slep \\
\hline Boundary Condition & Infinite Plane Source \\
\hline $\mathrm{x}$ & $100.0 \mathrm{~m}$ \\
\hline$y$ & $0.0 \mathrm{~m}$ \\
\hline$d$ & $\infty$ \\
\hline u & $10.0 \mathrm{~m} / \mathrm{yr}$ \\
\hline$v$ & $0.0 \mathrm{~m} / \mathrm{yr}$ \\
\hline \multirow[t]{2}{*}{$D_{x x}$} & Case $1 \mathrm{~A}: 1.0 \mathrm{~m}^{2} / \mathrm{yr}$ \\
\hline & Case 1B: $0.0 \mathrm{~m}^{2} / \mathrm{yr}$ \\
\hline$D_{y y}$ & $0.0 \mathrm{~m}^{2} / \mathrm{yr}$ \\
\hline$D_{y x}$ & $0.0 \mathrm{~m}^{2} / \mathrm{yr}$ \\
\hline$D_{\mathrm{p}}$ & $0.01 \mathrm{~m}^{2} / \mathrm{yr}$ \\
\hline$T_{1 / 2}$ & $2.14 \times 10^{6} \mathrm{yr}$ \\
\hline b & $0.005 \mathrm{~m}$ \\
\hline$\phi$ & $10 \cdot 2$ \\
\hline R & 1 \\
\hline$R^{\prime}$ & $1,10^{2}, 10^{4}$ \\
\hline
\end{tabular}




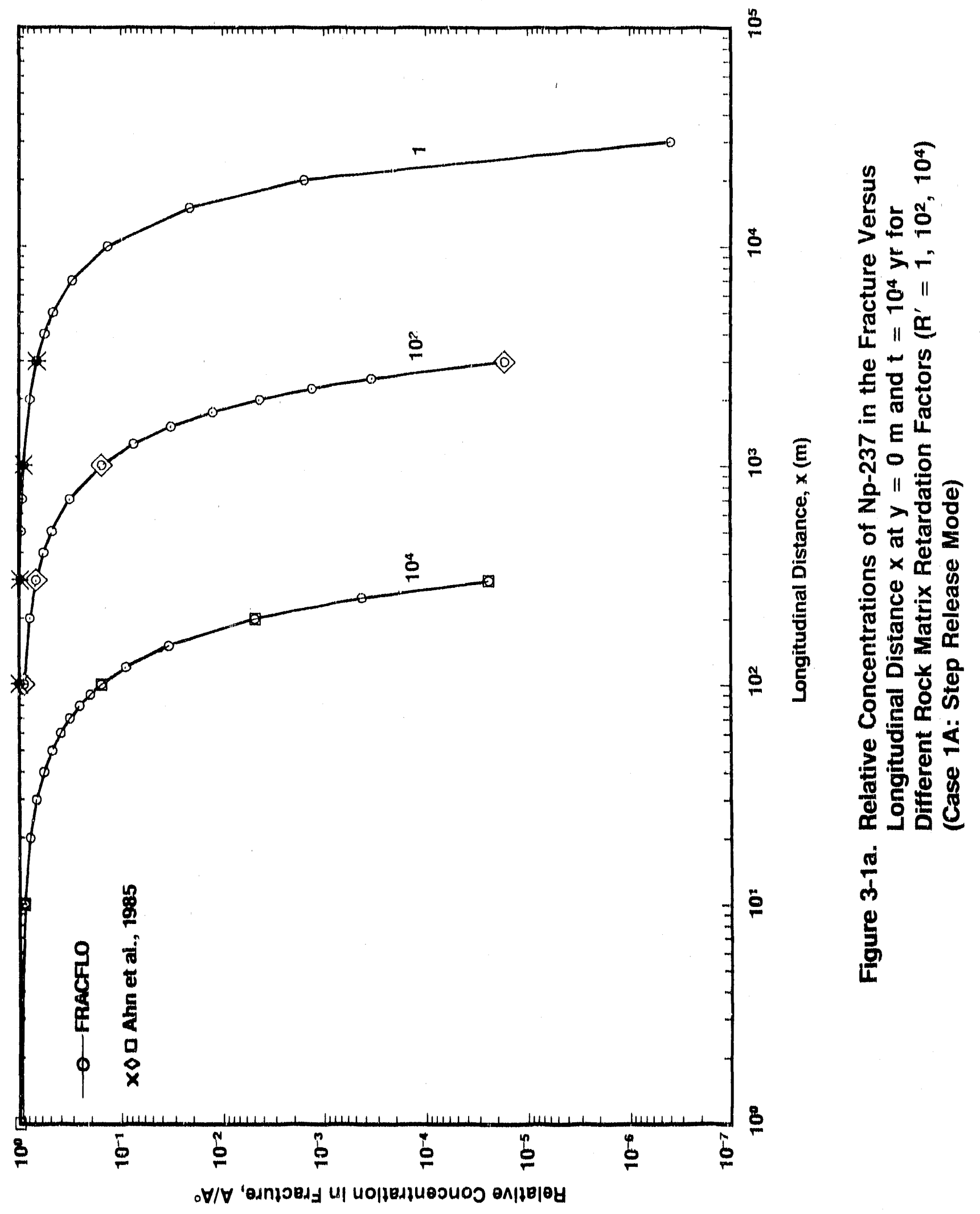




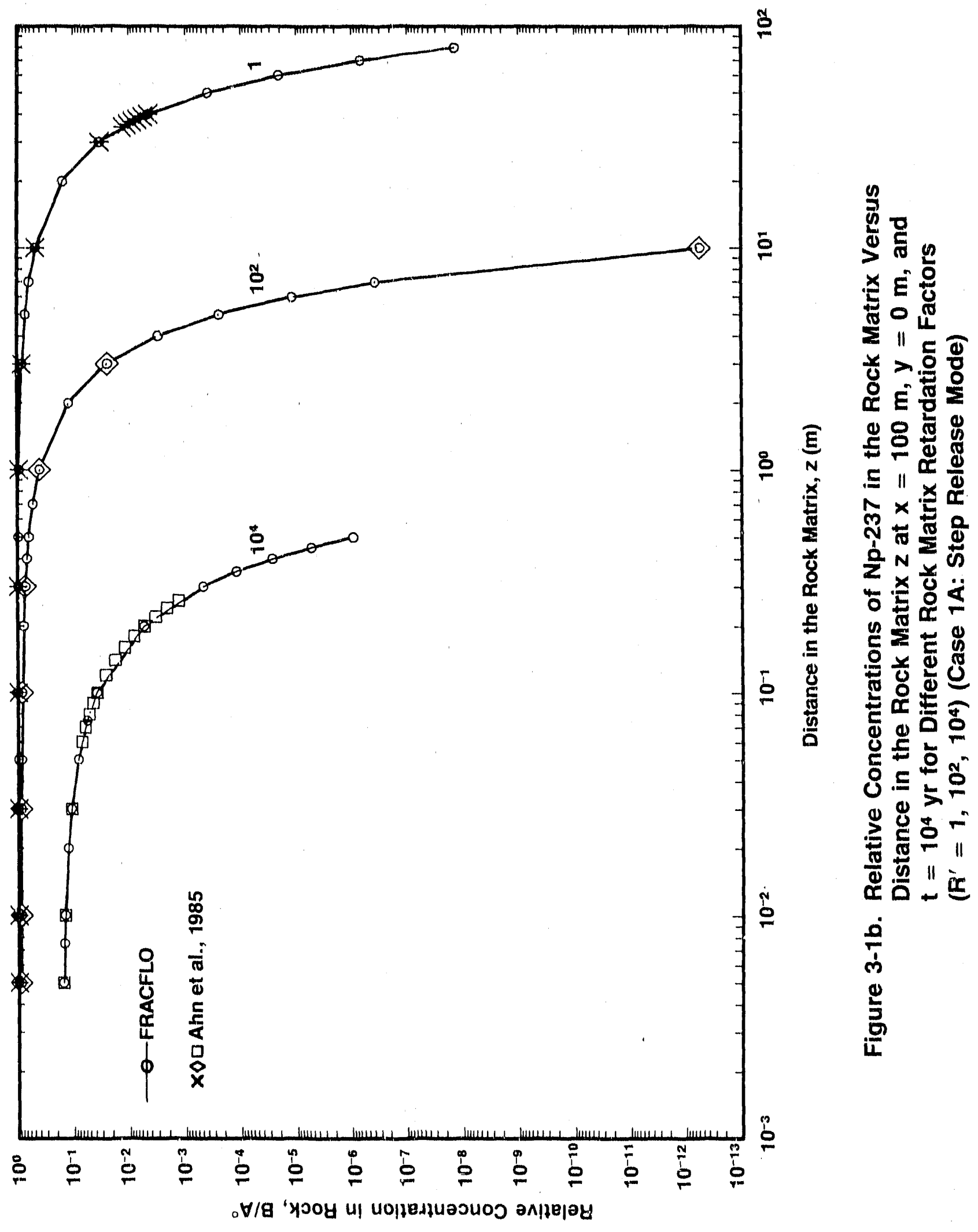


Table 3-2a. Case 1A Results: Relative Concentration, Mass Flux, and Cumulative Mass Flux in the Fracture for $\mathrm{Np}-237 \mathrm{With}$ Infinite Diffusion at Time $t=10^{4} \mathrm{yr}$.and Rock . Matrix Retardation Factor $\mathrm{R}^{\prime}=1$ (Step Release Mode)

\begin{tabular}{|c|c|c|c|}
\hline $\begin{array}{l}\text { Longi tudinal } \\
\text { Distance } \\
\qquad \times(m)\end{array}$ & $\begin{array}{c}\text { Concentration } \\
{ }_{0}^{\circ} / A^{-}\end{array}$ & $\begin{array}{c}\text { Mass Flux } \\
0_{0} / A(m / y r)\end{array}$ & $\begin{array}{c}\text { Cumulative } \\
\text { Mass Flux } \\
\text { M/A (m) }\end{array}$ \\
\hline $\begin{array}{l}1.01 \quad+01 \\
1.00 \quad+02 \\
1.200 E+02 \\
1.500 E+02 \\
2.000 E+02\end{array}$ & $\begin{array}{l}9.956 E-01 \\
9.855 E-01 \\
9.833 E-01 \\
9.799 E-01 \\
9.743 E-01\end{array}$ & $\begin{array}{l}9.957 E+\infty 0 \\
9.855 E+00 \\
9.833 E+00 \\
9.799 E+00 \\
9.743 E+00\end{array}$ & $\begin{array}{l}9.961 E+04 \\
9.751 E+04 \\
9.705 E+04 \\
9.638 E+04 \\
9.522 E+04\end{array}$ \\
\hline $\begin{array}{l}2.500 E+02 \\
3.000 E+02 \\
4.000 E+02 \\
5.000 E+02 \\
7.000 E+02\end{array}$ & $\begin{array}{l}9.686 E-01 \\
8.630 E-01 \\
9.517 E-01 \\
9.404 E-01 \\
9.179 E-01\end{array}$ & $\begin{array}{l}9.686 E+00 \\
9.630 E+00 \\
9.517 E+00 \\
9.404 E+00 \\
9.179 E+00\end{array}$ & $\begin{array}{l}9.409 E+04 \\
9.297 E+04 \\
9.076 E+04 \\
8.859 E+04 \\
8.437 E+04\end{array}$ \\
\hline $\begin{array}{l}1.000 E+03 \\
1.250 E+03 \\
1.500 E+03 \\
1.750 E+03 \\
2.000 E+03\end{array}$ & $\begin{array}{l}8.841 E-01 \\
8.560 E-01 \\
8.281 E-01 \\
8.002 E-01 \\
7.726 E-01\end{array}$ & $\begin{array}{l}8.841 E+00 \\
8.560 E+00 \\
8.281 E+00 \\
8.002 E+00 \\
7.726 E+00\end{array}$ & $\begin{array}{l}7.834 E+04 \\
7.357 E+04 \\
6.903 E+04 \\
6.471 E+04 \\
6.060 E+04\end{array}$ \\
\hline $\begin{array}{l}2.250 E+03 \\
2.500 E+03 \\
3.000 E+03 \\
4.000 E+03 \\
5.000 E+03\end{array}$ & $\begin{array}{l}7.452 E-01 \\
7.180 E-01 \\
6.645 E-01 \\
5.619 E-01 \\
4.667 E-01\end{array}$ & $\begin{array}{l}7.452 E+00 \\
7.180 E+\infty 0 \\
6.645 E+00 \\
5.619 E+00 \\
4.667 E+00\end{array}$ & $\begin{array}{l}5.670 E+04 \\
5.301 E+04 \\
4.619 E+04 \\
3.465 E+04 \\
2.556 E+04\end{array}$ \\
\hline $\begin{array}{l}7.000 E+03 \\
1.000 E+04 \\
1.500 E+04 \\
2.000 E+04 \\
3.000 E+04\end{array}$ & $\begin{array}{l}3.037 E-01 \\
1.356 E-01 \\
2.133 E-02 \\
1.561 E-03 \\
3.959 E-07\end{array}$ & $\begin{array}{l}3.037 E+00 \\
1.356 E+00 \\
2.133 E-01 \\
1.561 E-02 \\
3.960 E-06\end{array}$ & $\begin{array}{l}1.318 E+04 \\
4.202 E+03 \\
3.894 E+02 \\
1.746 E+01 \\
1.827 E-03\end{array}$ \\
\hline
\end{tabular}


Table 3-2b. Case 1A Results: Relative Concentration, Mass Flux, and Cumulative Mass Flux in the Fracture for $\mathrm{Np}-237 \mathrm{With}$ Infinite Diffusion at Time $t=10^{4} \mathrm{yr}$ and Rock. Matrix Retardation Factor $\mathrm{R}^{\prime}=100$ (Step Release Mode)

\begin{tabular}{|c|c|c|c|}
\hline $\begin{array}{l}\text { Longitudinal } \\
\text { Distance } \\
\qquad \times(m)\end{array}$ & $\begin{array}{c}\text { Concentration } \\
{ }_{A}{ }^{\circ}\end{array}$ & $\begin{array}{l}\text { Mass Flux } \\
0^{0}\left(m / A^{\prime}(m)\right)\end{array}$ & $\begin{array}{c}\text { Cumulative } \\
\text { Mass Flux } \\
0_{0}^{0}(m)\end{array}$ \\
\hline $\begin{array}{l}1.000 E+01 \\
1.000 E+02 \\
1.200 E+02 \\
1.500 E+02 \\
2.000 E+02\end{array}$ & $\begin{array}{l}9.855 E-01 \\
8.846 E-01 \\
8.624 E-01 \\
8.292 E-01 \\
7.746 E-01\end{array}$ & $\begin{array}{l}9.856 E+00 \\
8.847 E+00 \\
8.625 E+00 \\
8.293 E+00 \\
7.747 E+00\end{array}$ & $\begin{array}{l}9.782 E+04 \\
7.915 E+04 \\
7.545 E+04 \\
7.017 E+04 \\
6.202 E+04\end{array}$ \\
\hline $\begin{array}{l}2.500 E+02 \\
3.000 E+02 \\
4.000 E+02 \\
5.000 E+02 \\
7.000 E+02\end{array}$ & $\begin{array}{l}7.210 E-01 \\
6.688 E-01 \\
5.690 E-01 \\
4.769 E-01 \\
3.195 E-01\end{array}$ & $\begin{array}{l}7.211 E+\infty 0 \\
6.689 E+00 \\
5.691 E+\infty 0 \\
4.770 E+00 \\
3.196 E+00\end{array}$ & $\begin{array}{l}5.465 E+04 \\
4.801 E+04 \\
3.671 E+04 \\
2.771 E+04 \\
1.516 E+04\end{array}$ \\
\hline $\begin{array}{l}1.000 E+03 \\
1.250 E+03 \\
1.500 E+03 \\
1.750 E+03 \\
2.000 E+03\end{array}$ & $\begin{array}{l}1.548 E-01 \\
7.508 E-02 \\
3.251 E-02 \\
1.252 E-02 \\
4.277 E-03\end{array}$ & $\begin{array}{l}1.548 E+00 \\
7.511 E-01 \\
3.252 E-01 \\
1.253 E-01 \\
4.279 E-02\end{array}$ & $\begin{array}{l}5.517 E+03 \\
2.142 E+03 \\
7.531 E+02 \\
2.385 E+02 \\
6.781 E+01\end{array}$ \\
\hline $\begin{array}{l}2.250 E+03 \\
2.500 E+03 \\
3.000 E+03\end{array}$ & $\begin{array}{l}1.292 E-03 \\
3.442 E-04 \\
1.664 E-05\end{array}$ & $\begin{array}{l}1.292 E-02 \\
3.444 E-03 \\
1.685 E-04\end{array}$ & $\begin{array}{l}1.724 E+01 \\
3.905 E+00 \\
1.402 E-01\end{array}$ \\
\hline
\end{tabular}

Table 3-2c. Case 1A Results: Relative Concentration, Mass Flux, and Cumulative Mass Flux in the Fracture for Np-237 With Infinite Diffusion at Time $t=10^{4} \mathrm{yr}$ and Rock Matrix Retardation Factor $R^{\prime}=10,000$ (Step Release Mode)

\begin{tabular}{|c|c|c|c|}
\hline $\begin{array}{l}\text { Longitudinal } \\
\text { Distance } \\
\qquad \times(m)\end{array}$ & $\begin{array}{c}\text { Concentration } \\
A / A^{0}\end{array}$ & $\begin{array}{c}\text { Mass Flux } \\
F / A(m / y r)\end{array}$ & $\begin{array}{l}\text { Cumulative } \\
\text { Mass Fiux } \\
\text { M/A (m) }\end{array}$ \\
\hline $\begin{array}{l}1.000 E+00 \\
1.000 E+01 \\
2.000 E+01 \\
3.000 E+01 \\
4.000 E+01\end{array}$ & $\begin{array}{l}9.855 E-01 \\
8.847 E-01 \\
7.748 E-01 \\
6.693 E-01 \\
5.700 E-01\end{array}$ & $\begin{array}{l}9.866 E+00 \\
8.858 E+00 \\
7.759 E+00 \\
6.704 E+00 \\
5.709 E+00\end{array}$ & $\begin{array}{l}9.783 E+04 \\
7.943 E+04 \\
6.235 E+04 \\
4.838 E+04 \\
3.708 E+04\end{array}$ \\
\hline $\begin{array}{l}5.000 E+01 \\
6.000 E+01 \\
7.000 E+01 \\
8.000 E+01 \\
9.000 E+01\end{array}$ & $\begin{array}{l}4.783 E-01 \\
3.953 E-01 \\
3.217 E-01 \\
2.576 E-01 \\
2.030 E-01\end{array}$ & $\begin{array}{l}4.792 E+00 \\
3.961 E+00 \\
3.224 E+00 \\
2.582 E+00 \\
2.035 E+00\end{array}$ & $\begin{array}{l}2.808 E+04 \\
2.099 E+04 \\
1.549 E+04 \\
1.127 E+04 \\
8.095 E+03\end{array}$ \\
\hline $\begin{array}{l}1.000 E+02 \\
1.200 E+02 \\
1.500 E+02 \\
2.000 E+02 \\
2.500 E+02\end{array}$ & $\begin{array}{l}1.574 E-01 \\
8.997 E-02 \\
3.418 E-02 \\
4.786 E-03 \\
4.262 E-04\end{array}$ & $\begin{array}{l}1.578 E+00 \\
9.024 E-01 \\
3.430 E-01 \\
4.807 E-02 \\
4.284 E-03\end{array}$ & $\begin{array}{l}5.732 E+03 \\
2.753 E+03 \\
8.192 E+02 \\
7.956 E+01 \\
5.139 E+00\end{array}$ \\
\hline $\begin{array}{l}3.000 E+02 \\
4.000 E+02 \\
5.000 E+02\end{array}$ & $\begin{array}{l}2.393 E-05 \\
1.863 E-08 \\
2.218 E-12\end{array}$ & $\begin{array}{l}2.408 E-04 \\
1.878 E-07 \\
2.240 E-11\end{array}$ & $\begin{array}{l}2.473 E-01 \\
1.047 E-04 \\
8.408 E-09\end{array}$ \\
\hline
\end{tabular}


Table 3-2d. Case 1A Results: Relative Concentration in Rock Matrix $\left(\mathrm{B} / \mathrm{A}^{\circ}\right)$ for Np-237 at $x=100 \mathrm{~m}$ (Step Release Mode)

\begin{tabular}{|c|c|c|c|}
\hline $\begin{array}{l}\text { Elevation } \\
z \quad(m)\end{array}$ & $R^{\prime}=1$ & $R^{\prime}=100$ & $R^{\prime}=10,000$ \\
\hline $\begin{array}{l}5.000 E-03 \\
7.500 E-03 \\
1.000 E-02 \\
2.000 E-02 \\
3.000 E-02\end{array}$ & $\begin{array}{l}9.855 E-04 \\
9.854 E-01 \\
9.852 E-01 \\
9.847 E-01 \\
9.841 E-01\end{array}$ & $\begin{array}{l}8.846 E-01 \\
8.832 E-01 \\
8.818 E-01 \\
8.763 E-01 \\
8.707 E-01\end{array}$ & $\begin{array}{l}1.574 E-01 \\
1.523 E-01 \\
1.473 E-01 \\
1.286 E-01 \\
1.118 E-01\end{array}$ \\
\hline $\begin{array}{l}5.000 E-02 \\
6.000 E-02 \\
7.000 E-02 \\
7.500 E-02 \\
8.000 E-02\end{array}$ & $\begin{array}{l}9.830 E-01 \\
9.824 E-01 \\
9.819 E-01 \\
9.816 E-01 \\
9.813 E-01\end{array}$ & $\begin{array}{l}8.598 E-01 \\
8.541 E-01 \\
8.485 E-01 \\
8.458 E-01 \\
8.430 E-01\end{array}$ & $\begin{array}{l}8.339 E-02 \\
7.156 E-02 \\
6.114 E-02 \\
5.642 E-02 \\
5.201 E-02\end{array}$ \\
\hline $\begin{array}{l}9.000 E-02 \\
1.000 E-01 \\
1.200 E-01 \\
1.400 E-01 \\
1.600 E-01\end{array}$ & $\begin{array}{l}9.807 E-01 \\
9.802 E-01 \\
9.790 E-01 \\
9.779 E-01 \\
9.768 E-01\end{array}$ & $\begin{array}{l}8.375 E-01 \\
8.320 E-01 \\
8.210 E-01 \\
8.100 E-01 \\
7.991 E-01\end{array}$ & $\begin{array}{l}4.405 E-02 \\
3.714 E-02 \\
2.606 E-02 \\
1.796 E-02 \\
1.215 E-02\end{array}$ \\
\hline $\begin{array}{l}1.800 E-01 \\
2.000 E-01 \\
2.200 E-01 \\
2.400 E-01 \\
2.800 E-01\end{array}$ & $\begin{array}{l}9.757 E-01 \\
9.745 E-01 \\
9.734 E-01 \\
9.723 E-01 \\
9.712 E-01\end{array}$ & $\begin{array}{l}7.882 E-01 \\
7.774 E-01 \\
7.866 E-01 \\
7.558 E-01 \\
7.451 E-01\end{array}$ & $\begin{array}{l}8.078 E-03 \\
5.271 E-03 \\
3.377 E-03 \\
2.124 E-03 \\
1.311 E-03\end{array}$ \\
\hline $\begin{array}{l}\text { 3. OOOE-01 } \\
3.500 E-01 \\
4.000 E-01 \\
4.500 E-01 \\
5.000 E-01\end{array}$ & $\begin{array}{l}9.689 E-01 \\
9.661 E-01 \\
9.633 E-01 \\
9.605 E-01 \\
9.577 E-01\end{array}$ & $\begin{array}{l}7.239 E-01 \\
6.976 E-01 \\
6.716 E-01 \\
6.461 E-01 \\
6.209 E-01\end{array}$ & $\begin{array}{l}4.726 E-04 \\
1.187 E-04 \\
2.848 E-05 \\
5.244 E-06 \\
9.212 E-07\end{array}$ \\
\hline $\begin{array}{l}7.000 E-01 \\
1.000 E+00 \\
2.000 E+00 \\
3.000 E+00 \\
4.000 E+00\end{array}$ & $\begin{array}{l}9.464 E-01 \\
9.296 E-01 \\
8.738 E-01 \\
8.185 E-01 \\
7.642 E-01\end{array}$ & $\begin{array}{l}5.249 E-01 \\
3.966 E-01 \\
1.201 E-01 \\
2.373 E-02 \\
2.990 E-03\end{array}$ & \\
\hline $\begin{array}{l}5.000 E+00 \\
6.000 E+00 \\
7.000 E+00 \\
1.000 E+01 \\
2.000 E+01\end{array}$ & $\begin{array}{l}7.109 E-01 \\
6.591 E-01 \\
6.088 E-01 \\
4.692 E-01 \\
1.528 E-01\end{array}$ & $\begin{array}{l}2.369 E-04 \\
1.168 E-05 \\
3.568 E-07 \\
5.479 E-13\end{array}$ & \\
\hline $\begin{array}{l}3.000 E+01 \\
3.500 E+01 \\
3.600 E+01 \\
3.700 E+01 \\
3.800 E+01\end{array}$ & $\begin{array}{l}3.256 E-02 \\
1.274 E-02 \\
1.041 E-02 \\
8.476 E-03 \\
6.867 E-03\end{array}$ & & \\
\hline $\begin{array}{l}3.800 E+01 \\
4.000 E+01 \\
5.000 E+01 \\
6.000 E+01 \\
7.000 E+01\end{array}$ & $\begin{array}{l}5.538 E-03 \\
4.446 E-03 \\
3.824 E-04 \\
2.051 E-05 \\
6.812 E-07\end{array}$ & & \\
\hline $8.000 E+01$ & $1.395 E-O B$ & & \\
\hline
\end{tabular}


Figures 3-1c and 3-1d show the relative mass flux and cumulative mass flux in the fracture as a function of distance for a leaching time of $10^{4}$ years for the three values of the retardation factor. Results reported in Tables 3.2a through 3-2c agree very well with those reported by Ahn et al. (1985). In both cases the influence of an increasing retardation factor of the rock matrix seems to manifest itself by a decreasing mass accumulation at a given point, a consequence of the decreasing concentrations registered in such a situation.

Case 1A - Time-Dependent Concentrations, Mass Flux, and Cumulative Mass Flux

F'igures 3-1e, 3-1f, and 3-1g show the breakthrough curves of $\mathrm{Np}-237$ in the fracture, the temporal variations of the relative mass flux, and cumulative mass flux at an observation point located $100 \mathrm{~m}$ downstream from the source. These results were obtained through the solution of the general form of the transport equation. Tabulated results given in Tables 3-2e, 3-2f, and 3-2g indicate excellent agreement with those of Ahn et al. (1985).

Case 1B - Influence of Retardation in the Rock Matrix (No Longitudinal Dispersion)

Using the same set of data as for Case $1 \mathrm{~A}$ (see Table 3-1), a similar investigation was subsequently carried out, ignoring the longitudinal dispersion effects (i.e., $D_{x x}=0$ ) in order to verify this particular solution method (see Section 3.2).

Figures 3-2a, 3-2b, 3-2c, and 3-2d show the concentration in the fracture, the concentration in the rock matrix, the relative mass flux, and cumulative mass flux (at a distance $100 \mathrm{~m}$ downstream from the source). Tabulated results indicate excellent agreement with those of Ahn et al. (1985) (see also Tables 3-3a, 3-3b, 3-3c, and 3-3d). Note that because of the small magnitude in the value of the longitudinal dispersion considered in the former case (i.e., $\mathrm{D}_{\mathrm{xx}}=1.0 \mathrm{~m}^{2} / \mathrm{yr}$ ), the results yielded by their respective solutions are practically undistinguishable.

Case 1B - Time-Dependent Concentrations, Mass Flux, and Cumulative Mass Flux

Figures 3-2e, 3-2f, and 3-2g show the breakthrough curves of $\mathrm{Np}-237$ in the fracture, the variations of the relative mass flux, and cumulative mass flux at $100 \mathrm{~m}$ downstream from the source, respectively. Tabulated results given in Tables $3-3 e, 3-3 f$, and $3-3 g$, indicate excellent agreement with those of Ahn et al. (1985). 


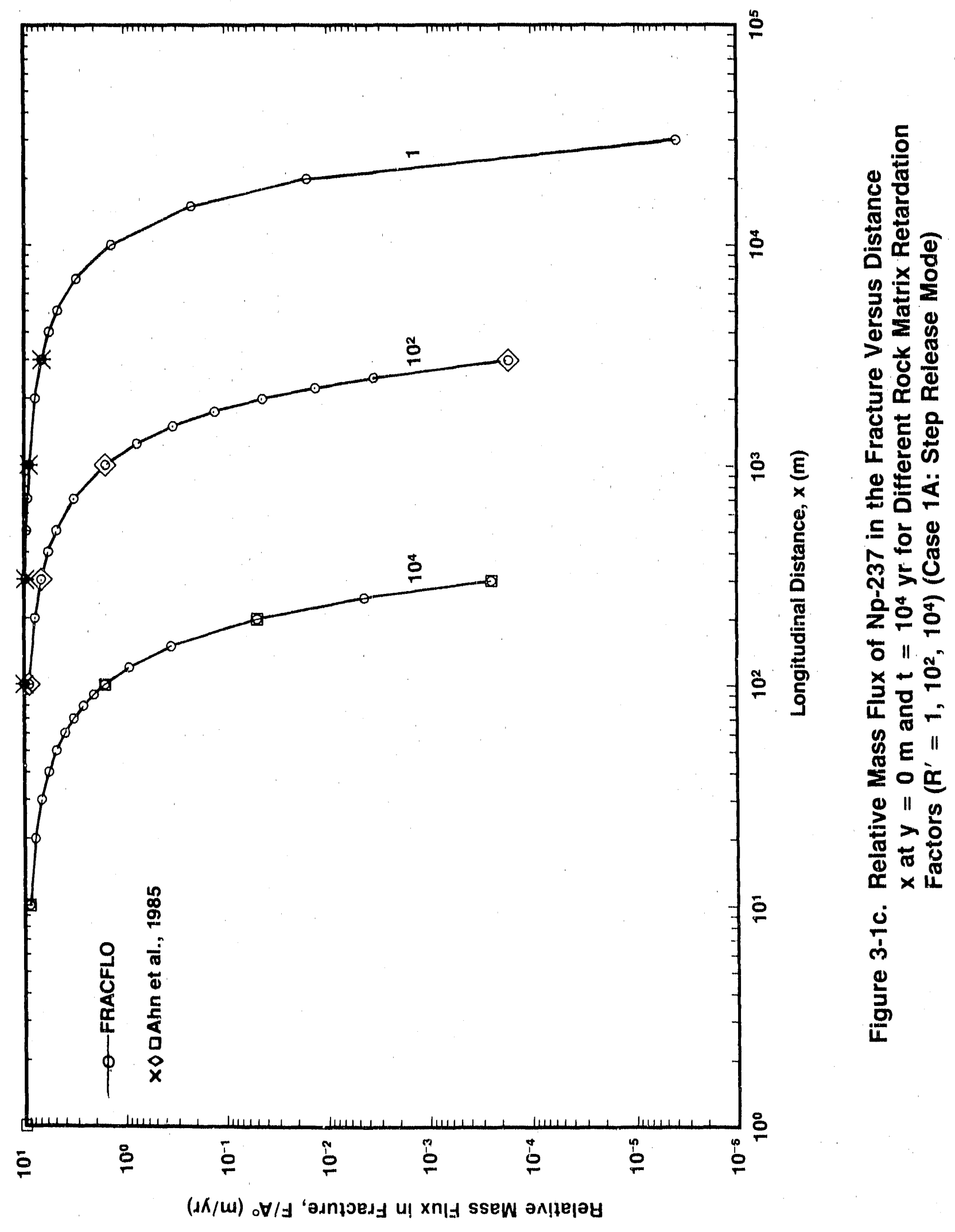




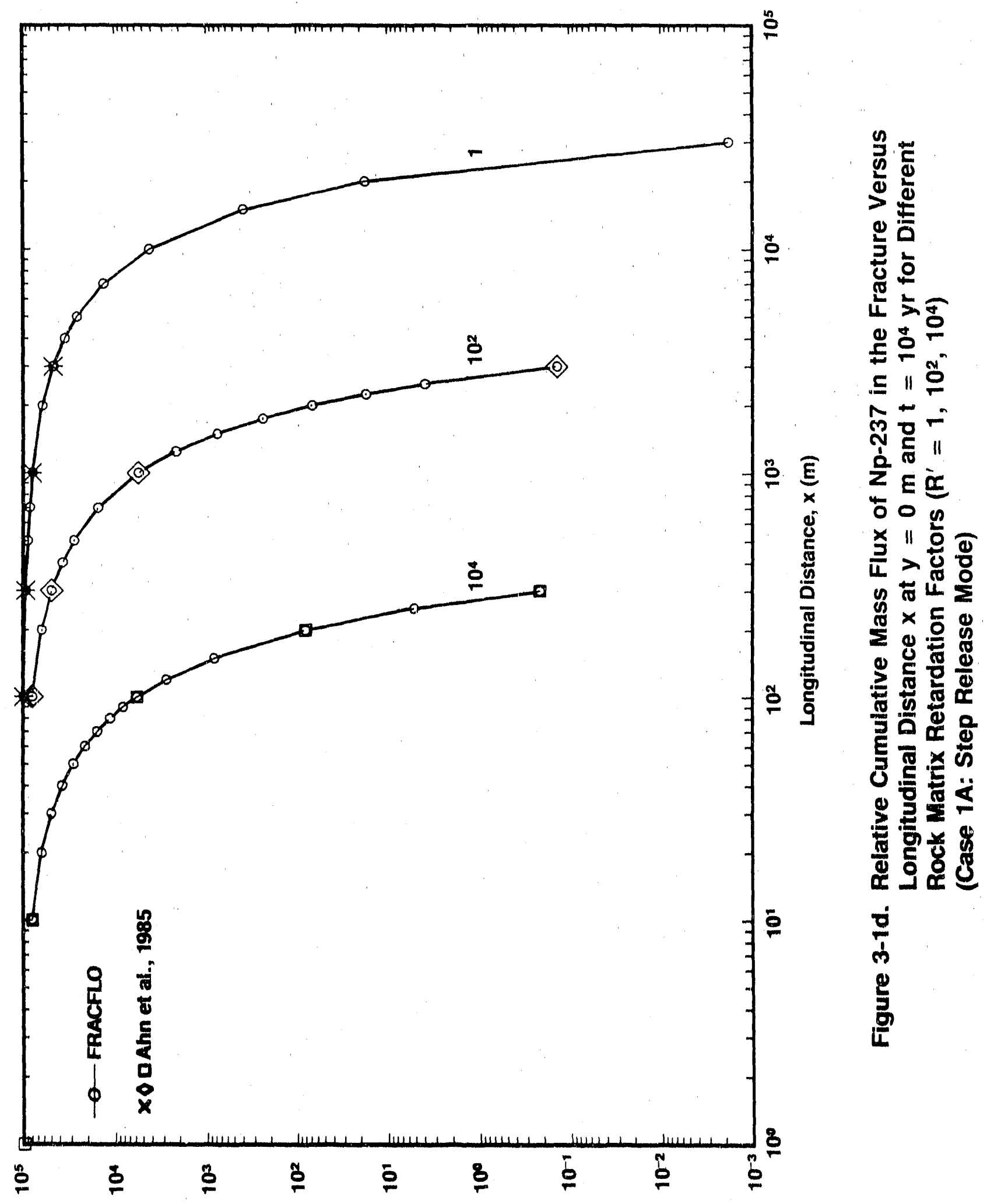

(w) $\circ \forall / W$ ' 


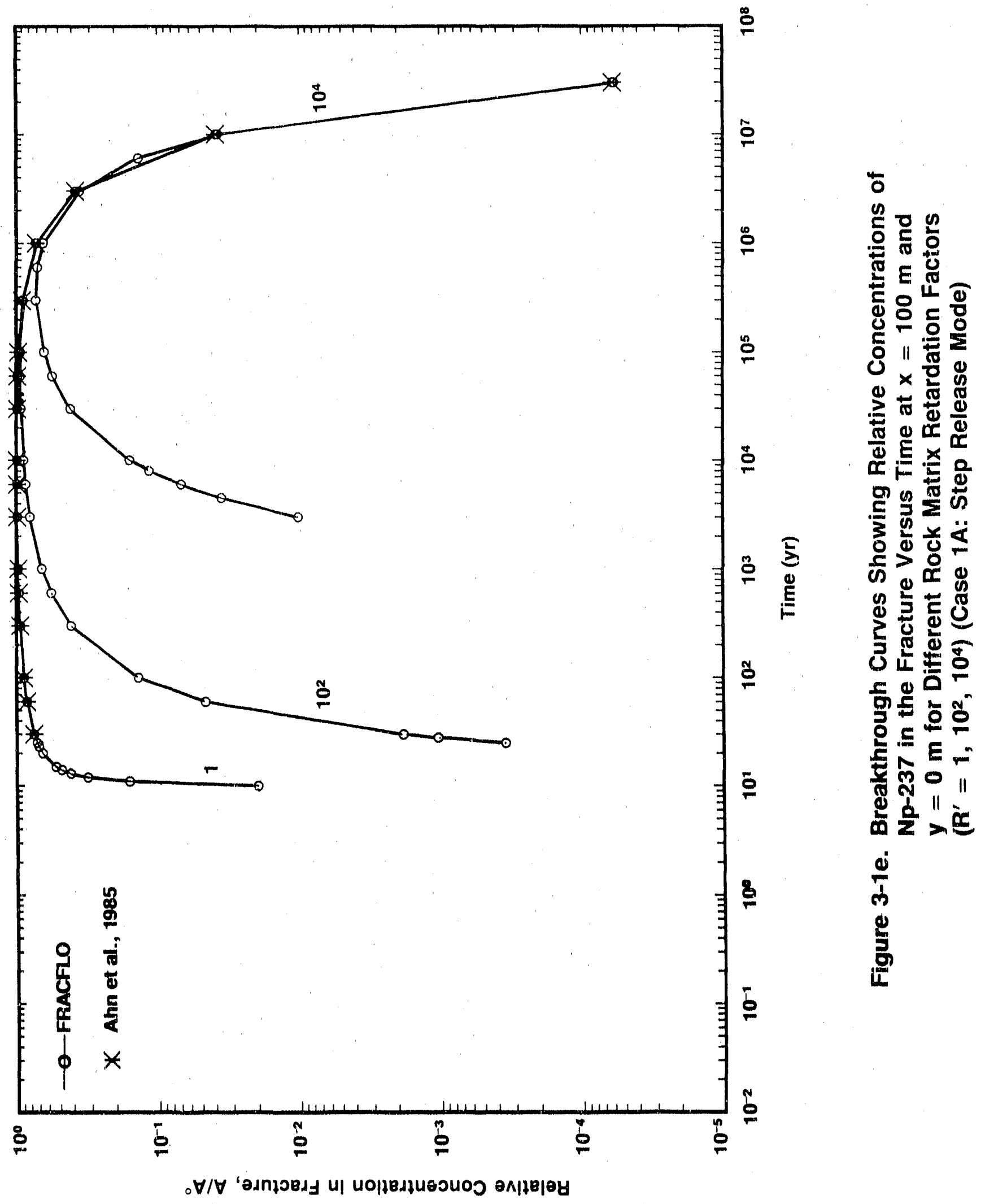




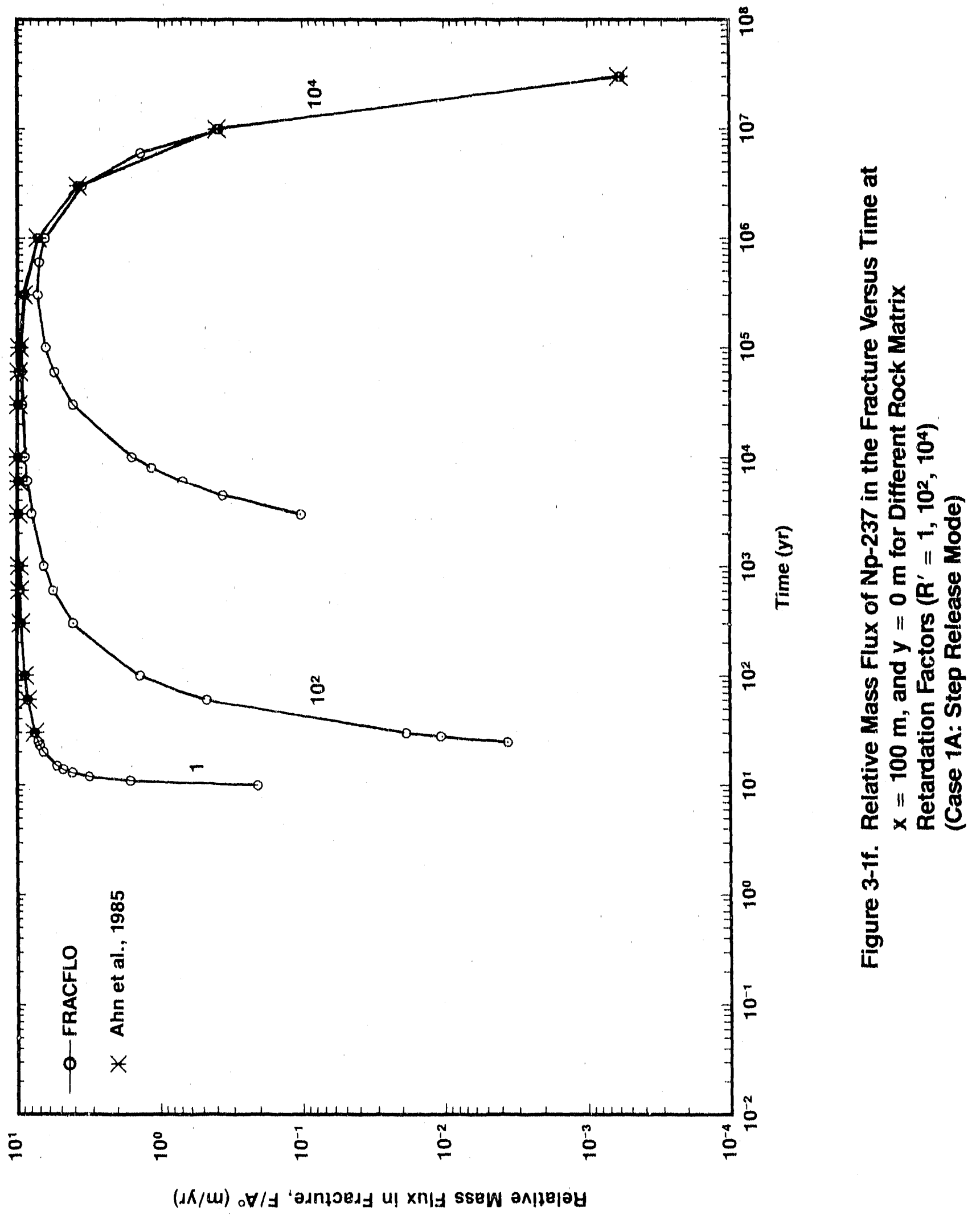




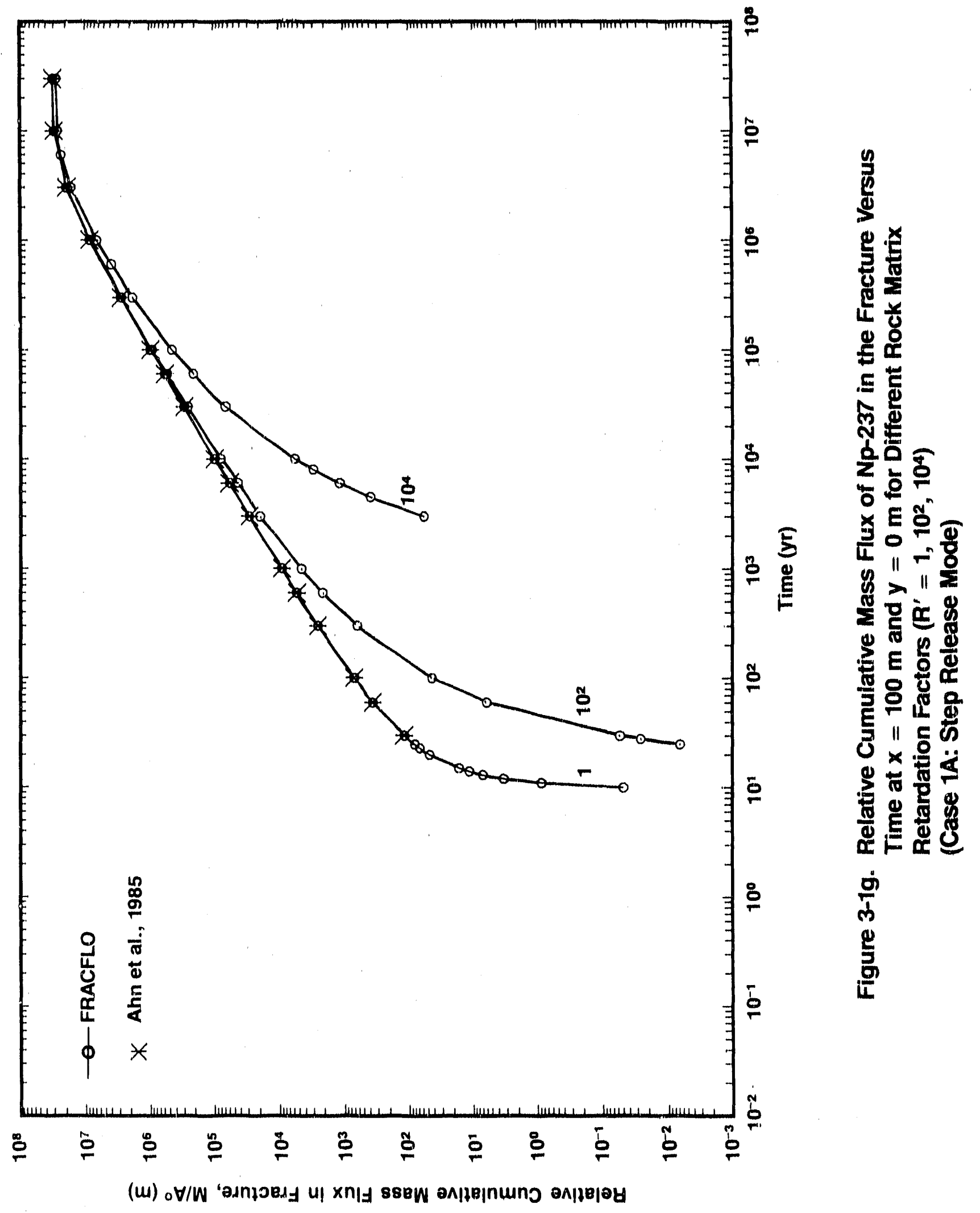


T'able 3.20. Case IA Results: Rolativo Concontration, Mass Flux, and Cumblative Mass Flux in tho Fracture for Np-237 Over'Timo With Rock Matrix Retardation Factor $R^{\prime}=1$ (Stop Roloaso Modo)

\begin{tabular}{|c|c|c|c|}
\hline Time $(y r)$ & $\begin{array}{c}\text { Comoentration } \\
A / A^{0}\end{array}$ & $\begin{array}{l}\text { Mass Flux } \\
F / A_{0}^{(m / y n)}\end{array}$ & $\begin{array}{c}\text { Cumulative } \\
\text { Mass Flux. } \\
\text { M/A }^{\circ}(m)\end{array}$ \\
\hline $\begin{array}{l}1.000 E+01 \\
1.100 E+01 \\
1.200 E+01 \\
1.300 E+01 \\
1.400 E+01\end{array}$ & $\begin{array}{l}1.881 E-02 \\
1.587 E-01 \\
3.120 E-01 \\
4.109 E-01 \\
4.774 E-01\end{array}$ & $\begin{array}{l}2.084 E-01 \\
1.608 E+00 \\
3.137 E+00 \\
4.122 E+00 \\
4.784 E+00\end{array}$ & $\begin{array}{l}4,921 E-02 \\
8,813 E-01 \\
3,283 E+00 \\
0,948 E+00 \\
1,142 E+01\end{array}$ \\
\hline $\begin{array}{l}1.500 E+01 \\
2.000 E+01 \\
2.300 E+01 \\
2.500 E+01 \\
2.800 E+01\end{array}$ & $\begin{array}{l}6.257 E-01 \\
6.543 E-01 \\
6.946 E-01 \\
7.148 E-01 \\
7.387 E-01\end{array}$ & $\begin{array}{l}8.26 E E+00 \\
6.848 E+00 \\
6.960 E+00 \\
7.182 E+00 \\
7.390 E+00\end{array}$ & $\begin{array}{l}1.648 E+01 \\
4.649 E+01 \\
\text { B.677E+01 } \\
8.088 E+01 \\
1.027 \mathrm{E}+02\end{array}$ \\
\hline $\begin{array}{l}3.000 E+01 \\
\text { B. } 000 E+01 \\
1.000 E+02 \\
\text { 3. } 000 E+02 \\
\text { B. } 000 E+02\end{array}$ & $\begin{array}{l}7.517 E-01 \\
8.414 E-01 \\
8.815 E-01 \\
9.337 E-01 \\
9.534 E-01\end{array}$ & $\begin{array}{l}7.520 E+00 \\
8.416 E+00 \\
8.816 E+00 \\
9.338 E+00 \\
9.534 E+00\end{array}$ & $\begin{array}{l}1.178 E+02 \\
\text { 3. } 898 E+02 \\
7.084 E+02 \\
2.836 E+03 \\
\text { E. } 372 E+03\end{array}$ \\
\hline $\begin{array}{l}1.000 E+03 \\
3.000 E+03 \\
4.500 E+03 \\
6.000 E+03 \\
8.000 E+03\end{array}$ & $\begin{array}{l}9.838 E-01 \\
9.784 E-01 \\
9.817 E-01 \\
9.835 E-01 \\
9.848 E-01\end{array}$ & $\begin{array}{l}9.839 E+00 \\
9.784 E+00 \\
9.817 E+00 \\
9.835 E+00 \\
9.848 E+00\end{array}$ & $\begin{array}{l}9.209 E+03 \\
2.867 E+04 \\
4.338 E+04 \\
5.812 E+04 \\
7.780 E+04\end{array}$ \\
\hline $\begin{array}{l}1.000 E+04 \\
3.000 E+04 \\
6.000 E+04 \\
1.000 E+05 \\
3.000 E+05\end{array}$ & $\begin{array}{l}9.855 E-01 \\
9.839 E-01 \\
9.762 E-01 \\
9.647 E-01 \\
9.055 E-01\end{array}$ & $\begin{array}{l}9.8 E 5 E+00 \\
9.839 E+00 \\
9.762 E+00 \\
9.647 E+00 \\
9.055 E+00\end{array}$ & $\begin{array}{l}9.751 E+04 \\
2.84 B E+05 \\
5.88 B E+05 \\
9.788 E+05 \\
2.847 E+06\end{array}$ \\
\hline $\begin{array}{l}\text { B. } \\
1.000 E+005 \\
3.000 E+00 \\
6.000 E+06 \\
1.000 E+07\end{array}$ & $\begin{array}{l}8.222 E-01 \\
7.22 E E-01 \\
3.782 E-01 \\
1.431 E-01 \\
3.919 E-02\end{array}$ & $\begin{array}{l}8.222 E+00 \\
7.225 E+00 \\
3.782 E+00 \\
1.431 E+00 \\
3.919 E-01\end{array}$ & $\begin{array}{l}\text { E. } 437 E+06 \\
8.522 E+0 B \\
1.818 E+07 \\
2.842 E+07 \\
2.863 E+07\end{array}$ \\
\hline $3.000 E+07$ & $6.024 E-05$ & 6. $024 E-04$ & $3.084 E+07$ \\
\hline
\end{tabular}


I'ablo 3-2f. Case 1A Results: Rolatlvo Concontrution, Mrasg F'lux, und

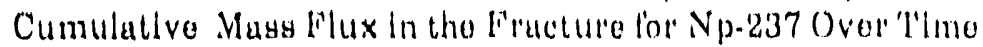
With Rook Matrix Retardation Fuctor' $R^{\prime}=100$ (Step Reluase Made)

\begin{tabular}{|c|c|c|c|}
\hline$T$ tme $(y r)$ & $\begin{array}{c}\text { Conoentration } \\
A / A\end{array}$ & $\begin{array}{c}\operatorname{Masx} F 1 u x \\
F / A_{0}(m / y r)\end{array}$ & $\begin{array}{c}\text { Cumulat fve } \\
\text { Mass Flux } \\
M / A(m)\end{array}$ \\
\hline $\begin{array}{l}2, \text { SOOE +01 } \\
2.800 E+01 \\
3,000 E+01 \\
8,000 E+01 \\
1.000 E+02\end{array}$ & $\begin{array}{l}3,501 E-04 \\
1.042 E-03 \\
1.824 E-03 \\
4,849 E-02 \\
1.370 E-01\end{array}$ & $\begin{array}{l}3.562 E-03 \\
1.057 E-02 \\
1.848 E-02 \\
4.673 E-01 \\
1.374 E+00\end{array}$ & $\begin{array}{l}\text { G. EEEE-O3 } \\
\text { 2. 6E5E-02 } \\
\text { E. } 512 E-02 \\
\text {. . } 03 E E+00 \\
4.281 E+01\end{array}$ \\
\hline $\begin{array}{l}3, \text { OOOE +02 } \\
3, \text { OOOE +02 } \\
1,000 E+03 \\
3, \text { OOOE +03 } \\
4, \text { SOOE+03 }\end{array}$ & $\begin{array}{l}\text { 4. O6BE-01 } \\
\text { E. } 904 E-01 \\
6.929 E-01 \\
7.9 B 2 E-01 \\
8.316 E-01\end{array}$ & $\begin{array}{l}4.170 E+00 \\
5.5 O B E+00 \\
f .533 E+00 \\
7.854 E+00 \\
8.318 E+00\end{array}$ & $\begin{array}{l}8.325 E+02 \\
2.118 E+03 \\
4.068 E+03 \\
1.942 E+04 \\
3.108 E+04\end{array}$ \\
\hline $\begin{array}{l}\text { B. OOOE +03 } \\
8, \text { OOOE +03 } \\
1, \text { OOOE+04 } \\
3,000 E+04 \\
\text { B. OOOE +04 }\end{array}$ & $\begin{array}{l}8, B 3 . E-01 \\
8,720 E-01 \\
8,848 E-01 \\
9.259 E-01 \\
9,386 E-01\end{array}$ & $\begin{array}{l}8,535 E+00 \\
8,722 E+00 \\
8.847 E+00 \\
8.259 E+00 \\
8.35 B E+00\end{array}$ & $\begin{array}{l}4.431 E+04 \\
0.158 E+04 \\
7.915 E+04 \\
2.615 E+08 \\
5.412 E+08\end{array}$ \\
\hline $\begin{array}{l}1.000 E+05 \\
3.000 E+05 \\
6.000 E+05 \\
1.000 E+0 B \\
3.000 E+0 B\end{array}$ & $\begin{array}{l}9.336 E-01 \\
8,887 E-01 \\
8.114 E-01 \\
7.182 E-01 \\
3.780 E-01\end{array}$ & $\begin{array}{l}9.33 E E+O O \\
8.887 E+O O \\
8.114 E+O O \\
7.152 E+O O \\
3.78 O E+O O\end{array}$ & $\begin{array}{l}8,153 E+O B \\
2,741 E+O B \\
5,291 E+O B \\
8,341 E+O B \\
1,890 E+07\end{array}$ \\
\hline $\begin{array}{l}\text { a, OOOE+0E } \\
1,000 E+07 \\
3,000 E+07\end{array}$ & $\begin{array}{l}1.42 E E-01 \\
3.90 E E-02 \\
6.013 E-05\end{array}$ & $\begin{array}{l}1.426 E+00 \\
3.906 E-01 \\
6.013 E-04\end{array}$ & $\begin{array}{l}2,612 E+07 \\
2.932 E+07 \\
3.052 E+07\end{array}$ \\
\hline
\end{tabular}


T'able 3-2g. Caso 1A Rosults: Rolative Concontration, Mass filux, and Cumulative Mass Hlax in the Fracture for . Vp.237 Ovor Timo With Rock Matrlx Rotardation Factor R' $=10,000$ (Stop Rolease Modo)

\begin{tabular}{|c|c|c|c|}
\hline Time $(y r)$ & $\begin{array}{c}\text { Conoentration } \\
0_{A}^{\circ} A^{\circ}\end{array}$ & $\begin{array}{l}\text { Mass Fiux } \\
F / A(\ln / y r)\end{array}$ & $\begin{array}{c}\text { Cumulative } \\
\text { Mass Fiux } \\
0_{0}^{0} \text { (m) }\end{array}$ \\
\hline $\begin{array}{l}3.0008+03 \\
4.400 E+03 \\
8.000 E+03 \\
8.000 E+03 \\
1.000 E+04\end{array}$ & $\begin{array}{l}1.018 E-02 \\
3.8 B 7 E-02 \\
6.844 E-02 \\
1.142 E-01 \\
1.574 E-01\end{array}$ & $\begin{array}{l}1,028 E-01 \\
3,875 E-01 \\
6,872 E-01 \\
1.148 E+00 \\
1.578 E+00\end{array}$ & $\begin{array}{l}8.797 E+01 \\
3.883 E+02 \\
1.167 E+03 \\
3.002 E+03 \\
\text { 8. } 732 E+03\end{array}$ \\
\hline $\begin{array}{l}3.000 E+04 \\
6.000 E+04 \\
1.000 E+08 \\
3.000 E+05 \\
8.000 E+08\end{array}$ & $\begin{array}{l}\text { A. } 104 E-01 \\
5.829 E-01 \\
\text { B. } 339 E-01 \\
7.228 E-01 \\
7.041 E-01\end{array}$ & $\begin{array}{l}4.109 E+00 \\
8.533 E+00 \\
8.342 E+00 \\
7.227 E+00 \\
7.042 E+00\end{array}$ & $\begin{array}{l}9.687 E+04 \\
2.148 E+05 \\
4.844 E+08 \\
1.848 E+06 \\
4.002 E+08\end{array}$ \\
\hline $\begin{array}{l}1.000 E+08 \\
3.000 E+08 \\
8.0008+08 \\
1.000 E+07 \\
3.000 E+07\end{array}$ & $\begin{array}{l}\text { 8. } 420 E-01 \\
3.538 E-01 \\
1.368 E-01 \\
3.780 E-02 \\
5 ., 901 E-08\end{array}$ & $\begin{array}{l}\text { B. } 421 E+00 \\
3.538 E+00 \\
1.380 E+00 \\
3.781 E-01 \\
5.901 E-04\end{array}$ & $\begin{array}{l}6.698 E+06 \\
1.644 E+07 \\
2.330 E+07 \\
2.638 E+07 \\
2.765 E+07\end{array}$ \\
\hline
\end{tabular}




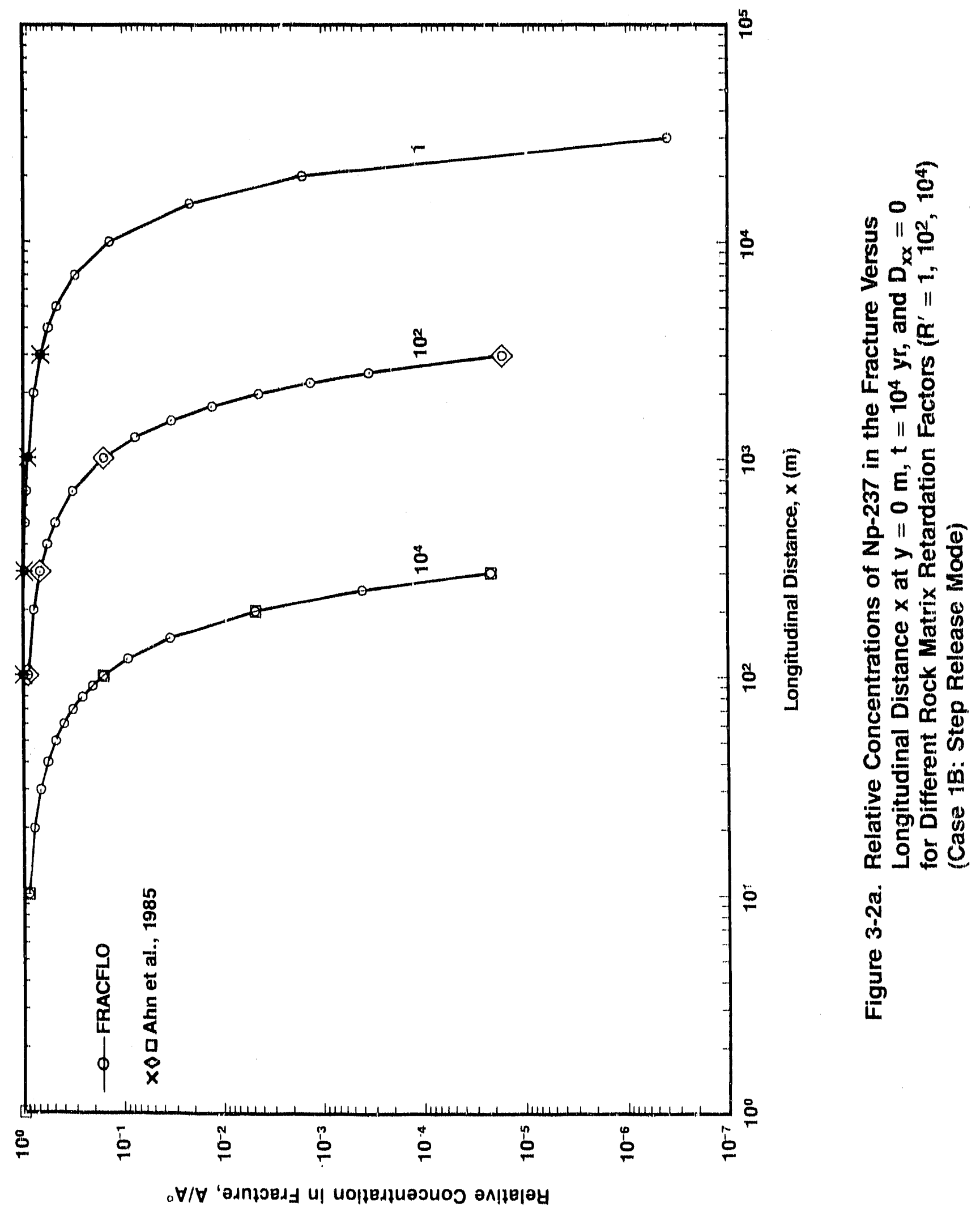




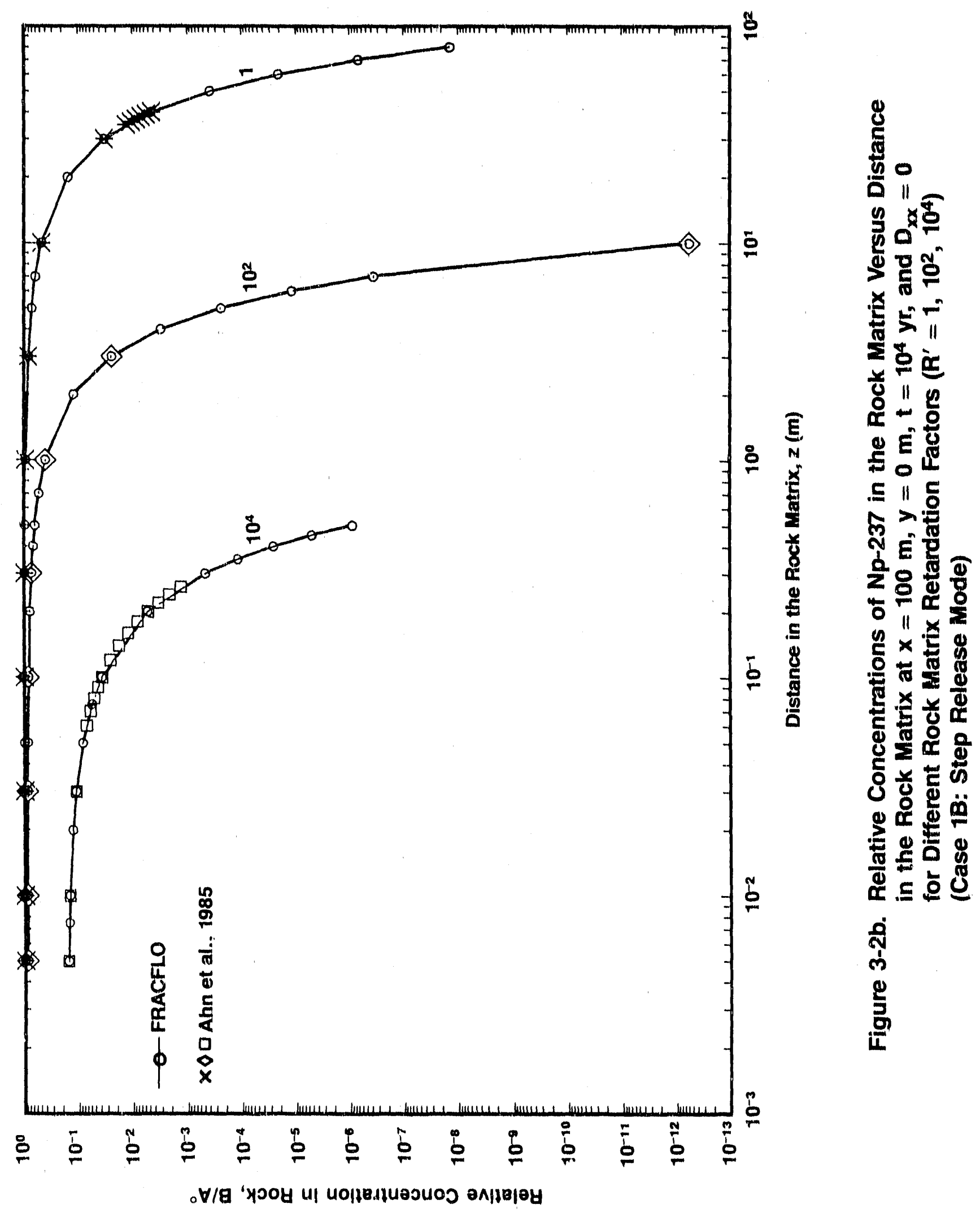




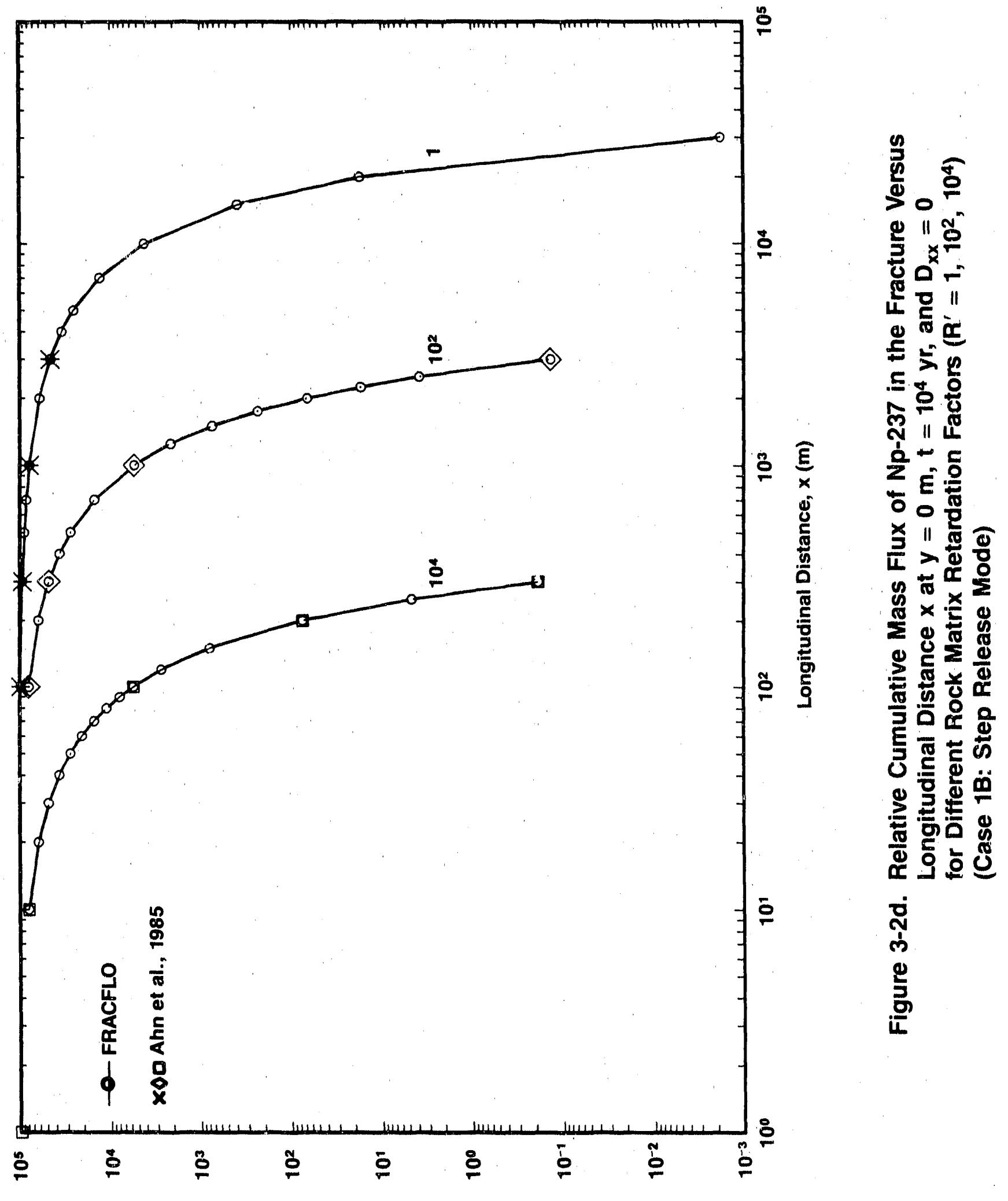

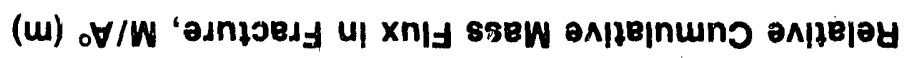




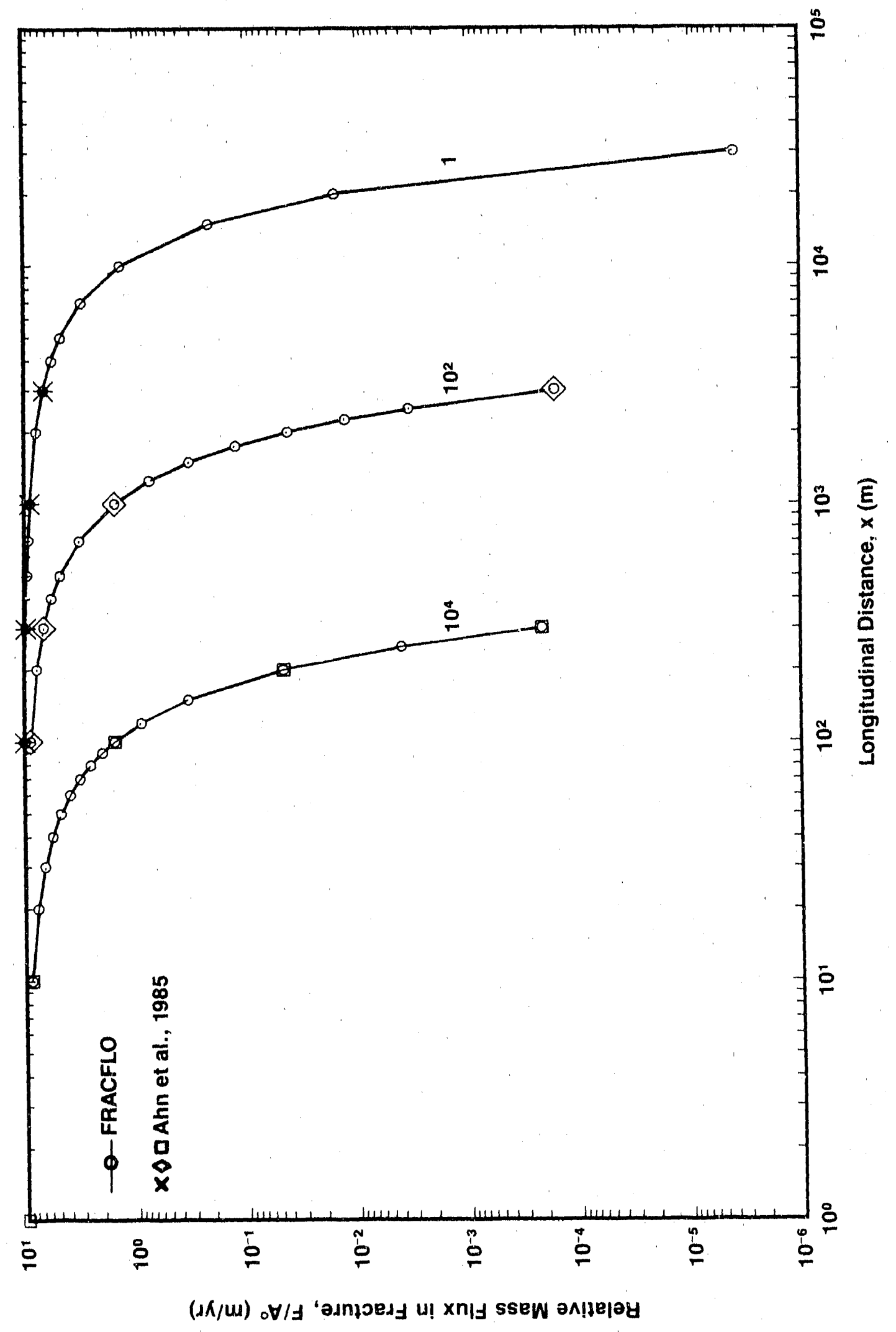

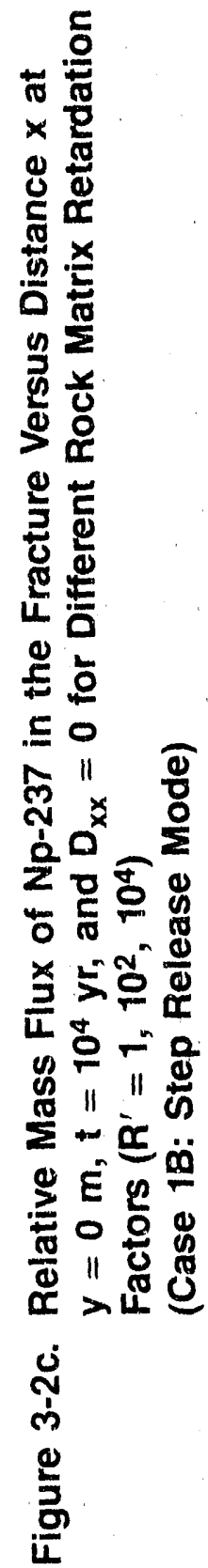


Table 3-3a. Case 1B Results: Relative Concentration, Mass Flux, and Cumulative Mass Flux in the Fracture for . Np.237 With Infinite Diffusion at Time $t=10^{4} \mathrm{yr}$ and Rock. Matrix Retardation Factor $R^{\prime}=1$ (Step Release . Mode)

\begin{tabular}{|c|c|c|c|}
\hline $\begin{array}{l}\text { Longitudinal } \\
\text { Distance } \\
\qquad \times(m)\end{array}$ & $\begin{array}{c}\text { Concentration } \\
{ }_{A}{ }^{\circ}\end{array}$ & $\begin{array}{l}\text { Mass Flux } \\
F / A(m / y r)\end{array}$ & $\begin{array}{c}\text { Cumulative } \\
\text { Mass Flux } \\
0 \\
\begin{array}{c}\text { M/A } \\
\text { (m) }\end{array}\end{array}$ \\
\hline $\begin{array}{l}1.000 E+01 \\
1.000 E+02 \\
1.200 E+02 \\
1.500 E+02 \\
2.000 E+02\end{array}$ & $\begin{array}{l}8.956 E-01 \\
9.855 E-01 \\
9.833 E-01 \\
9.799 E-01 \\
9.743 E-01\end{array}$ & $\begin{array}{l}9.956 E+00 \\
9.855 E+00 \\
9.833 E+00 \\
9.799 E+00 \\
9.743 E+00\end{array}$ & $\begin{array}{l}9.960 E+04 \\
9.750 E+04 \\
9.704 E+04 \\
9.1335 E+04 \\
9.521 E+04\end{array}$ \\
\hline $\begin{array}{l}2.500 E+02 \\
3.000 E+02 \\
4.000 E+02 \\
5.000 E+02 \\
7.000 E+02\end{array}$ & $\begin{array}{l}9.686 E-01 \\
9.630 E-01 \\
8.517 E-01 \\
9.404 E-01 \\
9.179 E-01\end{array}$ & $\begin{array}{l}9.68 E E+00 \\
9.630 E+00 \\
9.517 E+00 \\
9.404 E+00 \\
9.179 E+00\end{array}$ & $\begin{array}{l}9.408 E+04 \\
9.296 E+04 \\
9.075 E+04 \\
8.859 E+04 \\
8.437 E+04\end{array}$ \\
\hline $\begin{array}{l}1.000 E+03 \\
1.250 E+03 \\
1.500 E+03 \\
1.750 E+03 \\
2.000 E+03\end{array}$ & $\begin{array}{l}8.841 E-01 \\
8.560 E-01 \\
8.281 E-01 \\
8.002 E-01 \\
7.726 E-01\end{array}$ & $\begin{array}{l}8.841 E+00 \\
8.560 E+00 \\
8.281 E+00 \\
8.002 E+00 \\
7.726 E+00\end{array}$ & $\begin{array}{l}7.833 E+04 \\
7.356 E+04 \\
6.902 E+04 \\
6.470 E+04 \\
6.080 E+04\end{array}$ \\
\hline $\begin{array}{l}2.250 E+03 \\
2.500 E+03 \\
3.000 E+03 \\
4.000 E+03 \\
5.000 E+03\end{array}$ & $\begin{array}{l}7.452 E-01 \\
7.180 E-01 \\
6.645 E-01 \\
5.619 E-01 \\
4.666 E-01\end{array}$ & $\begin{array}{l}7.452 E+\infty 0 \\
7.180 E+00 \\
6.645 E+00 \\
5.619 E+00 \\
4.666 E+00\end{array}$ & $\begin{array}{l}5.670 E+04 \\
5.301 E+04 \\
4.619 E+04 \\
3.465 E+04 \\
2.556 E+04\end{array}$ \\
\hline $\begin{array}{l}7.000 E+03 \\
1.000 E+04 \\
1.500 E+04 \\
2.000 E+04 \\
3.000 E+04\end{array}$ & $\begin{array}{l}3.037 E-01 \\
1.356 E-01 \\
2.133 E-02 \\
1.560 E-03 \\
3.946 E-07\end{array}$ & $\begin{array}{l}3.037 E+00 \\
1.356 E+00 \\
2.133 E-01 \\
1.560 E-02 \\
3.946 E-06\end{array}$ & $\begin{array}{l}1.318 E+04 \\
4.201 E+03 \\
3.892 E+02 \\
1.744 E+01 \\
1.820 E-03\end{array}$ \\
\hline
\end{tabular}


Table 3-3b. Case 1B Results: Relative Concentration, Mass Flux, and Cumulative Mass Flux in the Fracture for Np-237 With Infinite Diffusion at Time $t=10^{4} \mathrm{yr}$ and Rock . Matrix Retardation Factor $R^{\prime}=100$ (Step Release Mode)

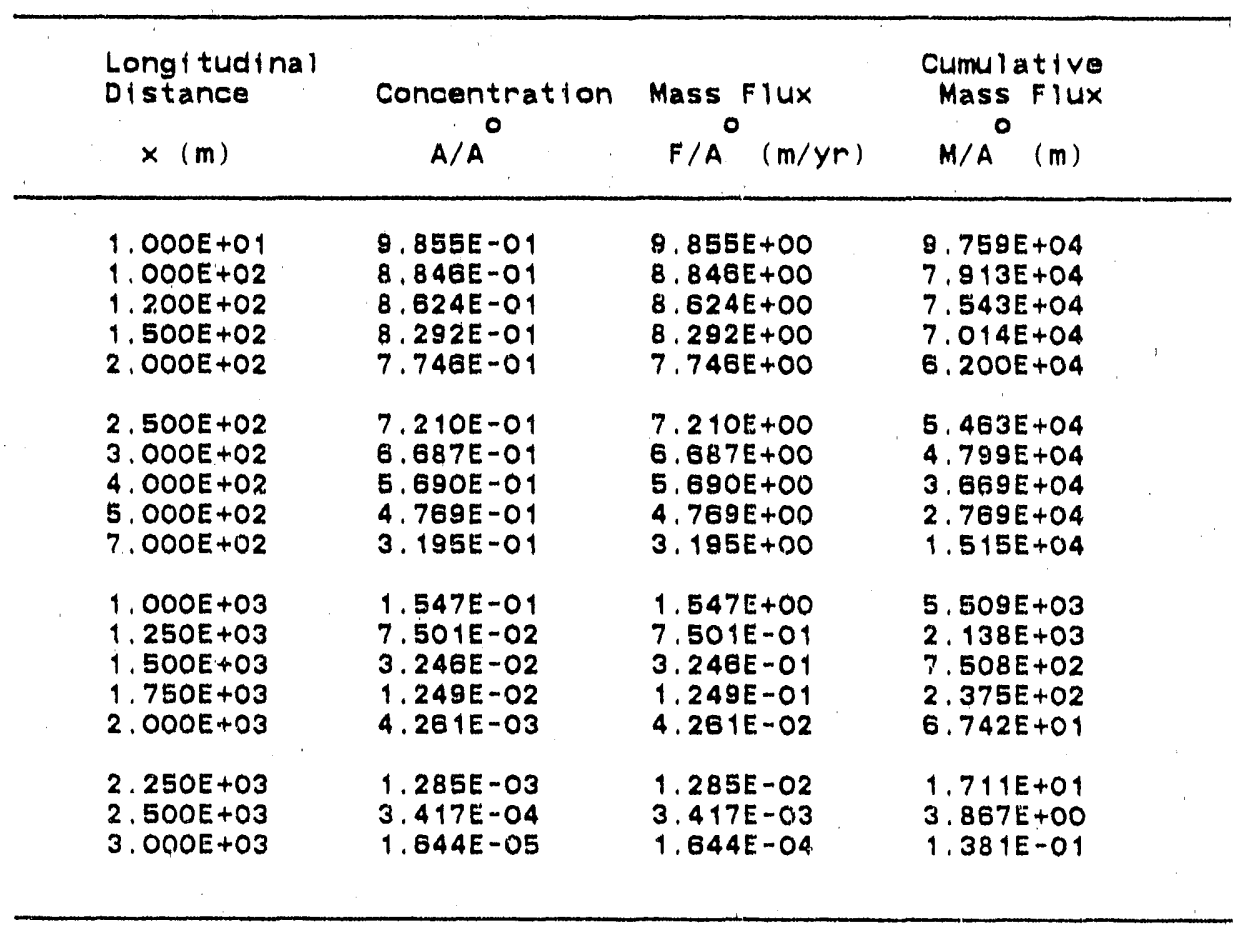

Table 3-3c. Case 1B Results: Relative Concentration, Mass Flux, and Cumulative Mass Flux in the Fracture for $\mathrm{Np}-237 \mathrm{With}$ Infinite Diffusion at Time $t=10^{4} \mathrm{yr}$ and Rock . Matrix Retardation Factor $R^{\prime}=10,000$ (Step Release Mode)

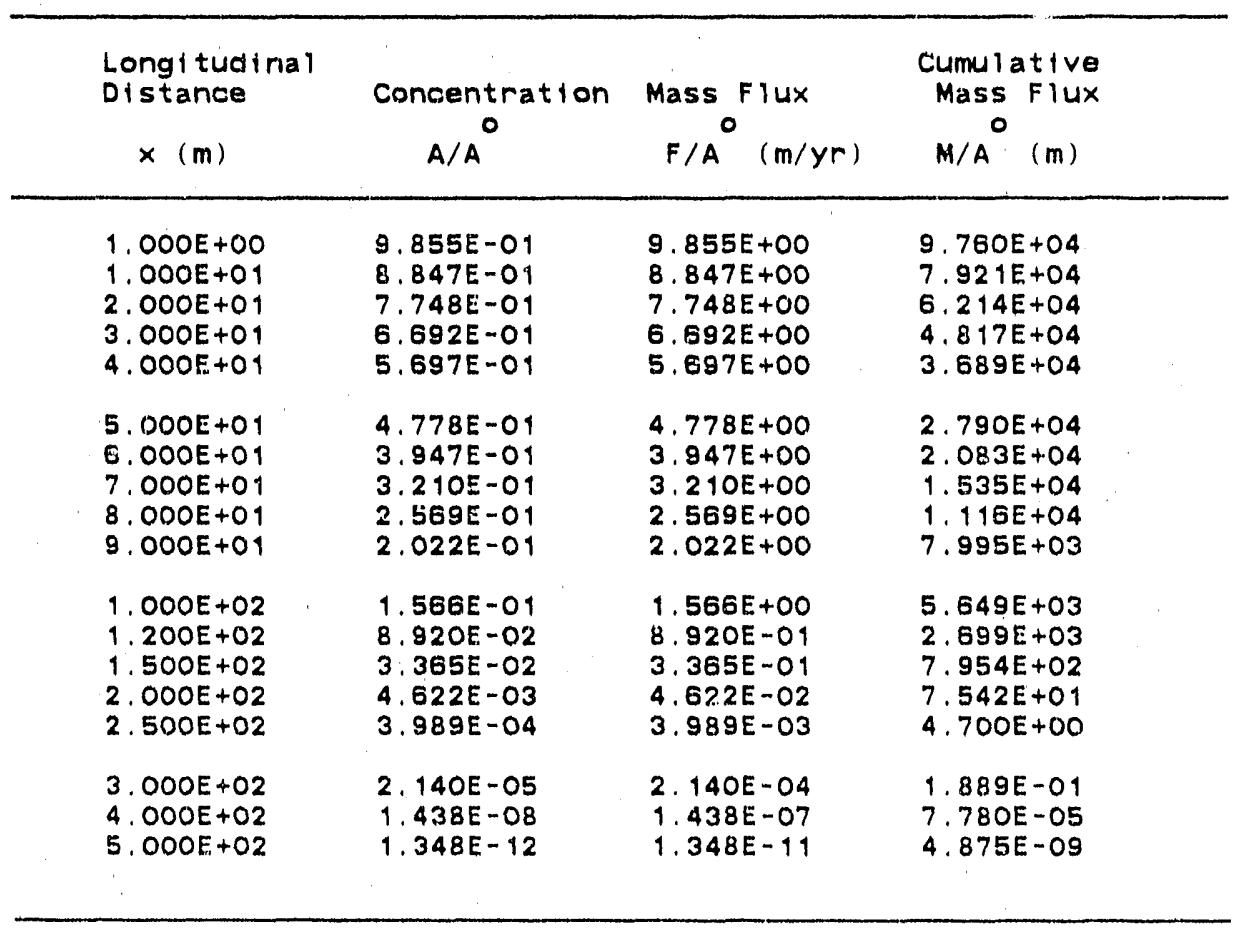


Table 3-3d. Case 1B Results: Relative Concentration in Rock Matrix (B/A ${ }^{\circ}$ for Np-237 at $\mathrm{x}=100 \mathrm{~m}$ and $\mathrm{D}_{\mathrm{xx}}=0$ (Step Release Mode)

\begin{tabular}{|c|c|c|c|}
\hline $\begin{array}{l}\text { Elevation } \\
z(m)\end{array}$ & $R^{\prime}=1$ & $R^{\prime}=100$ & $R^{\prime}=10,000$ \\
\hline $\begin{array}{l}5.000 E-03 \\
7.500 E-03 \\
1.000 E-02 \\
2.000 E-02 \\
3.000 E-02\end{array}$ & $\begin{array}{l}9.855 E-01 \\
9.854 E-01 \\
9.852 E-01 \\
9.847 E-01 \\
9.841 E-01\end{array}$ & $\begin{array}{l}8.846 E-01 \\
8.832 E-01 \\
8.818 E-01 \\
8.763 E-01 \\
8.707 E-01\end{array}$ & $\begin{array}{l}1.566 E-01 \\
1.515 E-01 \\
1.465 E-01 \\
1.278 E-01 \\
1.111 E-01\end{array}$ \\
\hline $\begin{array}{l}5.000 E-02 \\
6.000 E-02 \\
7.000 E-02 \\
7.500 E-02 \\
8.000 E-02\end{array}$ & $\begin{array}{l}9.830 E-01 \\
9.824 E-01 \\
9.819 E-01 \\
9.816 E-01 \\
9.813 E-01\end{array}$ & $\begin{array}{l}8.596 E-01 \\
8.541 E-01 \\
8.485 E-01 \\
8.458 E-01 \\
8.430 E-01\end{array}$ & $\begin{array}{l}8.278 E-02 \\
7.100 E-02 \\
6.063 E-02 \\
5.593 E-02 \\
5.155 E-02\end{array}$ \\
\hline $\begin{array}{l}9.000 E-02 \\
1.000 E-01 \\
1.200 E-01 \\
1.400 E-01 \\
1.600 E-01\end{array}$ & $\begin{array}{l}9.807 E-01 \\
9.802 E-01 \\
9.790 E-01 \\
9.779 E-01 \\
9.768 E-01\end{array}$ & $\begin{array}{l}8.375 E-01 \\
8.320 E-01 \\
8.210 E-01 \\
8.100 E-01 \\
7.891 E-01\end{array}$ & $\begin{array}{l}4.363 E-02 \\
3.877 E-02 \\
2.576 E-02 \\
1.773 E-02 \\
1.198 E-02\end{array}$ \\
\hline $\begin{array}{l}1.800 E-01 \\
2.000 E-01 \\
2.200 E-01 \\
2.400 E-01 \\
2.600 E-01\end{array}$ & $\begin{array}{l}9.757 E-01 \\
9.745 E-01 \\
9.734 E-01 \\
9.723 E-01 \\
9.712 E-01\end{array}$ & $\begin{array}{l}7.882 E-01 \\
7.774 E-01 \\
7.666 E-01 \\
7.558 E-01 \\
7.451 E-01\end{array}$ & $\begin{array}{l}7.953 E-03 \\
5.182 E-03 \\
3.314 E-03 \\
2.081 E-03 \\
1.282 E-03\end{array}$ \\
\hline $\begin{array}{l}3.000 E-01 \\
3.500 E-01 \\
4.000 E-01 \\
4.500 E-01 \\
5.000 E-0.1\end{array}$ & $\begin{array}{l}9.689 E-01 \\
9.661 E-01 \\
9.633 E-01 \\
9.605 E-01 \\
9.577 E-01\end{array}$ & $\begin{array}{l}7.238 E-01 \\
6.976 E-01 \\
6.716 E-01 \\
6.461 E-01 \\
6.209 E-01\end{array}$ & $\begin{array}{l}4.604 E-04 \\
1.150 E-04 \\
2.552 E-05 \\
5.024 E-06 \\
8.766 E-07\end{array}$ \\
\hline $\begin{array}{l}7.000 E-01 \\
1.000 E+00 \\
2.000 E+00 \\
3.000 E+00 \\
4.000 E+00\end{array}$ & $\begin{array}{l}9.464 E-01 \\
9.296 E-01 \\
8.738 E-01 \\
8.185 E-01 \\
7.642 E-01\end{array}$ & $\begin{array}{l}5.249 E-01 \\
3.966 E-01 \\
1.201 E-01 \\
2.372 E-02 \\
2.990 E-03\end{array}$ & \\
\hline $\begin{array}{l}5.000 E+00 \\
6.000 E+00 \\
7.000 E+00 \\
1.000 E+01 \\
2.000 E+01\end{array}$ & $\begin{array}{l}7.109 E-01 \\
6.591 E-01 \\
6.088 E-01 \\
4.692 E-01 \\
1.526 E-01\end{array}$ & $\begin{array}{l}2.368 E-04 \\
1.168 E-05 \\
3.566 E-07 \\
5.473 E-13\end{array}$ & \\
\hline $\begin{array}{l}3.000 E+01 \\
3.500 E+01 \\
3.600 E+01 \\
3.700 E+01 \\
3.800 E+01\end{array}$ & $\begin{array}{l}3.256 E-02 \\
1.274 E-02 \\
1.041 E-02 \\
8.476 E-03 \\
6.867 E-03\end{array}$ & . & \\
\hline $\begin{array}{l}3.900 E+01 \\
4.000 E+01 \\
5.000 E+01 \\
6.000 E+01 \\
7.000 E+01\end{array}$ & $\begin{array}{l}5.538 E-03 \\
4.448 E-03 \\
3.824 E-04 \\
2.051 E-05 \\
6.812 E-07\end{array}$ & & \\
\hline $8.000 E+01$ & $1.395 E-08$ & & \\
\hline
\end{tabular}




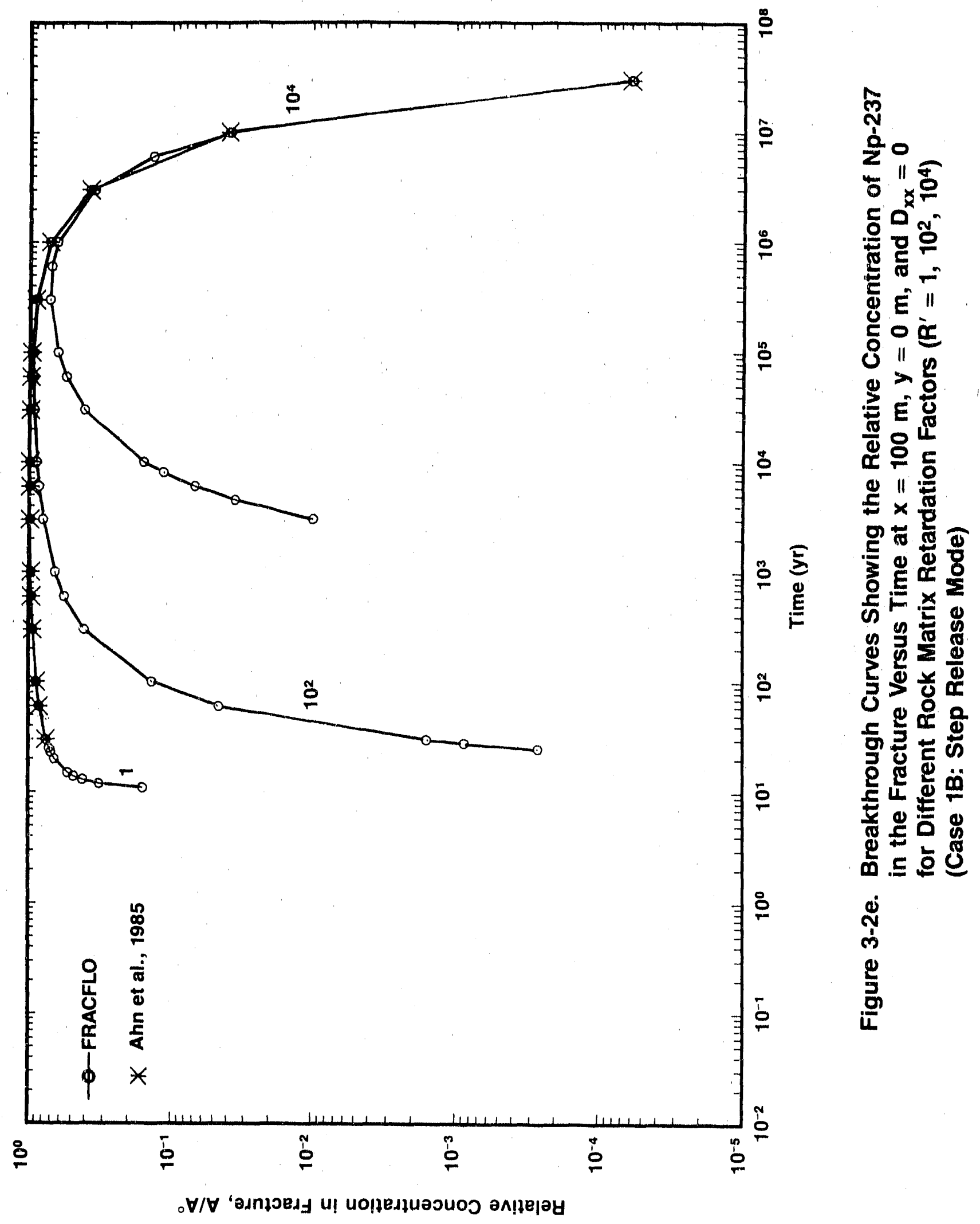




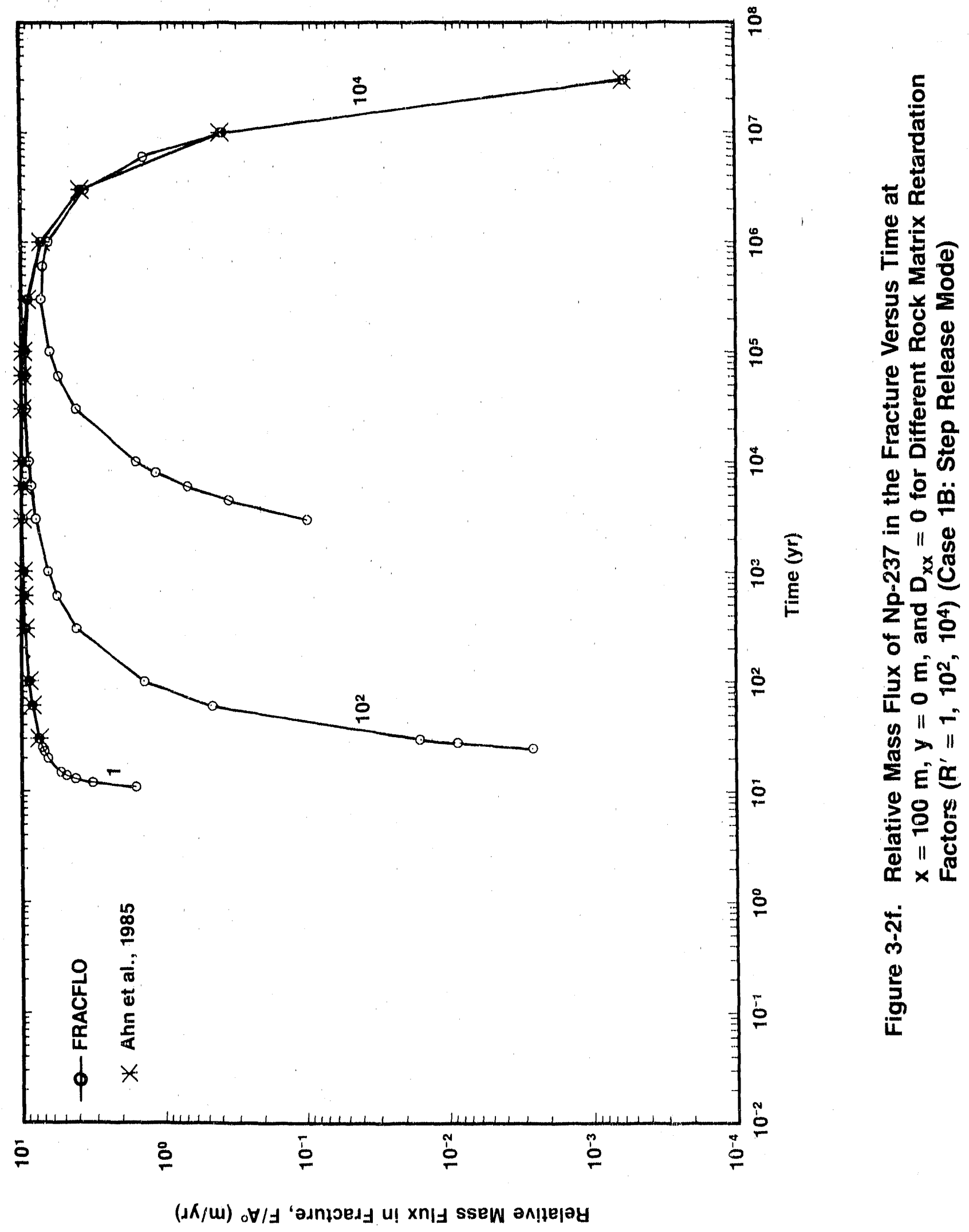




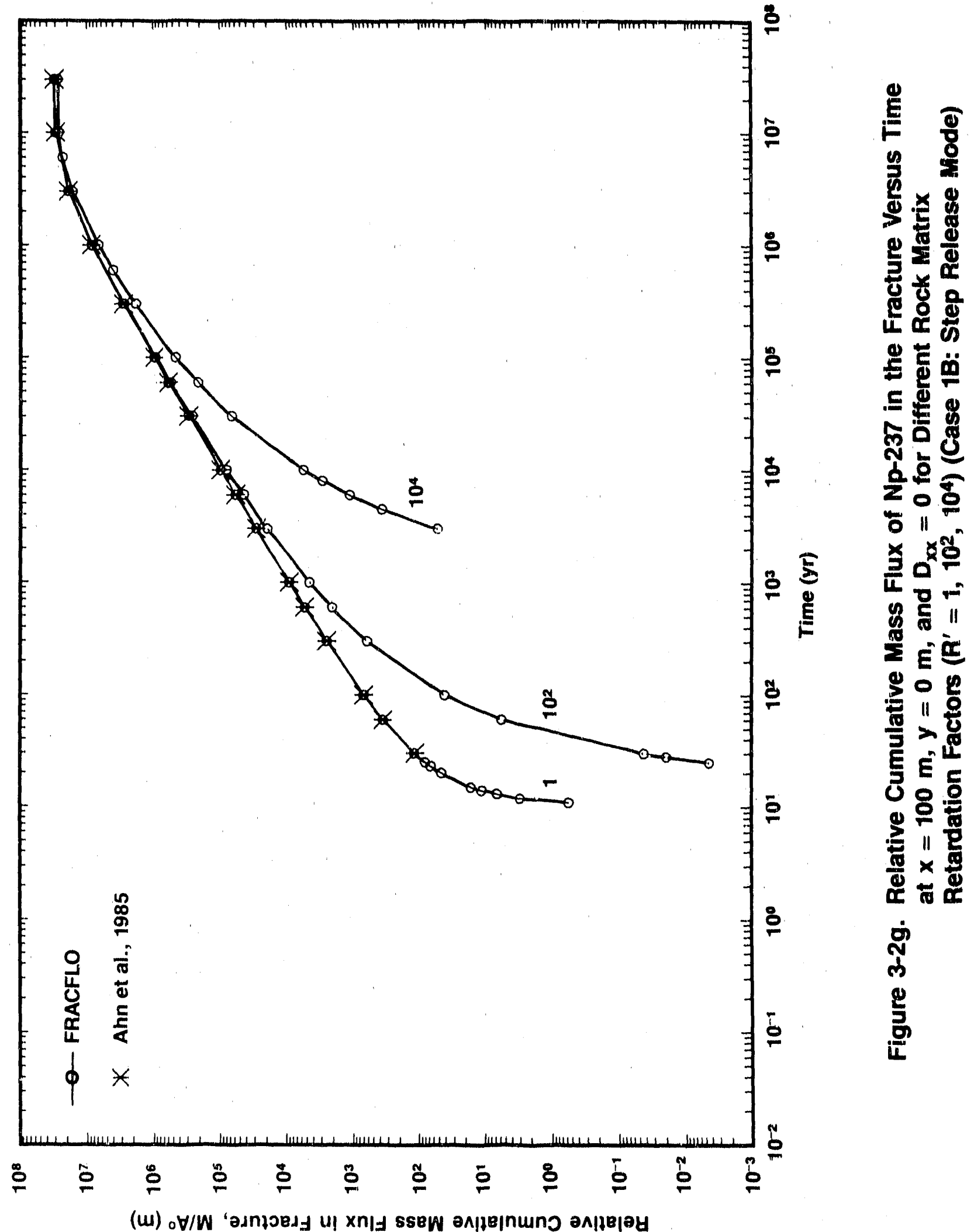


Table 3-3e. Case 1B Results: Rolative Concentration, Mass Flux, and Cumulative Mass Flux in the firacture for Np-237 Over T'ime With Rock Matrix Rotardation Factor R' $=1$ (Stop Rolease Mode)

\begin{tabular}{|c|c|c|c|}
\hline Time $(y r)$ & $\begin{array}{c}\text { Concentration } \\
{ }^{\circ} / A^{-}\end{array}$ & $\begin{array}{l}\text { Mass } F / u x \\
F / A(m / y r)\end{array}$ & $\begin{array}{c}\text { Cumulative } \\
\text { Mass Fiux } \\
M / A^{\circ} \text { (m) }\end{array}$ \\
\hline $\begin{array}{l}1.000 E+01 \\
1.100 E+01 \\
1.200 E+01 \\
1.300 E+01 \\
1.400 E+01\end{array}$ & $\begin{array}{l}0.000 E+00 \\
1.573 E-01 \\
3.173 E-01 \\
4.142 E-01 \\
4.795 E-01\end{array}$ & $\begin{array}{l}0.000 E+00 \\
1.573 E+00 \\
3.173 E+00 \\
4.142 E+00 \\
4.785 E+00\end{array}$ & $\begin{array}{l}0.000 E+00 \\
5.079 E-01 \\
3.014 E+00 \\
6.707 E+00 \\
1.110 E+01\end{array}$ \\
\hline $\begin{array}{l}\text { 1. } 500 E+01 \\
2.000 E+01 \\
2.300 E+01 \\
2.500 E+01 \\
2.800 E+01\end{array}$ & $\begin{array}{l}5.271 E-01 \\
6.547 E-01 \\
6.949 E-01 \\
7.150 E-01 \\
7.389 E-01\end{array}$ & $\begin{array}{l}5.271 E+00 \\
6.547 E+00 \\
6.949 E+00 \\
7.150 E+00 \\
7.389 E+00\end{array}$ & $\begin{array}{l}1.624 E+01 \\
4.628 \mathrm{E}+01 \\
6.656 \mathrm{E}+01 \\
8.067 \mathrm{E}+01 \\
1.025 \mathrm{E}+02\end{array}$ \\
\hline $\begin{array}{l}3.000 E+01 \\
6.000 E+01 \\
1.000 E+02 \\
3.000 E+02 \\
6.0001+02\end{array}$ & $\begin{array}{l}7.518 E-01 \\
8.415 E-01 \\
8.815 E-01 \\
9.337 E-01 \\
9.534 E-01\end{array}$ & $\begin{array}{l}7.518 E+00 \\
8.415 E+00 \\
8.815 E+00 \\
9.337 E+00 \\
9.534 E+00\end{array}$ & $\begin{array}{l}1.174 E+02 \\
3.594 E+02 \\
7.051 E+02 \\
2.535 E+03 \\
5.371 E+03\end{array}$ \\
\hline $\begin{array}{l}1.000 E+03 \\
3.000 E+03 \\
4.500 E+03 \\
8.000 E+03 \\
8.000 E+03\end{array}$ & $\begin{array}{l}9.838 E-01 \\
9.784 E-01 \\
9.817 E-01 \\
9.835 E-01 \\
9.848 E-01\end{array}$ & $\begin{array}{l}9.838 E+00 \\
9.784 E+00 \\
8.817 E+00 \\
9.835 E+00 \\
9.848 E+00\end{array}$ & $\begin{array}{l}9.208 E+03 \\
2.087 E+04 \\
4.338 E+04 \\
5.812 E+04 \\
7.780 E+04\end{array}$ \\
\hline $\begin{array}{l}1.000 E+04 \\
3.000 E+04 \\
6.000 E+04 \\
1.000 E+05 \\
3.000 E+05 \\
6.000 E+05 \\
1.000 E+08 \\
3.000 E+06 \\
6.000 E+08 \\
1.000 E+07\end{array}$ & $\begin{array}{l}9.855 E-01 \\
9.839 E-01 \\
9.752 E-01 \\
9.847 E-01 \\
9.055 E-01 \\
8.222 E-01 \\
7.225 E-01 \\
3.782 E-01 \\
1.431 E-01 \\
3.819 E=02\end{array}$ & $\begin{array}{l}9.855 E+00 \\
9.839 E+00 \\
9.762 E+00 \\
9.647 E+00 \\
9.055 E+00 \\
8.222 E+00 \\
7.225 E+00 \\
3.782 E+00 \\
1.431 E+00 \\
3.919 E-01\end{array}$ & $\begin{array}{l}8.750 E+04 \\
2.946 E+05 \\
5.886 E+05 \\
8.768 E+05 \\
2.847 E+06 \\
5.436 E+06 \\
8.522 E+06 \\
1.916 E+07 \\
2.642 E+07 \\
2.963 E+07\end{array}$ \\
\hline $3.000 E+07$ & $6.024 E-05$ & $6.024 E-04$ & $3.084 E+07$ \\
\hline
\end{tabular}


Table 3-3f. Caso 1B Rosults: Rolative Concontration, Mass Flux, and Cumulative Mass Flux in the Eracture for . Np-237 Over Tho Whath Rock . Matrix Rotardation Factor' $R^{\prime}=100$ (Step Releaso Mode)

\begin{tabular}{|c|c|c|c|}
\hline Time $(y r)$ & $\begin{array}{c}\text { Conoentration } \\
{ }_{A}^{\circ}{ }^{\circ}\end{array}$ & $\begin{array}{l}\text { Mass Flux } \\
F / A(m / y n)\end{array}$ & $\begin{array}{c}\text { Cumulat ive } \\
\text { Mass Fiux } \\
M_{0}^{0}(m)\end{array}$ \\
\hline $\begin{array}{l}2.500 E+01 \\
2.800 E+01 \\
3,000 E+01 \\
8.000 E+01 \\
1.000 E+02\end{array}$ & $\begin{array}{l}2.807 E-04 \\
8.581 E-04 \\
1.585 E-03 \\
4.550 E-02 \\
1.360 E-01\end{array}$ & $\begin{array}{l}2.807 E-03 \\
8.581 E-03 \\
1.565 E-02 \\
4.850 E-01 \\
1.380 E+00\end{array}$ & $\begin{array}{l}4.403 E-03 \\
1.987 E-02 \\
4.374 E-02 \\
\text { B. } 789 E+00 \\
4.211 E+01\end{array}$ \\
\hline $\begin{array}{l}3,000 E+02 \\
6,000 E+02 \\
1,000 E+03 \\
3,000 E+03 \\
4.500 E+03\end{array}$ & $\begin{array}{l}\text { 4. } 062 E-01 \\
5.003 E-01 \\
5,529 E-01 \\
7.951 E-01 \\
8.316 E-01\end{array}$ & $\begin{array}{l}4,082 E+00 \\
5,003 E+00 \\
6,528 E+00 \\
7,981 E+00 \\
8.316 E+00\end{array}$ & $\begin{array}{l}8.298 E+02 \\
2.114 E+03 \\
4.582 E+03 \\
1.841 E+04 \\
3.104 E+04\end{array}$ \\
\hline $\begin{array}{l}6.000 E+03 \\
8.000 E+03 \\
1.000 E+04 \\
3.000 E+04 \\
6.000 E+04\end{array}$ & $\begin{array}{l}8.534 E-01 \\
8.720 E-01 \\
8.84 B E-01 \\
8.259 E-01 \\
9.350 E-01\end{array}$ & $\begin{array}{l}8.534 E+00 \\
8.720 E+00 \\
8,846 E+00 \\
8.258 E+00 \\
9.358 E+00\end{array}$ & $\begin{array}{l}4.429 E+04 \\
6.158 E+04 \\
7.813 E+04 \\
2.814 E+05 \\
5.412 E+08\end{array}$ \\
\hline $\begin{array}{l}1.000 E+05 \\
3.000 E+05 \\
6.000 E+05 \\
1.000 E+08 \\
3.000 E+08\end{array}$ & $\begin{array}{l}9.336 E-01 \\
8.887 E-01 \\
8.114 E-01 \\
7.152 E-01 \\
3.7 B O E-01\end{array}$ & $\begin{array}{l}9.338 E+00 \\
8, B B 7 E+00 \\
8,114 E+00 \\
7,152 E+00 \\
3,760 E+00\end{array}$ & $\begin{array}{l}8.153 E+08 \\
2.741 E+08 \\
5.291 E+08 \\
8.340 E+08 \\
1.890 E+07\end{array}$ \\
\hline $\begin{array}{l}6.000 E+05 \\
1.000 E+07 \\
3.000 E+07\end{array}$ & $\begin{array}{l}1.428 E-01 \\
3.906 E-02 \\
6.013 E-05\end{array}$ & $\begin{array}{l}1.426 E+00 \\
3.906 E-01 \\
6.013 E-04\end{array}$ & $\begin{array}{l}2.612 E+07 \\
2.932 E+07 \\
3.052 E+07\end{array}$ \\
\hline
\end{tabular}

Table 3-3g. Case 1B Results: Relative Concentration, Mass Flux, and Cumulative . Mass Flux in the Fracture for $\mathrm{Np}-237$ Over Time With Rock. Matrix Returdation Factor $R^{\prime}=10,000$ (Step Release Model

\begin{tabular}{|c|c|c|c|}
\hline Tyme (yr) & $\begin{array}{c}\text { Concentration } \\
{ }_{A}{ }^{\circ}\end{array}$ & $\begin{array}{l}\text { Mass Flux } \\
F / A(m / y r)\end{array}$ & $\begin{array}{c}\text { Cumulative } \\
\text { Mass Flux } \\
\mathrm{D}^{\circ} \text { (m) }\end{array}$ \\
\hline $\begin{array}{l}3.000 E+03 \\
4.500 E+03 \\
6.000 E+03 \\
8.000 E+03 \\
1.000 E+04\end{array}$ & $\begin{array}{l}9.682 E-03 \\
3,476 E-02 \\
6.753 E-02 \\
1.133 E-01 \\
1.566 E-01\end{array}$ & $\begin{array}{l}9.892 E-02 \\
3.478 E-01 \\
6.753 E-01 \\
1.133 E+00 \\
1.568 E+00\end{array}$ & $\begin{array}{l}\text { 5. } 354 E+01 \\
3.719 E+02 \\
1.134 E+03 \\
2.944 E+03 \\
5.648 E+03\end{array}$ \\
\hline $\begin{array}{l}3.000 E+04 \\
6.000 E+04 \\
1.000 E+05 \\
3.000 E+05 \\
6.000 E+05\end{array}$ & $\begin{array}{l}4.101 E-01 \\
5.528 E-01 \\
6.338 E-01 \\
7.225 E-01 \\
7.041 E-01\end{array}$ & $\begin{array}{l}4.101 E+00 \\
5.528 E+00 \\
8.338 E+00 \\
7.225 E+00 \\
7.041 E+00\end{array}$ & $\begin{array}{l}\text { 6. } 659 E+04 \\
2.143 E+05 \\
4.538 E+05 \\
1.847 E+06 \\
4.000 E+00\end{array}$ \\
\hline $\begin{array}{l}1.000 E+06 \\
3.000 E+06 \\
8.000 E+06 \\
1.000 E+07 \\
3.000 E+07\end{array}$ & $\begin{array}{l}0.420 E-01 \\
3.538 E-01 \\
1.386 E-01 \\
3.780 E-02 \\
5.901 E-05\end{array}$ & $\begin{array}{l}6.420 E+00 \\
3.538 E+00 \\
1.388 E+00 \\
3.780 E=01 \\
5.901 E-0.4\end{array}$ & $\begin{array}{l}\text { 8. } 097 E+08 \\
1.644 E+07 \\
2.330 E+07 \\
2.638 E+07 \\
2.755 E+07\end{array}$ \\
\hline
\end{tabular}




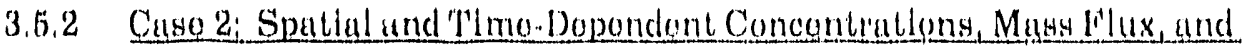 Cumulativo Mass Filux Subloct Lo a Band Relouso Modo in tho Abononco of Longltudinal Disporston}

Thig tost caso doals with the migration of Np-237 in ano dimonsional llow domain in tho absonce of longitudinal disporston. The concontration at the source is subjoctod to a band rolouso modo whth a loach time corrosponding to 5,000 yours, and tho rotardation fuator of tho fracturo lis taken as unity. Similar to tho provious caso, the influonco of the rock maldx rotardation fiator on the concentration in the fracturo and rock matrix was invostigatod. 'Tho input dala portaining to this caso ares presented in 'Table 3-4. 'The roported rosults are obtainod through tho nondisporstu form of the general solution.

Figures 3-3a, 33-3b, 3-3c show tho rolativo concontration, tho mass flux, and cumulativo mass flux of $\mathrm{Np}-237$ in the fracturo; Figuro 3 -3d shows tho rolativo concontration in tho rock matrix at a dis. Lance of $100 \mathrm{~m}$ downstroam from the sourco. 'I'hroo valuos of rock matrix rotardation factor $(R '=1$, 100, and 10,000) aro oxaminod. 'Tabulatod rosults in 'Tablos 3-5 and 3-6 show excollont agroomont with thoso reportod by Ahn ot al, (1985).

Figures 3.4a, 3-4b, and 3-4c show the timedependont relative concontrution, mass flux, and cumulative mass flux in the fracture at a distance of $100 \mathrm{~m}$ from the sourco. Again, throo valuos of rock matrix rotardation are examined. The peak of the curves shown in Figures 3-4a and 3-4b donotes the marked influence of the rock matrix rotardation factor. 'The rate of concentration decrouse of $\mathrm{Np}-237$ at this monitoring station past the leaching time is influonced to a large extent by the provailing concentration gradient at tho fracture wall, which goars tho (rovorsed) diffusion process (i.e., rock matrix to fracture; the higher the rotardation factor the highor the gradiont). 'The timo lapse for the concontration to "each a zero value at this point will dopend on the mass of $\mathrm{Np}-237$ uccumulatod in the rock matrix; the lowor tho retardation factor tho longor the timo lapse. 'I'abulated rosults in 'Table 3-7 show oxcollent agreemont with those reported by Ahn at al, (1985) for $R$ ' $=1$. 
'Tablo 3.4. Input Pan'umotar's for Cano 2

\begin{tabular}{|c|c|}
\hline Specier & $N p-237$ \\
\hline $\begin{array}{l}\text { Initial Concentration } \mathrm{A}^{\prime \prime} \\
\left.\text { (arbitrary units of activity/L, }{ }^{(3)}\right)\end{array}$ & 1 \\
\hline 'Typo of Roleuso Modo & Band \\
\hline Boundary Condition & Inllnite Plane Source \\
\hline$x$ & $100.0 \mathrm{~m}$ \\
\hline$y$ & $0.0 \mathrm{~m}$ \\
\hline$d$ & $\infty$ \\
\hline$u$ & $10.0 \mathrm{~m} / \mathrm{yr}$ \\
\hline$v$ & $0.0 \mathrm{~m} / \mathrm{yr}$ \\
\hline$D_{x x}$ & $0,0 \mathrm{~m}^{2} / \mathrm{yr}$ \\
\hline $\mathrm{D}_{y y}$ & $0.0 \mathrm{~m}^{2} / \mathrm{yr}$ \\
\hline$D_{y x}$ & $0.0 \mathrm{~m}^{2} / \mathrm{yr}$ \\
\hline$D_{p}$ & $0.01 \mathrm{~m}^{2} / \mathrm{yr}$ \\
\hline $\mathrm{T}_{1 / 2}$ & $2.14 \times 10^{6} \mathrm{yr}$ \\
\hline $\mathrm{T}$ & $5 \times 10^{3} \mathrm{yr}$ \\
\hline$b$ & $0.005 \mathrm{~m}$ \\
\hline$\phi$ & $10 \cdot 2$ \\
\hline R & 1 \\
\hline$R^{\prime}$ & $1,10^{2}, 10^{4}$ \\
\hline
\end{tabular}




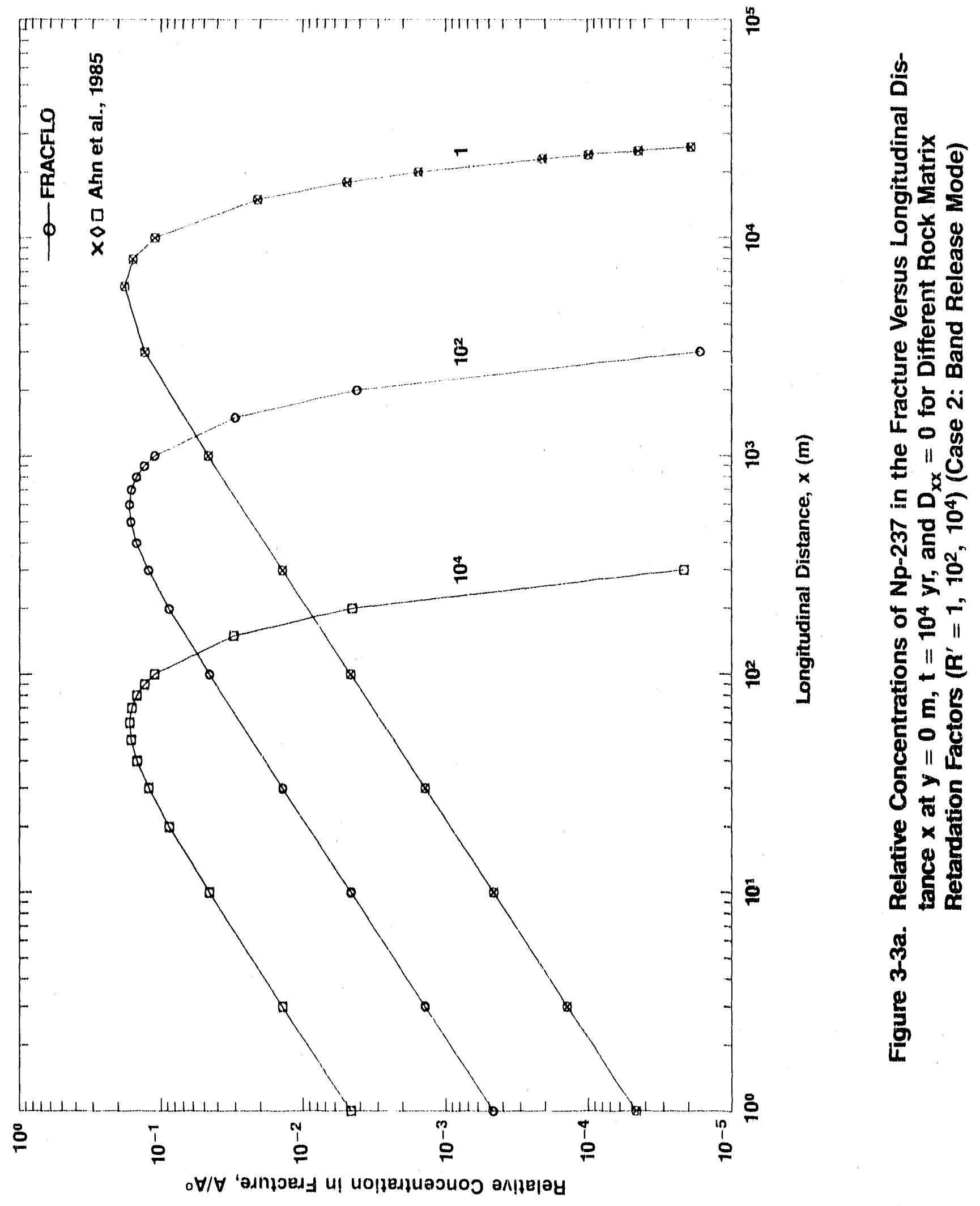




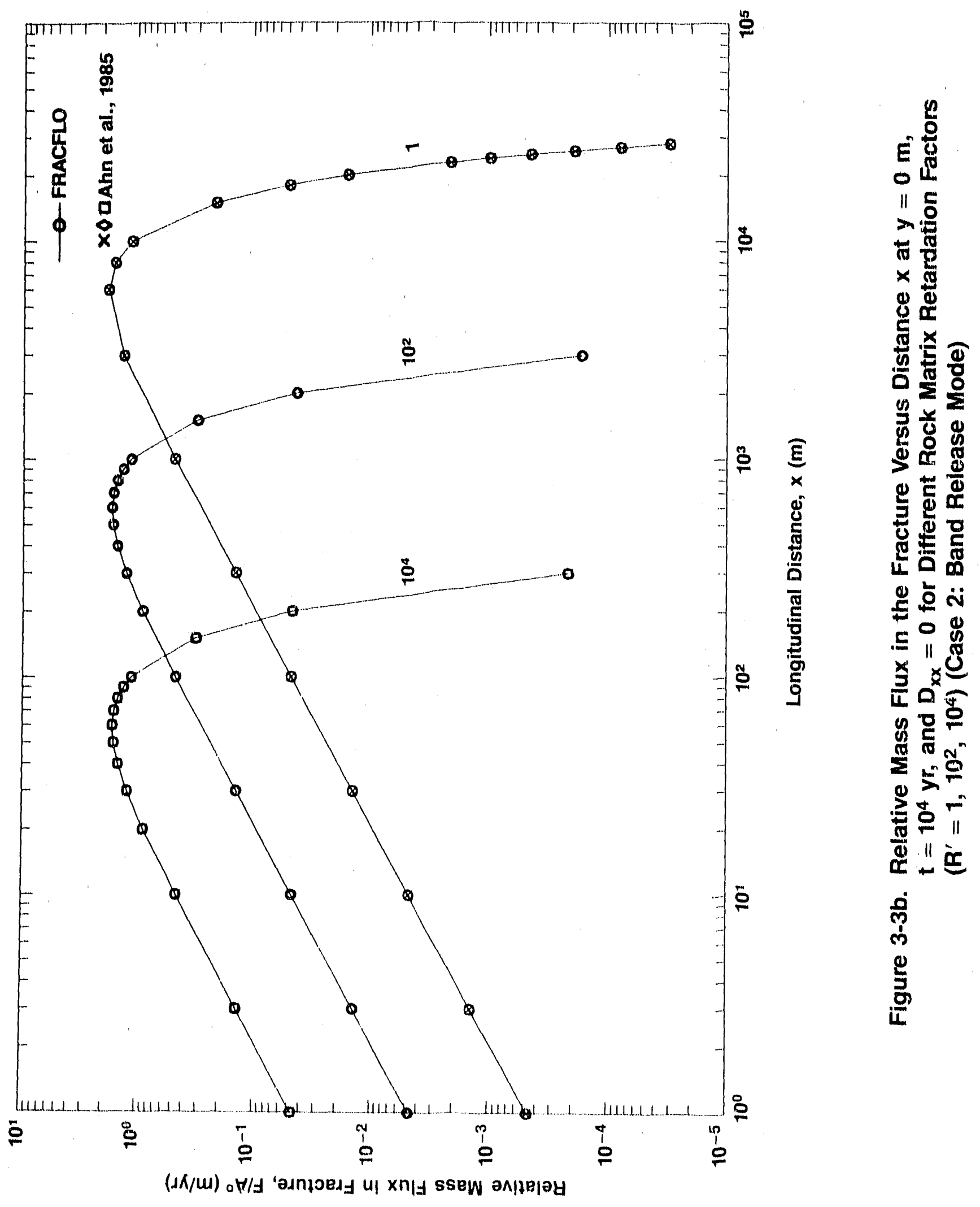




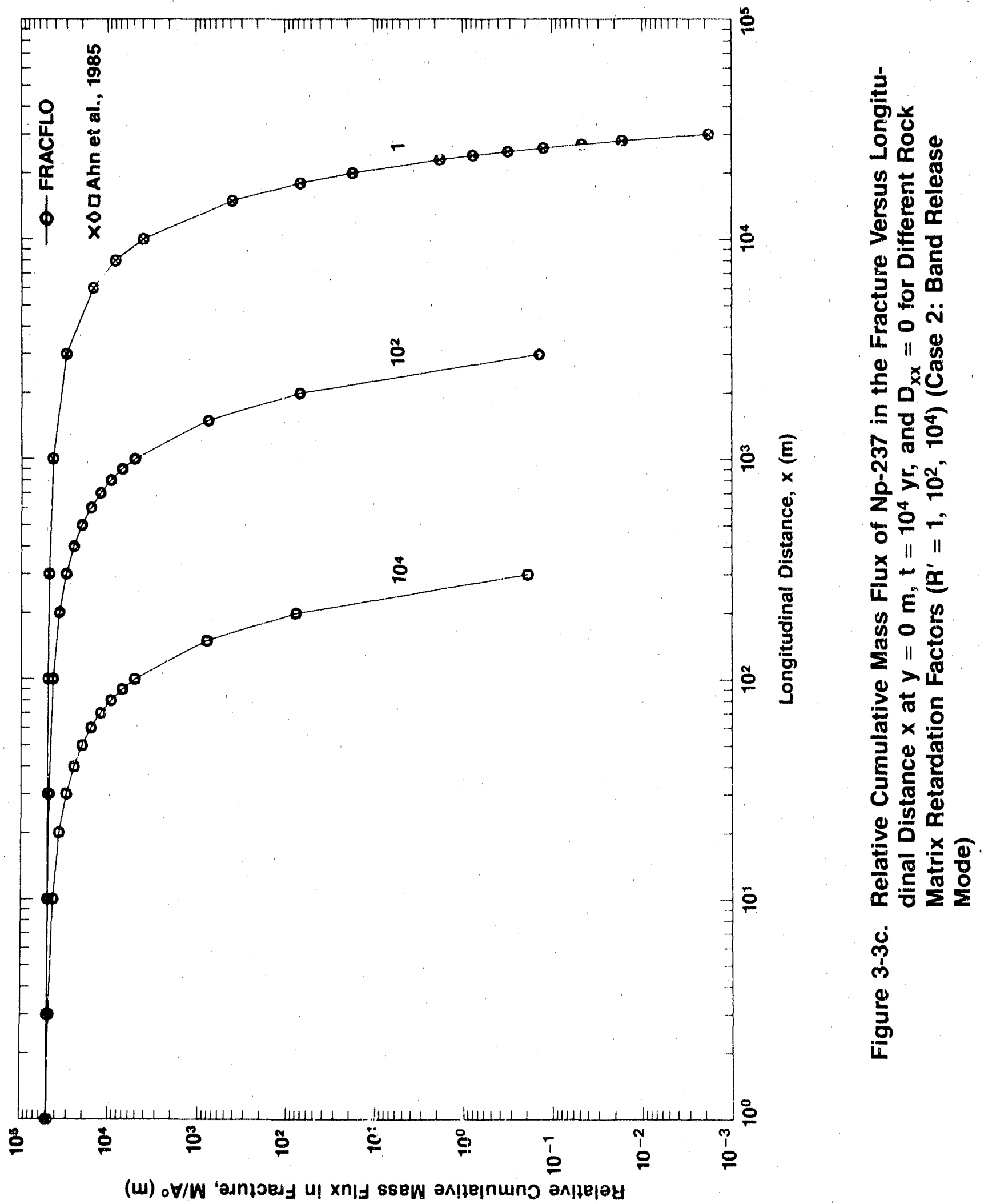




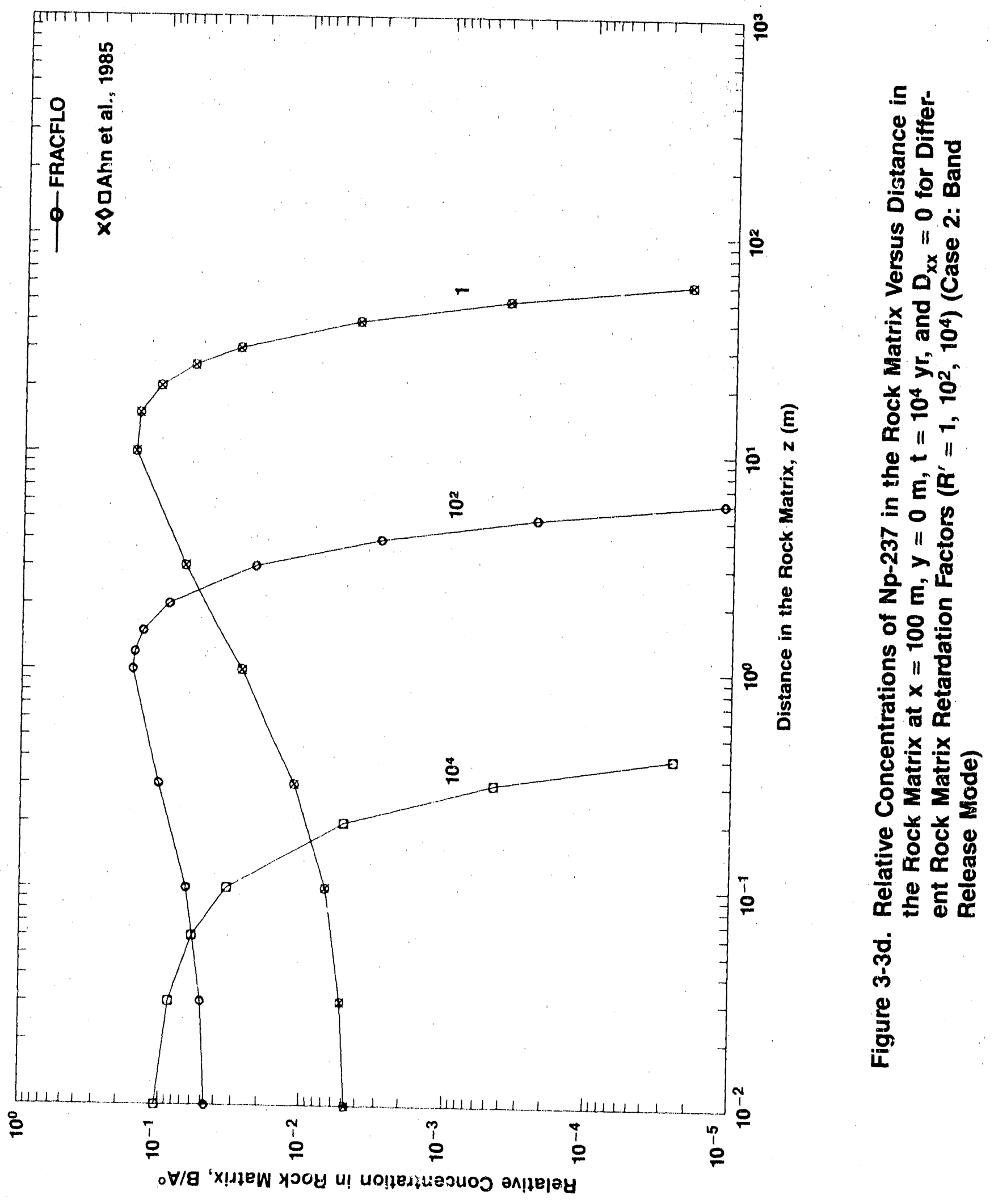


Table 3-5a. Case 2 Results: Relative Concentration, Mass Flux, and Cumulative Mass Flux in the Fracture for Np-237 with Infinite Diffusion at Time $t=10^{4} \mathrm{yr}$ and Rock Matrix Retardation Factor $\mathrm{R}^{\prime}=1$ (Band Release Mode)

\begin{tabular}{|c|c|c|c|c|}
\hline & $\begin{array}{l}\text { Longl tudinal } \\
\text { Distance } \\
\quad x(m)\end{array}$ & $\begin{array}{c}\text { Concentration } \\
A / A^{\circ}\end{array}$ & $\begin{array}{ll}\text { Mass } & \text { F } 1 u x \\
\text { F } / A^{\circ} & (m / y r)\end{array}$ & $\begin{array}{c}\text { Cumulative } \\
\text { Mass Flux } \\
M / A^{\circ}(m)\end{array}$ \\
\hline \multirow[t]{5}{*}{. } & $\begin{array}{l}1.000 E+00 \\
3.000 E+00 \\
1.000 E+01 \\
3.000 E+01 \\
1.000 E+02\end{array}$ & $\begin{array}{l}4.659 E-05 \\
1.398 E-04 \\
4.660 E-04 \\
1.399 E-03 \\
4.668 E-03\end{array}$ & $\begin{array}{l}4.659 E-04 \\
1.398 E-03 \\
4.660 E-03 \\
1.399 E-02 \\
4.668 E-02\end{array}$ & $\begin{array}{l}4.995 E+04 \\
4.994 E+04 \\
4.989 E+04 \\
4.976 E+04 \\
4.930 E+04\end{array}$ \\
\hline & $\begin{array}{l}3.000 E+02 \\
1.000 E+03 \\
3.000 E+03 \\
6.000 E+03 \\
8.000 E+03\end{array}$ & $\begin{array}{l}1.405 E-02 \\
4.693 E-02 \\
1.302 E-01 \\
1.801 E-01 \\
1.568 E-01\end{array}$ & $\begin{array}{l}1.405 E-01 \\
4.693 E-01 \\
1.302 E+00 \\
1.801 E+00 \\
1.568 E+00\end{array}$ & $\begin{array}{l}4.797 E+04 \\
4.333 E+04 \\
3.055 E+04 \\
1.506 E+04 \\
8.198 E+03\end{array}$ \\
\hline & $\begin{array}{l}1.000 E+04 \\
1.500 E+04 \\
1.800 E+04 \\
2.000 E+04 \\
2.300 E+04\end{array}$ & $\begin{array}{l}1.103 E-01 \\
2.099 E-02 \\
4.914 E-03 \\
1.560 E-03 \\
2.092 E-04\end{array}$ & $\begin{array}{l}1.103 E+00 \\
2.099 E-01 \\
4.914 E-02 \\
1.580 E-02 \\
2.092 E-03\end{array}$ & $\begin{array}{l}3.976 E+03 \\
3.879 E+02 \\
6.661 E+01 \\
1.744 E+01 \\
1.772 E+00\end{array}$ \\
\hline & $\begin{array}{l}2.400 E+04 \\
2.500 E+04 \\
2.600 E+04 \\
2.700 E+04 \\
2.800 E+04\end{array}$ & $\begin{array}{l}9.858 E-05 \\
4.441 E-05 \\
1.911 E-05 \\
7.831 E-08 \\
3.051 E-06\end{array}$ & $\begin{array}{l}9.856 E-04 \\
4.441 E-04 \\
1.911 E-04 \\
7.831 E-05 \\
3.051 E-05\end{array}$ & $\begin{array}{l}7.631 E-01 \\
3.146 E-01 \\
1.240 E-01 \\
4.659 E-02 \\
1.666 E-02\end{array}$ \\
\hline & $\begin{array}{l}3.000 E+04 \\
4.000 E+04\end{array}$ & $\begin{array}{l}3.946 E-07 \\
2.8 O E E-13\end{array}$ & $\begin{array}{l}3.946 E-08 \\
2.806 E-12\end{array}$ & $\begin{array}{l}1.820 E-03 \\
5.792 E-10\end{array}$ \\
\hline
\end{tabular}


Tablo 3-5b. Case 2 Results: Relative Concentration, Mass Flux, and Cumulative .Mass Flux in the Fracture for Np-237 at Time $t=$ $104 \mathrm{yr}$ and Rock Matrix Retardation Factor $R^{\prime}=100$ (Band Release Mode)

\begin{tabular}{|c|c|c|c|c|}
\hline '. & $\begin{array}{c}\text { Longitudinal } \\
\text { Distance } \\
\times(m)\end{array}$ & $\begin{array}{c}\text { Concentration } \\
A / A^{\circ}\end{array}$ & $\begin{array}{l}\text { Mass Flux } \\
0^{\circ} / A^{(m / y r)}\end{array}$ & $\begin{array}{c}\text { Cumulative } \\
\text { Mass Flux } \\
0 \\
M / A(m)\end{array}$ \\
\hline & $\begin{array}{l}1.000 E+00 \\
3.000 E+00 \\
1.000 E+01 \\
3.000 E+01 \\
1.000 E+02\end{array}$ & $\begin{array}{l}4.659 E-04 \\
1.398 E-03 \\
4.659 E-03 \\
1.397 E-02 \\
4.601 E-02\end{array}$ & $\begin{array}{l}4.659 E-03 \\
1.398 E-02 \\
4.659 E-02 \\
1.397 E-01 \\
4.601 E-01\end{array}$ & $\begin{array}{l}4.989 E+04 \\
4.97 E E+04 \\
4.930 E+04 \\
4.797 E+04 \\
4.337 E+04\end{array}$ \\
\hline & $\begin{array}{l}2.000 E+02 \\
3.000 E+02 \\
4.000 E+02 \\
5.00 O E+02 \\
6.0 O O E+02\end{array}$ & $\begin{array}{l}8.823 E-02 \\
1.232 E-01 \\
1.485 E-01 \\
1.630 E-01 \\
1.669 E-01\end{array}$ & $\begin{array}{l}8.823 E-01 \\
1.232 E+00 \\
1.485 E+00 \\
1.630 E+00 \\
1.669 E+00\end{array}$ & $\begin{array}{l}3.696 E+04 \\
3.089 E+04 \\
2.532 E+04 \\
2.033 E+04 \\
1.599 E+04\end{array}$ \\
\hline .. & $\begin{array}{l}7.000 E+02 \\
8.000 E+02 \\
9.000 E+02 \\
1.000 E+03 \\
1.500 E+03\end{array}$ & $\begin{array}{l}1.614 E-01 \\
1.488 E-01 \\
1.313 E-01 \\
1.115 E-01 \\
3.015 E-02\end{array}$ & $\begin{array}{l}1.614 E+00 \\
1.488 E+00 \\
1.313 E+00 \\
1.115 E+00 \\
3.015 E-01\end{array}$ & $\begin{array}{l}1.232 E+04 \\
9.301 E+03 \\
6.875 E+03 \\
4.978 E+03 \\
7.342 E+02\end{array}$ \\
\hline & $\begin{array}{l}2.000 E+03 \\
3.000 E+03 \\
4.000 E+03\end{array}$ & $\begin{array}{l}4.216 E-03 \\
1.644 E-05 \\
7.739 E-09\end{array}$ & $\begin{array}{l}4.216 \varepsilon-02 \\
1.644 E-04 \\
7.739 E-08\end{array}$ & $\begin{array}{l}6.722 E+01 \\
1.381 E-01 \\
3.906 E-05\end{array}$ \\
\hline
\end{tabular}

Table 3.5c. Case 2 Results: Relative Concentration, Mass Flux, and Cumulative Mass Flux in the Eracture for $\mathrm{Np}-237$ at 'Time $\mathrm{t}=$ $10^{4} \mathrm{yr}$ and Rock Matrix Retardation Factor $R^{\prime}=10,000$ (Band Release Mode)

\begin{tabular}{|c|c|c|c|}
\hline $\begin{array}{c}\text { Longitudinal } \\
\text { Distance } \\
\times(m)\end{array}$ & $\begin{array}{c}\text { Concentration } \\
A / A^{0}\end{array}$ & $\begin{array}{c}\text { Mass Flux } \\
0 \\
F / A^{(m / y r)}\end{array}$ & $\begin{array}{c}\text { Cumulative } \\
\text { Mass Flux } \\
\text { M/A (m) }\end{array}$ \\
\hline $\begin{array}{l}1.000 E+00 \\
3.000 E+00 \\
1.000 E+01 \\
2.000 E+01 \\
3.000 E+01\end{array}$ & $\begin{array}{l}4.658 E-03 \\
1.396 E-02 \\
4.592 E-02 \\
8.789 E-02 \\
1.225 E-01\end{array}$ & $\begin{array}{l}4.658 E-02 \\
1.396 E-01 \\
4.592 E-01 \\
8.789 E-01 \\
1.225 E+00\end{array}$ & $\begin{array}{l}4.930 E+04 \\
4.797 E+04 \\
4.337 E+04 \\
3.697 E+04 \\
3.093 E+04\end{array}$ \\
\hline $\begin{array}{l}\text { 4. OOOE +01 } \\
\text { 5. OOOE +01 } \\
\text { 6. OOOE +01 } \\
\text { 7. OOOE + } 01 \\
\text { 8. OOOE + } 01\end{array}$ & $\begin{array}{l}1.475 E-01 \\
1.618 E-01 \\
1.656 E-01 \\
1.603 E-01 \\
1.479 E-01\end{array}$ & $\begin{array}{l}1.475 E+00 \\
1.618 E+00 \\
1.656 E+00 \\
1.603 E+00 \\
1.479 E+00\end{array}$ & $\begin{array}{l}2.537 E+04 \\
2.041 E+04 \\
1.608 E+04 \\
1.243 E+04 \\
9.408 E+03\end{array}$ \\
\hline $\begin{array}{l}\text { 9. OOOE +01 } \\
\text { 1. OOOE +02 } \\
1.5 O O E+02 \\
\text { 2. OOOE +02 } \\
\text { 3. OOOE + 02 }\end{array}$ & $\begin{array}{l}\text { 1. } 309 E-01 \\
1.114 E-01 \\
3.100 E-02 \\
4.560 E-03 \\
2.140 E-05\end{array}$ & $\begin{array}{l}1.309 E+00 \\
1.114 E+00 \\
3.100 E-01 \\
4.560 E-02 \\
2.140 E-04\end{array}$ & $\begin{array}{l}6.981 E+03 \\
5.073 E+03 \\
7.755 E+02 \\
7.512 E+01 \\
1.889 E-01\end{array}$ \\
\hline 4. OOOE + 02 & $1.438 \varepsilon-08$ & $1.438 E-07$ & $7.780 E-05$ \\
\hline
\end{tabular}


Table 3-6a. Case 2 Results: Relative Concentration in the Rock Matrix for Nip-237 at Time $t=104 \mathrm{yr}$ and Rock . Hatrix Retardation

F'actor $R^{\prime}=1$ (Band Releuse Vlode)

\begin{tabular}{cc}
$\begin{array}{c}\text { Vertical } \\
\text { Distance }\end{array}$ & $\begin{array}{c}\text { Concentration } \\
z(\mathrm{~m})\end{array}$ \\
\hline $1.000 E-02$ & $4.785 E-03$ \\
$3.000 E-02$ & $5.252 E-03$ \\
$1.000 E-01$ & $6.885 E-03$ \\
$3.000 E-01$ & $1.155 E-02$ \\
$1.000 E+00$ & $2.775 E-02$ \\
$3.000 E+00$ & $7.184 E-02$ \\
$1.000 E+01$ & $1.627 E-01$ \\
$1.50 O E+01$ & $1.536 E-01$ \\
$2.000 E+01$ & $1.095 E-01$ \\
$2.500 E+01$ & $6.280 E-02$ \\
$3.000 E+01$ & $3.006 E-02$ \\
$4.000 E+01$ & $4.389 E-03$ \\
$5.000 E+01$ & $3.819 E-04$ \\
$6.000 E+01$ & $2.051 E-05$ \\
& \\
\hline
\end{tabular}

Table 3-6b. Case 2 Results: Relative Concentration in the Rock Matrix for $\mathrm{Np}-237$ at Time $\mathrm{t}=1 \times 10^{4} \mathrm{yr}$ and Rock Matrix Retardation Factor $R^{\prime}=100$ (Band Release Mode)

\begin{tabular}{|c|c|}
\hline $\begin{array}{l}\text { Vertical } \\
\text { Distance } \\
\qquad z(m)\end{array}$ & $\begin{array}{c}\text { Concentration } \\
B / A^{\circ}\end{array}$ \\
\hline $\begin{array}{l}1.000 E-02 \\
3.000 E-02 \\
1.000 E-01 \\
3.000 E-01 \\
1.000 E+00\end{array}$ & $\begin{array}{l}4.712 E-02 \\
5.156 E-02 \\
6.670 E-02 \\
1.056 E-01 \\
1.657 E-01\end{array}$ \\
\hline $\begin{array}{l}1.200 E+00 \\
1.500 E+00 \\
2.000 E+00 \\
3.000 E+00 \\
4.000 E+00\end{array}$ & $\begin{array}{l}1.606 E-01 \\
1.403 E-01 \\
9.215 E-02 \\
2.234 E-02 \\
2.963 E-03\end{array}$ \\
\hline $\begin{array}{l}5.000 E+00 \\
6.000 E+00 \\
7.000 E+00 \\
8.000 E+00 \\
9.000 E+00\end{array}$ & $\begin{array}{l}2.366 E-04 \\
1.168 E-05 \\
3.566 E-07 \\
6.704 E-09 \\
7.739 E-11\end{array}$ \\
\hline $1.000 E+01$ & $5.473 E-13$ \\
\hline
\end{tabular}


Table 3-6c. Case 2 Results: Relative Concentration in the Rock Matrix for $\mathrm{Np}-237$ at Timet $=10^{4} \mathrm{yr}$ and Rock Matrix Retardation Factor $R^{\prime}=10,000$ (Band Release . Mode)

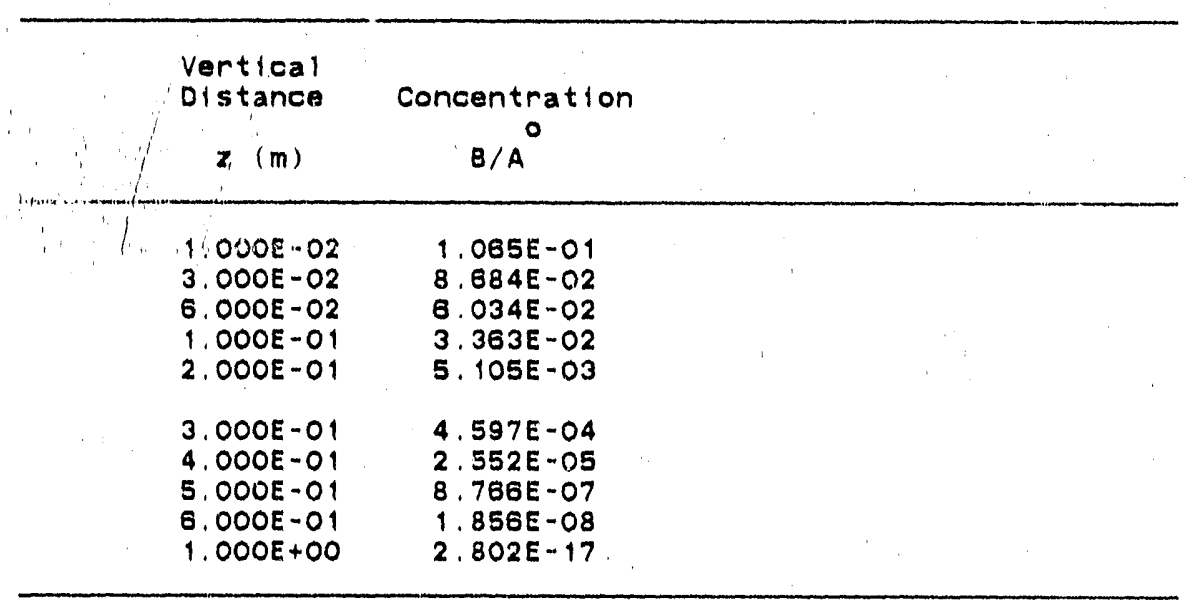




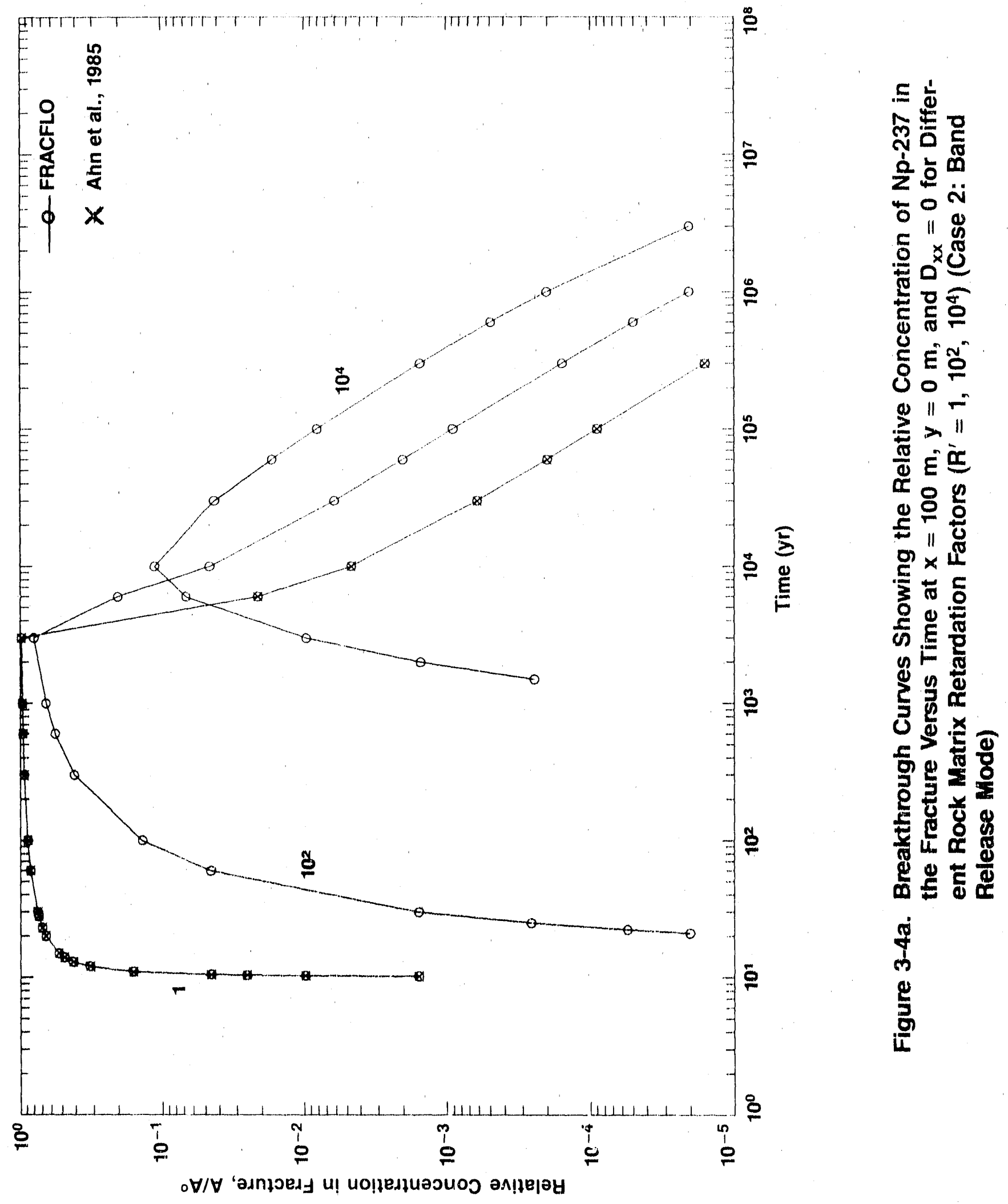




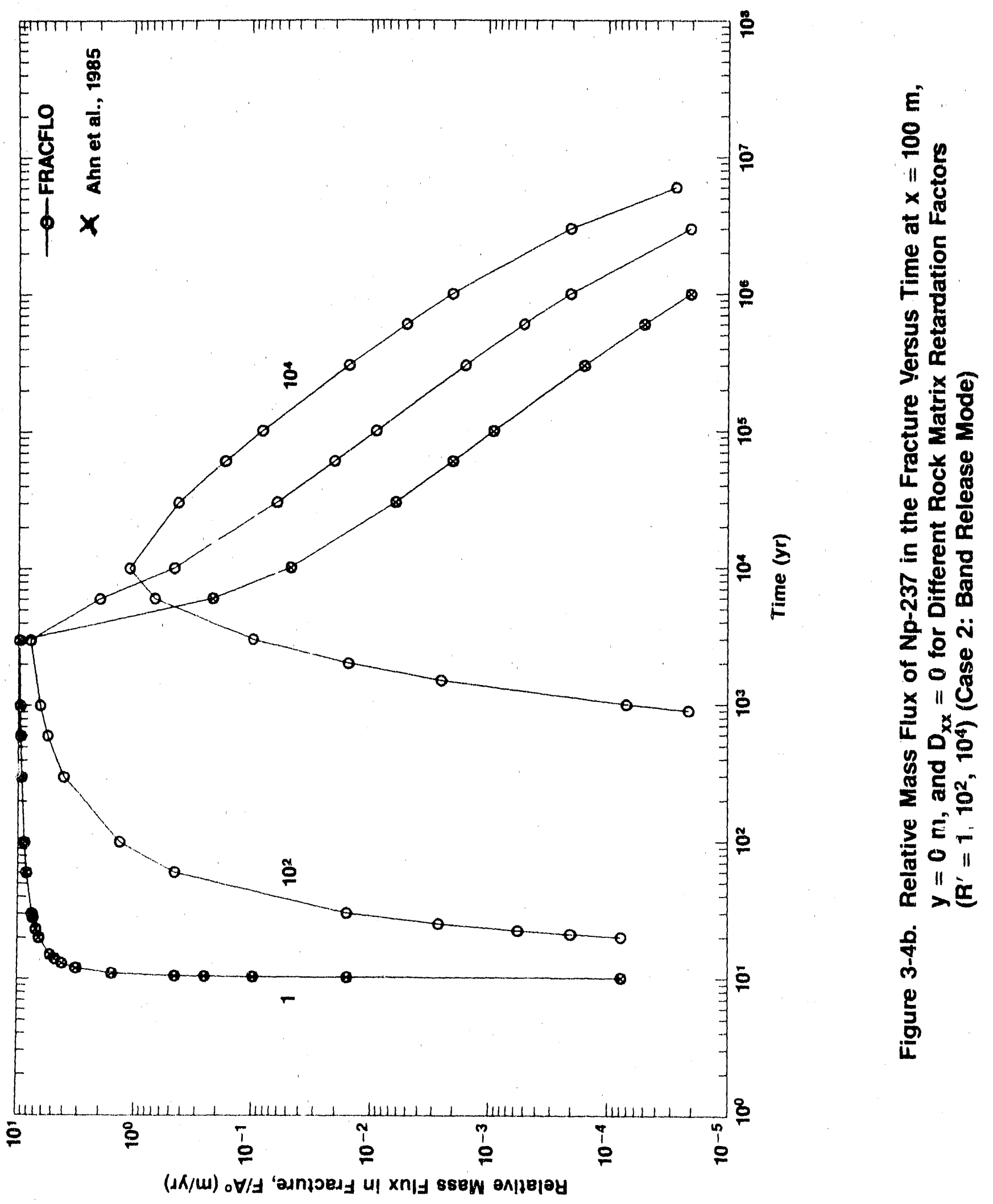




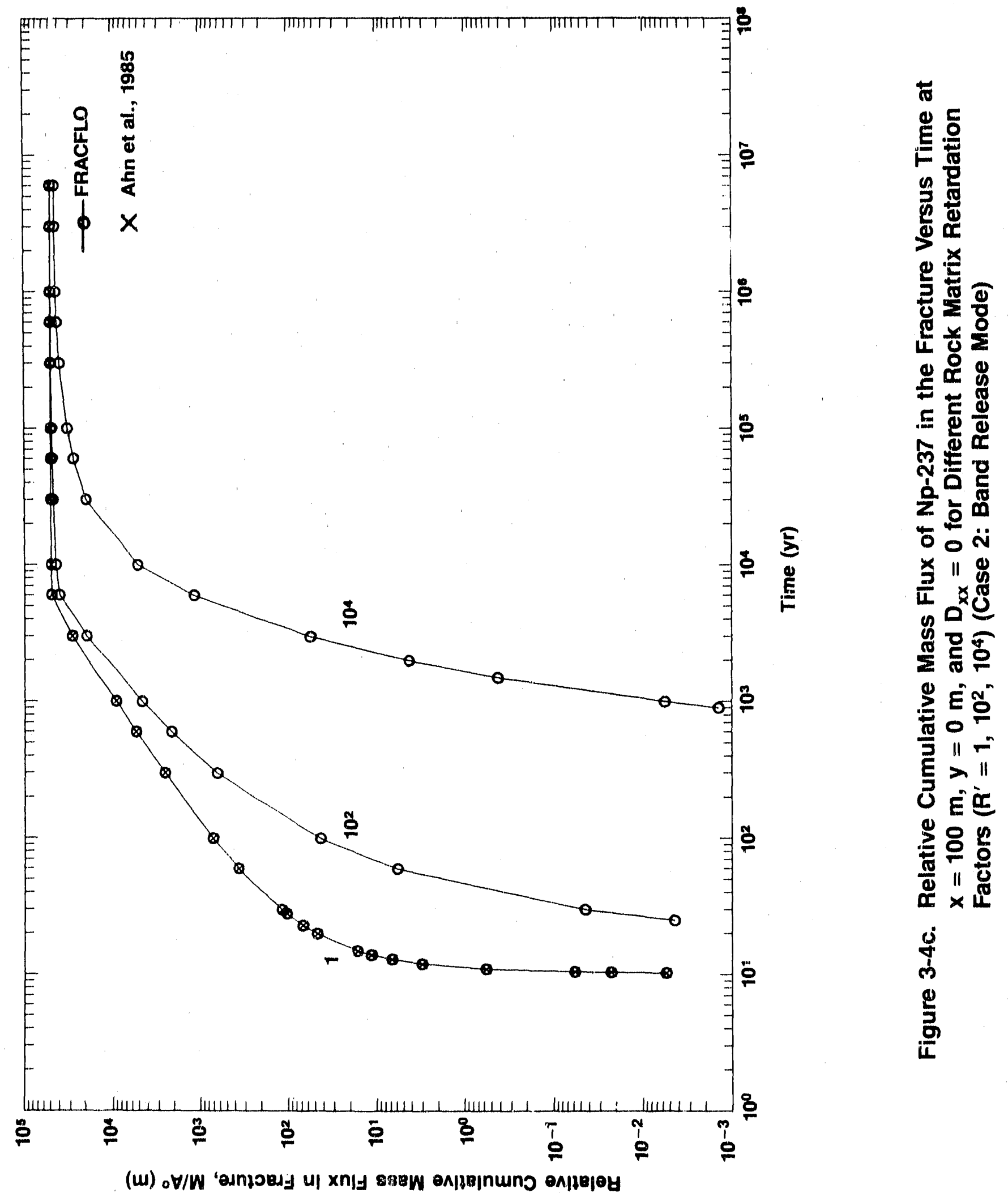


Table 3-7a. Case 2 Results: Relative Concentration, Mass Flux, and Cumulative Mass Flux in the Fracture for Np-237 Over Time with Rock Matrix Retardation Factor $R^{\prime}=1$ (Band Release Mode)

\begin{tabular}{|c|c|c|c|}
\hline Timo $(y r)$ & $\begin{array}{c}\text { Coneentration } \\
A / A^{0}\end{array}$ & $\begin{array}{l}\text { Mass } F / u x \\
F_{1} / A^{(m / y r)}\end{array}$ & $\begin{array}{c}\text { Cumulat lvo } \\
\text { Mass Flux } \\
\text { M/A (m) }\end{array}$ \\
\hline $\begin{array}{l}1.000 E+01 \\
1.010 E+01 \\
1.020 E+01 \\
1.030 E+04 \\
1.040 E+01\end{array}$ & $\begin{array}{l}0.000 E+00 \\
7.744 E-08 \\
1.565 E-03 \\
9.823 E-03 \\
2.53 E E-02\end{array}$ & $\begin{array}{l}0.000 E+00 \\
7.744 E-08 \\
1.585 E-02 \\
8.823 E-02 \\
2.835 E-01\end{array}$ & $\begin{array}{l}0.000 E+00 \\
5.303 E-07 \\
4.374 E-04 \\
8.458 E-03 \\
2.254 E-02\end{array}$ \\
\hline $\begin{array}{l}1.050 E+01 \\
1.100 E+01 \\
1.200 E+01 \\
1.300 E+01 \\
1.400 E+01\end{array}$ & $\begin{array}{r}4.580 E-02 \\
1.573 E-01 \\
3.173 E-01 \\
4.142 E-01 \\
4.705 E-01\end{array}$ & $\begin{array}{l}4.580 E-01 \\
1.573 E+00 \\
3.173 E+00 \\
4.142 E+00 \\
4.798 E+00\end{array}$ & $\begin{array}{l}8.789 E-02 \\
8.679 E-01 \\
3.014 E+00 \\
8.707 E+00 \\
1.119 E+01\end{array}$ \\
\hline $\begin{array}{l}1.500 E+01 \\
2.000 E+01 \\
2.300 E+01 \\
2.800 E+01 \\
3.000 E+01\end{array}$ & $\begin{array}{l}5.271 E-01 \\
8.847 F-01 \\
\text { B. } 949 E-01 \\
7.389 E-01 \\
7.818 E-01\end{array}$ & $\begin{array}{l}8.271 E+00 \\
6.847 E+00 \\
8.949 E+00 \\
7.388 E+00 \\
7.518 E+00\end{array}$ & $\begin{array}{l}1.624 E+01 \\
4.628 E+01 \\
e .858 E+01 \\
1.025 E+02 \\
1.174 E+02\end{array}$ \\
\hline $\begin{array}{l}6.000 E+01 \\
1.000 E+02 \\
3.000 E+02 \\
8.000 E+02 \\
1.000 E+03\end{array}$ & $\begin{array}{l}8.418 E-01 \\
8.818 E-01 \\
9.337 E-01 \\
9.634 E-01 \\
9.838 E-01\end{array}$ & $\begin{array}{l}8.415 E+00 \\
8.815 E+00 \\
9.337 E+00 \\
9.534 E+00 \\
9.838 E+00\end{array}$ & $\begin{array}{l}3.594 E+02 \\
7.051 E+02 \\
2.538 E+03 \\
5.371 E+03 \\
9.208 E+03\end{array}$ \\
\hline $\begin{array}{l}3.000 E+03 \\
6.000 E+03 \\
1.000 E+04 \\
3.000 E+04 \\
6.000 E+04\end{array}$ & $\begin{array}{l}9.784 E-01 \\
2.123 E-02 \\
4.888 E-03 \\
\text { 8. } 181 E-04 \\
2.000 E-04\end{array}$ & $\begin{array}{l}0.784 E+00 \\
2.123 E-01 \\
1.688 E-02 \\
6.161 E-03 \\
2.009 E-03\end{array}$ & $\begin{array}{l}2.867 E+04 \\
4.892 E+04 \\
4.930 E+04 \\
4.982 E+04 \\
4.972 E+04\end{array}$ \\
\hline $\begin{array}{l}1.00 O E+O B \\
3.000 E+05 \\
6.000 E+0 B \\
1.000 E+08 \\
3.00 O E+08\end{array}$ & $\begin{array}{l}8.97 E E-08 \\
1.578 E-05 \\
3.029 E-08 \\
2.048 E-08 \\
2.087 E-07\end{array}$ & $\begin{array}{l}B .978 E-04 \\
1.578 E-04 \\
5.028 E-08 \\
2.048 E-08 \\
2.087 E-08\end{array}$ & $\begin{array}{l}4.977 E+04 \\
4.985 E+04 \\
4.987 E+04 \\
4.988 E+04 \\
4.990 E+04\end{array}$ \\
\hline 8. $000 E+08$ & $2.751 E-08$ & $2.751 E-07$ & $4.900 E+04$ \\
\hline
\end{tabular}


Tablo 3-7b. Case 2 Results: Rolativo Concentration, Mass Flux, and Cumulative Mass Flux in the Fracturo for Np.237 Over Time With Rock Matrix Retardation Factor $R^{\prime}=100$ (Band Release Modo)

\begin{tabular}{|c|c|c|c|}
\hline$T$ ime $(y r)$ & $\begin{array}{c}\text { Conoentration } \\
A / A^{0}\end{array}$ & 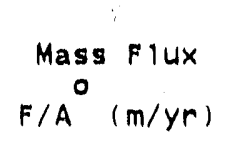 & $\begin{array}{c}\text { Cumulative } \\
\text { Mass Flux } \\
\text { M/A (m) }\end{array}$ \\
\hline $\begin{array}{l}1.000 E+01 \\
1.500 E+01 \\
2.000 E+01 \\
2.100 E+01 \\
2.230 E+01\end{array}$ & $\begin{array}{l}0.000 E+00 \\
2.540 E-10 \\
7.744 E-06 \\
2.008 E-0 E \\
\mathbf{5 . 5 2 1 E - 0 5}\end{array}$ & $\begin{array}{l}0.000 E+00 \\
2.540 E-09 \\
7.744 E-05 \\
2.008 E-04 \\
5.521 E-04\end{array}$ & $\begin{array}{l}0.000 E+00 \\
5.675 E-10 \\
6.303 E-05 \\
1.944 E-04 \\
8.541 E-04\end{array}$ \\
\hline $\begin{array}{l}2,500 E+01 \\
3,000 E+01 \\
8,000 E+01 \\
1,000 E+02 \\
3,000 E+02\end{array}$ & $\begin{array}{l}2.007 E-04 \\
1.565 E-03 \\
4.550 E-02 \\
1.360 E-01 \\
4.062 E-01\end{array}$ & $\begin{array}{l}2.607 E-03 \\
1.565 E-02 \\
4.550 E-01 \\
1.360 E+00 \\
4.062 E+00\end{array}$ & $\begin{array}{l}4.403 E-03 \\
4.374 E-02 \\
5.769 E+00 \\
4.211 E+01 \\
6.296 E+02\end{array}$ \\
\hline $\begin{array}{l}6.000 E+02 \\
1.000 E+03 \\
3.000 E+03 \\
6.000 E+03 \\
1.000 E+04\end{array}$ & $\begin{array}{l}5.603 E-01 \\
6.529 E-01 \\
7.951 E-01 \\
2.015 E-01 \\
4.601 E-02\end{array}$ & $\begin{array}{l}5.603 E+00 \\
6.529 E+00 \\
7.951 E+00 \\
2.015 E+00 \\
\$ .601 E-01\end{array}$ & $\begin{array}{l}2.114 E+03 \\
4.562 E+03 \\
1.941 E+04 \\
3.974 E+04 \\
4.337 E+04\end{array}$ \\
\hline $\begin{array}{l}3.000 E+04 \\
6.000 E+04 \\
1.000 E+05 \\
3.000 E+05 \\
6.000 E+05\end{array}$ & $\begin{array}{l}6.139 E-03 \\
2.006 E-03 \\
8.966 E-04 \\
1.577 E-04 \\
5.028 E-05\end{array}$ & $\begin{array}{l}\text { 6. } 139 E-02 \\
2.006 E-02 \\
8.966 E-03 \\
1.577 E-03 \\
5.028 E-04\end{array}$ & $\begin{array}{l}4.653 E+04 \\
4.757 E+04 \\
4.810 E+04 \\
4.883 E+04 \\
4.910 E+04\end{array}$ \\
\hline $\begin{array}{l}\text { 1. }, 000 E+O E \\
3,000 E+0 Q \\
6,000 E+0 B\end{array}$ & $\begin{array}{l}2.048 E-05 \\
2.057 E-06 \\
2.751 E-07\end{array}$ & $\begin{array}{l}2.04 B E-04 \\
2.057 E-05 \\
2.751 E-06\end{array}$ & $\begin{array}{r}4.923 E+04 \\
4.936 E+04 \\
4.939 E+04\end{array}$ \\
\hline
\end{tabular}


T'uble 3-7c. Case 2 Results: Relative Concentration, Mass Flux, and Cumulative Mass Flux in the Fracture for Np-237 Over Time with Rock Matrix Retardation Factor $R^{\prime}=10,000$ (Barid Release Mode)

\begin{tabular}{|c|c|c|c|}
\hline Time $(y r)$ & $\begin{array}{c}\text { Concentration } \\
\text { A/A }\end{array}$ & $\begin{array}{l}\text { Mass Flidx } \\
0^{0}(m / y r)\end{array}$ & $\begin{array}{c}\text { Cumulative } \\
\text { Mass Flux } \\
M / A_{0}^{\circ}(m)\end{array}$ \\
\hline $\begin{array}{l}1.000 E+02 \\
8.000 E+02 \\
9.000 E+02 \\
1.000 E+03 \\
1.500 E+03\end{array}$ & $\begin{array}{l}2.982 E-50 \\
4.884 E-07 \\
2.132 E-06 \\
8.988 E-08 \\
2.485 E-04\end{array}$ & $\begin{array}{l}2.982 E-48 \\
4.864 E-08 \\
2.132 E-0 \Xi \\
6.966 E-08 \\
2.485 E-03\end{array}$ & $\begin{array}{l}2.347 E-49 \\
2.595 E-04 \\
1.401 E-03 \\
5.567 E-03 \\
4.147 E-01\end{array}$ \\
\hline $\begin{array}{l}2.000 E+03 \\
3.000 E+03 \\
6.000 E+03 \\
1.000 E+04 \\
3.000 E+04\end{array}$ & $\begin{array}{l}1.522 E-03 \\
9,692 E-03 \\
6.752 E-02 \\
1.114 E-01 \\
4.272 E-02\end{array}$ & $\begin{array}{l}1.522 E-02 \\
9.692 E-02 \\
6.752 E-01 \\
1.114 E+00 \\
4.272 E-04\end{array}$ & $\begin{array}{l}4.217 E+00 \\
5.354 E+01 \\
1.134 E+03 \\
5.079 E+03 \\
1.957 E+04\end{array}$ \\
\hline $\begin{array}{l}\text { B. } 000 E+04 \\
1.000 E+05 \\
3.000 E+05 \\
8.000 E+05 \\
1.000 E+08\end{array}$ & $\begin{array}{l}1.688 E-02 \\
8.100 E-03 \\
1.525 E-03 \\
4.940 E-04 \\
2.028 E-04\end{array}$ & $\begin{array}{l}1.888 E-01 \\
8.100 E-02 \\
1.525 E-0.4 \\
4.948 E-03 \\
2.028 E-03\end{array}$ & $\begin{array}{l}2.755 E+04 \\
3.220 E+04 \\
3.905 E+04 \\
4.184 E+04 \\
4.291 E+04\end{array}$ \\
\hline $\begin{array}{l}: .000 E+0 B \\
i .000 E+0 B\end{array}$ & $\begin{array}{l}2.050 E-05 \\
2.748 E-06\end{array}$ & $\begin{array}{l}2.050 E-04 \\
2.746 E-08\end{array}$ & $\begin{array}{l}4.428 E+04 \\
4.453 E+04\end{array}$ \\
\hline
\end{tabular}




\subsubsection{Caso 3: Multiple Patch Source Sublect to Step Release and Band Release}

The two-dimensional solution restricted to the fracture plane was verified by means of a test example dealing with the transport of $\mathrm{Cm}-245$ subject to a step and band release mode. The geometry of the source corresponds to an array of patch sources ( 11 in total) with an individual width of 5 meter's and spaced at intervals of 5 meter's. The list of parameters related to this cuse is given in 'T'able 3-8. Test runs for four different times reported in Table 3-9 are in exact agreoment with results prodictod by MASCO'T (see Gureghian, 1987) for the same input parameters. Note that the two-dimensional model in MASCO'T simulates transport of a radionuclide decay chain in a fracture of unit thickness, whereby diffusion into the rock matrix is ignored.

Table 3-8. Input Parameters for Case 3

\begin{tabular}{|c|c|}
\hline Species & $\mathrm{Cm}-245$ \\
\hline $\begin{array}{l}\text { Initial Concentration } \mathrm{A}^{0} \\
\text { (arbitrary unit of } \\
\text { activity/L } / \mathrm{L}^{3} \text { ) }\end{array}$ & 1 \\
\hline Type of Release Mode & Step and Band \\
\hline Boundary Condition & $\begin{array}{l}\text { Array of finite patch sources (total } \\
\text { of 11) }\end{array}$ \\
\hline Location & 100.0 in downstroum \\
\hline$y_{1}$ & $100 \mathrm{~m}$ \\
\hline$d$ & $5.0 \mathrm{~m}$ \\
\hline Spacing Between Sources & $5.0 \mathrm{~m}$ \\
\hline u & $10.0 \mathrm{~m} / \mathrm{yr}$ \\
\hline$v$ & $0 \mathrm{~m} / \mathrm{yr}$ \\
\hline $\mathrm{D}_{\mathrm{xx}}$ & $1,000 \mathrm{~m}^{2} / \mathrm{yr}$ \\
\hline $\mathrm{D}_{\mathrm{yy}}$ & $200 \mathrm{~m}^{2} / \mathrm{yr}$ \\
\hline $\mathrm{D}_{\mathrm{yx}}$ & $0.0 \mathrm{~m}^{2} / \mathrm{yr}$ \\
\hline $\mathrm{D}_{\mathrm{p}}$ & $0.0 \mathrm{~m}^{2} / \mathrm{yr}$ \\
\hline $\mathrm{T}_{1 / 2}$ & $8,500 \mathrm{yr}$ \\
\hline $\mathrm{T}_{\mathrm{L}}$ & $10^{5} \mathrm{yr}$ \\
\hline b & $5 \times 10^{-3} \mathrm{~m} \mathrm{yr}$ \\
\hline $\mathrm{R}$ & 5,000 \\
\hline $\mathrm{R}^{\prime}$ & 1.0 \\
\hline
\end{tabular}


I'able 3-9. Caso 3 Results: Rolative Concentration in Fracturo (A/A $\mathrm{A}^{\circ}$ for $\mathrm{Cm} \cdot 245$

\begin{tabular}{|c|c|c|c|c|}
\hline \multirow{2}{*}{$\begin{array}{l}\text { Lateral } \\
\text { Distance } \\
(\mathrm{m})\end{array}$} & \multicolumn{4}{|c|}{$\operatorname{Tim} \theta$} \\
\hline & $1.0 \times 10^{4} \mathrm{yl}^{4}$ & $5.0 \times 10^{4} \mathrm{yr}$ & $1.5 \times 10^{5} \mathrm{yr}$ & $2.0 \times 10^{6} \mathrm{yr}$ \\
\hline 0.0 & $0.3004 \times 10.5$ & $0.8548 \times 10^{0.4}$ & $0.5897 \times 10.7$ & $0.5568 \times 10^{.9}$ \\
\hline 50.0 & $0.1083 \times 10^{-2}$ & $0.6852 \times 10.3$ & $0.1358 \times 10.6$ & $0.9476 \times 10.9$ \\
\hline 75.0 & $0.7469 \times 10^{.2}$ & $0.1687 \times 10^{-2}$ & $0.1835 \times 10^{.6}$ & $0.1443 \times 10^{.8}$ \\
\hline 100.0 & 0.0237 & $0.3327 \times 10^{.2}$ & $0.2280 \times 10.6$ & $0.1308 \times 10^{-8}$ \\
\hline 125.0 & 0.0364 & $0.4678 \times 10.2$ & $0.2600 \times 10.6$ & $0.1419 \times 10^{.8}$ \\
\hline 150.0 & 0.0393 & $0.5119 \times 10^{-2}$ & $0.2717 \times 10^{-6}$ & $0.1458 \times 10.8$ \\
\hline
\end{tabular}

Note: Values determined for this restricted case correspond exactly to values predicted by MASCO'T (Gureghian, 1987) for the same input parameters.

\subsubsection{Case 4: Two-Dimensional Transport of T'c-99 \\ in Fracture and Rock Matrix}

The results reported here lllustrate the full application of the solutions dealing with the three types of concentration distribution at inlet, namely finite patch, multiple patch, and Gaussian distributed source, subject to a step and band release mode. The input parameters pertinent to theso prob. lems are reported in Table 3-10. Graphical interpretation of the numerical results yielded by the finite line and a Gaussian distributed source are reported in the form of concentration isopleths; these iso. pleths were generated using a bilinear interpolation scheme. The simulation times for all throe test cases reported in the subsequent sections range between $2.5 \times 10^{4}$ and $5 \times 10^{4}$ years.

\section{Case 4A - Finite Patch Source}

Figures 3-5a (Step Release) and 3-5b (Band Release) show the relative concentration isoplethy for Tc. 99 in the fracture. Figures $3.5 \mathrm{c}$ and $3.5 \mathrm{~d}$ give corresponding data at $1 \mathrm{~m}$ in the rock matrix, and Figures 3.50 and $3.5 \mathrm{f}$ at $5 \mathrm{~m}$. The finite patch source is $50 \mathrm{~m}$ wide and centered at a diatance of $350 \mathrm{~m}$ on the y-axis. Results indicate that the axis of symmetry of the plume follows to a reasonable approximation the same prescribed direction (northwest) of ground-water flow in the fracture plane. The area of the plume defined here by the relative concentration isopleth of 0.001 seems to decrease with increasing height. Tabulated results are given in Tables 3-11a, 3-11b, 3-11 c, 3-11d, 3-11e, and 3-11f. 
Table 3-10. Input Parameters Used in Simulation of Tc-99 in Fracture and Rock Matrix for Case 4

\begin{tabular}{|c|c|c|c|}
\hline $\begin{array}{c}\text { Boundary } \\
\text { Type }\end{array}$ & $\begin{array}{c}\text { Case 4A } \\
\text { (FPS) }\end{array}$ & $\begin{array}{l}\text { Case 4B } \\
\text { (AFPS) }\end{array}$ & $\begin{array}{l}\text { Case 4C } \\
\text { (GDS) }\end{array}$ \\
\hline $\mathrm{u}(\mathrm{m} / \mathrm{yr})$ & 2. & 2. & 2. \\
\hline $\mathrm{v}(\mathrm{m} / \mathrm{yr})$ & 1. & 0. & 1. \\
\hline$a_{L}(m)$ & 5 & 5 & 5 \\
\hline$a_{T}(m)$ & 2 & 2 & 2 \\
\hline$D_{p}\left(m^{2 / y r}\right)$ & $10^{-2}$ & $10^{-2}$ & $10^{-2}$ \\
\hline$D_{d}\left(m^{2} / y r\right)$ & $1.2 \times 10^{-2}$ & $1.2 \times 10^{-2}$ & $1.2 \times 10^{-2}$ \\
\hline$\tau$ & 0.5 & 0.5 & 0.5 \\
\hline$\phi$ & $10^{-2}$ & $10^{-2}$ & $10^{-2}$ \\
\hline$b(m)$ & $5 \times 10^{-3}$ & $5 \times 10^{-3}$ & $5 \times 10^{-3}$ \\
\hline $\mathrm{R}$ & 10 & 10 & 10 \\
\hline $\mathrm{R}^{\prime}$ & 100 & 100 & 100 \\
\hline $\mathrm{T}(\mathrm{yr})$ & $10^{4}$ & -- & $10^{4}$ \\
\hline $\mathrm{T}_{1 / 2}(\mathrm{yr})$ & $2.13 \times 10^{5}$ & $2.13 \times 10^{5}$ & $2.13 \times 10^{5}$ \\
\hline$y_{0}(m)$ & -- & -- & 350 \\
\hline$\sigma(m)$ & -- & -- & 20 \\
\hline$d(m)$ & 50 & 10 & -. \\
\hline $\mathrm{y}_{1}(\mathrm{~m})$ & 350 & 100 & - \\
\hline $\mathrm{y}_{2}(\mathrm{~m})$ & - & 200 & -- \\
\hline$y_{3}(m)$ & -- & 300 & $\cdots$ \\
\hline
\end{tabular}

Note: Initial concentration at the source $\mathrm{A}^{\circ}$ (arbitrary unit of activity/L 3$)=1$

Key: FPS $=$ Finite Patch Source

AFPS $=$ Array of Finite Patch Sources

GDS = Gaussian Distributed Source 


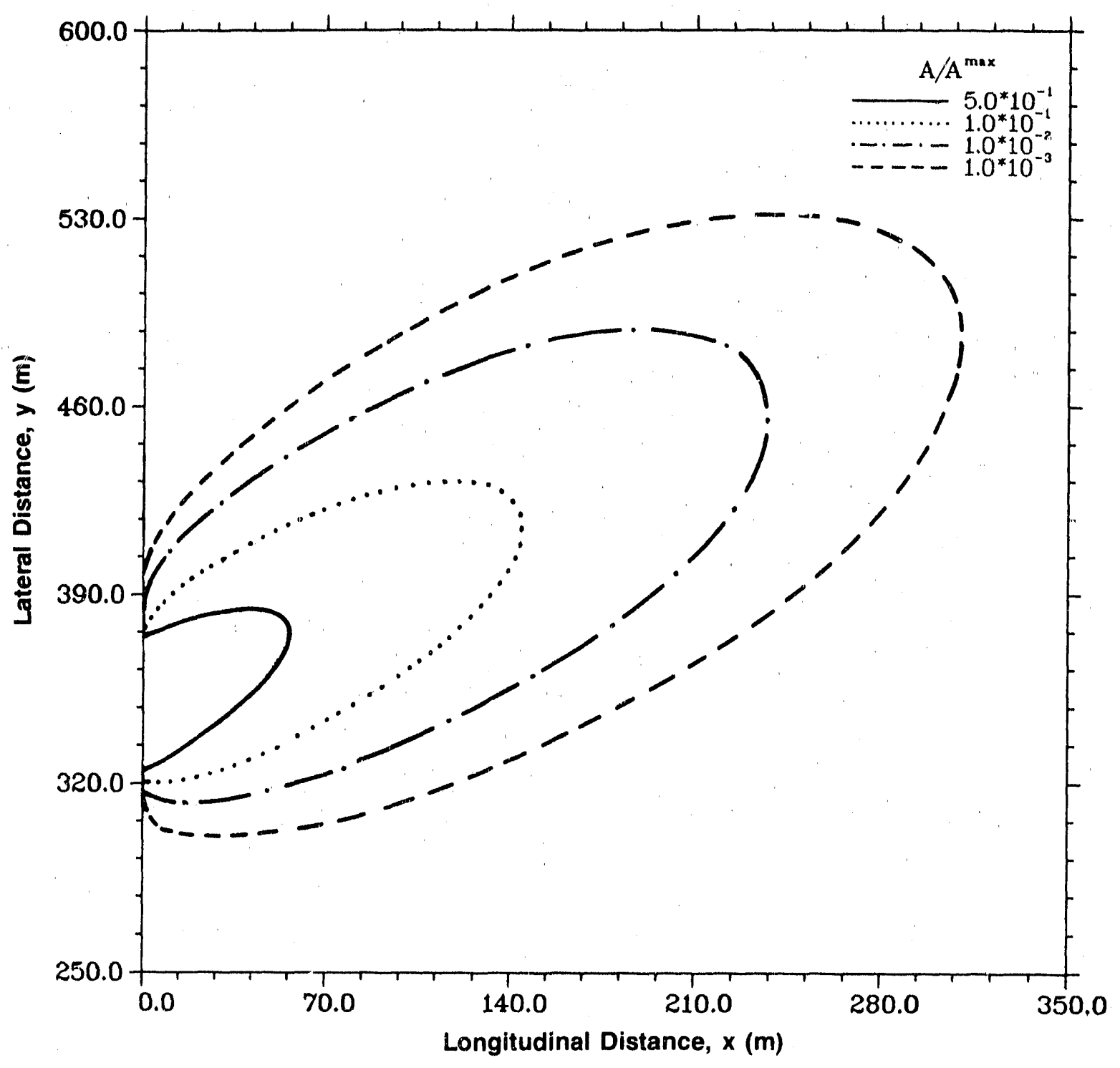

Figure 3-5a. Relative Concentration Isopleths for Tc-99 in the Fracture at $\mathbf{z}=0 \mathrm{~m}$ and $t=5 \times 10^{3}$ yr, Step Release Mode (Case 4A: Finite Patch Source) 


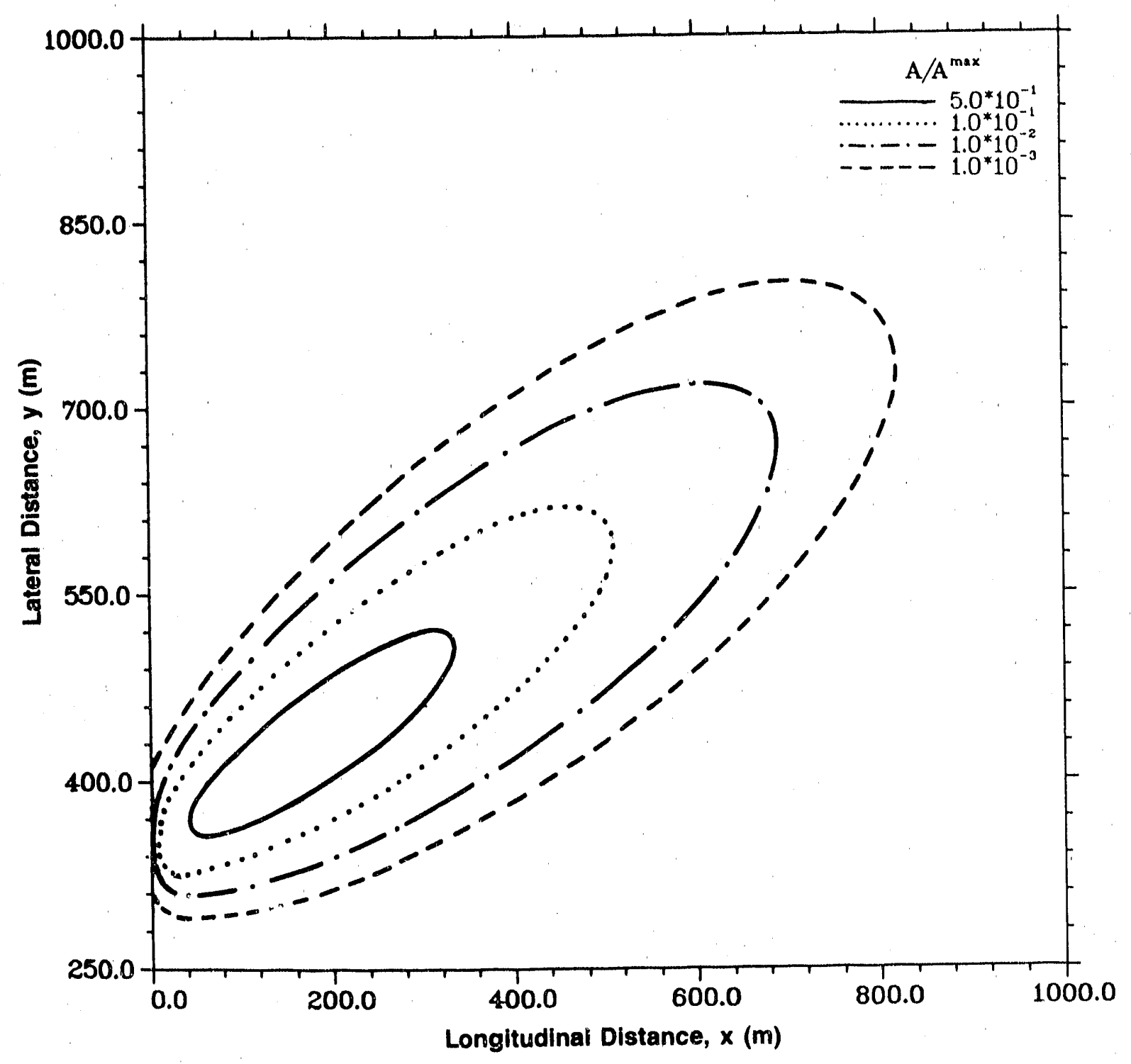

Figure 3-5b. Relative Concentration Isopleths for Tc-99 in the Fracture at $z=0 \mathrm{~m}$ and $t=2.5 \times 10^{4} \mathrm{yr}$, Band Release Mode (Case 4A: Finite Patch Source) 


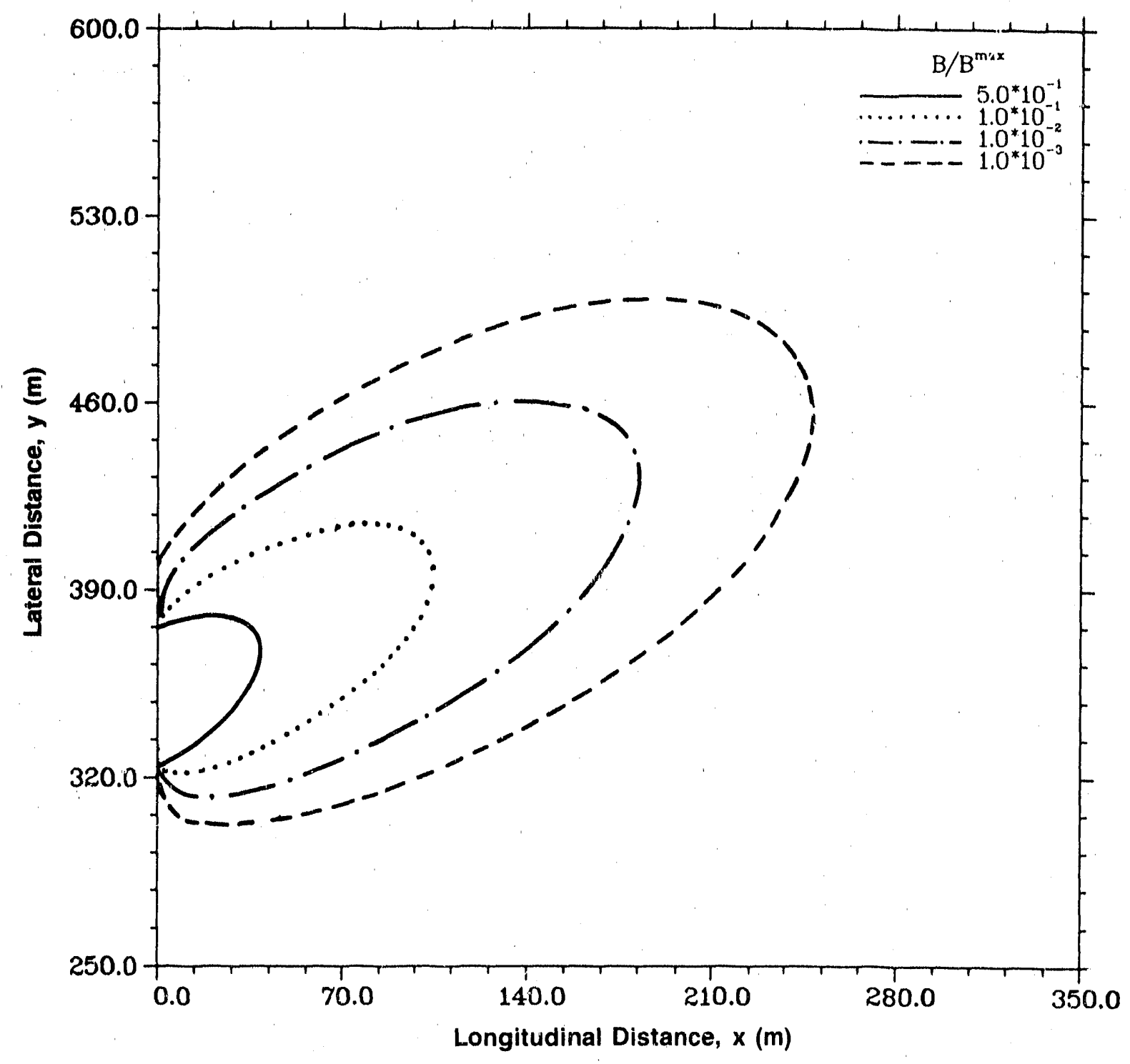

Figure 3-5c. Relative Concentration Isopleths for Tc-99 in the Rock Matrix at $z=1 \mathrm{~m}$ and $t=5 \times 10^{3} \mathrm{yr}$, Step Release Mode (Case 4A: Finite Patch Source) 


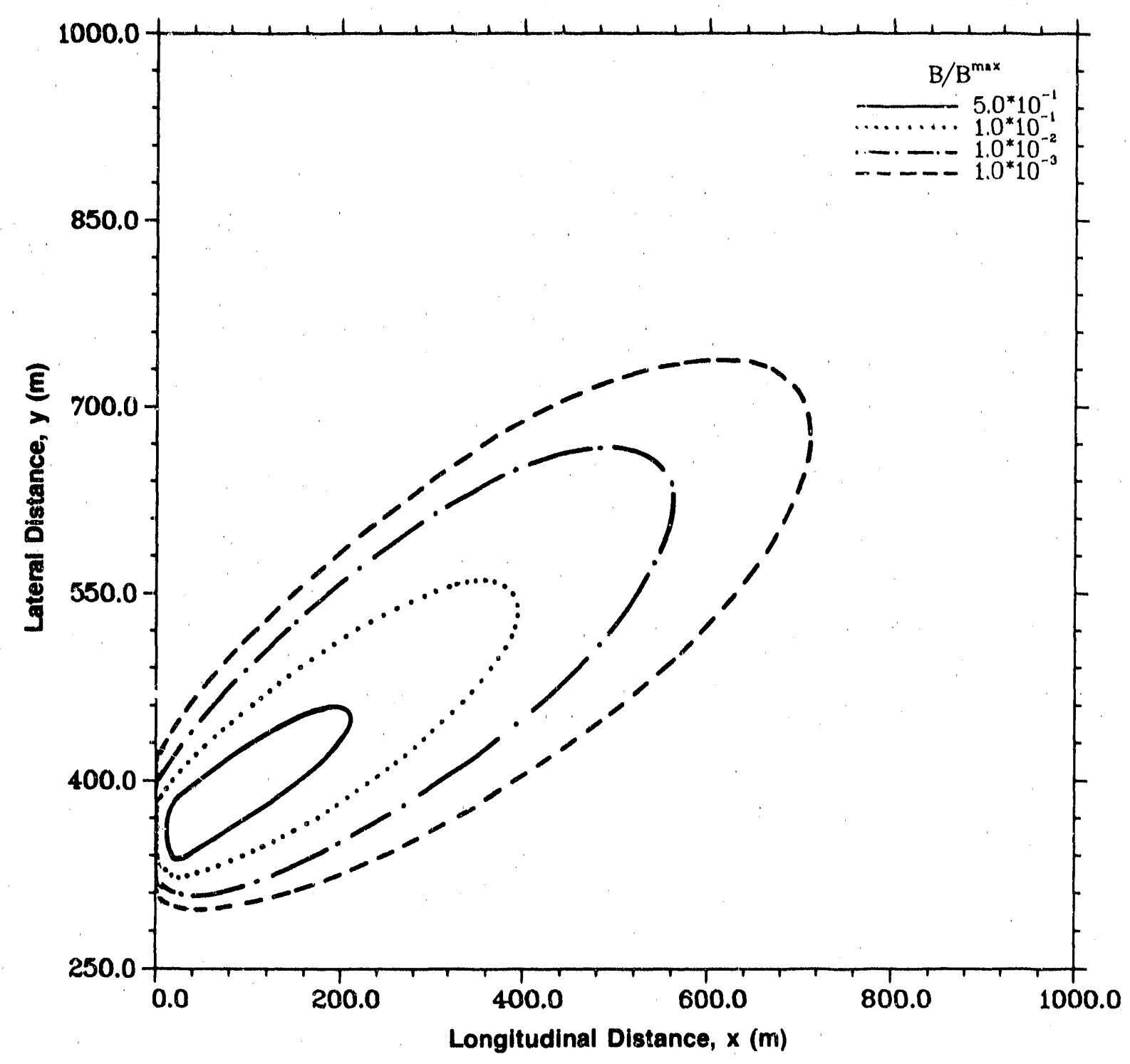

Figure 3-5d. Relative Concentration Isopleths for Tc-99 in the Rock Matrix at $z=1 \mathrm{~m}$ and $t=2.5=10^{4} \mathrm{yr}$, Band Release Mode (Case 4A: Finite Patch Source) 


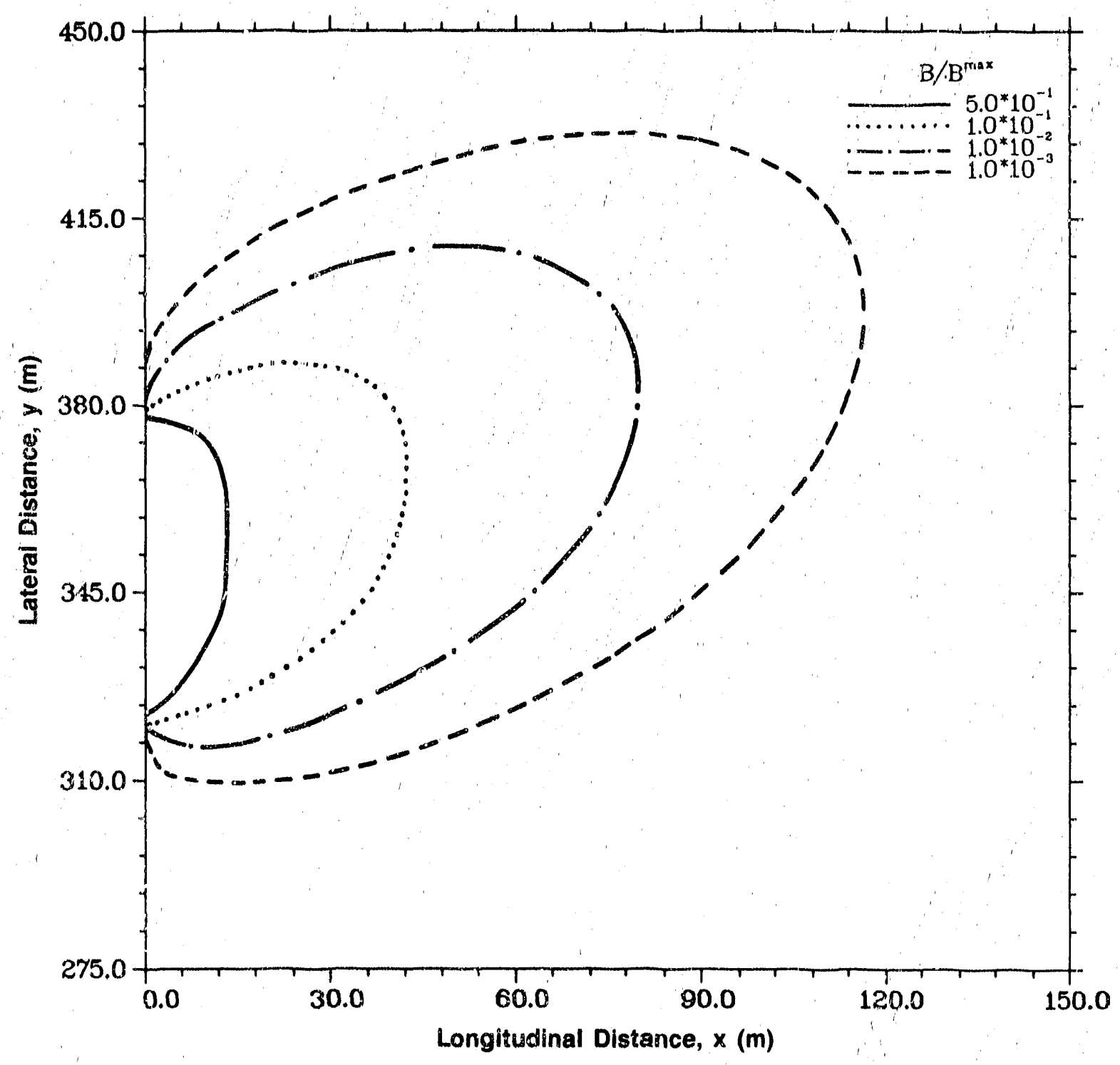

Figure 3-5e. Relative Concentration Isopleths for Tc-99 in the Rock Matrix at $z=5 \mathrm{~m}$ and $t=5 \times 10^{3} \mathrm{yr}$, Step Release Mode (Case 4A: Finite Patch Source) 


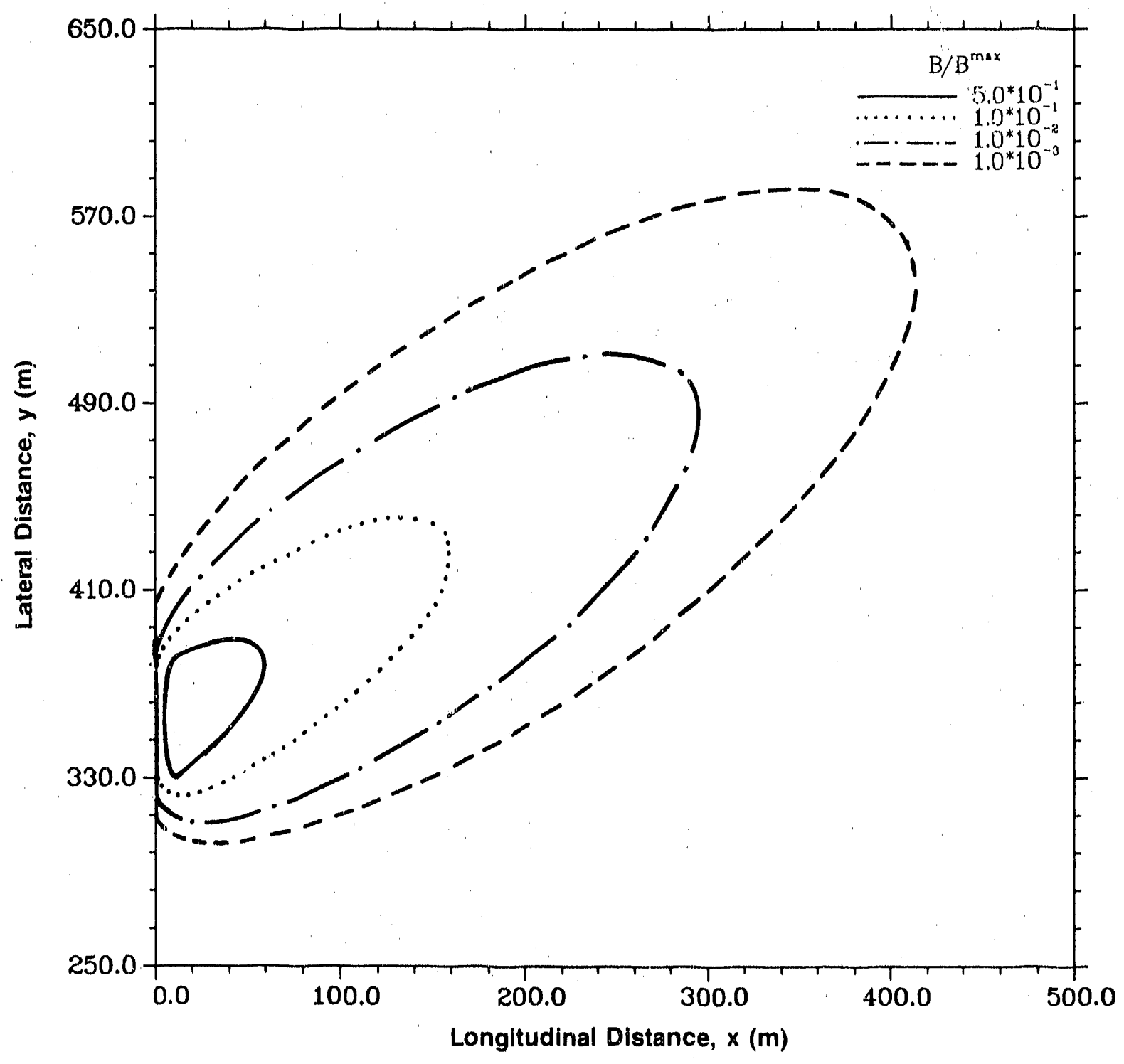

Figure 3-5f. Relative Concentration Isopleths for Tc-99 in the Rock Matrix at $z=5 \mathbf{m}$ and $t=2.5 \times 10^{4} \mathrm{yr}$, Band Release Mode (Case 4A: Finite Patch Source) 

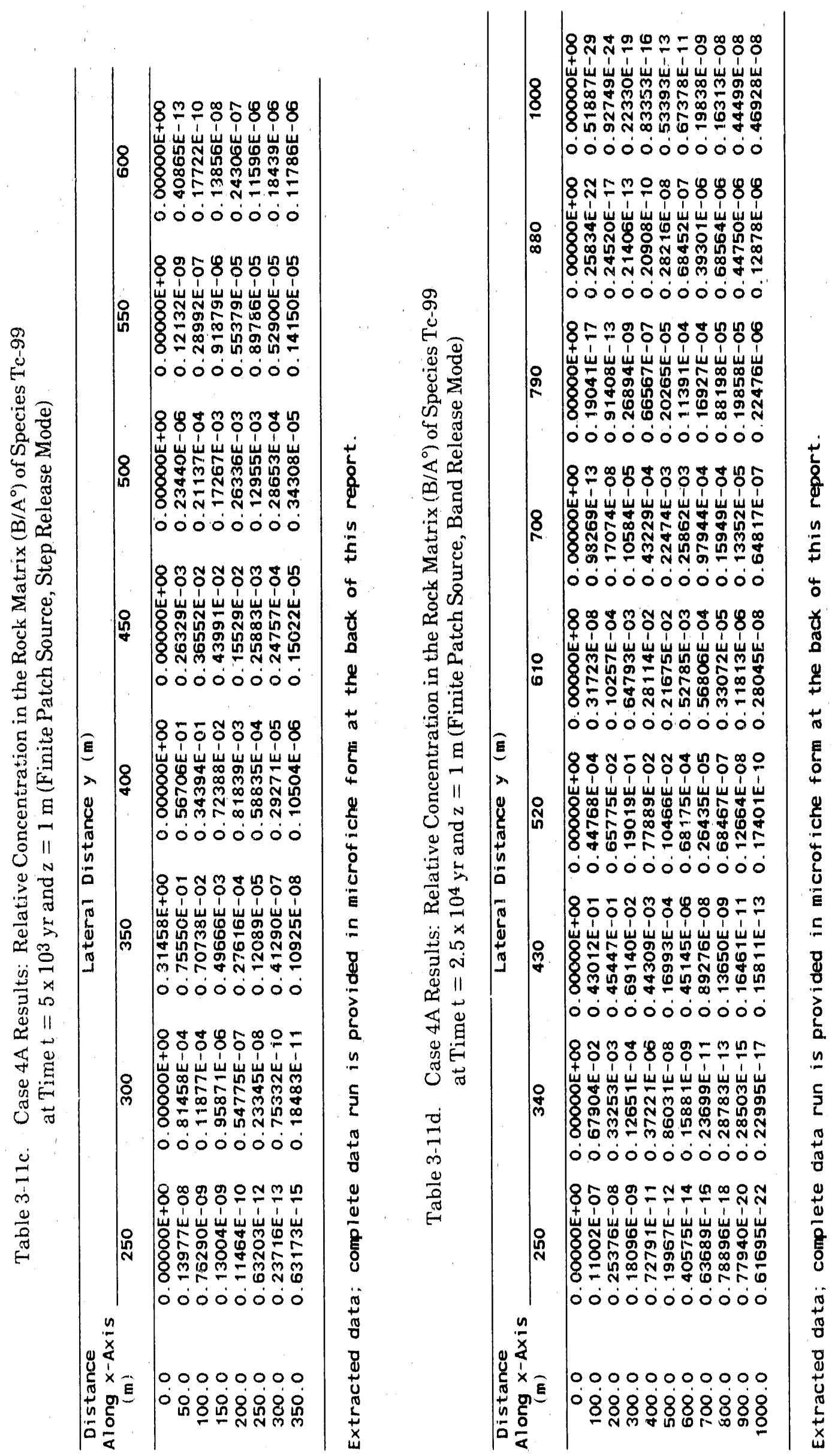


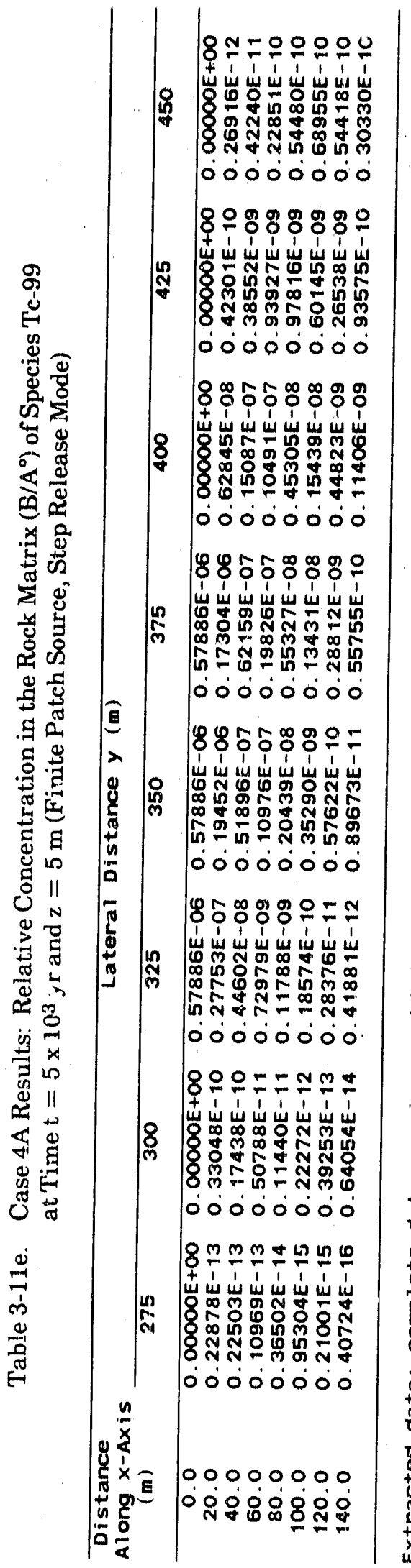


Figures 3-6a, 3-6b, 3-6c, and 3-6d show the relative concentration, relative mass flux, magnitude and direction of mass flux, and curnulative mass flux profiles of Tc-9,9 at various distances $x$ in the fracture. The figures depict stepwise release from three identical finite line sources $10 \mathrm{~m}$ wide and centered at $100 \mathrm{~m}, 200 \mathrm{~m}$, and $300 \mathrm{~m}$ along the $\mathrm{y}$-axis. The wave-like pattern, particularly at close distances from the source (denoting a relatively high concentration gradient in the transverse direction of the fracture), seems to be damped out at greater distances $x$. The impact of the lateral hydrodynamic dispersion mechanism on the migration process seems to manifest itself only at large distances from the source. Tabulated results are given in Tables 3-12a, 3-12b, 3-12c, and 3-12d.

Figures 3-6e, 3-6f, and 3-6g show the relative concentration profiles at different distances in the rock matrix. The shape of these curves is intimately related to the concentration profile in the fracture. This denotes that concentrations of Tc-99 (decreasing with the elevation $z$ ) are an immediate consequence of the diffusion mechanism, the sole process gearing the migration of the solute in the rock matrix. Results are given in Tables 3-12e, 3-12f, and 3-12g. Note that the superposition of the solution for a single line source has been adopted in this instance (see Equation 3-35).

Case 4C - Gaussian Distributed Source

Figures 3-7a (Step Release) and 3-7b (Band Release) show the relative concentration isopleths for Tc-99 in the fracture. Figures $3-7 \mathrm{c}$ and $3-7 \mathrm{~d}$ give corresponding data at $1 \mathrm{~m}$ in the rock matrix, and Figures 3-7e and 3-7f at $5 \mathrm{~m}$. The Gaussian source with a standard deviation of 20 is centered at a distance of $350 \mathrm{~m}$ on the $y$-axis. Conclusions very similar to the finite line source case may be drawn here, except the area of the plume is much larger; this is a consequence of the assumed concentration distribution at the source. Results are given in Tables 3-13a, 3-13b, 3-13c, 3-13d, 3-13e, and 3-13f.

Note: The maximum concentration in the fracture ( $A$ max) and in the rock (Bmax) is:

\begin{tabular}{ccccccc}
\hline & & \multicolumn{2}{c}{ Case 4A } & & \multicolumn{2}{c}{ Case 4C } \\
\cline { 3 - 4 } & & Step Release & Band Release & & Step Release & Band Release \\
\hline $\mathrm{A}^{\max }$ & 0.0 & $9.83681 \mathrm{E}-01$ & $6.60038 \mathrm{E}-02$ & & $9.83861 \mathrm{E}-01$ & $6.13422 \mathrm{E}-02$ \\
$\mathrm{~B}^{\max }$ & 1.0 & $3.14576 \mathrm{E}-01$ & $9.36598 \mathrm{E}-02$ & & $3.14576 \mathrm{E}-01$ & $8.34140 \mathrm{E}-02$ \\
$\mathrm{~B}^{\max }$ & 5.0 & $5.78862 \mathrm{E}-07$ & $1.77803 \mathrm{E}-02$ & & $5.78862 \mathrm{E}-07$ & $1.69540 \mathrm{E}-02$ \\
\hline
\end{tabular}




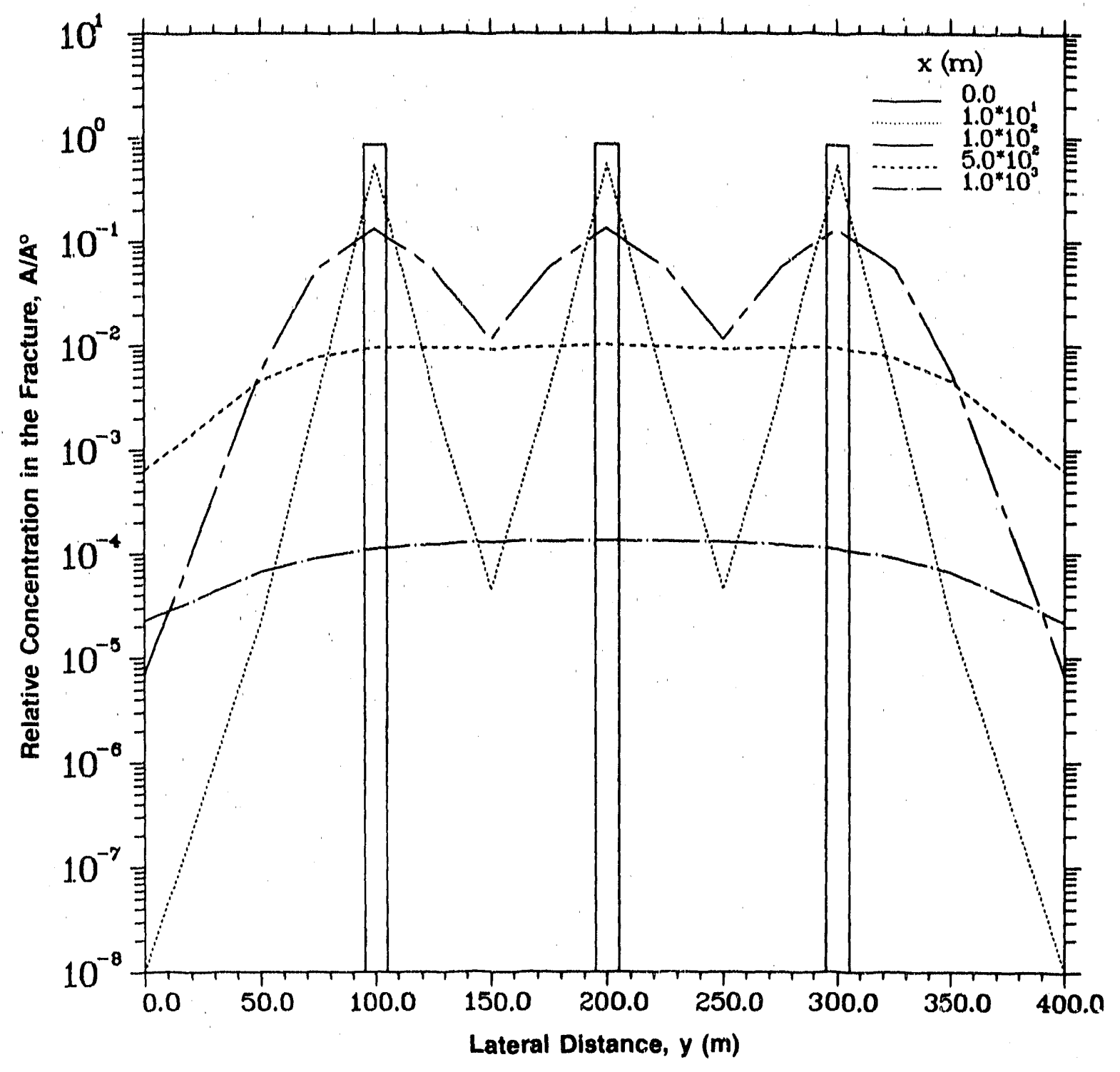

Figure 3-6a. Relative Concentration Profiles for Tc-99 in the Fracture at $\mathbf{z}=0 \mathrm{~m}$ and $t=5 \times 10^{4}$ yr (Case 4B: Multiple Patch Source) 


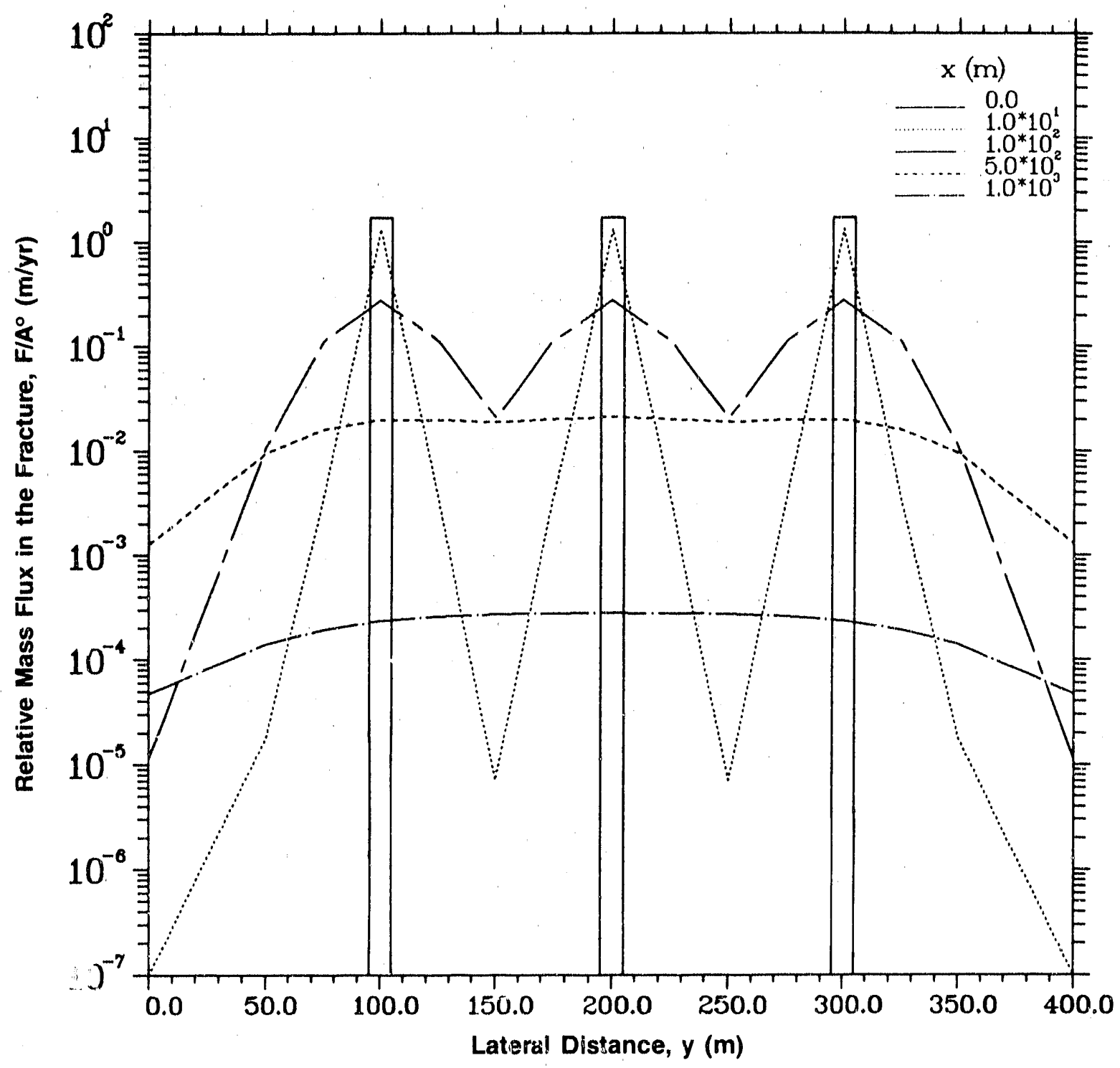

Figure 3-6b. Relative Mass Flux Profiles of Tc-99 in the Fracture at $z=$ $0 \mathrm{~m}$ and $\mathrm{t}=5 \times 10^{4}$ yr (Case 4B: Multiple Patch Source) 


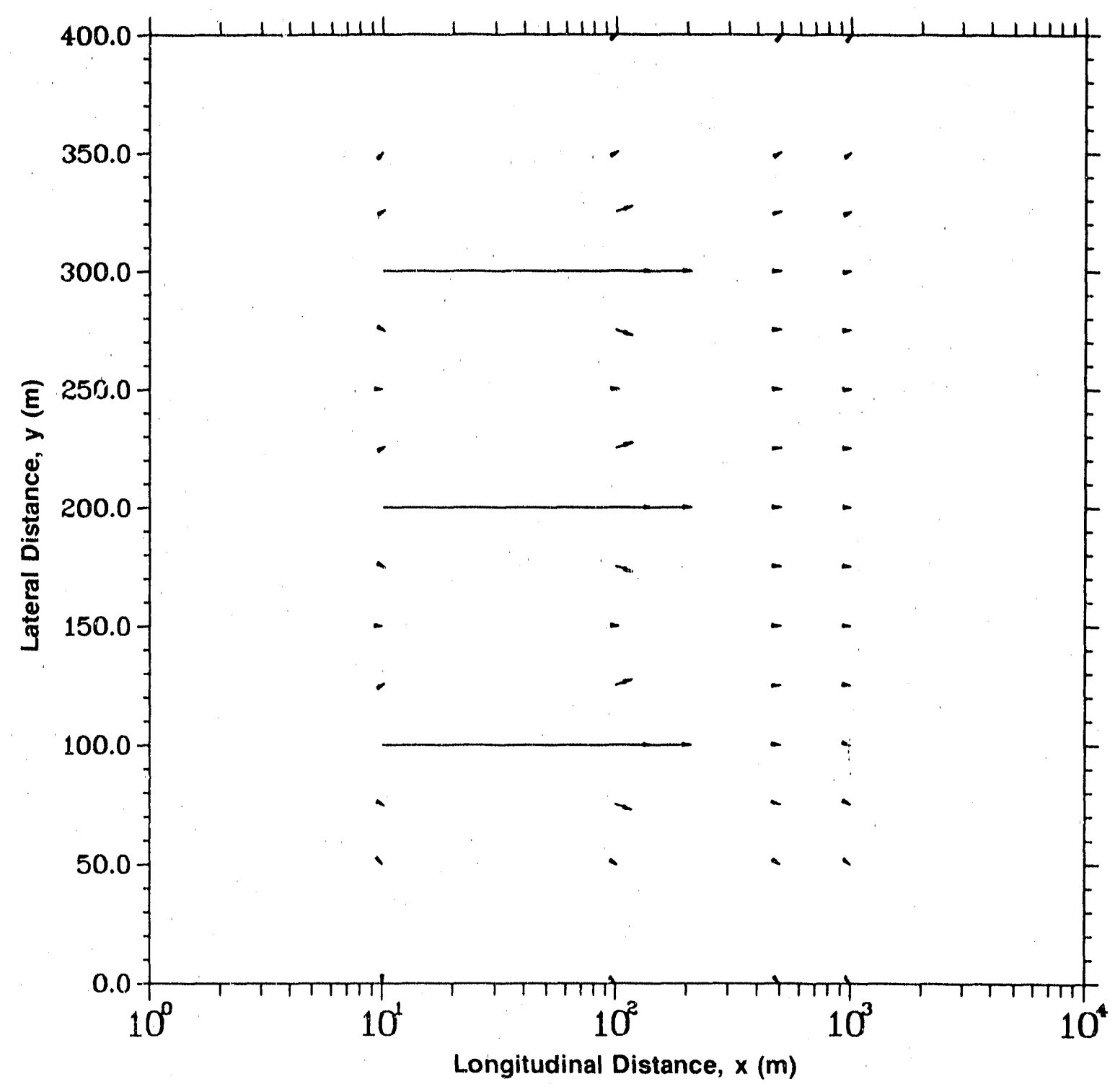

Figure 3-6c. Mass Flux Vector of Tc-99 at Discrete Points in the Fracture at $\mathrm{z}=0 \mathrm{~m}$ and $\mathrm{t}=5 \times 10^{4} \mathrm{yr}$ (Case 4B: Multiple Patch Source) 


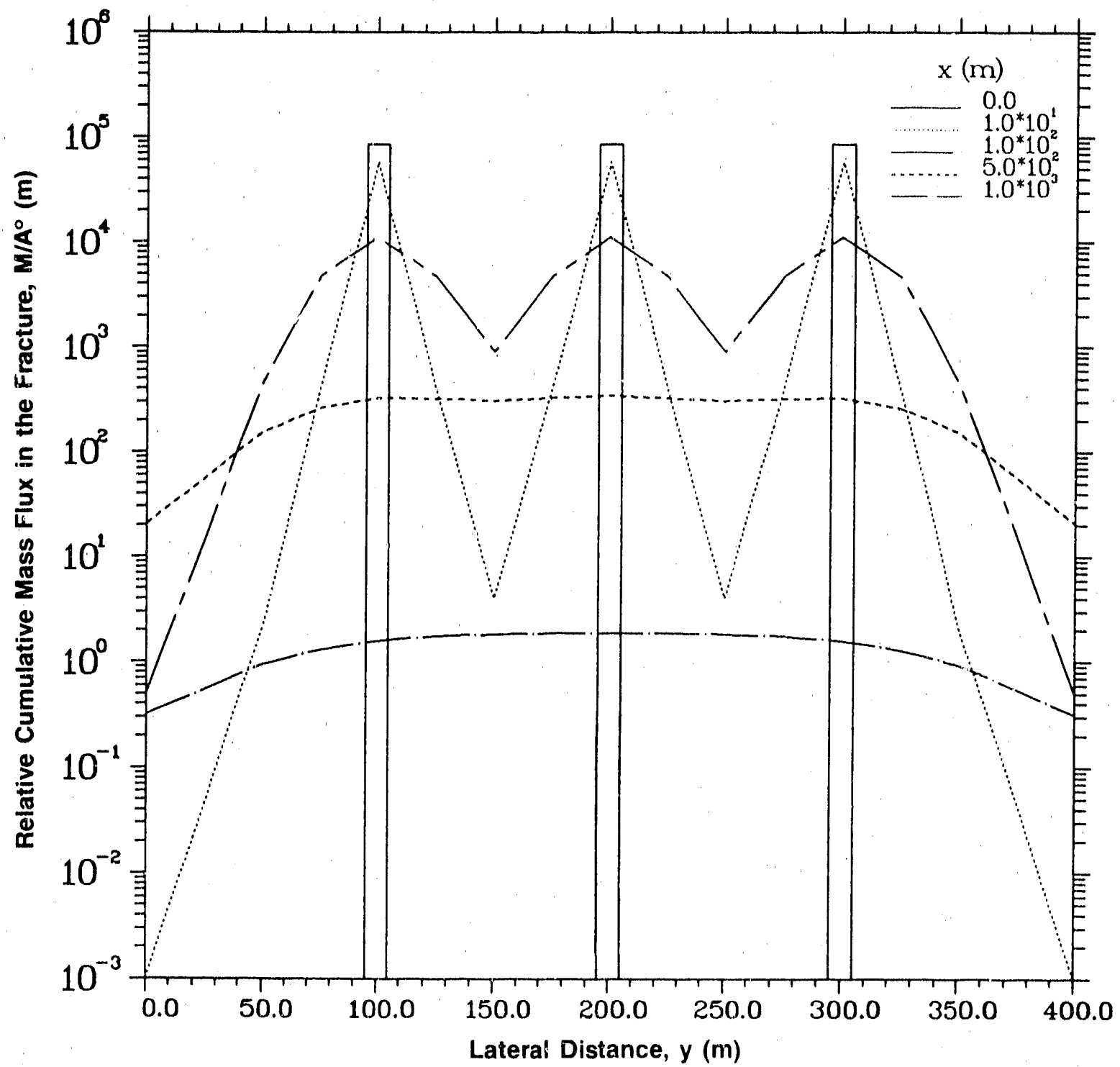

Figure 3-6d. Relative Cumulative Mass Flux of Tc-99 in the Fracture at $\mathbf{z}:=0 \mathrm{~m}$ and $t=5 \times 10^{4}$ yr (Case 4B: Multiple Patch Source) 

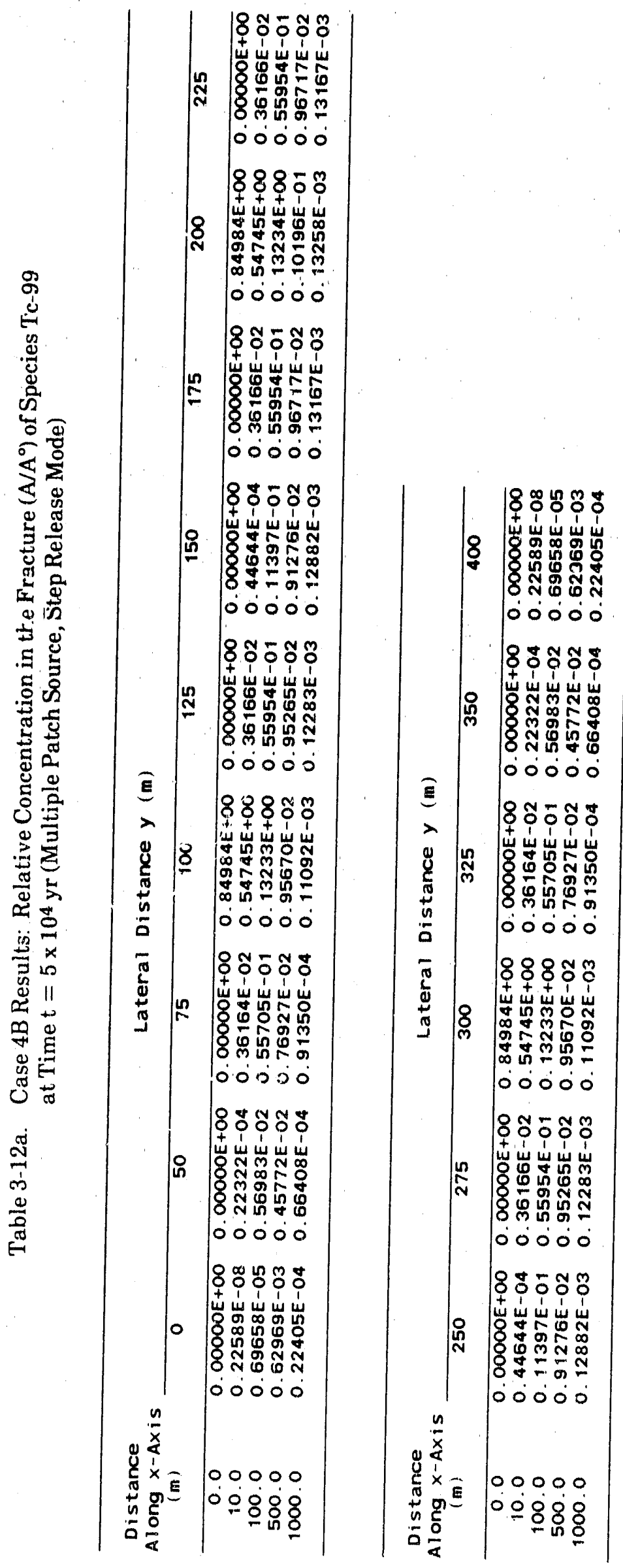

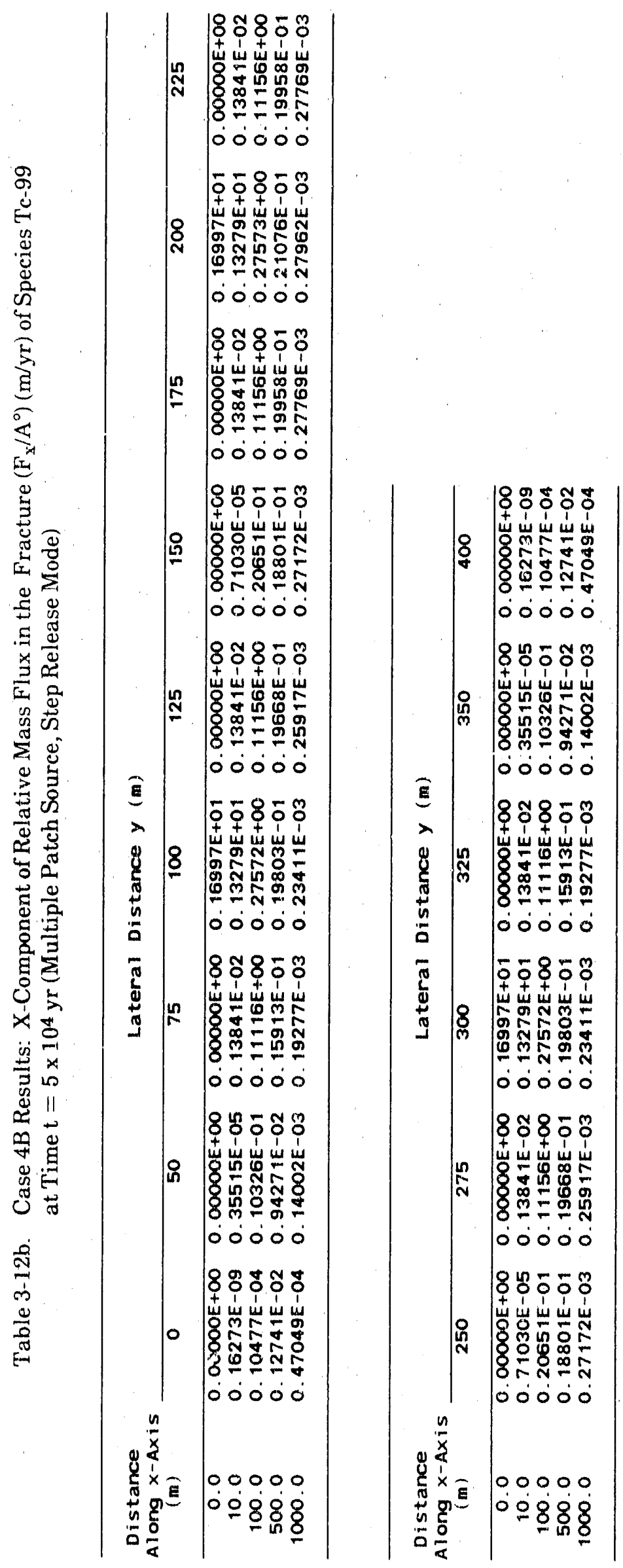

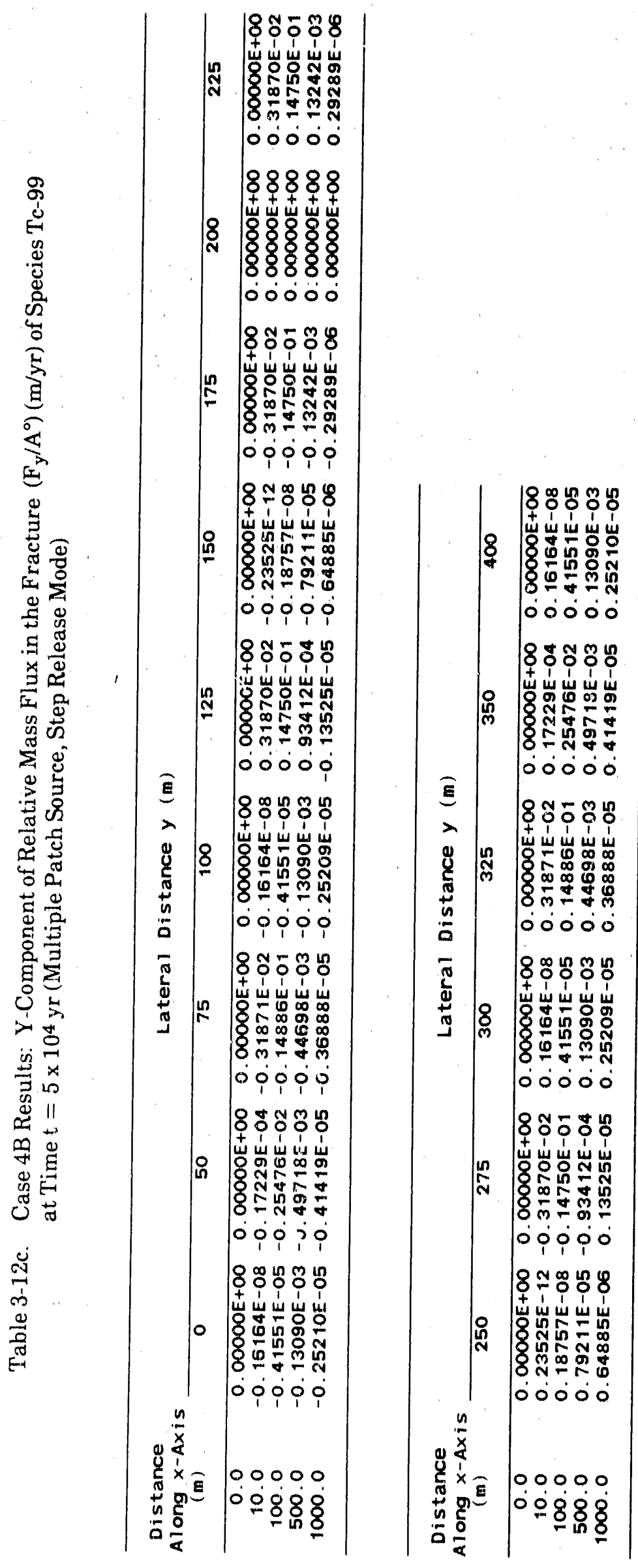

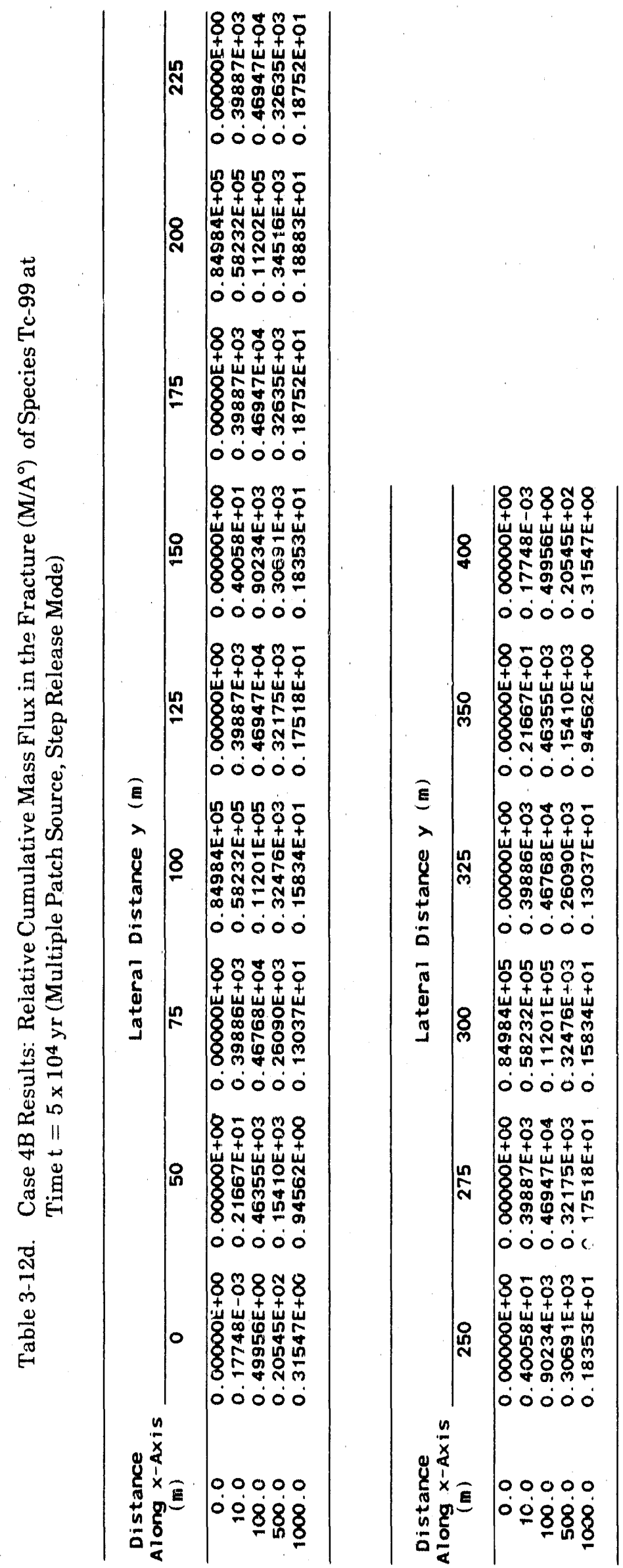


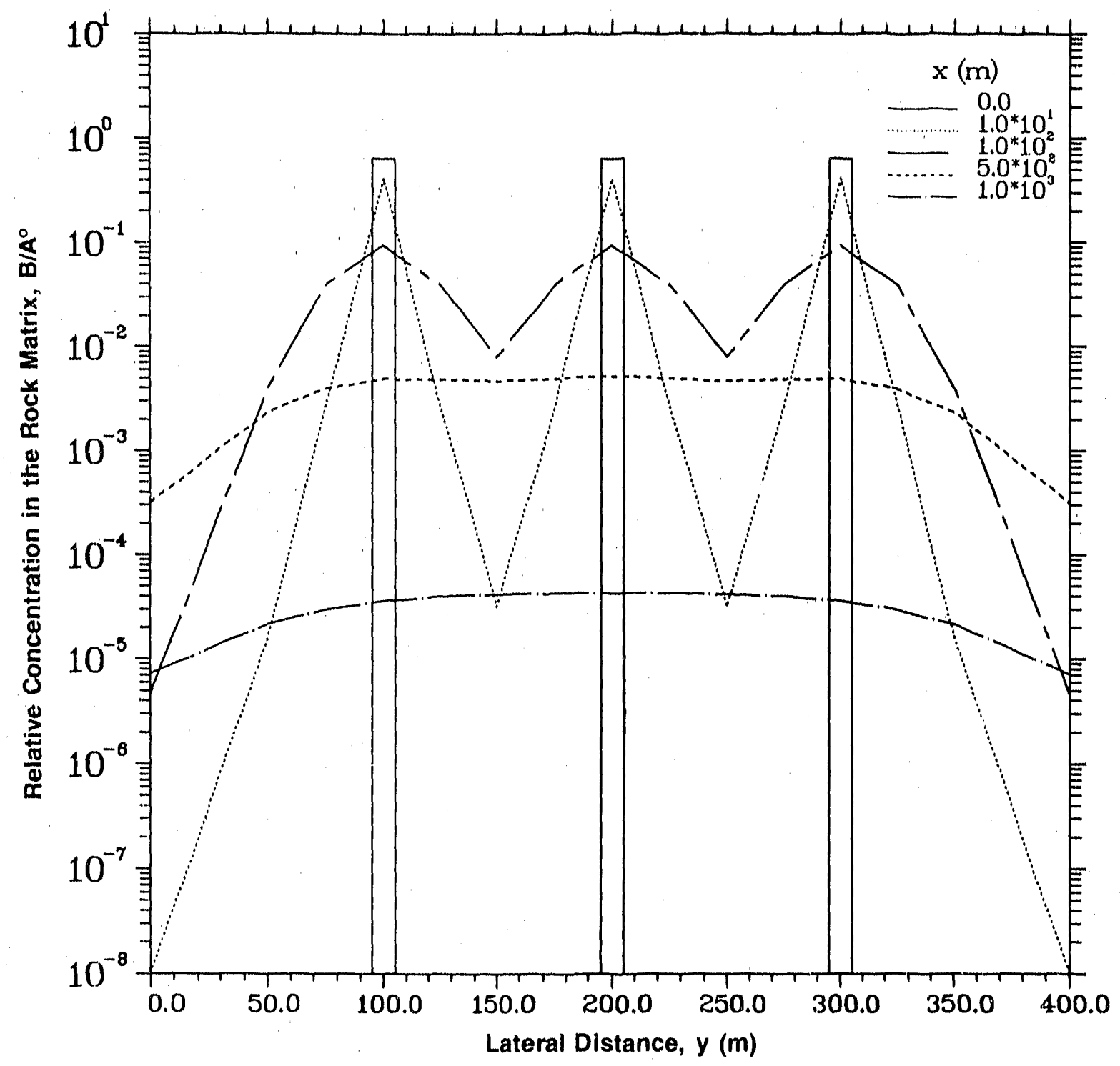

Figure 3-6e. Relative Concentration Profiles for Tc-99 in the Rock Matrix at $z=1 \mathrm{~m}$ and $t=5 \times 10^{4} \mathrm{yr}$ (Case 4B: Multiple Patch Source) 


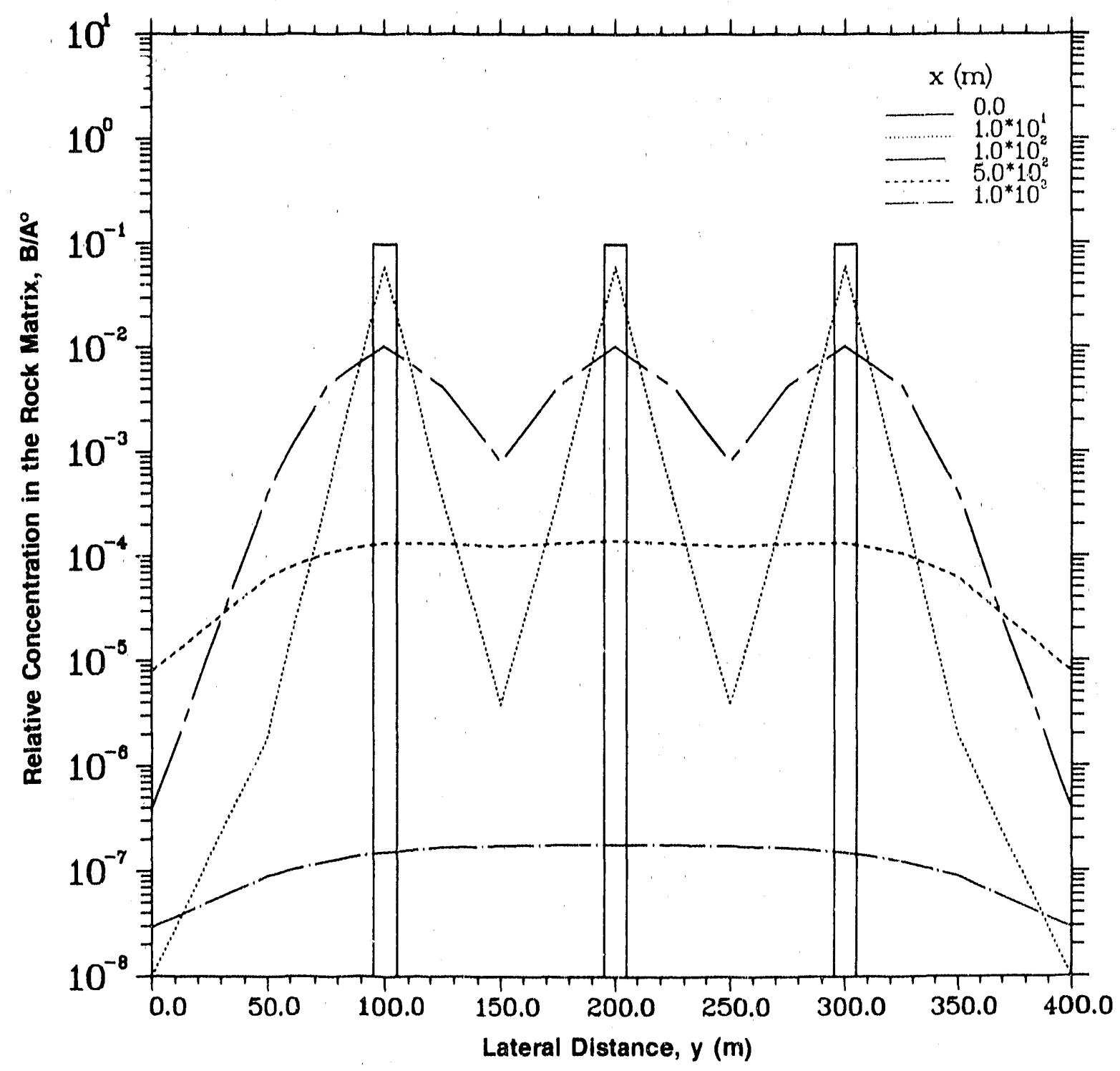

Figure 3-6f. Relative Concentration Profiles for Tc-99 in the Rock Matrix at $z=5 \mathrm{~m}$ and $\mathrm{t}=5 \times 10^{4} \mathrm{yr}$ (Case 4B: Multiple Patch Source) 


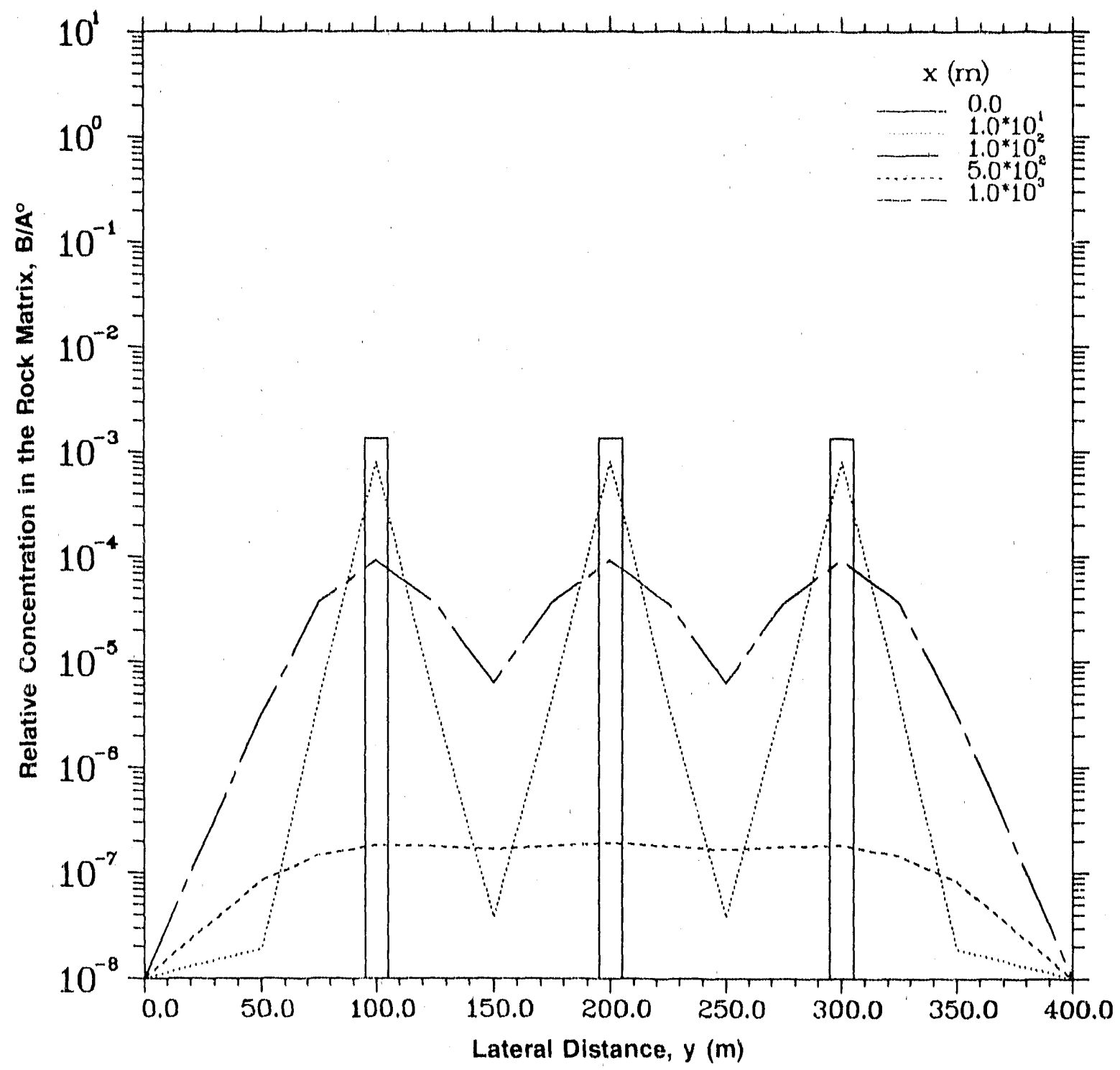

Figure 3-6g. Relative Concentration Profiles for Tc-99 in the Rock Matrix at $z=10 \mathrm{~m}$ and $t=5 \times 10^{4} \mathrm{yr}$ (Case 4B: Multiple Patch Source) 

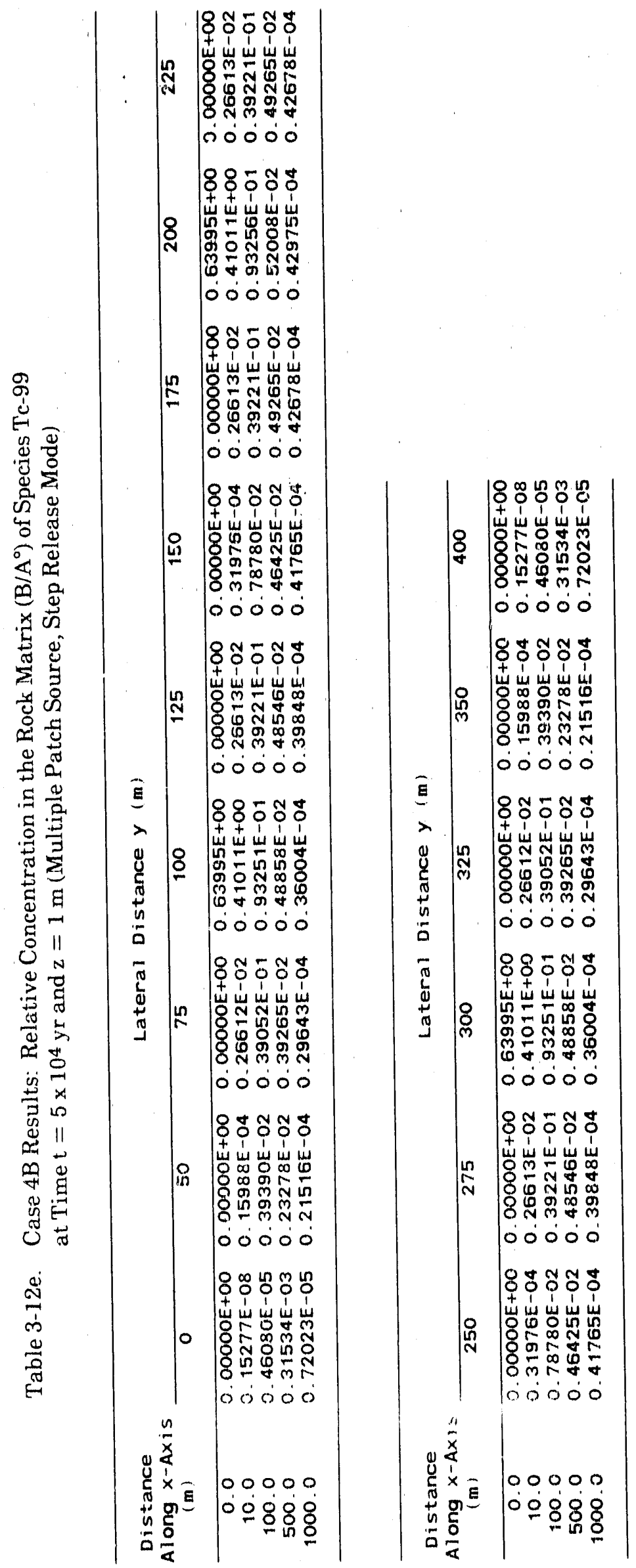

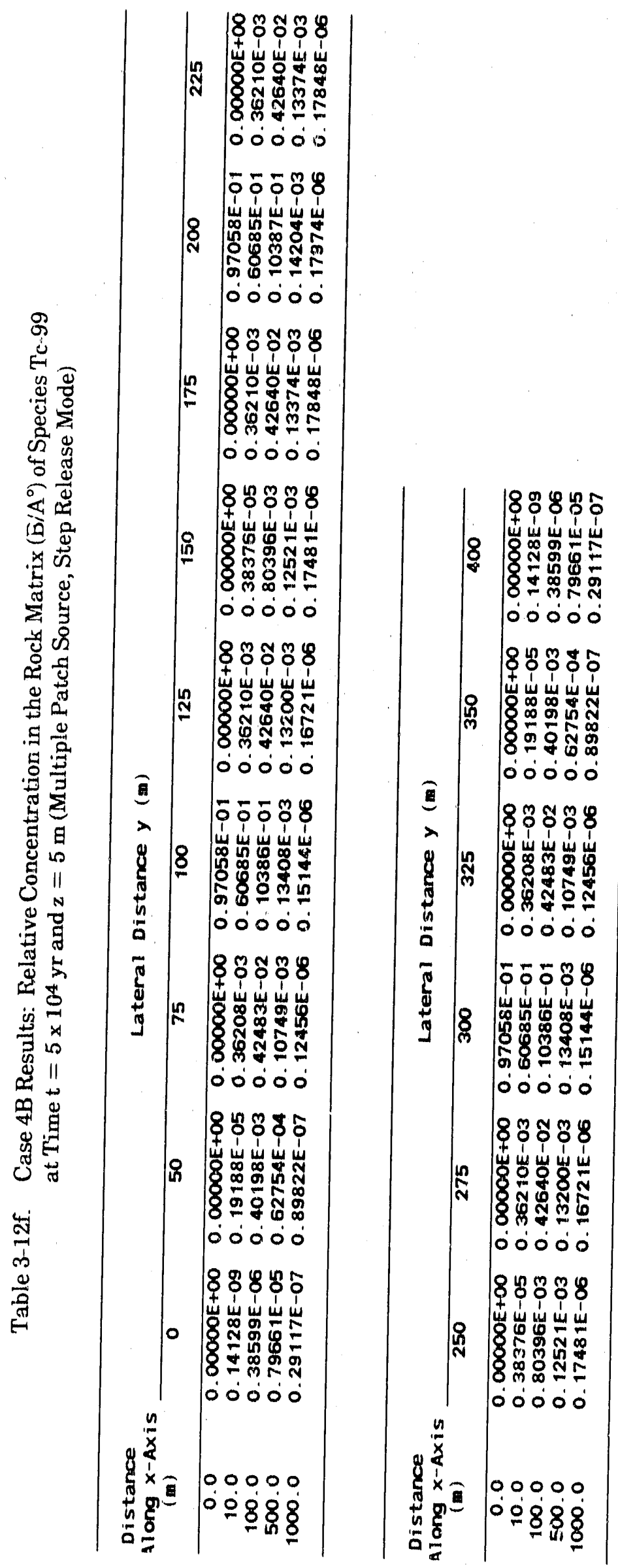

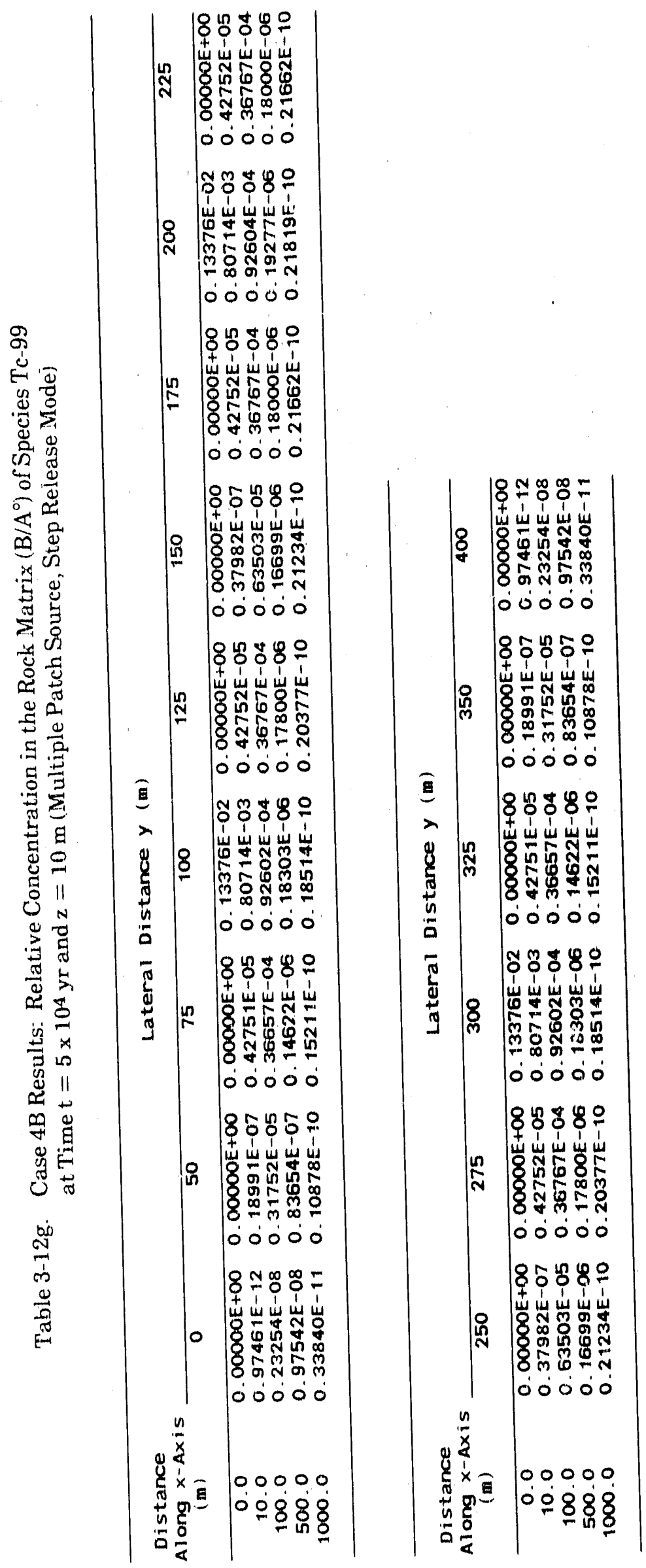


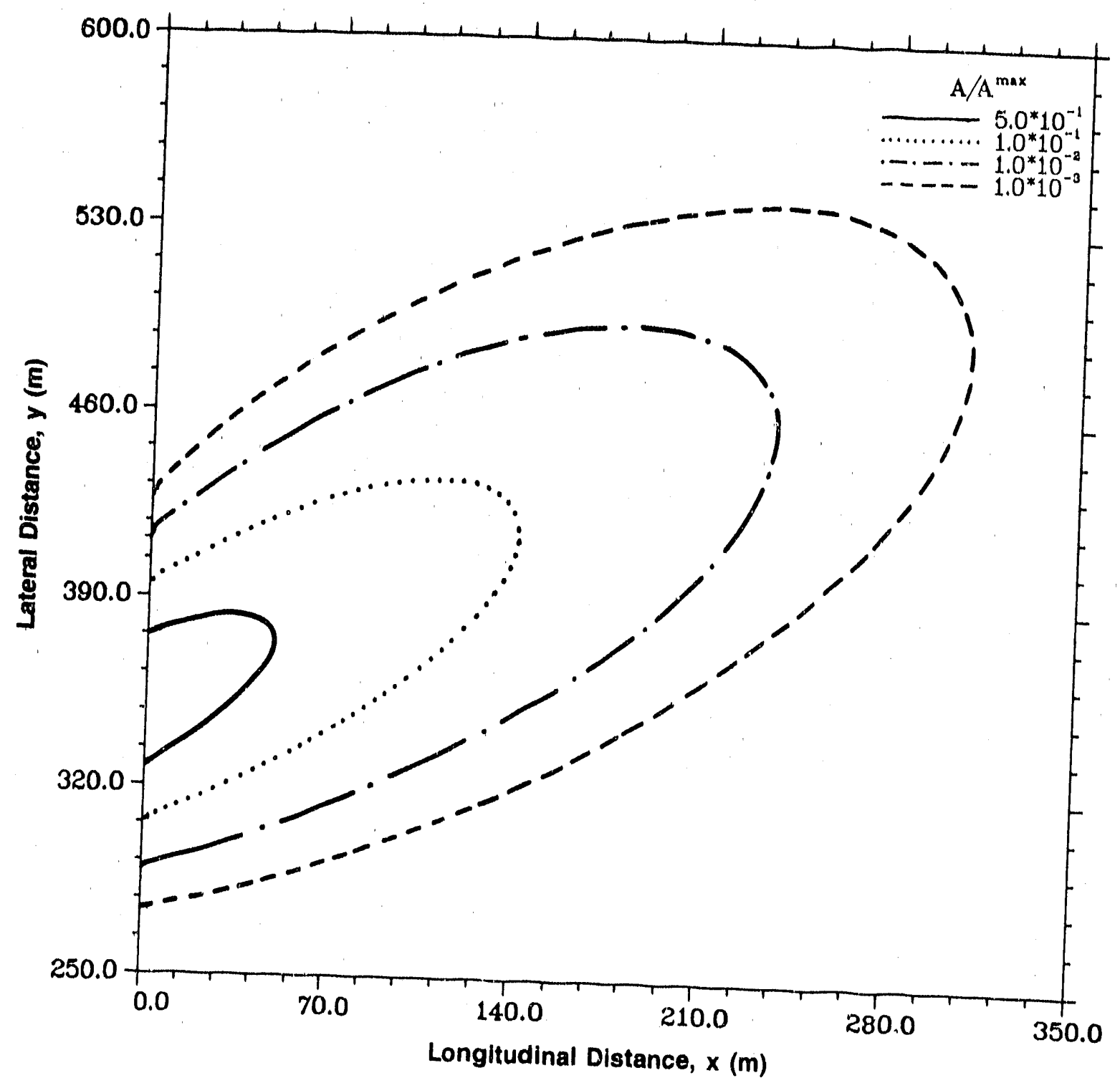

Figure 3-7a. Relative Concentration Isopleths for TC-99 in the Fracture at $z=0 \mathrm{~m}$ and $1=5 \times$
Source) 


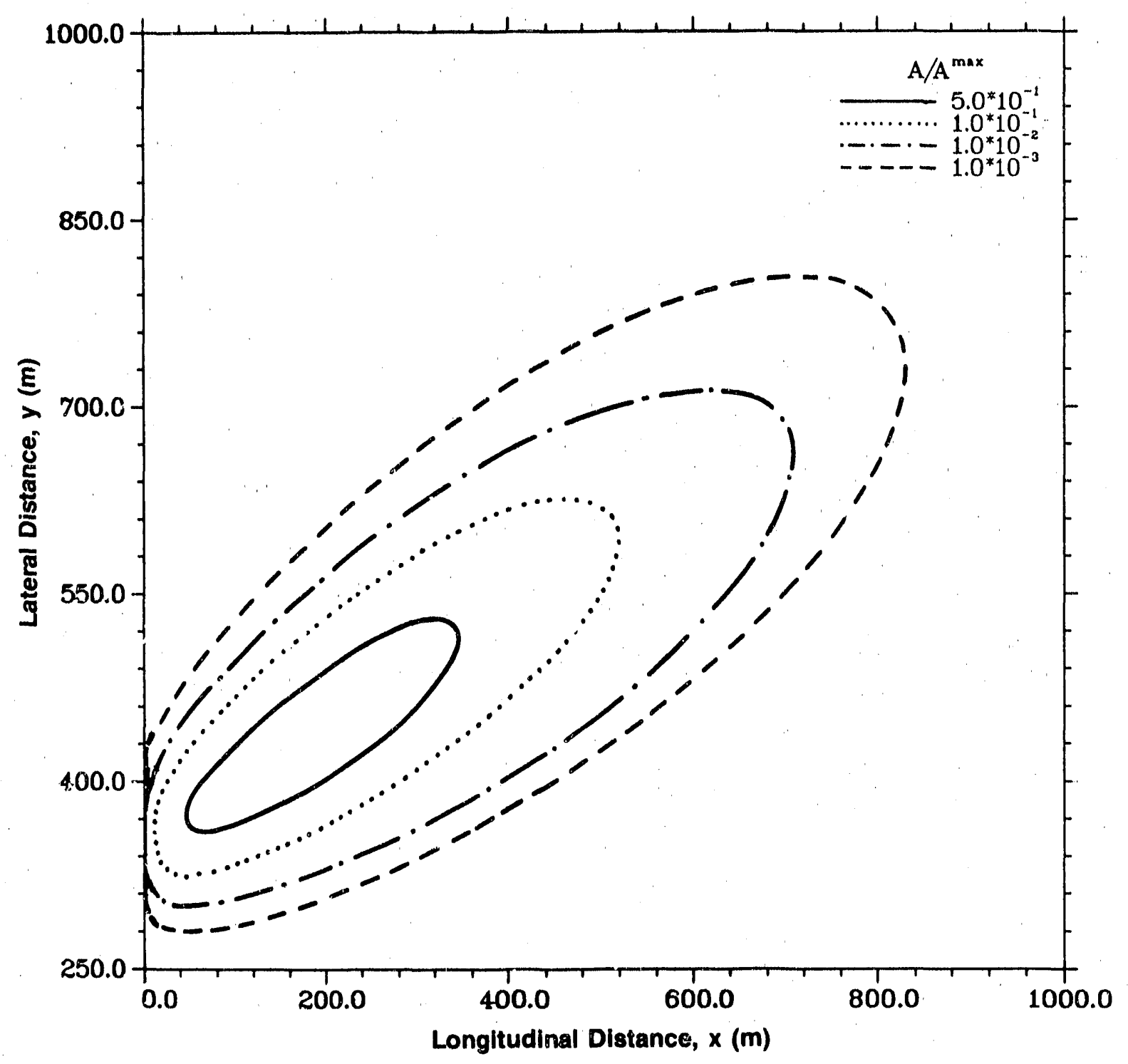

Figure 3-7b. Relative Concentration Isopleths for Tc-99 in the Fracture at $z=0 \mathrm{~m}$ and $t=2.5 \times 10^{4} \mathrm{yr}$, Band Release Mode (Case 4C: Gaussian Distributed Source) 


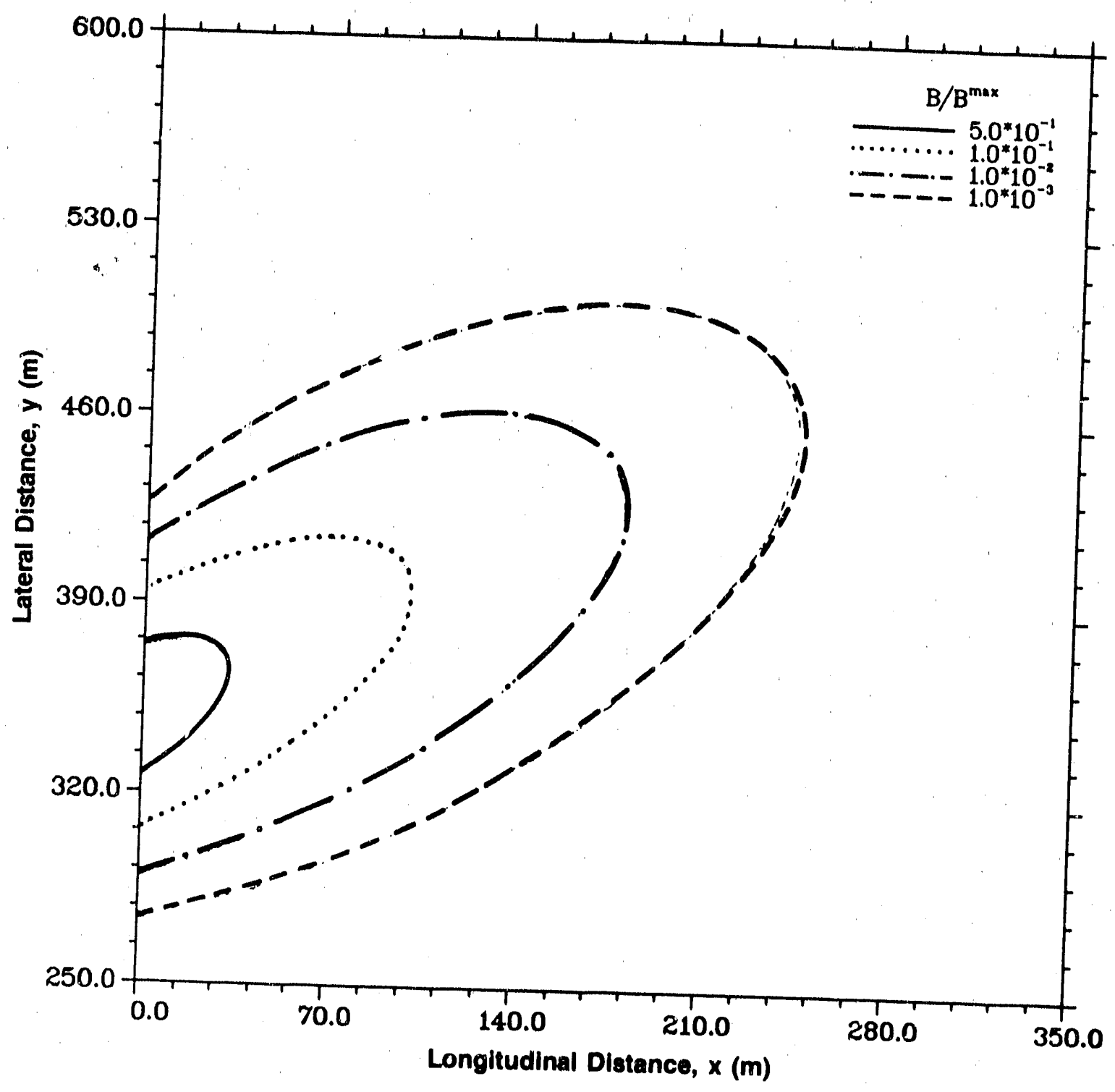

Figure 3-7c. Relative Concentration Isopleths for Tc-99 in the Rock Matrix at $z=1 \mathrm{~m}$ and $t=5 \times 10^{3}$ yr, Step Release Mode (Case 4C: Gaussian Distributed
Source) 


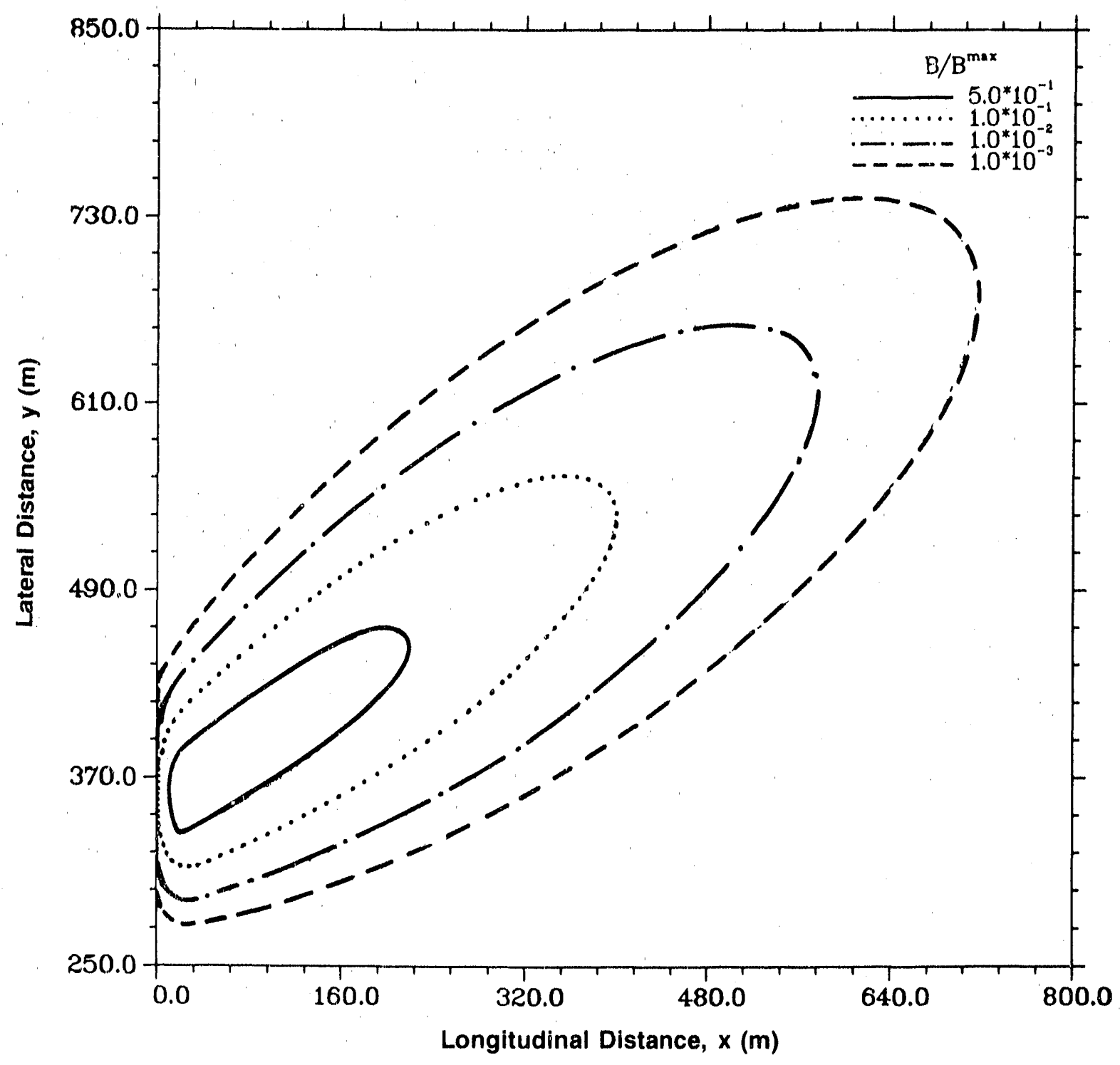

Figure 3-7d. Relative Concentration Isopleths for Tc-99 in the Rock Matrix at $z=1 \mathrm{~m}$ and $t=2.5 \times 10^{4} \mathrm{yr}$, Band Release Mode (Case 4C: Gaussian Distributed Source) 


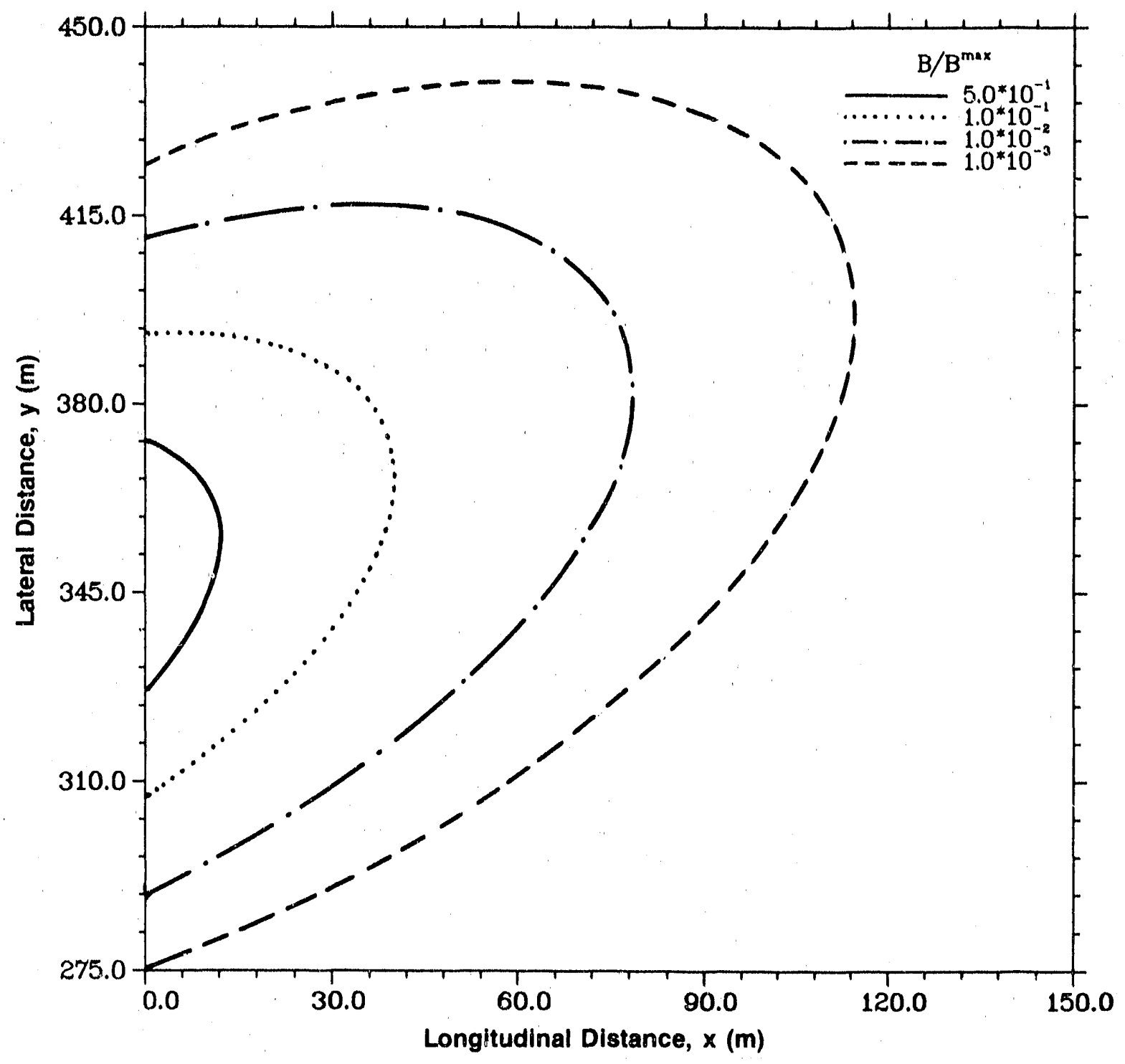

Figure 3-7e. Relative Concentration Isopleths for Tc-99 in the Rock Matrix at $z=5 \mathrm{~m}$ and $t=5 \times 10^{3} \mathrm{yr}$, Step Release Mode (Case 4C: Gaussian Distributed Source) 


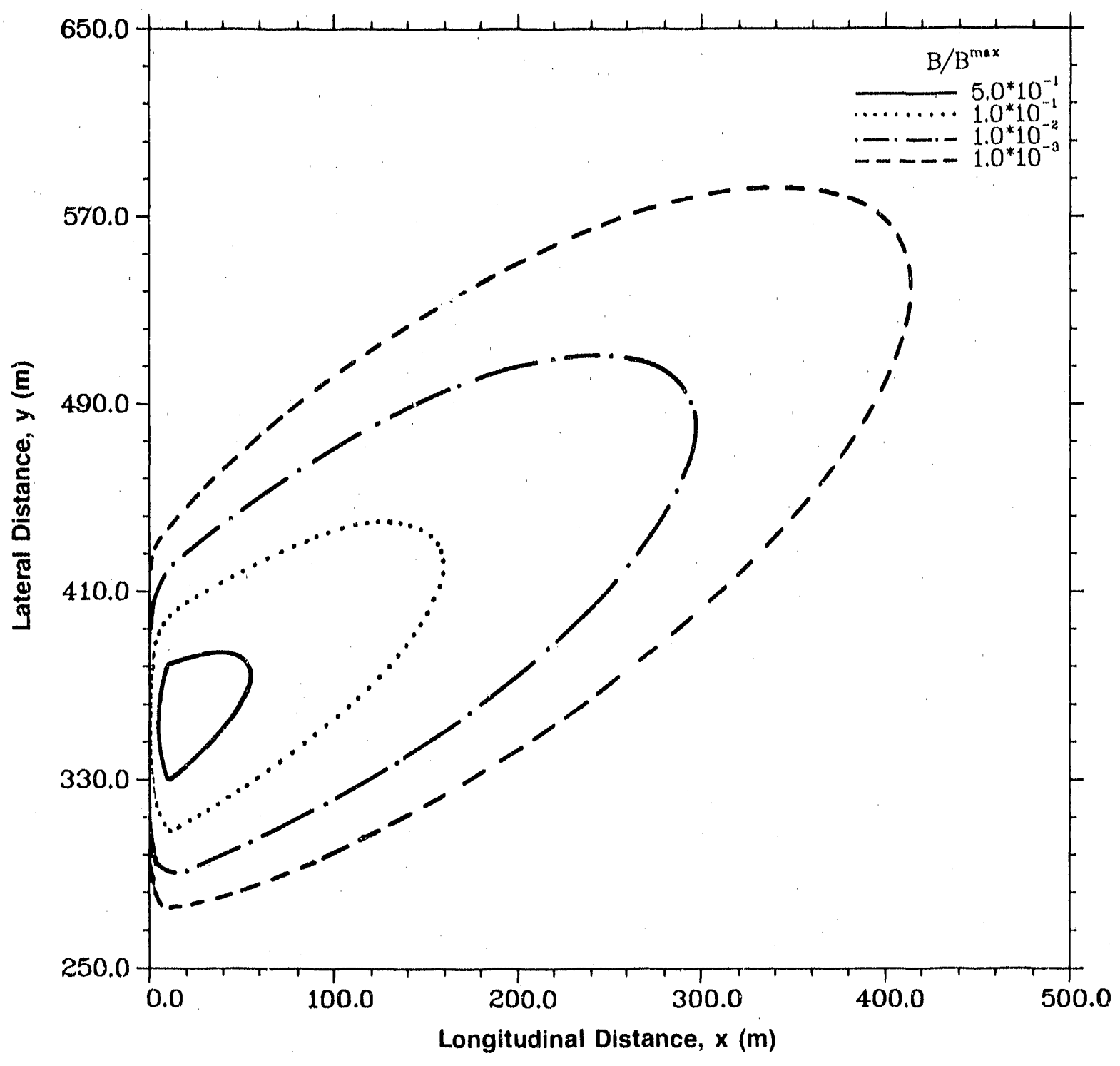

Figure 3-7f. Relative Concentration Isopleths for Tc-99 in the Rock Matrix at $z=5 \mathbf{m}$ and $t=2.5 \times 10^{4} \mathrm{yr}$, Band Release Mode (Case 4C: Gaussian Distributed Source) 

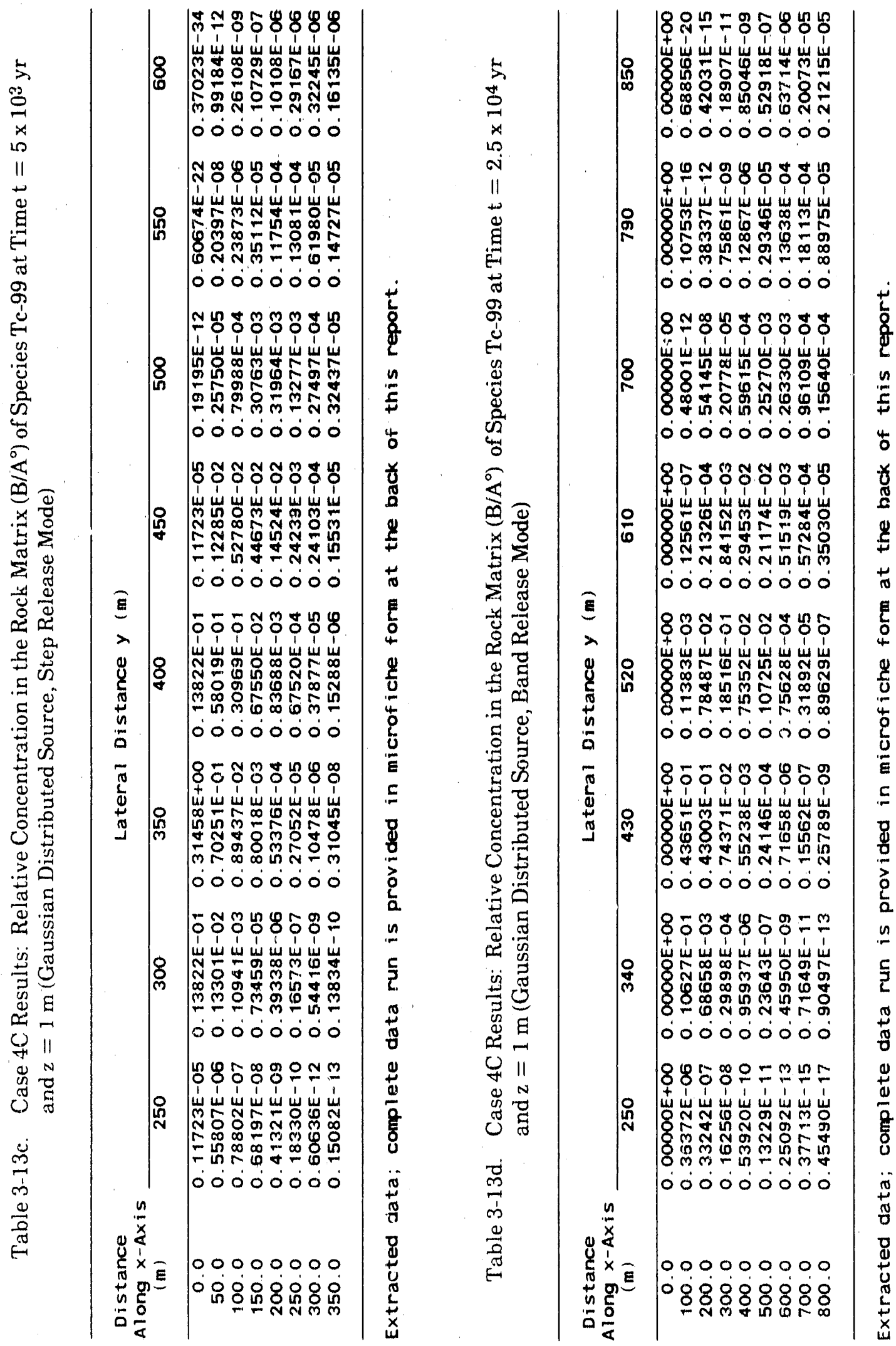

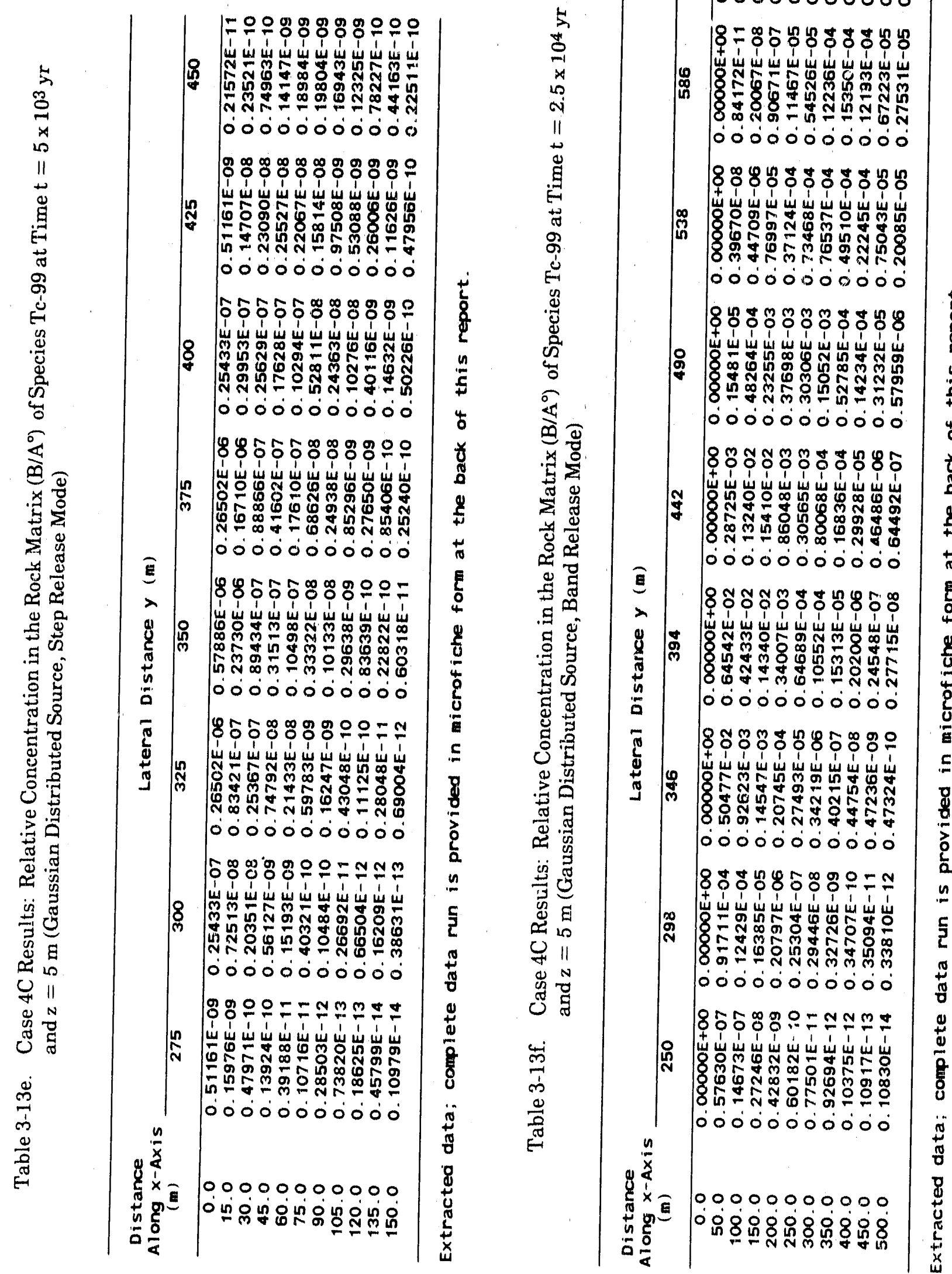


\section{PART 2}

\subsection{MULTIPLE PARALLEL FRAC'TURE CASE WITH FINI'TH DIFFUSION FIELD: SERIES SOLUTION}

\subsection{NON-ZERO LONGITUDINAL DISPERSION}

The Laplace transformation of Equation 2-11 with its associated boundary condition Equations 3-1 and 3-2 subject to its initial and boundary conditions Equations 2-15, 2-18c, and 3-45 has a solution of the form given by

$$
\bar{B}(x, y, z, s)=\cosh \left[r_{b}(z-L)\right] \operatorname{sech}\left[r_{b}(b-L)\right] \bar{A}(x, y, s)
$$

where $r_{b}$ is given by Equation 3-5a. The transformed diffusive flux at the interface of the fracture and rock matrix is given by

$$
\bar{J}=-\phi D_{e} \frac{\partial \bar{B}}{\partial z}(x, y, b, s)=-\phi D_{e} r_{b} \tanh \left[r_{b}(b-L)\right] \bar{A}(x, y, s) .
$$

\subsubsection{Fracture}

After proper substitution of the transform of the diffusive flux given by Equation $4-2$ into the Laplace transformation of Equation 2-10 and applying subsequently the Fourier integral transform (see Equations 3-7 to 3-21), we then obtain an expression identical to Equation 3-21 in which the term corresponding to $r_{a}$ given by Equation 3-22c will now take the following form

$$
r_{a}=-R(s+\lambda)-c_{f}(s+\lambda)^{1 / 2} \tanh \left[c_{r}(L-b)(s+\lambda)^{1 / 2}\right]
$$

whereas the remaining components of Equation 3-21 given by Equations 3-22a, 3-22b, and 3-22d will remain unaltered. Following the same procedure as outlined before (see Equations 3-24 to 3-42), the inverse Fourier integral transform will then have the same form as Equation 3-42. Rewriting the latter we have

$$
\overline{\mathrm{A}}(\mathrm{x}, \mathrm{y}, \mathrm{s})=\mathrm{A}^{0} \int_{0}^{\infty} \Psi(\mathrm{x}, \mathrm{o}) \mathrm{E}_{\Omega} \theta(\mathrm{s}) \mathrm{e}^{\mathrm{r}} \mathrm{a}^{\mathrm{x}} \mathrm{do} .
$$

To find the inverse Laplace transform of the above equation, we write

$$
L^{-1} \theta(s) e^{r}{ }^{r} X=e^{-\lambda t} L^{-1} \exp \left(-R_{X} s\right) G_{F}(s)
$$


where

$$
G_{F}(s)=\frac{\exp [-e \sqrt{s} \tanh \beta \sqrt{s}]}{s}
$$

with

$$
\begin{gathered}
\varepsilon=c_{f} X=\frac{\Phi}{b}\left(R^{\prime} D_{p}\right)^{1 / 2} X \\
\beta=c_{r}(L-b)=\left(\frac{R^{\prime}}{D_{p}}\right)^{1 / 2}(L-b) .
\end{gathered}
$$

Expanding the numerator of Equation 4-6 in power series we find that

$$
G_{F}(s)=\frac{1}{s}-\frac{\varepsilon}{\sqrt{s}} \tanh \beta \sqrt{s}+\frac{\varepsilon^{2}}{2 !} \tanh ^{2} \beta \sqrt{s}-\frac{\varepsilon^{3}}{3 !} \sqrt{s} \tanh ^{3} \beta \sqrt{s}+\ldots
$$

which may also be written as

$$
G_{F}(s)=\frac{1}{s}+\sum_{n=1}^{\infty}(-1)^{n} \frac{\varepsilon^{n}}{n !} g_{n}(s)
$$

where

$$
g_{n}(s)=\left.\right|_{s} ^{s(n-2) / 2} \frac{\tanh ^{n} \beta \sqrt{s}, n=2,4,6, \ldots}{\sqrt{s}}, n=1,3,5, \ldots
$$

The exponential series expansion for $\tanh \beta \sqrt{\mathrm{s}}$ may be written as

$$
\tanh \beta \sqrt{\mathrm{s}}=\sum_{k=0}^{\infty} a_{k} e^{-2 k \beta \sqrt{s}}
$$

where

$$
a_{k}=\mid \begin{array}{cc}
1, k=0 \\
2(-1)^{k}, k \geq 1
\end{array}
$$


and the corresponding series for tanh $\beta \sqrt{\mathrm{s}}$ raised to the $\mathrm{n}^{\text {th }}$ power (Gradshteyn and Ryzhik, 1980, p. 14) is glven by

$$
\tanh ^{n} \beta \sqrt{s}=\sum_{k=0}^{\infty}{ }_{n} \bar{b}_{k} e^{-2 k \beta \sqrt{s}}
$$

where

$$
n^{\bar{b}_{k}}=\left.\right|_{\frac{1}{k} \sum_{i=1}^{k}(1(n+1)-k) a_{i n} \bar{b}_{k-1}, k \geq 1 .} ^{, k=0}
$$

Substitution of Equation 4-13 in Equation 4-10 yields

$$
g_{n}(s)=\underbrace{g_{k=0}^{(n-1 / 2} \sum_{k=0}^{\infty} n^{n} \bar{b}_{k} \frac{e^{-2 k \beta \sqrt{s}}}{\sqrt{s}}, n=1,3,5, \ldots}_{s^{(n-2) / 2}}
$$

Using the inverse transforms of $e^{\cdot a} \sqrt{\mathrm{s}} / \sqrt{\mathrm{s}}, e^{\cdot a} \sqrt{\mathrm{s}}, 1 / \sqrt{\mathrm{s}}$, and $\mathrm{s}^{\mathrm{n}+1 / 2}$ (see Appendix A, Eqs. A.2-2 through A. 2-4 and A.3-10) and applying the differentiation theorem (Eq. A.1-3), the inverse Laplace transform of $\mathrm{G}_{\mathrm{F}}(\mathrm{s})$ (see Eq. 4-6) may then be written as

$$
G_{F}(t)=L^{-1}\left\{G_{F}(s)\right\}=g(t)+\sum_{n=1}^{\infty}(-1)^{n} \frac{\varepsilon^{n}}{n !} \bar{g}_{n}(t)
$$

where

$$
g(t)=1+\sum_{n=1}^{\infty}(-1)^{n} \frac{\varepsilon^{n}}{n !}\left|\frac{1}{\sqrt{n t^{n}}} \prod_{i=0}^{(n-3) / 2}\left(\frac{1+2 i}{2}\right)\right| n=1,3,5, \ldots
$$

and

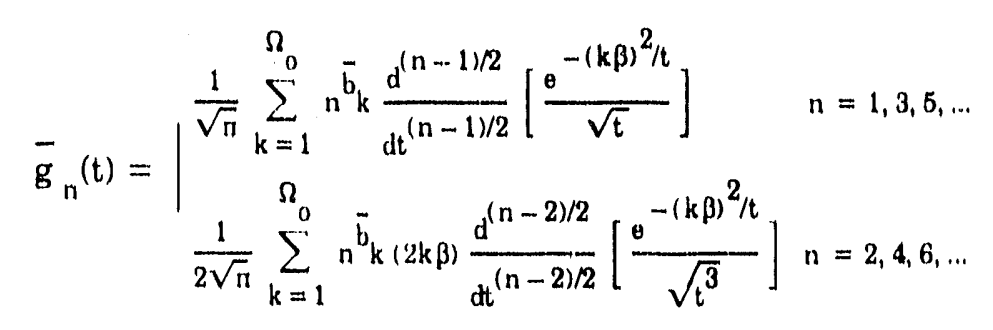


Expansion of the first member of Equation 4-17 in series form yields

$$
g(t)=1-\frac{2}{\sqrt{\pi}}\left[\frac{\varepsilon}{2 \sqrt{t}}-\frac{1}{3}\left(\frac{\varepsilon}{2 \sqrt{t}}\right)^{3}+\frac{1}{10}\left(\frac{\varepsilon}{2 \sqrt{t}}\right)^{5}-\ldots+\ldots\right] .
$$

Noting that the second member of the above equation corresponds to the exponential series form of the error function (see Eq. 3-60b) with argument $\varepsilon=c_{p}$, Equation 4-18a becomes

$$
g(t)=1-\operatorname{erf}\left(\frac{\varepsilon}{2 \sqrt{t}}\right)=\operatorname{erfc}\left(\frac{c_{f} X}{2 \sqrt{t}}\right)
$$

and Equation 4-16 may now be written as

$$
G_{F}(t)=\operatorname{erfc}\left(\frac{c_{f} X}{2 \sqrt{t}}\right)+\sum_{n=1}^{\infty}(-1)^{n} \frac{e^{n}}{n !} \bar{g}_{n}(t)
$$

The derivative terms in Equations 4-18a and 4-18b are obtained after using Leibnitz's theorem for differentiation of a product (Abramowitz and Stegun, 1972) (see also Appendix C):

$$
\frac{d^{n}}{d t^{n}}\left(t^{p} e^{a / t}\right)=t^{(p-n)} e^{a / t} \sum_{r=0}^{n}\left({ }_{r}^{n}\right) \prod_{i=1}^{n-r}(p-i+1) \cdot(-1)^{r} \sum_{m=1}^{r} \prod_{j=1}^{m-1}(r-j)\left(\begin{array}{c}
r \\
m-1
\end{array}\right)\left(\frac{a}{t}\right)^{r-m+1}
$$

where

$$
\mathrm{a}:=-(\mathrm{k} \beta)^{2}
$$

and

$$
p=\mid \begin{aligned}
& -\frac{1}{2}, n=1,3,5, \ldots \\
& -\frac{3}{2}, n=2,4,6, \ldots
\end{aligned}
$$

Because of the slow convergence exhibited by such an approach, particularly when the value of $c_{\mathrm{f}} \mathrm{X}$ becomes large, an alternative form of the second member of Equation 4-21 was sought. Writing

$$
\begin{aligned}
& a_{k}=\frac{k \beta}{\sqrt{t}} \\
& h=\frac{\varepsilon}{2 \sqrt{t}}
\end{aligned}
$$


expansion of the second member of Equation 4-21 using Equations 4-18, 4-22, and 4-24a yields

$$
\begin{aligned}
\sum_{n=1}^{\infty}(-1)^{n} \frac{\varepsilon^{n}}{n !} \bar{g}_{n}(t) & =\sum_{k=1}^{\Omega_{0}} \frac{1}{\sqrt{n}} e^{-a_{k}^{2}} \mid \vec{b}_{k} \frac{\varepsilon}{\sqrt{t}}-{ }_{2} \vec{b}_{k} \frac{\varepsilon^{2}}{2 !} \frac{a_{k}}{t}+{ }_{3} \bar{b}_{k} \frac{\varepsilon^{3}}{3 !} \frac{1}{\sqrt{t^{3}}}\left(a_{k}^{2}-\frac{1}{2}\right) \\
& -{ }_{4} \bar{b}_{k} \frac{\varepsilon^{4}}{4 !} \frac{a_{k}}{t^{2}}\left(a_{k}^{2}-\frac{3}{2}\right)+{ }_{5} \bar{b}_{k} \frac{\varepsilon^{5}}{5 !} \frac{1}{\sqrt{t^{5}}}\left(a_{k}^{4}-3 a_{k}^{2}+\frac{3}{4}\right)-\ldots \mid
\end{aligned}
$$

With the nth derlvative of the error function (Abramowitz and Stegun, 1972, p. 298) defined as

$$
\frac{d^{n+1}}{d z^{n+1}} \operatorname{erf}(z)=(-1)^{n} \frac{2}{\sqrt{n}} H_{n}(z) e^{-z^{2}}, n=0,1,2,3, \ldots
$$

where $H_{\mathrm{n}}$ are the Hermite polynomials (see Appendix A.4) and using 'Taylor's theorem, we may write

$$
\operatorname{erf}\left(a_{k}+h\right)=\operatorname{erf}\left(a_{k}\right)+h \frac{d}{d a_{k}}\left(\operatorname{erf}\left(a_{k}\right)\right)+\frac{h^{2}}{2 !} \frac{d^{2}}{d a_{k}^{2}}\left(\operatorname{erf}\left(a_{k}\right)\right)+\frac{h^{3}}{3 !} \frac{d^{3}}{d a_{k}^{3}}\left(\operatorname{erf}\left(a_{k}\right)\right)+\ldots
$$

Expanding the right-hand side using Equation 4-26, the above equation becomes

$$
\begin{aligned}
\operatorname{erf}\left(a_{k}+\frac{\varepsilon}{2 \sqrt{t}}\right) & =\operatorname{erf}\left(a_{k}\right)+\frac{1}{\sqrt{n}} e^{-a_{k}^{2}}\left[\frac{\varepsilon}{\sqrt{t}}-\frac{\varepsilon^{2}}{2 !} \frac{a_{k}}{t}+\frac{\varepsilon^{3}}{3 !} \frac{1}{\sqrt{t^{3}}}\left(a_{k}^{2}-\frac{1}{2}\right)\right. \\
& \left.-\frac{\varepsilon^{4}}{4 !} \frac{a_{k}}{t^{2}}\left(a_{k}^{2}-\frac{3}{2}\right)+\frac{\varepsilon^{5}}{5 !} \frac{1}{\sqrt{t^{5}}}\left(a_{k}^{4}-3 a_{k}^{2}+\frac{3}{4}\right)-\ldots\right] .
\end{aligned}
$$

Comparing Equations 4-25 and 4-28, we find

$$
H_{1}(t)=\sum_{n=1}^{\infty}(-1)^{n} \frac{\varepsilon^{n}}{n !} g_{n}(t)=\sum_{k=1}^{\Omega_{0}} \sum_{m=1}^{k} a_{k m} e^{m} \frac{d^{m}}{d \varepsilon^{m}}\left|\operatorname{erf}\left(a_{k}+\frac{\varepsilon}{2 \sqrt{t}}\right)\right|
$$

with

$$
\begin{gathered}
a_{i j}=0, j>i \\
a_{i 1}=-\frac{1 \bar{b}_{i}}{c_{11}}=(-1)^{i+1}(2)
\end{gathered}
$$




$$
a_{i j}=\left((-1)^{j} \tilde{b}_{i}\right)-\sum_{k=1}^{j-1} c_{k j j} \cdot a_{i k} / c_{j j}, j>1
$$

where

$$
\begin{gathered}
c_{i j}=(-1)^{j+1} \prod_{k=0}^{i-1}(j-k), j \geq 1 \\
c_{i j}=0, j<i .
\end{gathered}
$$

A set of values for $\bar{b}_{j}, a_{i j}$, and $c_{i j}$ is reported in Tables 4-1a, 4-1b, and 4-1c.

Equation 4-21 now may be written as

$$
G_{F}(t)=\operatorname{erfc}\left(\frac{c_{f} X}{2 \sqrt{t}}\right)+\sum_{k=1}^{\Omega_{0}} \sum_{m=1}^{k} a_{k m}\left(c_{f} x\right)^{m} \frac{d^{m}}{d \varepsilon^{m}}\left|\operatorname{arf}\left(\frac{2 k \beta+\varepsilon}{2 \sqrt{t}}\right)\right| .
$$

where

$$
\frac{\mathrm{d}^{\mathrm{n}+1}}{\mathrm{d \textrm {e } ^ { \mathrm { n } + 1 }}}[\operatorname{erf}(z)]=(-1)^{\mathrm{n}} \frac{2}{\sqrt{\mathrm{n}}} H_{\mathrm{n}}(z) \mathrm{e}^{-z^{2}}\left(\frac{1}{2 \sqrt{\mathrm{t}}}\right)^{\mathrm{n}+1}, \mathrm{n}=0,1,2,3, \ldots
$$

and

$$
z=\frac{2 \mathrm{k} \beta+\varepsilon}{2 \sqrt{t}}
$$

Substituting Equation 4-31 into Equation 4-5 and applying subsequently the translation theorem (Fy. A.1-1), the inverse Laplace transform of Equation 4-4 yielding the solution of the concentration in the fracture may be written as

$$
A(x, y, t)=A^{0} e^{-\lambda t} \int_{0}^{\infty} \psi(x, \sigma) E_{\Omega} G_{F}\left(t-R_{X}\right) U\left(t-R_{X}\right) d o
$$

Note that when the contribution of the second member of Equation 4-31a becomes negligible, the above equation will be identical to Equation 3-43. Discussions pertaining to the magnitude of $\Omega_{0}$ will be deferred to Section 4.5 . 


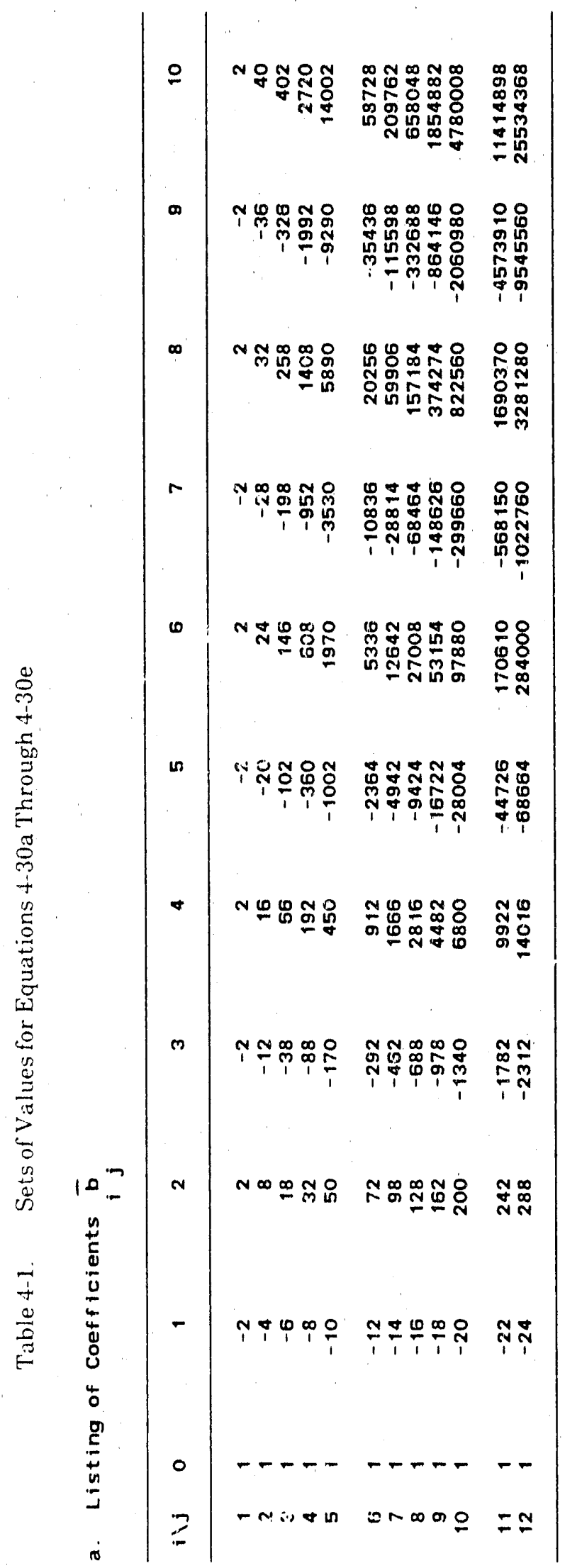



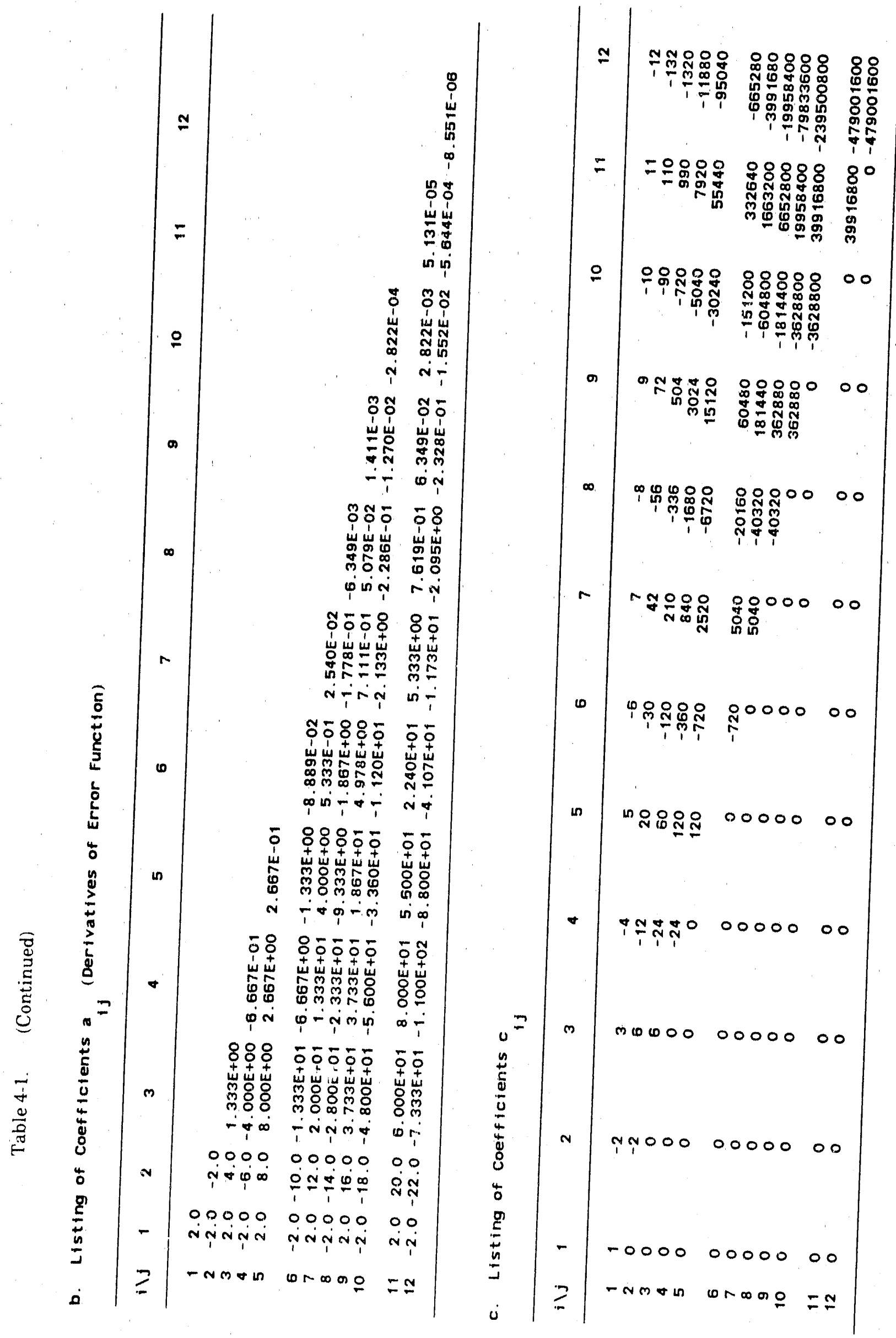


\subsubsection{Rock Matrix}

Substitution of Equation 4-4 into Equation 4-1 gives the transformation of the concentration in the rock as

$$
\bar{B}(x, y, z, s)=A^{0} \int_{0}^{\infty} \psi(x, a) E_{\Omega} \theta(s) e^{r_{a} x} \cosh \left|r_{b}(z-L)\right| \operatorname{sech}\left(r_{b}(b)-L\right) \mid d o
$$

To find the inverse Laplace transform of the above equation, we write

$$
L^{-1} \theta(s) e^{r}{ }_{a}^{X} \cosh \left[r_{b}(z-L)\right] \operatorname{sech}\left[r_{b}\left(b-L_{L}\right)\right]=e^{-\lambda t} L^{-1} \exp \left(-R_{X} s\right) \cdot G_{R}(s)
$$

where

$$
G_{R}(s)=G_{F}(s) \frac{\cosh \mu \sqrt{s}}{\cosh \beta \sqrt{s}},(\beta>\mu)
$$

with

$$
\mu=c_{r}(L-z)=\left(\frac{R^{\prime}}{D_{e}}\right)^{1 / 2}(L-z)
$$

Writing

$$
H(s)=\frac{\cosh \mu \sqrt{s}}{\cosh \beta \sqrt{s}}=\frac{e^{\mu \sqrt{s}}+e^{-\mu \sqrt{s}}}{e^{\beta \sqrt{s}}+e^{-\beta \sqrt{s}}}=\left|e^{(\mu \cdots \beta) \sqrt{s}}+e^{-(\mu+\beta) \sqrt{s}}\right|\left(1+e^{-2 \beta \sqrt{s}}\right)^{-1}
$$

expanding the second term on the right-hand side into a binomial series, we find that

$$
H(s)=\sum_{i=1}^{\infty}(-1)^{i+1}\left|e^{-|(2 i-1) \beta-\mu| \sqrt{s}}+e^{-|(2 i-1) \beta+\mu| \sqrt{s}}\right| .
$$

Substituting Equation 4-9 and Equation 4-38 into Equation 4-35, we obtain after some algebraic manipulation the equation

$$
G_{R}(s)=\tilde{g}(s)+\sum_{n=1}^{\infty}(-1)^{n} \frac{\varepsilon^{n}}{n !} \tilde{g}_{n}(s)
$$


where

$$
\tilde{\mathrm{g}}(\mathrm{s})=\frac{\mathrm{H}(\mathrm{s})}{\mathrm{s}}
$$

and

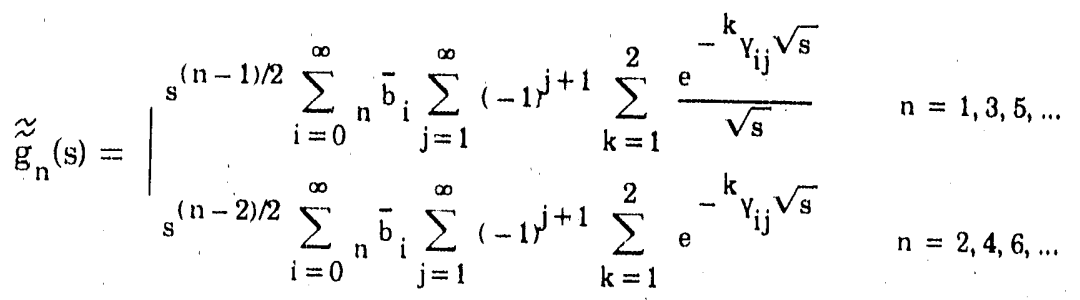

with

$$
\begin{gathered}
{ }^{1} Y_{i j}=[2(i+j)-1] \beta-\mu \\
{ }^{2} Y_{i j}=[2(i+j)-1] \beta+\mu .
\end{gathered}
$$

Using the inverse transforms of $e^{-a} \sqrt{\mathrm{s}} / \mathrm{s}, e^{-a} \sqrt{\mathrm{s}} / \sqrt{\mathrm{s}}$, and $e^{-a \sqrt{\mathrm{s}}}$ (see Appendix A, Eqs. A.2-1 through A.2-3) and applying as before the multiplication theorem strictly to the second member on the righthand side of Equation 4-39, the inverse Laplace transform of $G_{R}(s)$ may then be written as

$$
G_{R}(t)=L^{-1}\left\{G_{R}(s)\right\}=\tilde{g}(t)+\sum_{n=1}^{\infty}(-1)^{n} \frac{\varepsilon^{n}}{n !} \widetilde{\sigma}_{n}(t)
$$

where

$$
\tilde{g}(t)=\sum_{i=1}^{\Omega^{\prime}}(-1)^{i+1} \sum_{k=1}^{2}\left(\operatorname{erfc}\left[\frac{{ }^{k} Y_{0 i}}{2 \sqrt{t}}\right]\right)
$$


and

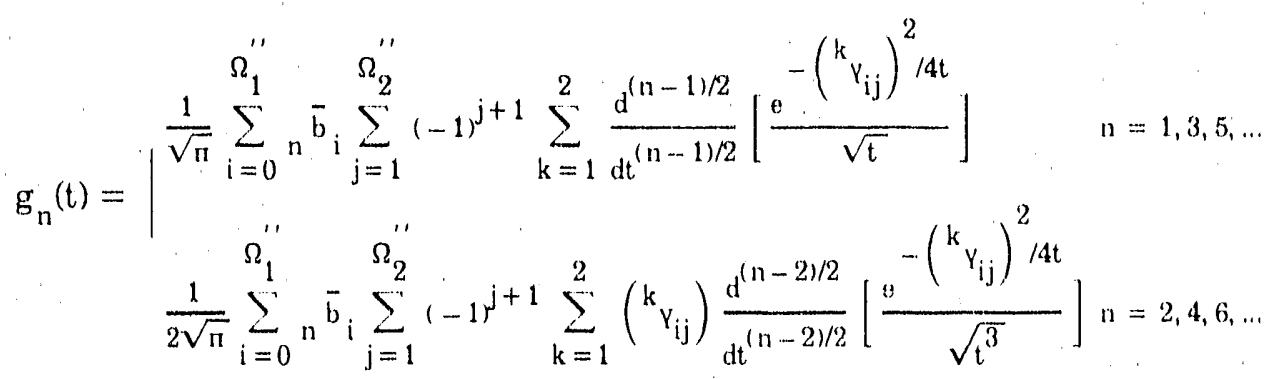

By taking an approach similar to the one outlined in the previous section (see Eqs, 4-24 through 4-29) with ${ }^{{ }} Y_{i j} / 2 \sqrt{ }$ t substituting for $a_{k}$, it may be shown that the second member of Equation 4.43 is written as

$$
\begin{aligned}
& \sum_{n=1}^{\infty}(-1)^{n} \frac{e^{n}}{n !} \widetilde{\sigma}_{n}(t)=\widetilde{\widetilde{g}}_{1}(t)+\widetilde{\tilde{g}}_{2}(t) \\
& g_{1}(t)=\sum_{i=1}^{\Omega_{1}^{\prime \prime}}(-1)^{i} \sum_{k=1}^{2} \operatorname{erf}\left[\frac{{ }^{k} Y_{0 i}+\varepsilon}{2 \sqrt{t}}\right\rfloor-\sum_{i=1}^{\Omega^{\prime}}(-1)^{i} \sum_{k=1}^{2} \operatorname{erf}\left|\frac{{ }^{k} Y_{0 i}}{2 \sqrt{t}}\right| \\
& =\sum_{i=1}^{\Omega_{0}^{\prime \prime}}(-1)^{i+1} \sum_{k=1}^{2} \operatorname{erfc}\left\lfloor\frac{{ }^{k} Y_{0 i}+\varepsilon}{2 \sqrt{t}}\right\rfloor-\sum_{i=1}^{\Omega^{\prime}}(-1)^{i+1} \sum_{k=1}^{2} \operatorname{erfc}\left\lfloor\frac{{ }^{k} Y_{0 i}}{2 \sqrt{t}}\right\rfloor
\end{aligned}
$$

and

$$
\widetilde{\widetilde{g}}_{2}(\mathrm{t})=\sum_{\mathrm{i}=1}^{\Omega_{1}^{\prime \prime}} \sum_{j=1}^{\Omega_{2}^{\prime \prime}}(-1)^{j+1} \sum_{k=1}^{2} \sum_{m=1}^{i} a_{i m} \varepsilon^{m} \frac{d^{m}}{d \varepsilon^{m}}\left|\operatorname{erf}\left(\frac{{ }^{k} Y_{i j}+\varepsilon}{2 \sqrt{t}}\right)\right|
$$

Note that Equation 4-47 corresponds to the terms in the summation series given by Equations 4-45a and $4-45 \mathrm{~b}$ with i set to zero, in which case ${ }_{n} b_{0}$ is equal to unity for all values of $n$ (see Eq. 4-41a). The result for this set of conditions is a correspondence between the left-hand side of Equation 4-46 and $g_{1}(t)$ given by Equation 4-47 which becomes exact after premultiplying the latter by minus one. 
Combining Equations 4-44 and 4-47, we have

$$
\widetilde{g}(t)+\widetilde{g}_{1}(t)=\sum_{i=1}^{\Omega_{0}^{\prime \prime}}(-1)^{i+1} \sum_{k=1}^{2} \operatorname{erfc}\left|\frac{Y_{0 i}+\varepsilon}{2 \sqrt{t}}\right|
$$

Hence Equation $4-43$ becomes

$$
G_{R}(t)=\sum_{i=1}^{\Omega_{0}^{\prime \prime}}(-1)^{i+1} \sum_{k=1}^{2} \operatorname{erfc}\left[\frac{Y_{i 0}+c_{f} x}{2 \sqrt{t}}\right]+\sum_{i=1}^{\Omega_{1}^{\prime \prime}} \sum_{j=1}^{\Omega_{2}^{\prime \prime}}(-1)^{j+1} \sum_{k=1}^{2} \sum_{m=1}^{i} a_{i m}\left(c_{f} x\right)^{m} \frac{d^{m}}{d \varepsilon^{m}}\left|\operatorname{erf}\left(\frac{{ }^{k} Y_{i j}+\varepsilon}{2 \sqrt{t}}\right)\right|^{4}
$$

Substituting Equation 4-31 into Equation 4-34 and applying subsequently the translation theorem (Eq. A.1-1), the inverse Laplace transform of Equation 4-25 yielding the solution of the concentration in the rock then may be written as

$$
B(x, y, z, t)=A^{0} e^{-\lambda t} \int_{0}^{\infty} \Psi(x, \sigma) E_{\Omega} G_{R}\left(t-R_{X}\right) U\left(t-R_{X}\right) d \sigma
$$

It may be worthwhile noting that under some circumstances Equation 4-51 will become identical to Equation 3-45 (see Section 4.5 for discussion). Details regarding the integration of Equations 4-32 and 4-51 may be found in Appendix B.

\subsubsection{Mass Flux}

The general equation for the mass flux in the fracture is given by Equation 3-53 in which the Laplace transforms of the derivative terms $\partial \overline{\mathrm{A}} / \partial \mathrm{x}$ and $\partial \overline{\mathrm{A}} / \partial \mathrm{y}$ have the same form as Equations $3-55$ and $3-56$, with the noted difference that the coefficient of $X$ in the exponential argument is given in this instance by Equation 4-3.

The evaluation of $a \bar{A} / \partial \mathrm{x}$ requires a new estimate of the $\mathrm{x}$-derivative of $\mathrm{e}^{\mathrm{r}_{\mathrm{a}} \mathrm{X}}$ based on Equation 4-3 and in this case Equation 3-55 becomes

$$
\frac{\partial \overline{\mathrm{A}}}{\partial \mathrm{x}}=\mathrm{A}^{0} \int_{0}^{\infty} \theta(\mathrm{s}) \mathrm{e}^{\mathrm{r}_{\mathrm{a}} \mathrm{x}} \psi(\mathrm{x}, \mathrm{o})\left[2 \alpha_{1}\left(\sigma-\alpha_{1} \mathrm{x}\right) \mathrm{E}_{\Omega}+\mathrm{E}_{\Omega}^{\mathrm{x}}-\mathrm{E}_{\Omega} \bar{\beta} \mathrm{f}_{1}(\mathrm{~s}+\lambda)\right] \mathrm{do}
$$


where

$$
f_{1}(s)=R s+c_{f} \sqrt{s} \tanh \beta \sqrt{s}
$$

and $\alpha_{1}, \bar{\beta}$ are given by Equations 3-57b and 3-59, and $\mathrm{E}_{\Omega}^{\mathrm{x}}$ by either Equation 3-62 or Equation 3-64, all depending upon the type of boundary condition imposed at the source. Writing

$$
L^{-1} \theta(s) e^{r}{ }^{X} f_{t}(s+\lambda)=e^{-\lambda t} L_{L}^{-1} \exp \left(-R_{X} s\right) G_{F}^{*}(s)
$$

where

$$
\begin{gathered}
G_{F}^{*}(s)=G_{F}(s) \cdot f_{1}(s) \\
=R_{s} G_{F}(s)-c_{f} \frac{d}{d \varepsilon}\left|G_{F}(s)\right|
\end{gathered}
$$

with $\mathrm{G}_{\mathrm{F}}(\mathrm{s})$ given by Equation 4-9. Using Equation 4-31 and applying Theorem A.1.3a to $\mathrm{sG}_{\mathrm{F}}(\mathrm{s})$ in Equation 4-55b, and subsequently Theorem A.1-1, the inverse Laplace transform of Equation 4-52 becomes

$$
\begin{aligned}
& \frac{\partial A}{\partial x}=A^{0} e^{-\lambda t} \int_{0}^{\infty} \Psi(x, a)\left|\left(2 a_{1}\left(\sigma-a_{1} x\right) E_{\Omega}+E_{\Omega}^{x}\right) G_{F}\left(t-R_{X}\right)-E_{\Omega} \bar{\beta}\right| R\left(\frac{\varepsilon}{\sqrt{n}} \frac{e^{-\bar{\varepsilon}^{2} \mu\left(1-R_{X}\right)}}{\sqrt{\left(t-R_{X}\right)^{3}}}+\right. \\
& \left.\sum_{n=1}^{\infty}(-1)^{n} \frac{\varepsilon^{n}}{n !} \bar{g}_{n}^{\prime}\left(t-R_{X}\right)\right)+c_{f}\left(\frac{1}{\sqrt{n}} \frac{e^{-\bar{\varepsilon}^{2} /\left(t-R_{X}\right)}}{\sqrt{\left(t-R_{X}\right)}}-\sum_{n=1}^{\infty}(-1)^{n} \frac{\varepsilon^{n-1}}{(n-1) !} \bar{g}_{n}\left(t-R_{X}\right)\right)|| U\left(t-R_{X}\right) d o
\end{aligned}
$$

where $\bar{g}_{n}^{\prime}(t)$ corresponds to the time derivative of $g_{n}(t)$ given by Equations $4-18$.

The inverse Laplace transform of the $y$-derivative of $A$ which has a form identical to Fquation 3-68b may be written as

$$
\frac{\partial A}{\partial y}=A^{0} e^{-\lambda t} \int_{0}^{\infty} \Psi(x, \sigma) E_{\Omega}^{y} G_{F^{\prime}}\left(t-R_{X}\right) U\left(t-R_{X}\right) d \sigma
$$

where $\mathrm{E}_{\Omega}^{\mathrm{x}}, \mathrm{E}_{\Omega}^{\mathrm{y}}, \bar{\varepsilon}$, and $\mathrm{G}_{\mathrm{F}}(\mathrm{t})$ are given by Equations $3-63,3-65,3-67 \mathrm{~d}$, and 4-31a, respectively. 
Referring to Equation 4-25 we have

$$
\begin{gathered}
H_{2}(t)=\sum_{n=1}^{\infty}(-1)^{n} \frac{\varepsilon^{n}}{n !} \bar{g}_{n}^{\prime}(t)=\left.\sum_{k=1}^{\Omega_{0}} \frac{1}{\sqrt{n}} e^{-a_{k}^{2}}\right|_{1} \bar{b}_{k} \frac{\varepsilon}{\sqrt{t^{3}}}\left(a_{k}^{2}-\frac{1}{2}\right)-\bar{b}_{2} \frac{\varepsilon^{2}}{2 !} \frac{a_{k}}{t^{2}}\left(a_{k}^{2}-\frac{3}{2}\right) \\
+{ }_{3} \bar{b}_{k} \frac{\varepsilon^{3}}{3 !} \frac{1}{\sqrt{t^{5}}}\left(a_{k}^{4}-3 a_{k}^{2}+\frac{3}{4}\right)-\ldots \mid
\end{gathered}
$$

Comparing Equations 4-58 and 4-28 we find

$$
H_{2}(t)=\sum_{k=1}^{\Omega} \sum_{m=1}^{k} a_{k m} e^{m} \frac{d^{m+2}}{d e^{m+2}}\left|\operatorname{orf}\left(\frac{2 k \beta+\varepsilon}{2 \sqrt{i}}\right)\right| .
$$

Referring to Equation 4-29 and differentiating both sides with respect to e yiolds

$$
\begin{aligned}
H_{3}(t)= & \sum_{n=1}^{\infty}(-1)^{n} \frac{\varepsilon^{n-1}}{(n-1) !} g_{n}(t)=\sum_{k=1}^{\Omega_{n}} \sum_{m=1}^{k} a_{k m}\left|m \varepsilon^{m-1} \frac{d^{m}}{d \varepsilon^{m}}\right| \operatorname{erf}\left(\frac{2 k \beta+\varepsilon}{2 \sqrt{t}}\right) \mid \\
& +\varepsilon^{m} \frac{d^{m+1}}{d \varepsilon^{m+1}}\left|\operatorname{erf}\left(\frac{2 k \beta+\varepsilon}{2 \sqrt{t}}\right)\right| \mid
\end{aligned}
$$

The components of the mass flux given by liduations 3-54 may now be written as

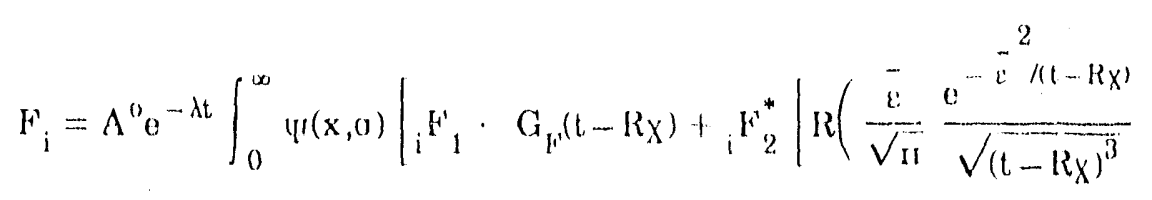

$$
\begin{aligned}
& \left.+H_{2}\left(t-R_{X}\right)\right)+c_{f}\left(\frac{1}{\sqrt{11}} \frac{e^{-r^{2} /(t-R X)}}{\sqrt{\left(t-R_{X}\right)}}-H_{3}\left(t-R_{X}\right)\right)|| U\left(t-R_{X}\right) d o,(i=x, y)
\end{aligned}
$$

with

$$
\mathrm{F}_{\mathrm{z}} \mathrm{F}_{\mathrm{z}}^{*}=\mathrm{D}_{\mathrm{ix}} \mathrm{E}_{\Omega \Omega} \bar{\beta},(\mathrm{i} \cdots \mathrm{x}, \mathrm{y})
$$

where ${ }_{x} \mathrm{~F}_{1}, \mathrm{~F}_{1}, \mathrm{G}_{\mathrm{F}}(\mathrm{t}), \mathrm{H}_{2}(\mathrm{t})$, and $\mathrm{H}_{3}(\mathrm{t})$ are given by figlutions, $3-67 \mathrm{a}, 3-67 \mathrm{e}, 4-31,4-59$, and 4-60, respectively. 


\subsubsection{Cumulativo Mass lilux}

The cumulative mass flux mu be written as

$$
M(t)=\int_{R_{X}}^{t} F(t) d t
$$

whore $\mathrm{F}(6)$ is given by Lquation 3.70b.

Unidimensional Flow $\left(k_{y}^{\prime}=0\right)$

Substituling for F( 1 ) given by Lquation 4-61a and interchanging the order of integration (see Ecas. 3-71 through 3-73), the above equation may now bo written as

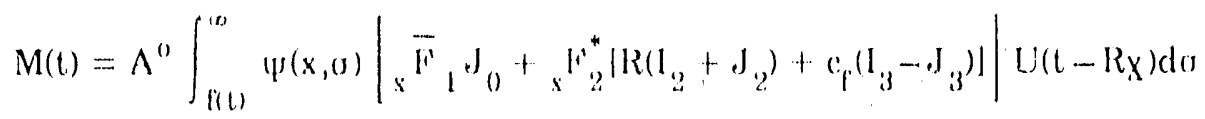

where $\bar{F}_{1}{ }_{1}$ and $\mathrm{F}_{\mathrm{x}}{ }_{2}^{*}$ are given by bquations 3 .74at and 4-62, and

$$
\begin{aligned}
& J_{0}=\int_{R x}^{t} e^{\cdots \lambda t} C_{\mu}(t) d t=I_{1}+J_{1} \\
& I_{1}=\int_{R X}^{t} e^{-\lambda} \operatorname{erfc}\left|\frac{\bar{\varepsilon}}{\sqrt{t-\ldots R_{X}}}\right| d c=K_{0}(\varepsilon)+\frac{\bar{\varepsilon} v^{-\lambda R x}}{\lambda \sqrt{11}} K_{2}(\bar{\varepsilon}) \\
& J_{1}=\int_{R X}^{t} H_{1}(t) e^{-\cdots \lambda t} d t \\
& I_{2}=\frac{\bar{\varepsilon} e^{-\lambda R x}}{\sqrt{11}} \int_{0}^{t-R x} \frac{e^{-\lambda t-\frac{\varepsilon^{2}}{t}}}{\sqrt{i^{3}}} d t=\frac{\bar{\varepsilon} e^{-\lambda \lambda x}}{\sqrt{I 1}} K_{2}(\bar{\varepsilon}) \\
& J_{2}=\int_{R_{X}}^{t} H_{2}(t) \theta^{-\lambda t} d \iota
\end{aligned}
$$




$$
\begin{aligned}
& I_{3}=\frac{0^{-\lambda R x}}{\sqrt{11}} \int_{R x}^{t} \frac{0^{-\lambda i \frac{i^{2}}{1}}}{\sqrt{i}} d v=\frac{0^{-\lambda \lambda x}}{\sqrt{\pi}} K_{1}(\ddot{\varepsilon}) \\
& J_{3}=\int_{R X}^{l} H_{i j}(\imath) e^{-\lambda \imath} d \iota
\end{aligned}
$$

where $\mathrm{K}_{0}, \mathrm{~K}_{1}$, and $\mathrm{K}_{2}$ are given by Lqualions $3.79 \mathrm{a}, 3-81$, and $3-82$, and $\mathrm{H}_{1}, \mathrm{H}_{2}$, and $\mathrm{H}_{3}$ are given by Fquations 4-29, 4-59, and 4-60, respectivoly. Writing

$$
\vec{\xi}_{k}=k \beta+\bar{\varepsilon}
$$

and while noting that

$$
\int_{\mathbb{R X}}^{t} e^{-\lambda} \frac{d^{\prime \prime}}{d \varepsilon^{\prime \prime}}\left|\operatorname{arf}\left(\frac{\vec{\xi}_{k}}{\sqrt{\iota-R_{X}}}\right)\right| d \iota=\frac{d^{\prime \prime}}{d \varepsilon^{\prime \prime}}\left|L\left(\xi_{k}\right)\right|
$$

where

$$
I .\left(\bar{\xi}_{k}\right)=e^{-\lambda R x} \int_{0}^{t-R x} e^{-\lambda t} \operatorname{arf}\left(\frac{\bar{\xi}_{k}}{\sqrt{l}}\right) d t .
$$

integration by parts yiolds

$$
\begin{aligned}
& L\left(\bar{\xi}_{k}\right)=-\frac{e^{-\lambda t}}{\lambda} \operatorname{erf}\left(\frac{\bar{\xi}_{k}}{\sqrt{t-R_{X}}}\right)+\frac{e^{-\lambda R_{X}}}{\lambda}-\frac{\ddot{\xi}_{k} e^{-\lambda \lambda X}}{\lambda \sqrt{11}} \int_{0}^{t-k x} \frac{e^{-\lambda t-\frac{\xi_{k}^{2}}{t}}}{\sqrt{i^{3}}} d t \\
& =-\frac{e^{-\lambda t}}{\lambda} \operatorname{erf}\left(\frac{\bar{\xi}_{k}}{\sqrt{t-R_{X}}}\right)+\frac{e^{-\lambda R x}}{\lambda}-\frac{\bar{\xi}_{k} e^{-\lambda R_{X}}}{\lambda \sqrt{\pi}} K_{2}\left(\bar{\xi}_{k}\right) .
\end{aligned}
$$

Substituting for $K_{2}\left(\ddot{\xi}_{k}\right)$ (Eq. 3-82) in the last torm of the above equation, it may then be shown that

$$
\begin{aligned}
& \frac{d^{n}}{d \varepsilon^{n}}\left|L\left(\bar{\xi}_{k}\right)\right|=-\frac{e^{-\lambda t}}{\lambda} \frac{d^{n}}{d \varepsilon^{n}}\left|\operatorname{erf}\left(\frac{\bar{\xi}_{k}}{\sqrt{l-I R X}}\right)\right|-\frac{e^{-\lambda R x}}{2 \lambda} \mid \lambda^{n / 2} e^{2 \bar{\varepsilon}_{k}}{ }^{\sqrt{\lambda}}+(-1)^{n} \lambda^{n / 2} e^{-2 \bar{\varepsilon}_{k}} \sqrt{\lambda} \\
& -\frac{d^{n}}{d e^{n}}\left|e^{2 \bar{\xi}_{k} \sqrt{\lambda}} \operatorname{erf}\left(\frac{\bar{\xi}_{k}}{\sqrt{t-R_{X}}}+\sqrt{\lambda\left(t-R_{X}\right)}\right)+e^{-2 \bar{\xi}_{k} \sqrt{\lambda}} \operatorname{arf}\left(\frac{\bar{\xi}_{k}}{\sqrt{t-R_{X}}}-\sqrt{\lambda(t-R X)}\right)\right| \mid
\end{aligned}
$$


'The last momber of the above oquation may bo ovaluated using Lolbnita's thoorom for difforon-

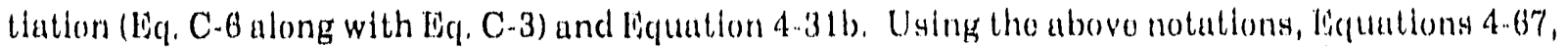
4-69, and 4-71 may now bo written as

$$
\begin{aligned}
& J_{1}=\sum_{k=1}^{\Omega_{0}} \sum_{m=1}^{k} a_{k m} e^{m ! n} \frac{d^{m}}{d k^{m}} \| L_{1}\left(\vec{\varepsilon}_{k}\right) \mid \\
& J_{2}=\sum_{k=1}^{\Omega_{0}} \sum_{m=1}^{k} a_{k m} \varepsilon^{m} \frac{d^{m+2}}{d e^{m+2}} \| L_{1}\left(\xi_{k}\right) \mid \\
& J_{3}=\sum_{k=1}^{\Omega_{0}} \sum_{m=1}^{k} a_{k m}\left|m \varepsilon^{m-1} \frac{d^{m}}{d e^{m !}}\right| L_{1}\left(\vec{\xi}_{k}\right)\left|+\varepsilon^{\prime \prime \prime} \frac{d^{m+1}}{d e^{m+1}}\right| L_{1}\left(\vec{\xi}_{k}\right)||
\end{aligned}
$$

Reverting to Equation 4-64 and using the abovo notations, this bocomes

$$
\begin{aligned}
M(t)= & A^{0} \int_{0}^{\infty} \psi(x, 0)\left|\bar{F}_{l}\right| K_{0}(\vec{\varepsilon})+\frac{\bar{\varepsilon} 0^{-\lambda R x}}{\lambda \sqrt{r 1}} K_{2}(\bar{\varepsilon})+J_{l} \mid \\
& +{ }_{x} F_{2}^{*}\left|R\left(\frac{\bar{\varepsilon} \theta^{-\lambda R x}}{\sqrt{11}} K_{2}(\bar{\varepsilon})+J_{2}\right)+c_{f}\left(\frac{e^{-\lambda R x}}{\sqrt{11}} K_{1}(\bar{\varepsilon})-J_{3}\right)\right| \mid U(t-R x) .
\end{aligned}
$$

\subsection{NO LONGITUDINAI, DISPERSION}

With the streamlines assumed normal to the source (i.e., $v=0$ ) and neglecling the longitudinal dispersion effects (i.e., $D_{x x}=D_{x y}=0$ ), Equations $4-1$ to $4-3$ are still satisfied. In this case, the solution in the fracture and rock matrix may bo obtained from lefuations 4.32 and 4-51 aftor implo. menting on the one hand the relation given by Equation 3-50 and proper substitution for the corrospondence of the variables $\varepsilon\left(i, \Theta, \varepsilon^{\prime}\right)$ and $X\left(i . e, X^{\prime}\right)$ on the other hand, to yiold

$$
\begin{aligned}
& A(x, y, t)=A^{\prime \prime} \theta^{-\lambda t_{2}} E_{\Omega} g_{F}^{\prime}\left(t-R X^{\prime}\right) U\left(l-R_{X}^{\prime}\right)
\end{aligned}
$$

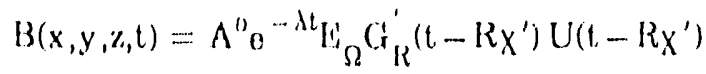

where

$$
G_{f^{\prime}}^{\prime}(t)=\operatorname{arfc}\left(\frac{c_{f} x^{\prime}}{2 \sqrt{t}}\right)+\sum_{k=1}^{s_{0}} \sum_{m=1}^{k} a_{k m}\left(c_{p} x^{\prime}\right)^{m n} \frac{d^{m}}{d \varepsilon^{\prime \prime \prime}}\left|\operatorname{orf}\left(\frac{2 k \beta+\varepsilon^{\prime}}{2 \sqrt{t}}\right)\right|
$$




$$
\begin{aligned}
& G_{k}^{\prime}(t)=\sum_{i=1}^{s \Omega_{0}^{\prime \prime}}(-1)^{1+1} \sum_{k=1}^{2} \operatorname{orfc}\left|\frac{{ }^{k} Y_{10}+c_{f} X^{\prime}}{2 \sqrt{t}}\right| \\
& +\sum_{i=1}^{s a_{1}^{\prime \prime}} \sum_{j=1}^{s a_{i}^{\prime \prime}}(-1)^{1+1} \sum_{k=1}^{2} \sum_{m=1}^{i} a_{i m}\left(c_{1} x^{\prime}\right) \frac{d^{m}}{d \varepsilon^{\prime \prime \prime}}\left|\operatorname{ort}\left(\frac{{ }^{k} Y_{j}+\varepsilon^{\prime}}{2 \sqrt{ }}\right)\right|
\end{aligned}
$$

Vivte that $x^{\prime}$ corrosponds to xiu.

Based on biguations 3.50 and 3.70b, tho mass flux and cumulative mass flux in the fracture may he obtained from líquations $4-61$ and 4-80.

$$
\begin{aligned}
& F^{\prime}(t)=\Lambda^{\prime \prime} e^{-\lambda T_{3}} G_{F^{\prime}}^{\prime}\left(t-R_{X^{\prime}}\right) U\left(t-R_{X^{\prime}}\right) \\
& M(t) \ldots A^{0} \mathrm{~F}_{3}\left(K_{0}(\vec{z})+\frac{\bar{z} 0^{-\lambda R X^{\prime}}}{\lambda V_{11}} K_{2}(\bar{\varepsilon})+d_{1}^{\prime}\right) U\left(t-R_{X^{\prime}}\right)
\end{aligned}
$$

where

$$
\begin{aligned}
& J_{1}^{\prime} \ldots \sum_{k=1}^{S_{0}} \sum_{m=1}^{k} a_{k m}\left(\varepsilon^{\prime}\right)^{m} \frac{d^{\prime \prime \prime}}{d\left(\varepsilon^{\prime}\right)^{m}}\left\|L_{1}\left(\vec{\xi}_{k}\right)\right\| \\
& \bar{\xi}_{k}=k \beta+\bar{\varepsilon} \\
& = \pm \frac{\varepsilon^{\prime}}{2}=\frac{c_{1} x^{\prime}}{2}
\end{aligned}
$$

and functions $\mathrm{K}_{0}, \mathrm{~K}_{2}$, and $\mathrm{F}_{3}$ uro givon by Equalions $3-79 \mathrm{a}, 3-82$, and 3-88, respoctively.

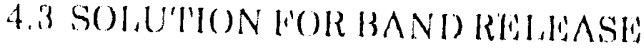

'The general form of the solution for the finite-duration band release mode based on tho boundary condition given by fiquation 220 and which uses tho superposition technique (soo Foglia ot al., 1979) may be written ass

$$
\begin{aligned}
& { }^{b} \Lambda(x, y, t)=\Lambda\left(x, y, t ; \Lambda^{\prime \prime}\right)-\Lambda\left(x, y, l-T^{\prime} ; \Lambda^{\prime} e^{-\lambda T^{\prime}}\right) U\left(t-T^{\prime}\right)
\end{aligned}
$$

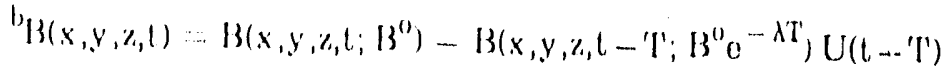

where 'l' enrresponds to the leach duration and superseript b indicutes the band roloase solution. 


\subsection{CONVERGENCL OF STRIES}

'The solutions prosented in this section Includo for the most part compononts in tho form of' sories. Although tentativo $1 \mathrm{~lm}$ ts of their upper bound for the longitudinal dispersion froesolutions have been proposed in Section 4.5, these might converge prematurely, particularly when the ratio of $8 / 2 \sqrt{t}$ becomos excessively smallor than unity.

Convergence of those serios is assumed to be roached when the following critoria aro simulta. neously met, i.e., for a givon series the absolute percentage relative error in two consecutive steps of the summation process is less than or equal to 0.1 and the absolute difforence at these stops is less than or equal to 10-6.

With a series at the nth step of its evaluation defined as

$$
S_{n}=\sum_{i=1}^{n} u_{i}
$$

the first convergence criterion corresponds to

$$
\left|\frac{S_{m}-S_{m-1}}{S_{m}}\right| \leq 10^{-3} ; m=n-1, n \text { (rolativo error) }
$$

whereas the second corresponds to

$$
\left|S_{n}-S_{n-1}\right| \leq 10^{-6} \cdot \text { (absolute error) }
$$

\subsection{REMARKS}

The series solution presented in this section includes a combination of complementary orror function and multiple derivatives of the error function. The number of significant terms in the sories summation is dependent to a large extent upon the argument of the error functions. Past a certain threshold the argument will render subsequent terms in the series negligibly small and, therefore, these terms may be neglected. For example, an argument for the error function corresponding to 5.5 will render both complementary error function and its dorivatives negligibly small. Since the argu. ment of the exponential term in the derivative expression of the crror function emerges as the square of its argument, the argument of the exponential and error function are accordingly related. In the related computer code, the error function is evaluatod internally (Cody, 1969) and assigned its 
maximum value of ono when its argument (1,6., ARG') becomes groater or oqual to tho square root of the maximum permissible value of the exponontial argument (i.o., ARG) as allowed by tho computor. An estimate of some tentative limits for the values of $\Omega_{0}^{\prime \prime}, \Omega_{1}^{\prime \prime}$, and $\Omega_{2}^{\prime \prime}$ (soe Eqg. $4-31$ a and 4-50) may bo obtatned aftor equating the argument of the complementary error function and oxponential argument appearing in the derivative terms of the error functions to $A R G{ }^{\prime}$ and $A R G$, rospectively. Moreovor, it may also bo shown that the reported solutions are dopencent on some dimensionless numbers, such as the fourior number dolined as

$$
r_{0}=\frac{D(l-R X)}{R^{\prime}(L-b)^{2}},
$$

a dimensionless number delermining tho penetration of the solute front into the rock matrix ovor a given poriod of timo, which is analogous to tho thoory of hout conduction in solids. 'Thus, the larger the Fourier number, the greater the olapsed time for the diffusion procoss.

\subsubsection{Fracture}

In order to determine a limiting value for $\Omega_{0}$ in liquation 4.31 a, we write

$$
\frac{\left(2 \Omega_{0} \beta+c_{1} X\right)^{2}}{4\left(1-R_{X}\right)} \leq \Delta R C
$$

Substituting for $\beta$ (see Ed. 4-7b) and using Wquation 4-94, we find that

$$
\Omega_{0} \leq\left|(A R G F(0))^{1 / 2}-P_{0}\right|
$$

where $P_{0}$ is a dimensionless number defined as

$$
P_{0}=\frac{\phi D_{1} X}{2 h(1,-b)}
$$

Note that in this case the second member on the right hand side of liquation $4-3$ a would contribute to the solution in the fracture only whon

$$
F_{0}=\frac{1}{A R G}\left|1+P_{0}\right|^{2}
$$


as otherwise Equation 4-31a now reduees to

$$
\mathrm{G}_{\mathrm{F}}(\mathrm{t})=\operatorname{erfc}\left(\frac{\mathrm{C}_{\mathrm{P}} \mathrm{X}}{2 \sqrt{\mathrm{l}}}\right), \mathrm{F}_{0}<\frac{1}{\mathrm{ARG}}\left|1+\mathrm{P}_{0}\right|^{2}
$$

which indicates that for this specific range of values of 'Fo based on a value for ARG greater than 30 , the solutions of the concentration in the fracture for infinite and finite diffusion into the rock matrix become practically identica

\subsection{2 $\underline{\text { Rock }}$}

Referring to the argument of the complementary error function term in Equation 4-50, which is obtained after setting $k=1$ (see Hq. 4-42a), the limiting value of $\Omega_{0}$ may be found after writing

$$
\frac{\left(2 \Omega_{0}^{\prime \prime}-1\right) \beta-\mu+c_{p} X}{2 \sqrt{t-R_{X}}} \leq A R G^{i}
$$

Substituting for $\beta$ and $\mu$, we find that

$$
\Omega_{0}^{\prime \prime} \leq A R G^{\prime} F_{0}{ }^{1 / 2}+\frac{1}{2}\left(\frac{L-z}{L-b}\right)+\frac{1}{2}-P_{0}
$$

where $\mu$ is given by Equation $4-36$. It may be shown that $\Omega_{0}$ will take its lowest value corresponding to unity when Fo satisfies the following condition

$$
F_{0} \geq \frac{1}{A R G}\left|\frac{1}{2}\left(\frac{a-b}{I_{1}-b}\right)+P_{0}\right|^{2}
$$

as otherwise Equation 4-50 now reduces to

$$
G_{r}(t)=\operatorname{erfc}\left(\frac{c_{r}(z-b)+c_{f} x}{2 \sqrt{l}}\right), F_{0}<\frac{1}{A R G}\left|\frac{1}{2}\left(\frac{z-b}{L-b}\right)+P_{0}\right|^{2} .
$$

Since in this case the second member of Equation 4-50 cannot be evaluated, the solution of the concentration in the rock matrix becomes identical to the single fracture case. 
Referring to the second term in Equation 4-50 and selecting the smallest argument (i.e., ${ }^{1} y_{1 j} / 4 t$ where ${ }^{1} Y_{i j}$ is given by Equation 4-42a), the value for $\Omega_{1}^{\prime \prime}$ may be found after writing

$$
\frac{\left[(2 m-1) \beta-\mu c_{f X}\right]^{2}}{4\left(t-R_{X}\right)} \leq \mathrm{ARG}
$$

where $\mathrm{m}=\Omega_{1}^{a^{\prime \prime}}=\Omega_{2}^{\prime \prime}$. Substituting for $\beta$ and $\mu$, we have

$$
\mathrm{m} \leq\left(\mathrm{ARG} \mathrm{F}_{0}\right)^{1 / 2}+\left(\frac{\mathrm{L}-\mathrm{z}}{\mathrm{L}-\mathrm{b}}\right)+\frac{1}{2}-\mathrm{P}_{0}
$$

and in this case the number of summations corresponds to

$$
\sum_{i=1}^{m} i
$$

Note that in the evaluation of $X$, the value of the variable $\sigma$ is taken to correspond to oUL given by Equation B.1-11b (see Appendix B). When the longitudinal dispersion effects are ignored, then $X$ is substituted by $X^{\prime}$. The reader may easily observe that for a given value of the dimensionless number $c_{f}$ $\mathrm{X} / 2 \mathrm{~V} t$, this particular solution method loses its viability with increasing values of the Fourier number. However, of interest are values of $c_{\mathrm{f}} \mathrm{x} / 2 \mathrm{Vt} \leq 0.1$ which render the terms associated to the innermost series summation in Equations 4-31a, 4-50, 4-60, 4-61a, 4-77, 4-78, 4-79, 4-84, and 4-87 negligibly small (i.e., <10.6) past the sixth term of the summation. Consequently, in such instances the series solution may conveniently substitute the contour integration solution (see Chapter 5), in which convergence characteristics are adversely affected by decreasing values of the dimensionless number. 


\subsection{MUL'TIPLE PARALLEL, FRAC'TURE CASE WI'TH FINITE \\ DIFFUSION FIELD: CON'TOUR IN'TEGRATION}

\subsection{FRACTURE}

Rewriting Equation 4-4:

$$
\bar{A}(x, y, s)=\int_{0}^{\infty} \psi(x, o) E_{\Omega} A^{\prime \prime} \theta(s) e^{r} a^{x} d o
$$

The inverse Laplace transform of the above equation may be sought after using the Bromwich complex inversion formula (Carslaw and Jaeger, 1958) and applying the Translation, Linear 'Transformation, and Convolution Theorems to the last two terms of Equation 5-1.

$$
\begin{aligned}
L^{-1}\left|\theta(s) e^{r} a^{x}\right| & =L^{-1}\left|\frac{\exp [-R X(s+\lambda)]}{(s+\lambda)} \exp \right|-c_{f} X(s+\lambda)^{1 / 2} \tanh \left(c_{r}(L-b)(s+\lambda)^{1 / 2}\right)|| \\
& =e^{-\lambda t} \int_{0}^{t-R x} G_{F}(c, \varepsilon, \beta) d t
\end{aligned}
$$

where

$$
\mathrm{C}_{\mathrm{F}}(\mathrm{c}, \varepsilon, \beta)=\mathrm{L}^{-1}\left|\exp \left[-\varepsilon(s)^{1 / 2} \tanh \left(\beta(\mathrm{s})^{1 / 2}\right)\right]\right|=\frac{1}{\pi} \int_{0}^{\infty} \eta \exp \left(\beta_{\mathrm{r}}\right) \cos \left(\beta_{\ell}\right) \mathrm{d} \eta
$$

with

$$
\begin{gathered}
\varepsilon=c_{f} X \\
\beta=c_{r}(L-b) \\
\beta_{r}=-\frac{\varepsilon \eta}{2}\left[\frac{\sinh (\beta \eta)-\sin (\beta \eta)}{\cosh (\beta \eta)+\cos (\beta \eta)}\right] \\
\beta_{\ell}=\frac{\eta^{2} \tau}{2}-Y_{\ell} \\
\left.Y_{\ell} \cdots \frac{\varepsilon \eta}{2} \mid \frac{\sinh (\beta \eta)+\sin (\beta \eta)}{\cosh (\beta \eta)+\cos (\beta \eta)}\right] .
\end{gathered}
$$

Note that Equation 5-3 was derived by Skopp and Warrick (1974). 
Writing the last term under the integral sign in Equation 5-3 (i.e., $\cos \beta_{\ell}$ ) in a more explicit form using Equation 5-4d, we have

$$
\cos \left(\beta_{\ell}\right)=\cos \left(\frac{\eta^{2}}{2} \tau\right) \cos \left(\gamma_{\ell}\right)+\sin \left(\frac{\eta^{2}}{2} \tau\right) \sin \left(\gamma_{\ell}\right)
$$

Integration of Equation 5-3 with respect to $t$ using Equation 5-5, we obtain

$$
G_{F}\left(t-R_{X}, \varepsilon, \beta\right)=\int_{0}^{t-R X} G_{F}(\tau, \varepsilon, \beta) d \tau=\frac{2}{\pi} \int_{0}^{\infty} \frac{\exp \left(\beta_{r}\right)}{\eta}\left[\sin (v) \cos \left(Y_{\ell}\right)+[1-\cos (v)] \sin \left(\gamma_{\ell}\right)\right] d \eta
$$

where

$$
v=\frac{\eta^{2}(t-R X)}{2}=\frac{\eta^{2}}{2}\left(t-\frac{R_{x}^{2}}{4 D_{x x} \sigma^{2}}\right)
$$

Using the formula

$$
\sin (a+b)=\sin (a) \cos (b)+\cos (a) \sin (b)
$$

the inverse Laplace transform of Equation $5-3$ yielding the final solution of the concentration in a system of parallel fractures may be written as

$$
A(x, y, t)=\frac{2}{\pi} A^{0} e^{-\lambda t} \int_{0}^{\infty} \Psi(x, \sigma) E_{\Omega} \int_{0}^{\infty} \frac{\exp \left(\beta_{r}\right)}{\eta} \cdot\left[\sin \left(\gamma_{\ell}\right)+\sin \left(v-y_{\ell}\right)\right] U\left(t-R_{X}\right) d r d \sigma
$$

where $X, Y e$, and $v$ are given by Equations 3-22d, 5-4e, and 5-7, respectively.

\subsection{ROCK MATRIX}

Substitution of Equation 5-1 in Equation 4-1 gives

$$
\bar{B}(x, y, z, s)=A^{0} \int_{0}^{\infty} \Psi(x, \sigma) E_{\Omega} \theta(s) e^{r_{a} x} \cosh \left[r_{b}(z-L)\right] \operatorname{sech}\left[r_{b}(b-L)\right] d o
$$

The inverse Laplace transform of Equation 5-10 after substituting for $r_{b}$ (see Equation 3-5a) may be obtained (see Appendix A, Equation A.2-5) from

$$
L^{-1} \frac{\cosh \left|\mu(s)^{1 / 2}\right| \operatorname{sech}\left|\beta(s)^{1 / 2}\right|}{s}=1-\sum_{n=0}^{\infty} \Gamma_{\delta} \exp \left(-\delta^{2} \mathrm{t}\right)
$$


where

$$
\begin{aligned}
\mu & =c_{r}(L-z) \\
\delta & =\frac{(2 n+1) \Pi}{2 \beta} \\
\Gamma_{\delta} & =(-1)^{n} \frac{4}{(2 n+1) \pi} \cos (\delta \mu) .
\end{aligned}
$$

Using Equations 5-3 and 5-11, the inverse Laplace transform of Equation 5-10 is obtained after applying the Translation, Linear Transformation, and Convolution Theorems, respectively. This may be written as

$$
\begin{gathered}
B(x, y, z, t)=\frac{A^{0}}{\pi} e^{-\lambda t} \int_{0}^{\infty} \Psi(x, \sigma) E_{\Omega} \int_{0}^{\infty} \eta \exp \left(\beta_{r}\right) \cdot \int_{0}^{t-R_{X}} \cos \left(\beta_{\ell}\right) \cdot\left[1-\sum_{n=0}^{\infty} \Gamma_{\delta} \exp \left[-\delta^{2}(t-\tau)\right]\right] \\
U\left(t-R_{X}\right) d \tau d \eta d o
\end{gathered}
$$

Note that $\cos \left(\beta_{\ell}\right)$ is given by Equation 5-5. Integration of Equation 5-13 with respect to $\tau$ while making use of the following formulae

$$
\begin{gathered}
\int e^{a z} \sin b z d z=\frac{e^{a z}}{a^{2}+b^{2}}(a \sin b z-b \cos b z) \\
\int e^{a z} \cos b z d z=\frac{e^{a z}}{a^{2}+b^{2}}(a \cos b z+b \sin b z) \\
\cos (a+b)=\cos (a) \cos (b)-\sin (a) \sin (b)
\end{gathered}
$$

will then yield a tentative solution of the concentration in the rock matrix. This may be written as

$$
\begin{gathered}
B(x, y, z, t)=\frac{A^{0}}{\pi} e^{-\lambda t} \int_{0}^{\infty} \Psi(x, \sigma) E_{\Omega} \int_{0}^{\infty} \eta \exp \left(\beta_{r}\right)\left\{\frac{2}{\eta^{2}}\left[\sin \left(\gamma_{\ell}\right)+\sin \left(v-Y_{\ell}\right)\right]-\sum_{m=0}^{\infty} \frac{\Gamma_{\delta}}{\delta^{4}+\eta^{4} / 4}\left[\exp \left(-\delta^{2} R_{X}\right)\right.\right. \\
\left.\left.\left[\delta^{2} \cos \left(v-Y_{\ell}\right)+\frac{\eta^{2}}{2} \sin \left(v-Y_{\ell}\right)\right]-\exp \left(-\delta^{2} t\right)\left[\delta^{2} \cos \left(\gamma_{\ell}\right)-\frac{\eta^{2}}{2} \sin \left(Y_{\ell}\right)\right]\right] U\left(t-R_{X}\right)\right\} d \eta d \sigma
\end{gathered}
$$

where $X, \chi_{\ell}, v, \delta$, and $\Gamma_{\delta}$ are given by Equations 3-22d, 5-4e, 5-7, 5-12b, and 5-12c, respectively. 
Because of the slow convergence registered by the solution given by Equation 5-15 for small Fourier numbers and its deficiency to cope adequately with large Fourier numbers (i.e., $>20$ ) since Equation 5-11 reduces to one in such a case; an alternative solution based on a contour integration along the imaginary axis was sought.

Referring to Equation 5-10 and applying to this the Convolution Theorem yields

$$
B(x, y, z, t)=A^{0} e^{-\lambda t} \int_{0}^{\infty} \Psi(x, \sigma) E_{\Omega} \int_{0}^{t} G_{R}(\tau, \varepsilon, \beta, \mu) d t d \sigma U(t-R X)
$$

where

$$
G_{R}(\tau, \varepsilon, \beta, \mu)=L^{-1} \exp \left[-\varepsilon(s)^{1 / 2} \tanh \beta(s)^{1 / 2}\right] \frac{\cosh \mu(s)^{1 / 2}}{\cosh \beta(s)^{1 / 2}}
$$

Substituting $\mathrm{s}=\mathrm{i} \mathrm{\eta}^{2 / 2}$ and and $\mathrm{s}=-\mathrm{i} \eta^{2 / 2}$ on the positive and negative parts of the imaginary axis in the above equation and using the following relations

$$
\begin{gathered}
\cosh (z)=\cosh x \cos y+i \sinh x \sin y \\
\tanh (z)=\frac{\sinh 2 x+i \sin 2 y}{\cosh 2 x+\cos 2 y}
\end{gathered}
$$

and multiplying both numerator and denominator of Equation 5-17 by the conjugate of Equation 5-18 yields

$$
\begin{aligned}
G_{R}(\tau, \varepsilon, \beta, \mu)= & \frac{1}{8 \pi} \int_{0}^{\infty} \sum_{m=1}^{2} \sum_{n=1}^{2} \sum_{p=1}^{2} \frac{\eta}{\delta_{1}} \exp \left[\beta_{r}+(-1)^{m+1} \frac{\beta \eta}{2}+(-1)^{n+1} \frac{\mu \eta}{2}\right] . \\
& \exp \left[i(-1)^{p+1}\left(\frac{\eta^{2} \tau}{2}-y_{\ell}+(-1)^{m} \frac{\beta \eta}{2}-(-1)^{n} \frac{\mu \eta}{2}\right)\right] d \eta
\end{aligned}
$$

where

$$
\delta_{1}=\cosh ^{2}\left(\frac{\beta \eta}{2}\right) \cos ^{2}\left(\frac{\beta \eta}{2}\right)+\sinh ^{2}\left(\frac{\beta \eta}{2}\right) \sin ^{2}\left(\frac{\beta \eta}{2}\right)
$$

and $\beta_{\mathrm{r}}$ is given by Equation $5-4 \mathrm{c}$.

Recognizing the following relation

$$
e^{i \theta}=\cos \theta+i \sin \theta
$$


Equation 5-20 may now be written as

$$
G_{R}(\tau, \varepsilon, \beta, \mu)=\frac{1}{4 n} \int_{0}^{\infty} \sum_{m=1}^{2} \sum_{n=1}^{2} \frac{\eta}{\delta_{1}} \operatorname{cxp}\left[\bar{\beta}_{r} \mid \cos \left[\bar{\beta}_{\ell}\right] d \eta\right.
$$

where

$$
\begin{gathered}
\bar{\beta}_{r}=\beta_{r}+(-1)^{m+1} \frac{\beta \eta}{2}+(-1)^{n+1} \frac{\mu \eta}{2} \\
\bar{\beta}_{\ell}=\frac{\eta^{2} \mathrm{r}}{2}-\bar{y}_{\ell} \\
\bar{y}_{\ell}=y_{\ell}+(-1)^{m+1} \frac{\beta \eta}{2}-(-1)^{n+1} \frac{\mu \eta}{2}
\end{gathered}
$$

Noting that Equations 5-23 and 5-24b have forms similar to Equations 5-3 and 5-4d, integration of $\cos \left[\beta_{\ell}\right]$ with respect to $\tau$, following identical steps given by Equations 5-5 through 5-8, will then yield the final solution of the concentration in the rock matrix which may be written as

$$
B(x, y, z, t)=\frac{1}{2 \pi} A^{\prime \prime} e^{-\lambda t} \int_{0}^{\infty} \psi(x, 0) E_{\Omega} \int_{0}^{\infty} \sum_{m=1}^{2} \sum_{n=1}^{2} \frac{\exp \left(\bar{\beta}_{r}\right)}{\delta_{1} \eta}\left[\sin \left(\bar{y}_{\ell}\right)+\sin \left(v-\bar{y}_{\ell}\right) \| U(t-R X) d \eta d \delta\right.
$$

where $v$ is given by Equation 5-7.

\subsection{MASS FLUX}

The general form of the equation for the mass flux in the fracture is given by Equation 3-53.

This requires the evaluation of the derivatives terms $\partial \mathrm{A} / \partial \mathrm{x}$ and $\partial \mathrm{A} / \partial \mathrm{y}$. Referring to Equation 5-9, one obtains

$$
\begin{aligned}
\frac{\partial A}{\partial x} & =\Lambda^{0} \mathrm{e}^{-\lambda t} \int_{0}^{\infty} \psi(x, \sigma)\left[\left(2 a_{1}\left(\sigma-a_{1} x\right) E_{\Omega}+F_{\Omega}^{x}\right) G_{F}\left(t-R_{X}, \varepsilon, \beta\right)\right. \\
& \left.+E_{\Omega} G_{F^{\prime}}^{x}\left(t-R_{X}, \varepsilon, \beta\right)\right] U\left(t-R_{X}\right) d o \\
\frac{\partial A}{\partial y} & =\Lambda^{0} e^{-\lambda t} \int_{0}^{\infty} \psi(x, o) E_{\Omega}^{y} G_{F^{\prime}}\left(t-R_{X}, \varepsilon, \beta\right) U\left(t-R_{X}\right) d o
\end{aligned}
$$


with

$$
\begin{gathered}
G_{F}^{x}\left(t-R_{X}, \varepsilon, \beta\right)=\frac{2}{\pi} \int_{0}^{\infty} \frac{\exp \left(\beta_{r}\right)}{\eta} \bar{\beta}\left(c_{f} \zeta_{r}\left(\sin \left(\gamma_{\ell}\right)\right)+\sin \left(v-\gamma_{\rho}\right)+c_{\rho} \zeta_{\ell} \cos \left(\gamma_{\rho}\right)\right. \\
\left.-\left(\frac{R \eta^{2}}{2}+c_{f} \zeta_{\ell}\right) \cos \left(v-\gamma_{\ell}\right)\right) d \eta \\
\zeta_{\ell}=Y_{\rho} / \varepsilon=\frac{\eta}{2}\left|\frac{\sinh (\beta \eta)+\sin (\beta \eta)}{\cosh (\beta \eta)+\cos (\beta \eta)}\right| \\
\zeta_{r}=\beta_{r} / \varepsilon=-\frac{\eta}{2}\left|\frac{\sinh (\beta \eta)-\sin (\beta \eta)}{\cosh (\beta \eta)+\cos (\beta \eta)}\right|
\end{gathered}
$$
3-64, and $\mathrm{E}_{\Omega}^{\mathrm{x}}$ by Equation 3-63 or 3-65.

With the proper substitution of Equations 5-9 and 5-26 into Equations 3-54 we find the solution for the components of the mass flux in the fracture written as

$$
\begin{aligned}
& F_{i}=\frac{2}{I I} A^{0} e^{-\lambda t} \int_{0}^{\infty} \Psi(x, \sigma) \int_{0}^{\infty} \frac{\exp \left(\beta_{r}\right)}{\eta} \mid\left(\sin \left(\gamma_{\ell}\right)+\sin \left(v-\gamma_{\ell}\right)\right)_{i} F_{1} \\
& -{ }_{i} F_{2}^{*}\left(c_{f} \zeta_{r}\left(\sin \left(\gamma_{\ell}\right)+\sin \left(v-\gamma_{\rho}\right)\right)+\cos \left(\gamma_{\ell}\right) c_{f} \zeta_{\ell}-\cos \left(v-\gamma_{\ell}\right)\left(\frac{R \eta_{l}^{2}}{2}+c_{f} \zeta_{\ell}\right)\right) \mid U\left(t-R_{X}\right) d \eta d a,(i=x, y)
\end{aligned}
$$

where ${ }_{i} F_{1}$ and ${ }_{i} F_{2}^{*}$ are given by Equations 3-67a and 4-62.

\subsection{CUMULATIVE MASS FLUX}

The general form of the equation describing the cumulative mass flux in the fracture is given by Equation 4-63.

\section{Unidimensional Flow $\left(F_{y}=0\right)$}

\section{Defining}

$$
I_{1}\left(t, \eta, v, Y_{\rho^{\prime}}, X\right)=\int_{0}^{t} e^{-\lambda t} \sin \left(Y_{\rho}\right) U\left(t-R_{X}\right) d \tau
$$




$$
\begin{aligned}
& =\int_{R_{x}}^{t} e^{-\lambda t} \sin \left(y_{\rho}\right) d t \\
& =\frac{\sin \left(y_{e}\right)}{\lambda}\left(\theta^{-\lambda R x}-e^{-\lambda t}\right)
\end{aligned}
$$

and

$$
\begin{aligned}
I_{2}\left(t, \eta, v, y_{\rho^{\prime}} x\right) & =\int_{0}^{l} e^{\cdots \lambda t} \sin \left(\frac{\eta^{2}(t-R x)}{2}-y_{\rho}\right) U(t-R x) d t \\
& =e^{-\lambda R x} \int_{0}^{t} e^{-\lambda t} \sin \left(\frac{\eta^{2} t}{2}-y_{\rho}\right) d t .
\end{aligned}
$$

Recognizing the following integral (Abramowitz and Stogun, 1972),

$$
\int e^{a x} \sin (b x+c) d x=\frac{e^{a x}}{a^{2}+b^{2}}|a \sin (b x+c)-b \cos (b x+c)|
$$

we may evaluate $I_{2}$ as

$$
\begin{aligned}
& I_{2}\left(t, \eta, v, \gamma_{\ell^{\prime}} x\right)=\frac{1}{\lambda^{2}+\eta \eta^{4} / 4}\left|e^{-\lambda R x}\left(\frac{\eta^{2}}{2} \cos \left(\gamma_{\rho}\right)-\lambda \sin \left(\gamma_{\rho}\right)-0^{-\lambda}\left(\frac{\eta^{2}}{2} \cos \left(v-\gamma_{\ell}\right)+\lambda \sin \left(v-\gamma_{\ell}\right)\right)\right)\right| . \\
& J_{1}\left(t, \eta, v, Y_{\ell}, X\right)=\int_{0}^{t} e^{-\lambda t} \cos \left(Y_{\rho}\right) U(t-R X) d \imath \\
& =0^{-\lambda R x} \int_{0}^{t-\lambda x} 0^{-\lambda t} \cos \left(y_{\ell}\right) d \imath=\frac{\cos \left(\gamma_{\rho}\right)}{\lambda}\left(0^{-\lambda R x}-e^{-\lambda t}\right) \\
& J_{2}\left(t, \eta, v, y_{\ell}, x\right)=\int_{0}^{t} e^{-\lambda t} \cos \left(v-y_{\ell}\right) U(t-R x) d \imath=e^{-\lambda R x} \int_{0}^{t-R x} e^{-\lambda t} \cos \left(\frac{\eta^{2}}{2} \imath-y_{\ell}\right) d t
\end{aligned}
$$

Recognizing the following integral (Abramowitz and Stegun, 1972)

$$
\int e^{a x} \cos (b x+c) d x=\frac{e^{a x}}{a^{2}+b^{2}}|a \cos (b x+c)+b \sin (b x+c)|
$$


wo muy ovaluato $J_{2}$ as

$$
J_{g}\left(l, \eta, v, \gamma_{p^{\prime}} x\right)=\frac{1}{\lambda^{2}+\eta^{4} / 4}\left|e^{-\cdots \lambda} x\left(\frac{\eta^{2}}{2} \sin \left(\gamma_{\rho}\right)+\lambda \cos \left(\gamma_{\rho}\right)\right)+0^{-\lambda(}\left(\frac{\eta^{2}}{2} \sin \left(v-\gamma_{\rho}\right)-\lambda \cos \left(v-\gamma_{p^{\prime}}\right)\right)\right|
$$

'l'he cumulutive mass flux is then given by

$$
\begin{aligned}
& M(l)=\left.\frac{2}{11} A^{0} \int_{0}^{\infty} \int_{0}^{\infty} \mu(x, 0) \frac{\operatorname{axp}\left(\beta_{r}\right)}{\eta}\right|_{x} \bar{F}_{1} \sum_{k=1}^{2} l_{k}\left(t, \eta, v, \gamma_{p^{\prime}} x\right)
\end{aligned}
$$

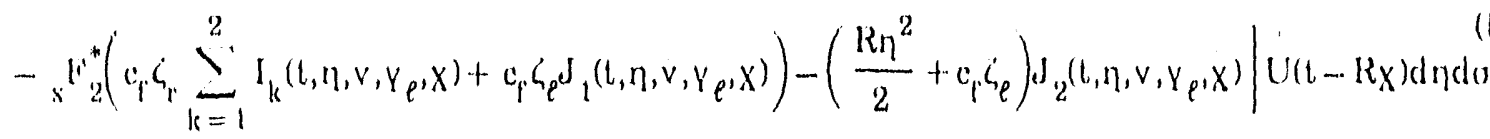

wheres ${ }_{1}$ and $\mathrm{F}_{2}{ }_{2}^{*}$ are given by lidquations 3-74a and 4-62. Detalls regarding the integration of Fiquations 5-9, 5-25, 5-29, and 5-38 may bo found in Appendix 13 .

\subsection{NOI,()NGITUDINAL DISPERSION}

With the stroumlines assumed normal to the source (i.e, $v=0$ ) and neglocting the longitudinal dispersion offects (i.e., D $)_{x x}=D_{x y}=0$ ), Equation $5-1$ is still satisfied. In this case, the solutions in the fracture and the rock matrix aro given by liquations 5-9 and 5-25 after implementing the rolation given by liquation 3.50 to yield

$$
\begin{aligned}
& A(x, y, t)=\frac{2}{n} A^{0} e^{-\lambda t} E_{\Omega} \int_{0}^{\infty} \frac{\exp \left(\beta_{r}^{\prime}\right)}{\eta}\left[\sin \left(\gamma_{\rho}^{\prime}\right)+\sin \left(v^{\prime}-\gamma_{\rho}^{\prime}\right) \mid U\left(t-R x^{\prime}\right) d \eta\right. \\
& B(x, y, z, t)=\frac{1}{2 n} A^{\prime \prime} e^{-\lambda t_{2}} \int_{0}^{\infty} \sum_{m=1}^{2} \sum_{n=1}^{2} \frac{\exp \left(\bar{\beta}_{r}^{\prime}\right)}{\delta_{1} \eta}\left[\sin \left(\bar{y}_{\rho}^{\prime}\right)+\sin \left(v^{\prime}-\bar{y}_{e}^{\prime}\right)\right] U\left(t-R x^{\prime}\right) d \eta
\end{aligned}
$$

where

$$
\begin{gathered}
\varepsilon^{\prime}=c_{f} x^{\prime}=c_{f} \frac{x}{u} \\
y_{\rho}^{\prime}=y_{\rho}\left(\varepsilon^{\prime}\right)
\end{gathered}
$$




$$
\begin{gathered}
v^{\prime}=v\left(x^{\prime}\right)=\frac{\eta^{2}}{2}\left(t-R x^{\prime}\right)=\frac{\eta^{2}}{2}\left(t-k \frac{x}{4}\right) \\
\beta_{r}^{\prime}=\beta_{r}\left(z^{\prime}\right) \\
\bar{\beta}_{r}^{\prime}=\ddot{\beta}_{r}\left(\varepsilon^{\prime}\right)
\end{gathered}
$$

and $\delta_{1}$ is givon by Equation 5-21.

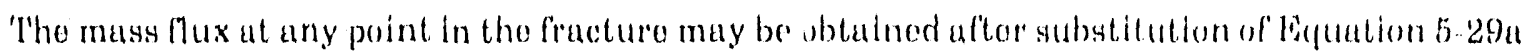
(with $\mathrm{F}_{2}^{*}=0$ ) and Equation 5-29b into Lequation 3-70b to yiold

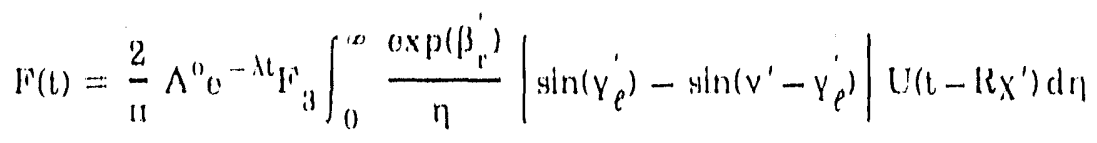

whore $\mathrm{F}_{3}$ is givon by Equation 3-88.

Similarly the cumulative mass flux is obtained aftor substitution of fifgution 5-42 into Equation 4-63 and writton as

$$
M(t)={ }_{11}^{2} \Lambda^{0} F_{3}^{\prime} \int_{0}^{\infty} \frac{\exp \left(\beta_{r^{\prime}}^{\prime}\right)}{\eta} \sum_{k=1}^{2} I_{k}\left(t, \eta, v^{\prime}, Y_{e^{\prime}}^{\prime} X^{\prime}\right) U\left(t-R x^{\prime}\right) d \eta
$$




\subsection{DISCUSSION AND RESULI'S FOR MULTIPLE PARALLEL F'RAC'IURE CASE WITH FINITE DIFFUSION}

The solutions for the multiple parallel fracture case using serles and the contour integration presented in Chapters 4 and 5 were veriffed by comparing their individual performance against onch other. The reported test cases included one- and two-dimensional simulations of the general form of the mass transport equation, as well as to the longitudinal dispersion-free form. 'I'wo types of radionuclide release modes were considered, step and band.

\subsection{DISCUSSION OF CASE 5: SPATIAL VARIATION OF CONCENTRATION OF Np-237}

This test case deals with the migration of $\mathrm{Np}-237$ in a one-dimensional flow domain, where the concentration at the source is subjected to a step and a bancl release mode. 'To this offoct, the llow field is assumed unidimensional ( $1, \theta, v=0, D_{y y}=D_{y x}=0$ ). The concentration at the source was simulated by means of a plane source of infinite width, whereas the parallel set of fractures with an aperture of $0.005 \mathrm{~m}$ were assumed to be $20 \mathrm{~m}$ apart. The input data for this test case are presented in Table 6-1. Results reported for Cases $5 \mathrm{~A}$ and $5 \mathrm{~B}$ are obtained through the longitudinal dispersion-froe form of the general solution. Note that in the case of the rock matrix, results were obtained for a point in space located $100 \mathrm{~m}$ downstream from the source. It may be added that the Fourier numbers encountered in these simulations ranged between approximately 0.01 and 1.0 .

\subsubsection{Results for Case 5A: Step Release Mode}

Figures 6-1a, 6-1b, 6-1c, and 6-1d show a comparison of the relative concentration, mass flux, and cumulative mass flux in the fracture and tho rock matrix for several points in time (i.e., $t=104$, $6 \times 10^{4}, 2 \times 10^{5}$, and $10^{6}$ years). Results reported in Tables 6-2a through 6-2e indicate that the two solution methods reported in Chapters 4 and 5 yield identical results, with the exception of points located close to the source, where the contour integration solution in the case of the fracture seems to display a poor converging characteristic, particularly with increasing times. Upon examination of the values of the dimensionless number $e / 2 \sqrt{t-R_{X}}$ at those points which exhibit these undesirable foatures, it was noted these were in all cases less than or equal to 0.1 . This supports the independent investigations reported also in Appendix B. As indicated in Appendix B, the solution donotes slow convergence properties in this critical region of the flow domain. Note that in the case of the rock matrix, the concentration profile corresponding to $t=10^{4}$ years is identical to one which might have been obtained using the single fracture solution, since in this instance the F'ourier number is atrout 0.01 with $P_{0}=0.01$, which satisfies the criterion proposed in Equation 4-98. 
Table 6-1. Input Parumotors for Caso 5

\begin{tabular}{|c|c|}
\hline Species & $N(1)-237$ \\
\hline $\begin{array}{l}\text { Initial Concentration } A^{\prime \prime} \\
\text { (arbitrary unit of activity/L,i) }\end{array}$ & 1 \\
\hline 'T'ype of' Rolouse Modo & $\begin{array}{l}\text { Case 5A: Stop } \\
\text { Case 5B: Band }\end{array}$ \\
\hline Boundary Condilton & Infinite Plane Sourco \\
\hline$x$ & $100.0 \mathrm{~m}$ (Case 5B) \\
\hline y & $0.0 \mathrm{~m}$ \\
\hline$d$ & $\infty$ \\
\hline$u$ & $10.0 \mathrm{~m} / \mathrm{yr}$ \\
\hline$v$ & $0.0 \mathrm{~m} / \mathrm{yr}$ \\
\hline$D_{x x}$ & $0.0 \mathrm{~m}^{2} / \mathrm{yr}$ \\
\hline $\mathrm{D}_{y y}$ & $0.0 \mathrm{~m}^{2} / \mathrm{yr}$ \\
\hline$D_{y x}$ & $0.0 \mathrm{~m}^{2}: \mathrm{yr}$ \\
\hline$D_{p}$ & $0.01 \mathrm{~m}^{2} / \mathrm{yr}$ \\
\hline L & $10.0 \mathrm{~m}$ \\
\hline $\mathrm{T}_{1 / 2}$ & $2.14 \times 10^{6} \mathrm{yr}$ \\
\hline $\mathrm{T}_{\mathrm{L}}$ & $3 \times 10^{4} \mathrm{yr}$ \\
\hline b & $0.005 \mathrm{~m}$ \\
\hline$\phi$ & $10^{\cdot 2}$ \\
\hline R & 1 \\
\hline$R^{\prime}$ & 100 \\
\hline
\end{tabular}



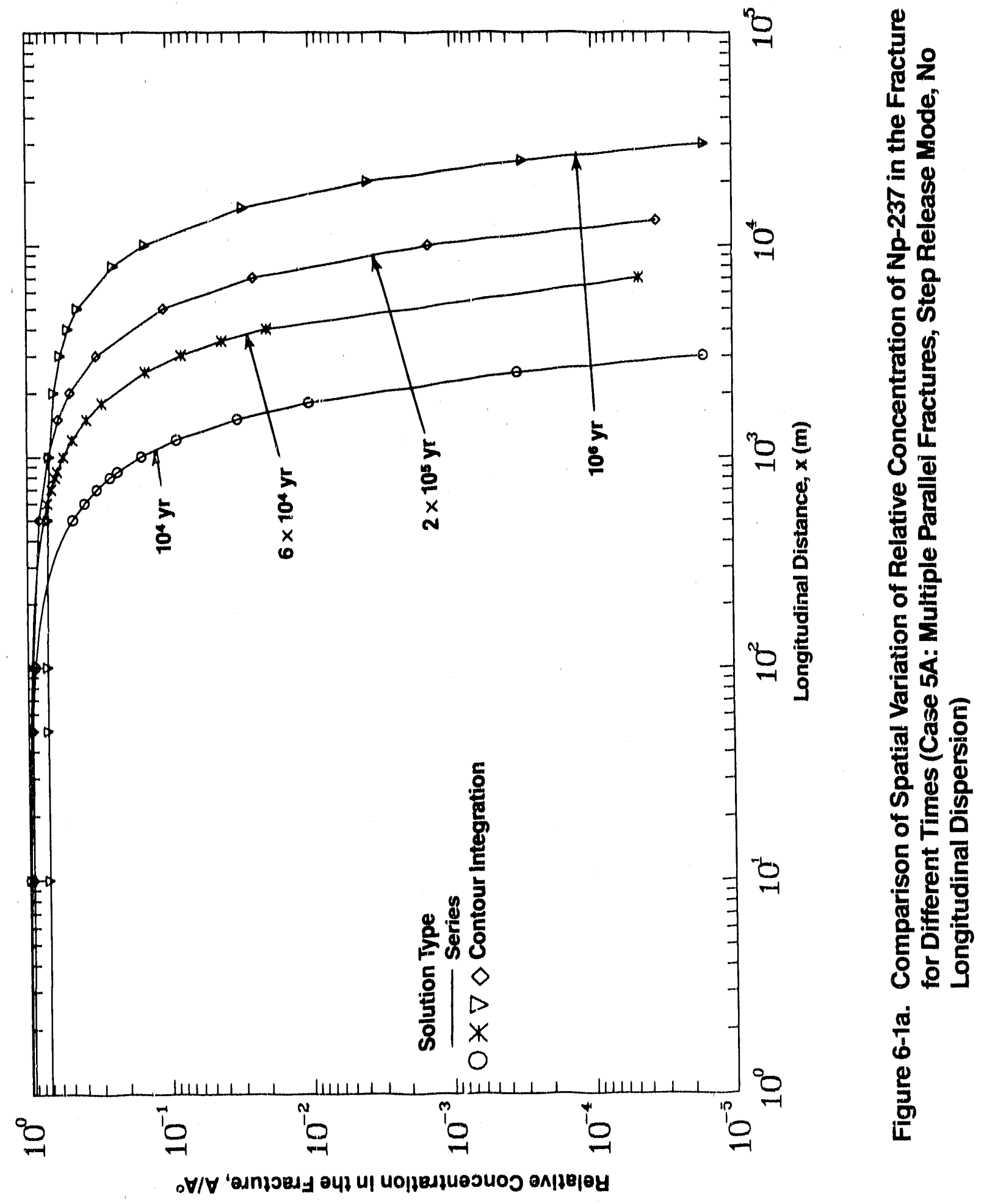


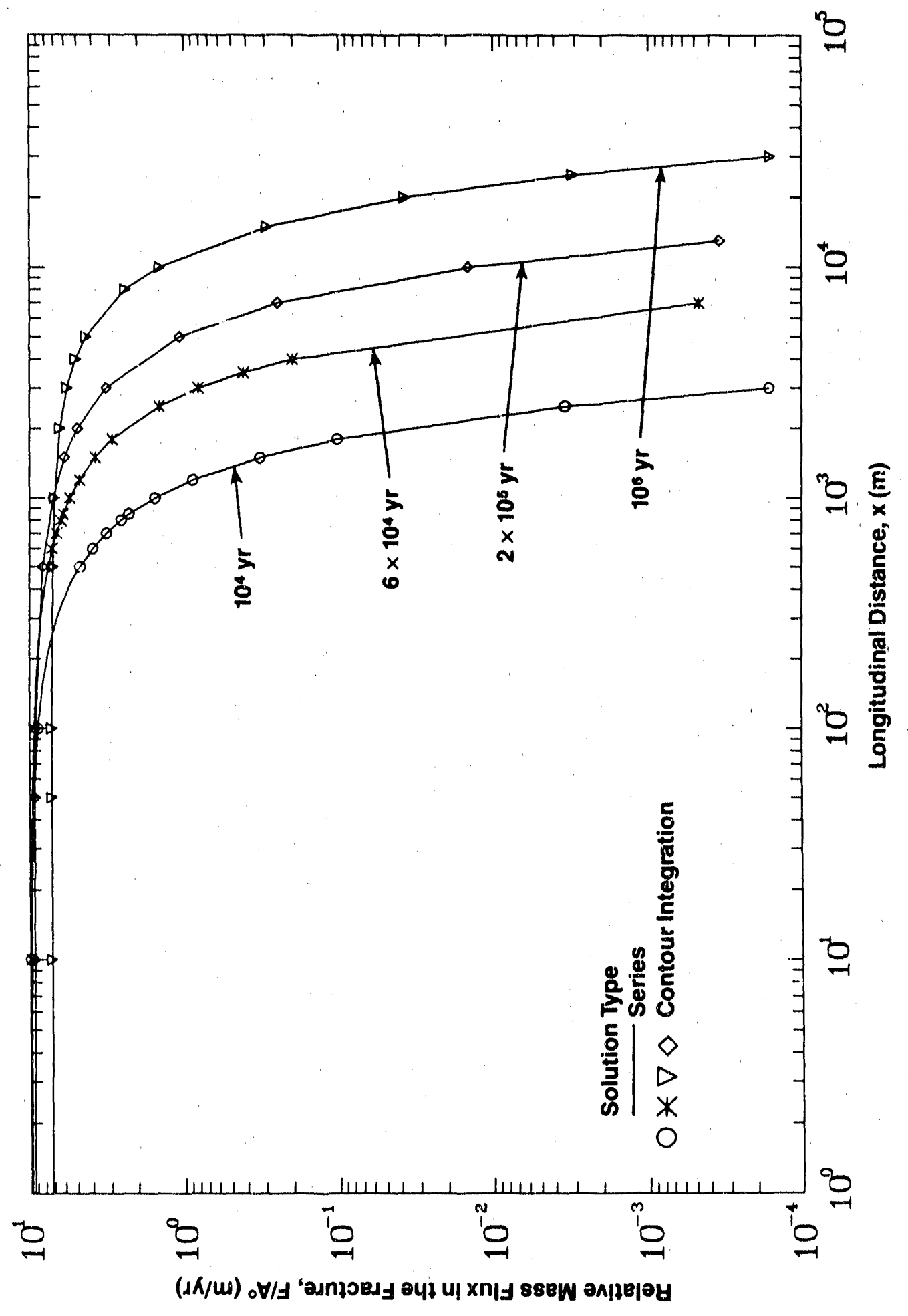

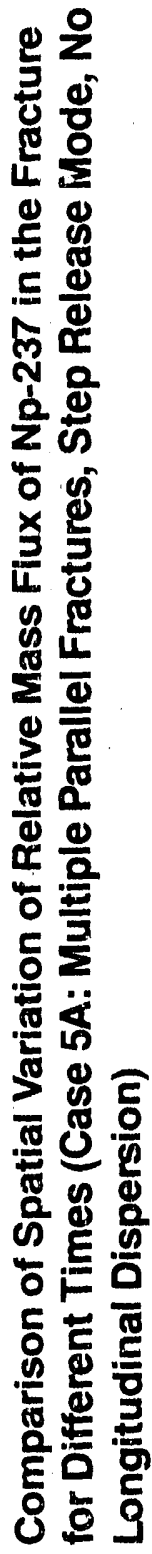

อ̊

옥 


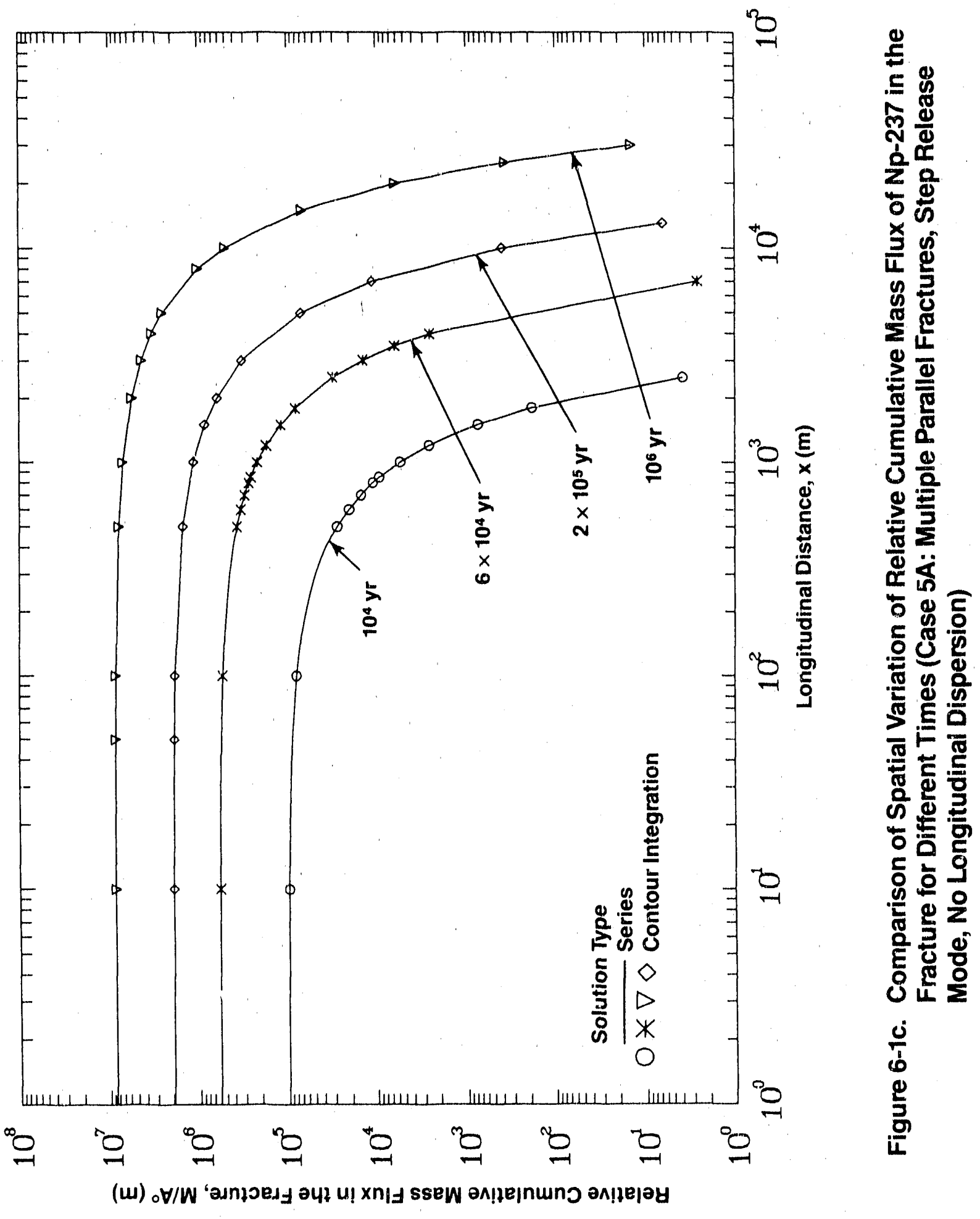




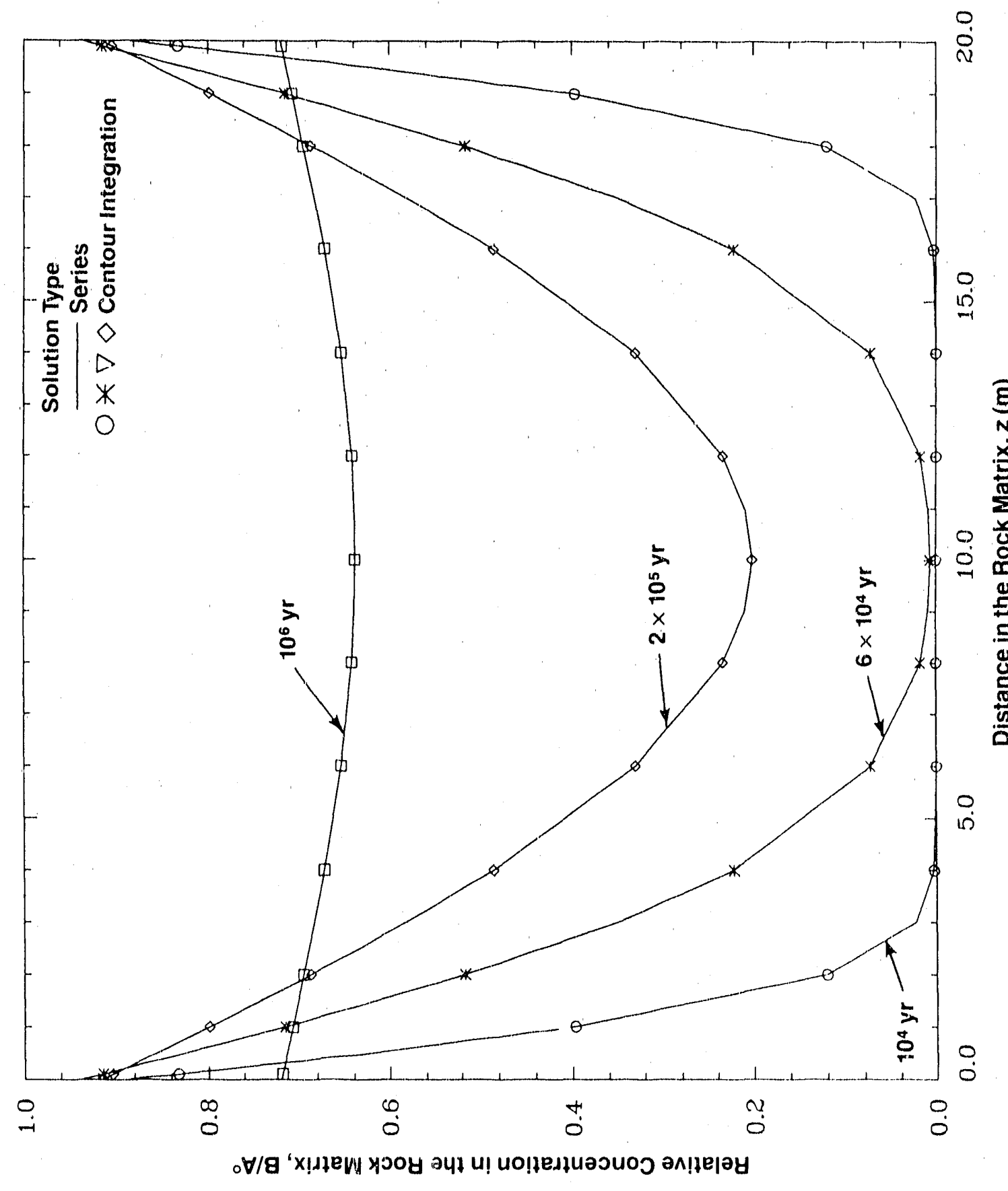

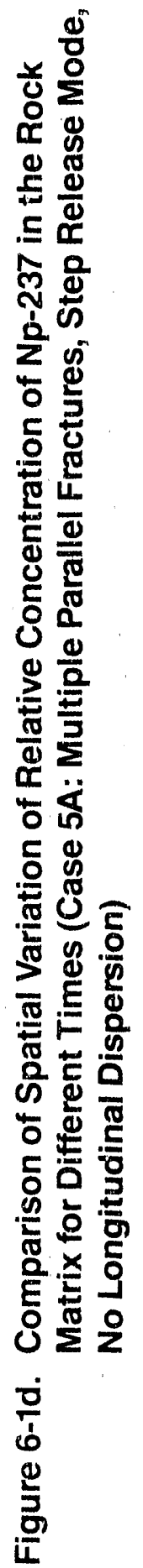




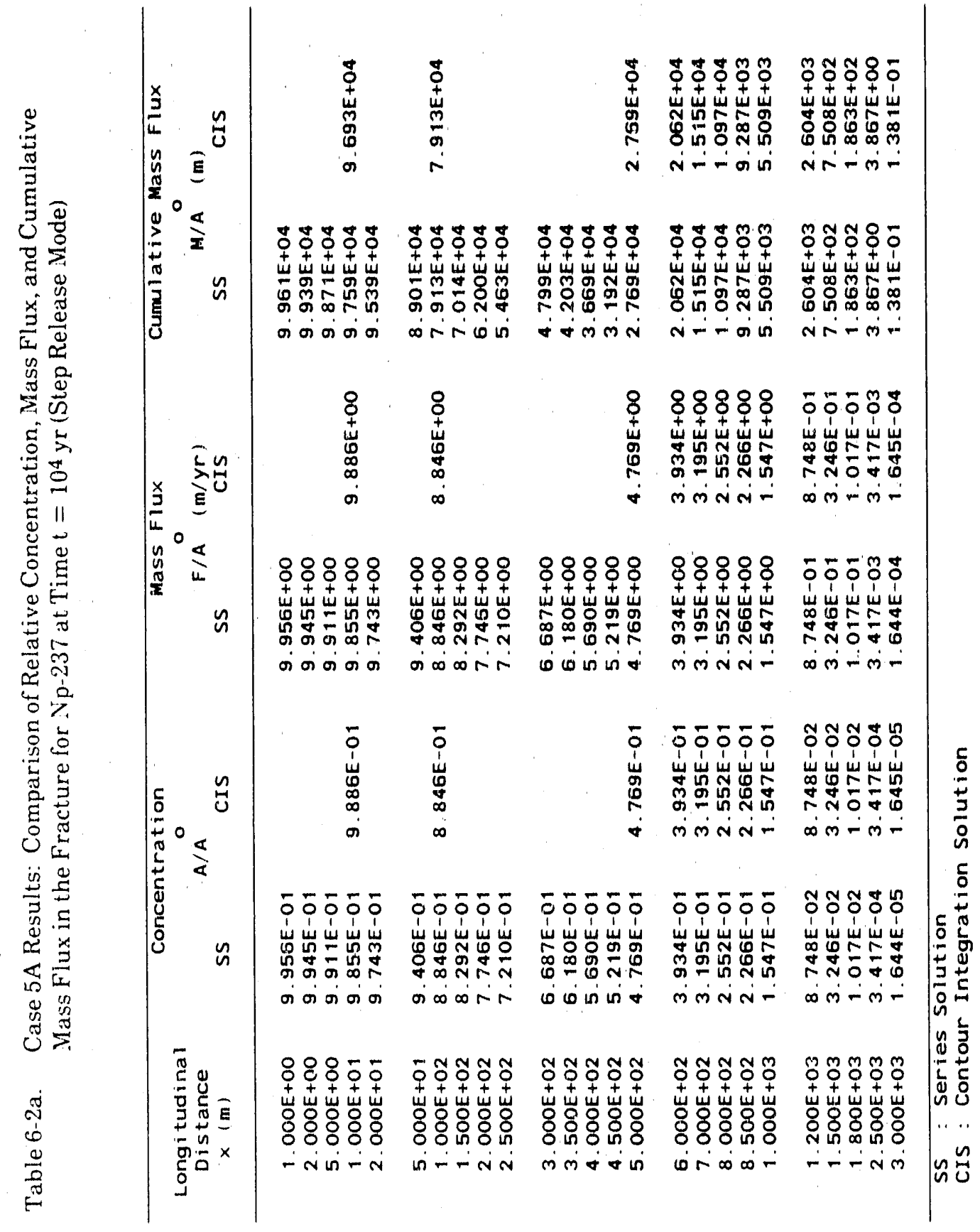




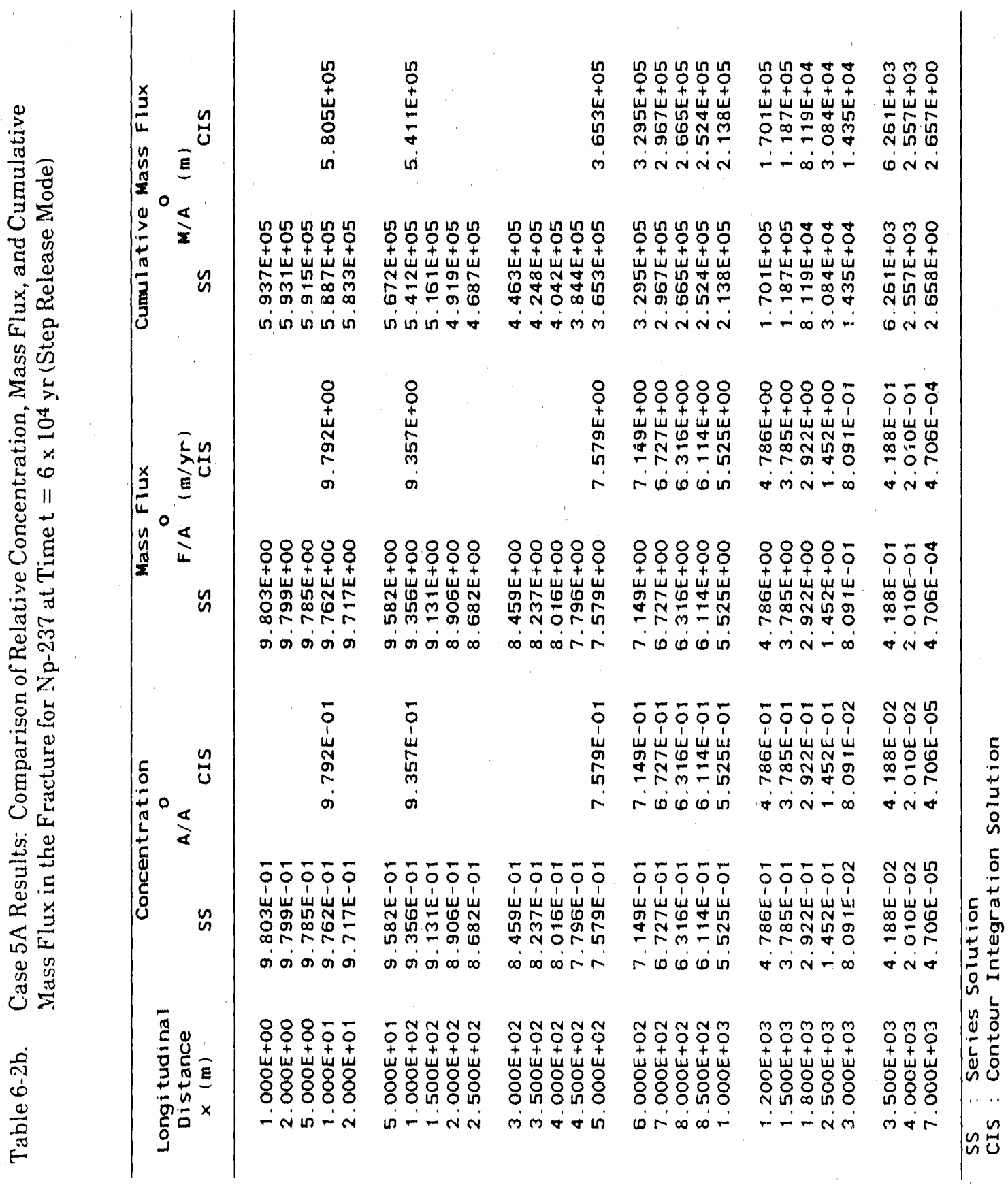




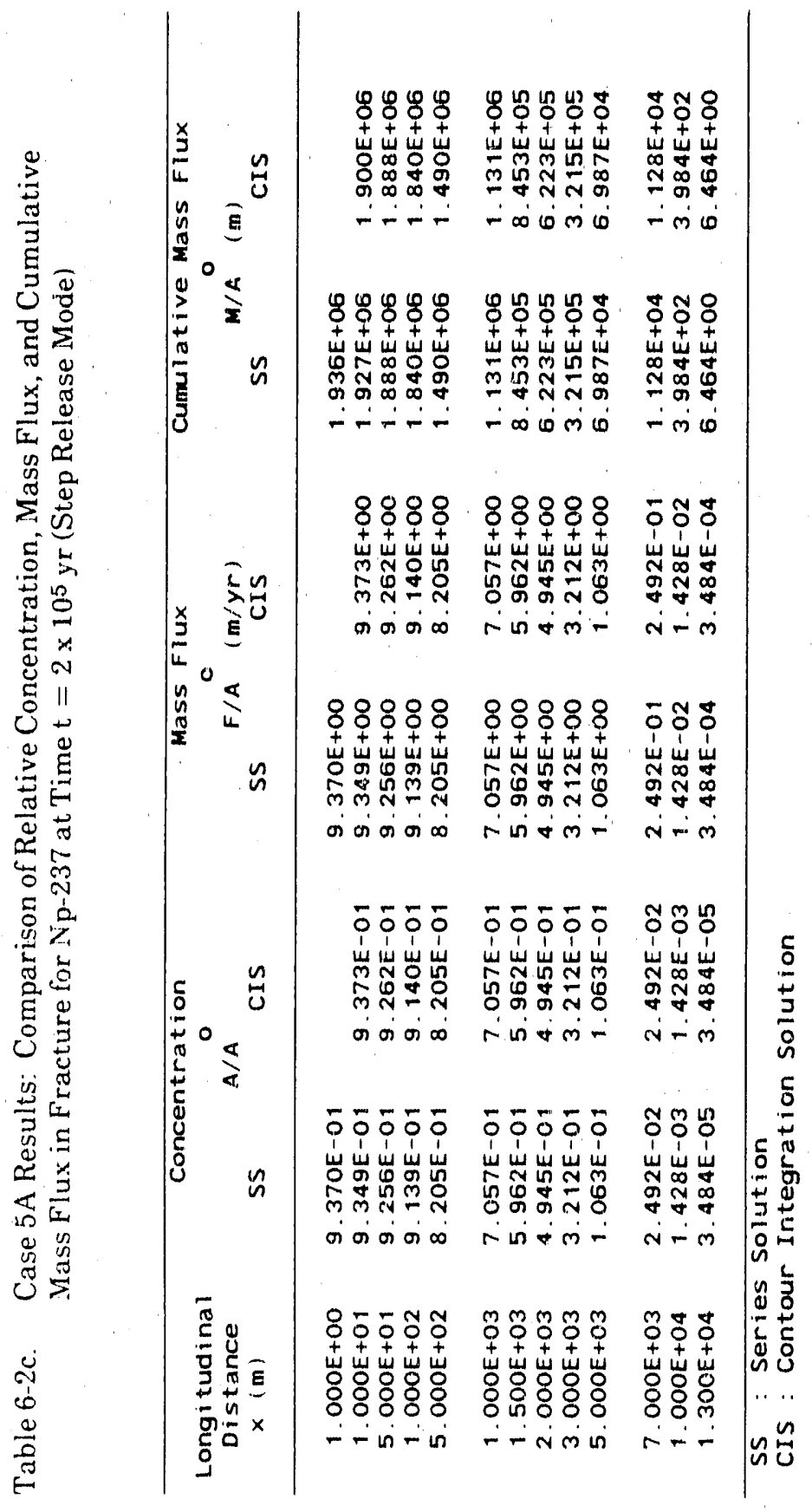




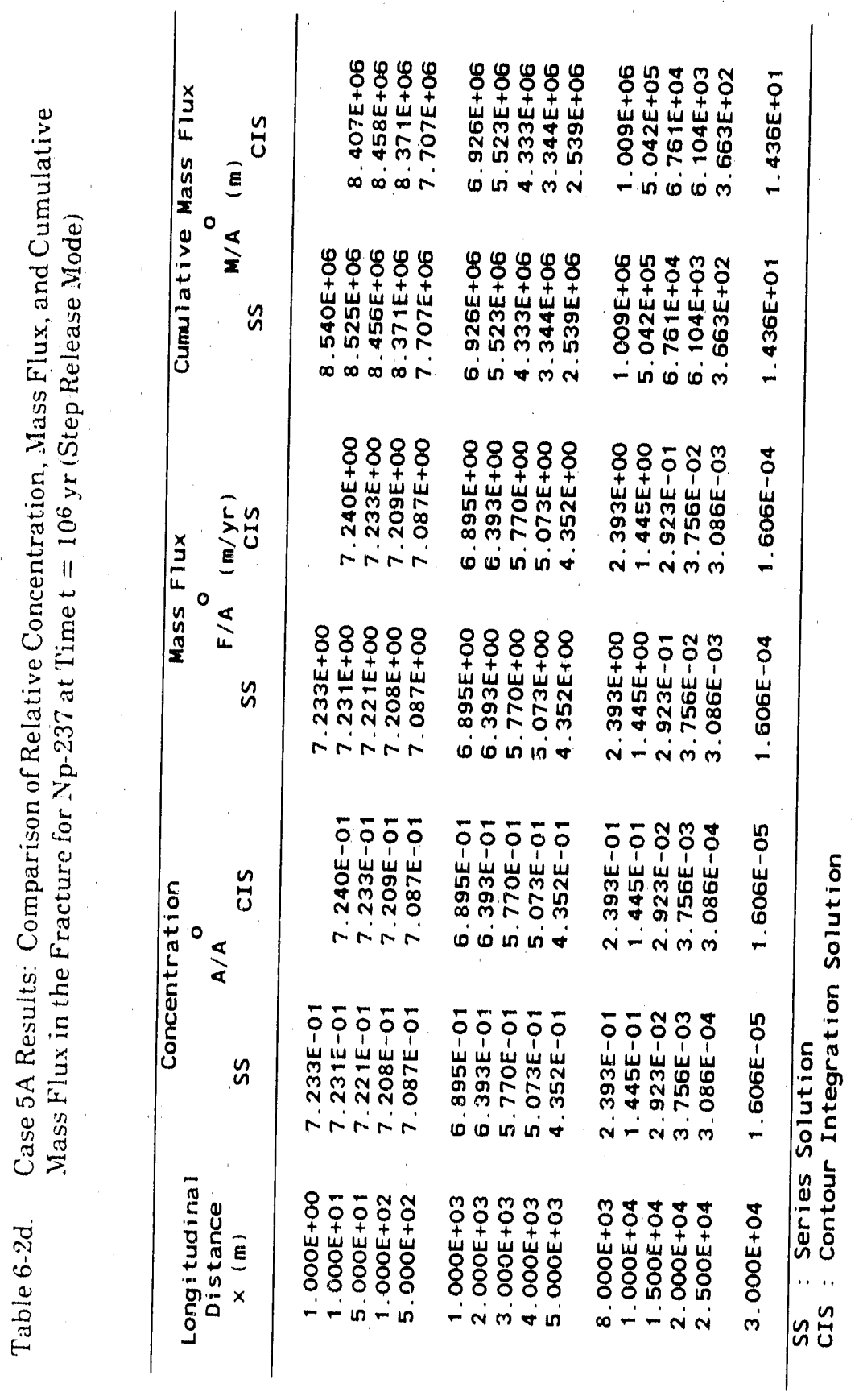




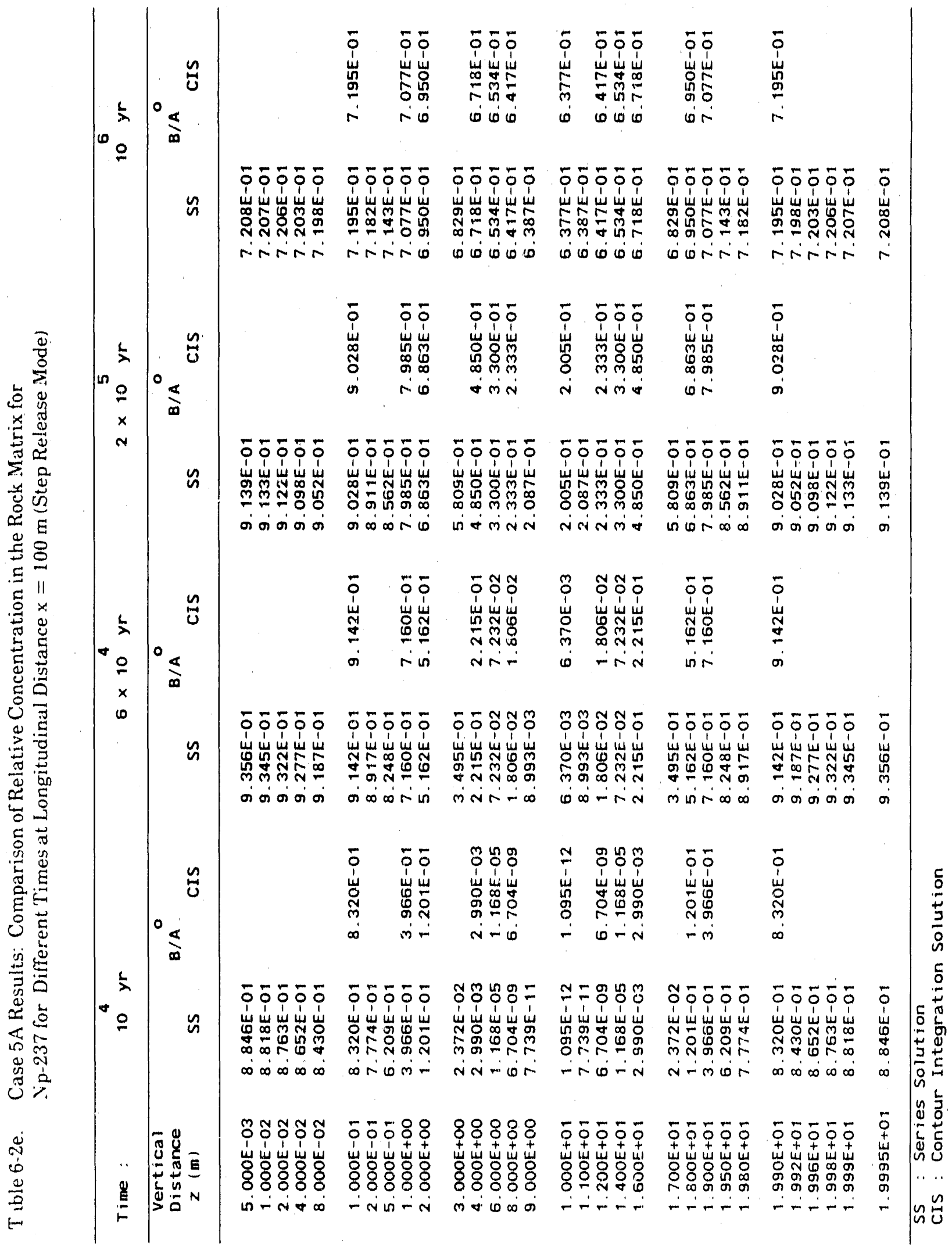




\subsubsection{Resulta for Case 5B: Band Rolouso Mode}

I'igures 6-2a, 6-2b, 6-2c, and 6-2d show tho relative concentration, mass flux, and cumulativo mass flux in the fracture and the rock matrix for several points in time $\left(1.0 ., t=10^{4}, 6 \times 10^{4}, 2 \times 10^{5}\right.$, and $10^{6}$ years). Rosults reported in Tablos 6-3a through 6.3d suggest similar conclusions as an the former case.

\subsection{DISCUSSION OF CASE 6: 'TEMPORAL VARIA'TION OF CONCEN'TRATION OF' NP-237, INI'LUENCE (OF' LONGI'TUDINAL DISPERSION}

This test case deals with the time-dopendent migration of $\mathrm{Np}-237$ in a one-dimensional flow domain, where longitudinal dispersion effects are considered and the concentration at the source is subjected to a step and band release mode. The observation point where the break through curves ure monitored is located at a distance of $500 \mathrm{~m}$ down gradient. The input data reported in Table 6.4 are essentially similar to those of Case 5 , except for the fracture spacing, which in this instance is assigned a value of $0.6 \mathrm{~m}$; i.: addition, three values for $D_{x}$ corresponding to 10,100 , and $1000 \mathrm{~m}^{2} / \mathrm{yr}$ were used with the main intent of verifying the two solution methods pertaining to the general form of the transport equation.

The Fourier numbers encountered in theso simulations ranged approximately between 0.1 and 23 , whereas the Peclet number $P e$ in the fracture (i.e., $P e=u L / D_{x}$, where $L=500 \mathrm{~m}$ ) ranged between 5 and $\infty$. Figures $6-3$ a through $6-3 \mathrm{~d}$ present a comparison of the relative concentration, mass flux, cumulative mass flux in the fracture, and the concentration at a distance $z=0.3 \mathrm{~m}$ in the rock matrix for the step release mode; Figures 6-4a through 6-4d show corresponding plots for the band release mode. Results reported in Tables 6-5 and 6-6 show excellent agreement between the two solutions, except for very small times whero the slight discrepancy displayed by the contour integration solution secms to be virtually eliminated with increasing values of the longitudinal dispersion. 'The impact of this parameter on the solution is reflected in the value of $X$, the magnitude of which is inversely proportional to $\mathrm{D}_{\mathrm{x}}$; hence, for a given time $t$ and position $\mathrm{x}$ the smaller $\mathrm{x}$, the higher the value of the Fourier number fo. Results also indicate that the influence of the longitudinal dispersion effects become important for values of this parameter greater than $10 \mathrm{~m}^{2} / \mathrm{yr}$ throughout the leaching period, beyond which the dispersive effects become less accentuated except for the case of the largest selected hypothetical value of $1000 \mathrm{~m}^{2} / \mathrm{yr}$. Note that in all cases reported for the rock matrix, the new contour integration based solution dorived in Chapter 5 displayed a high degree of accuracy and acceptable convergence propertios. 

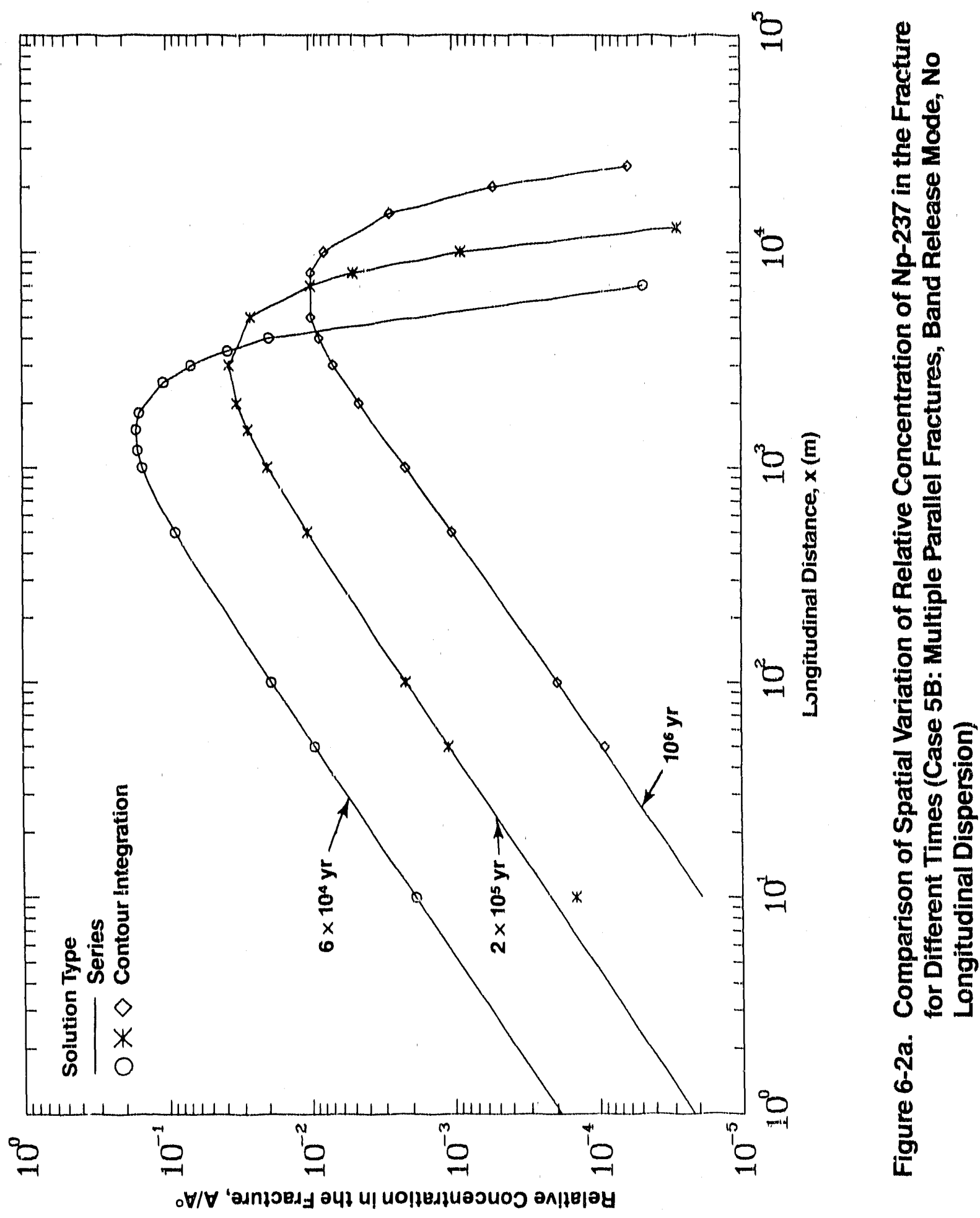

ญั่ 


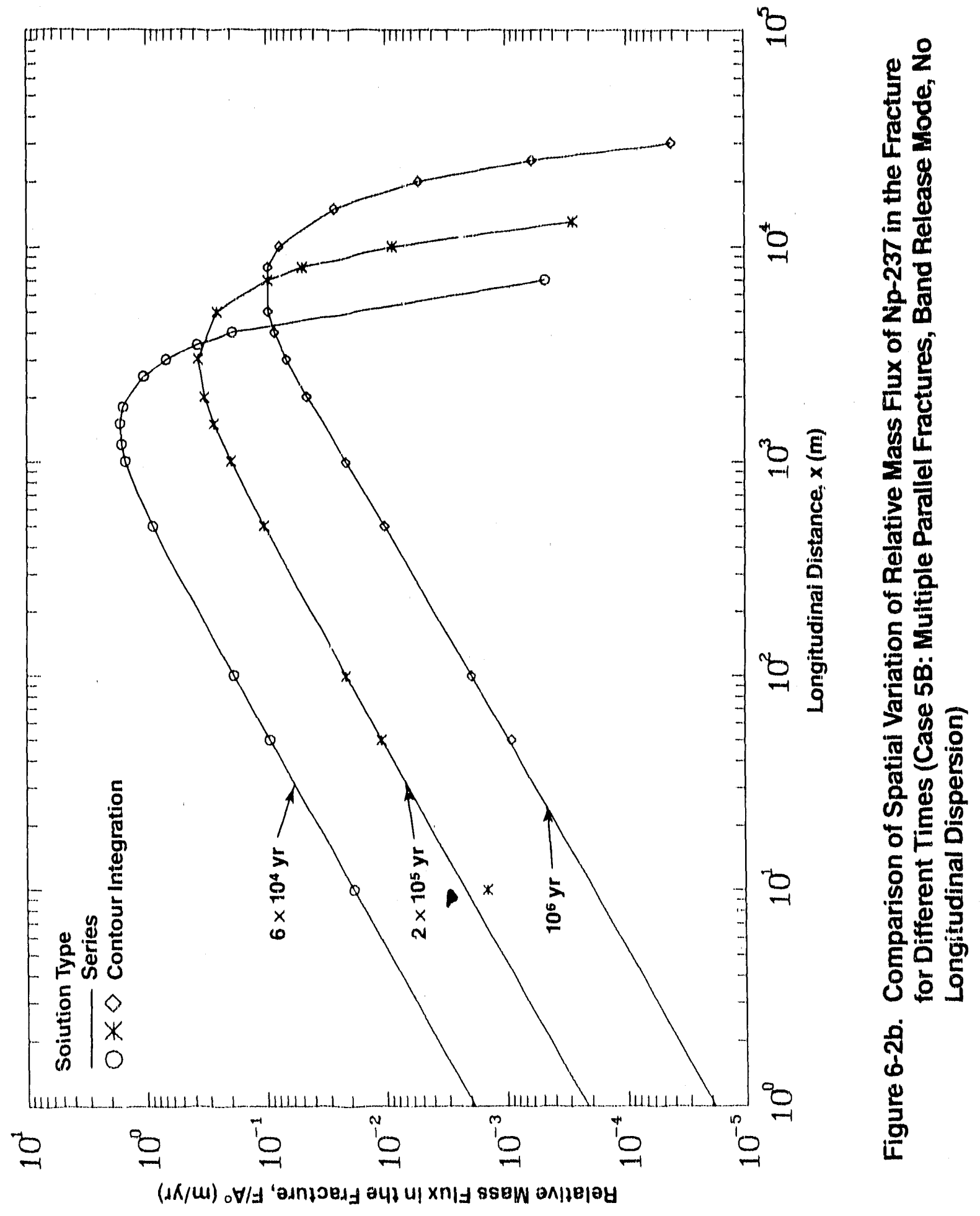




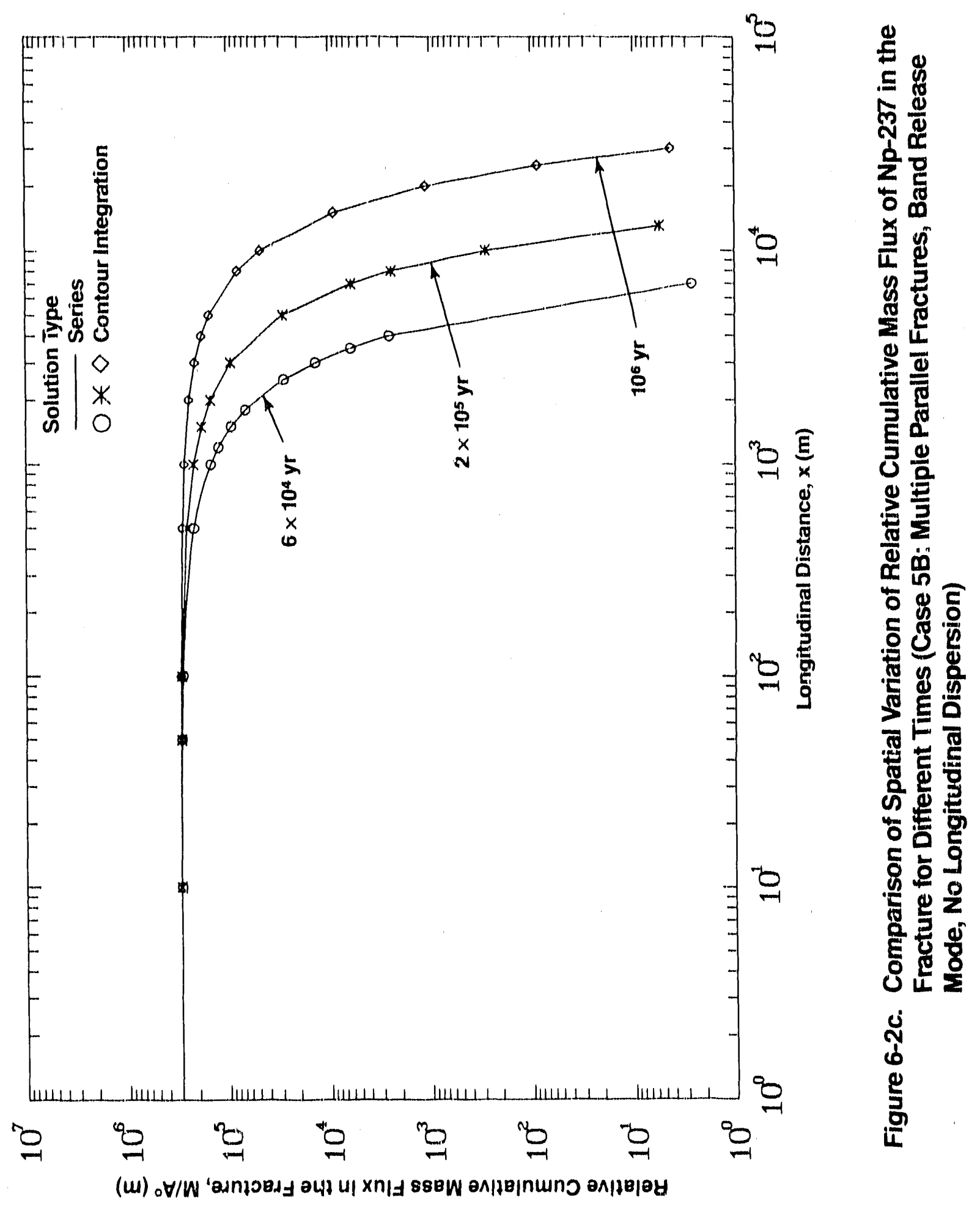




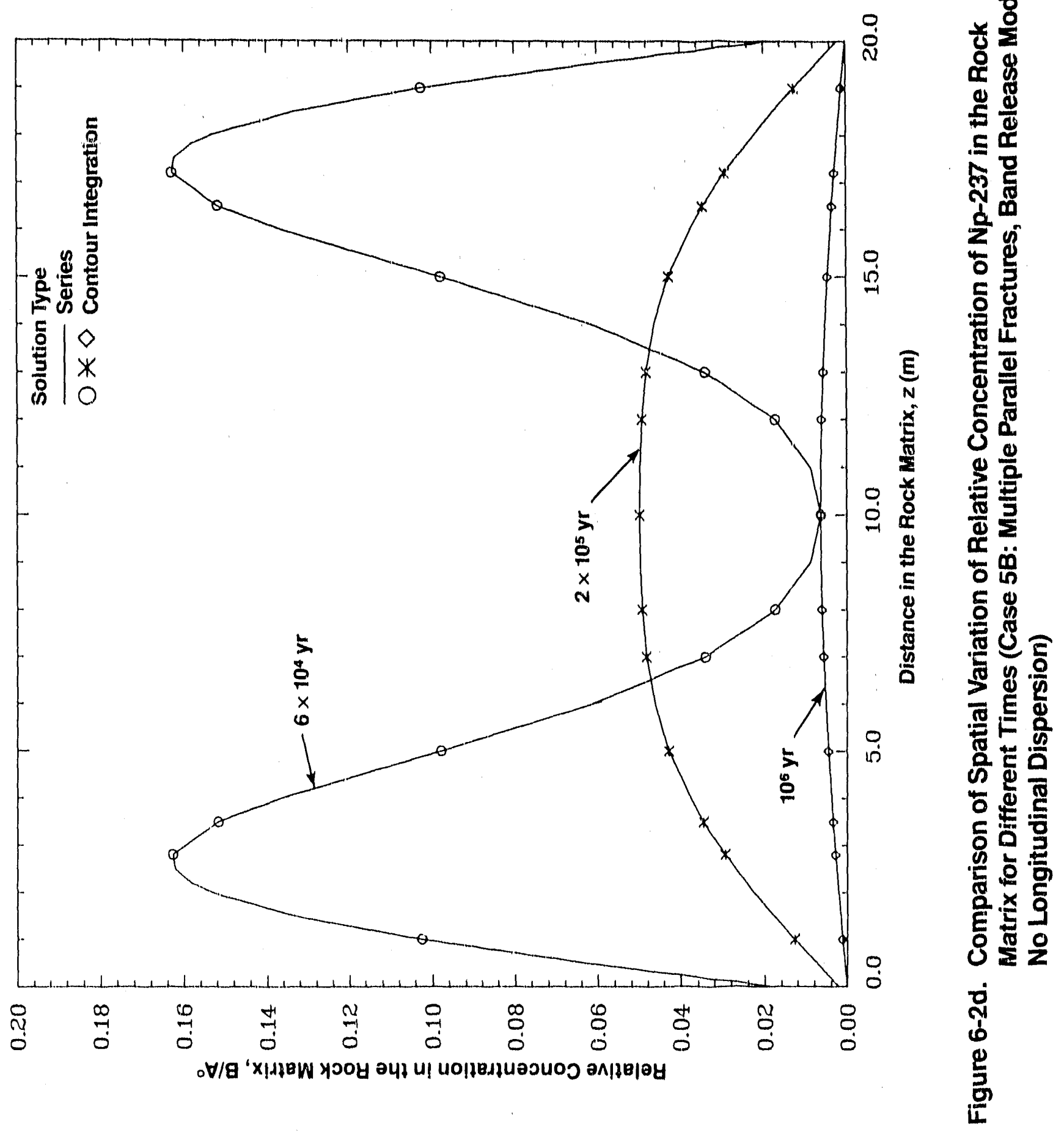




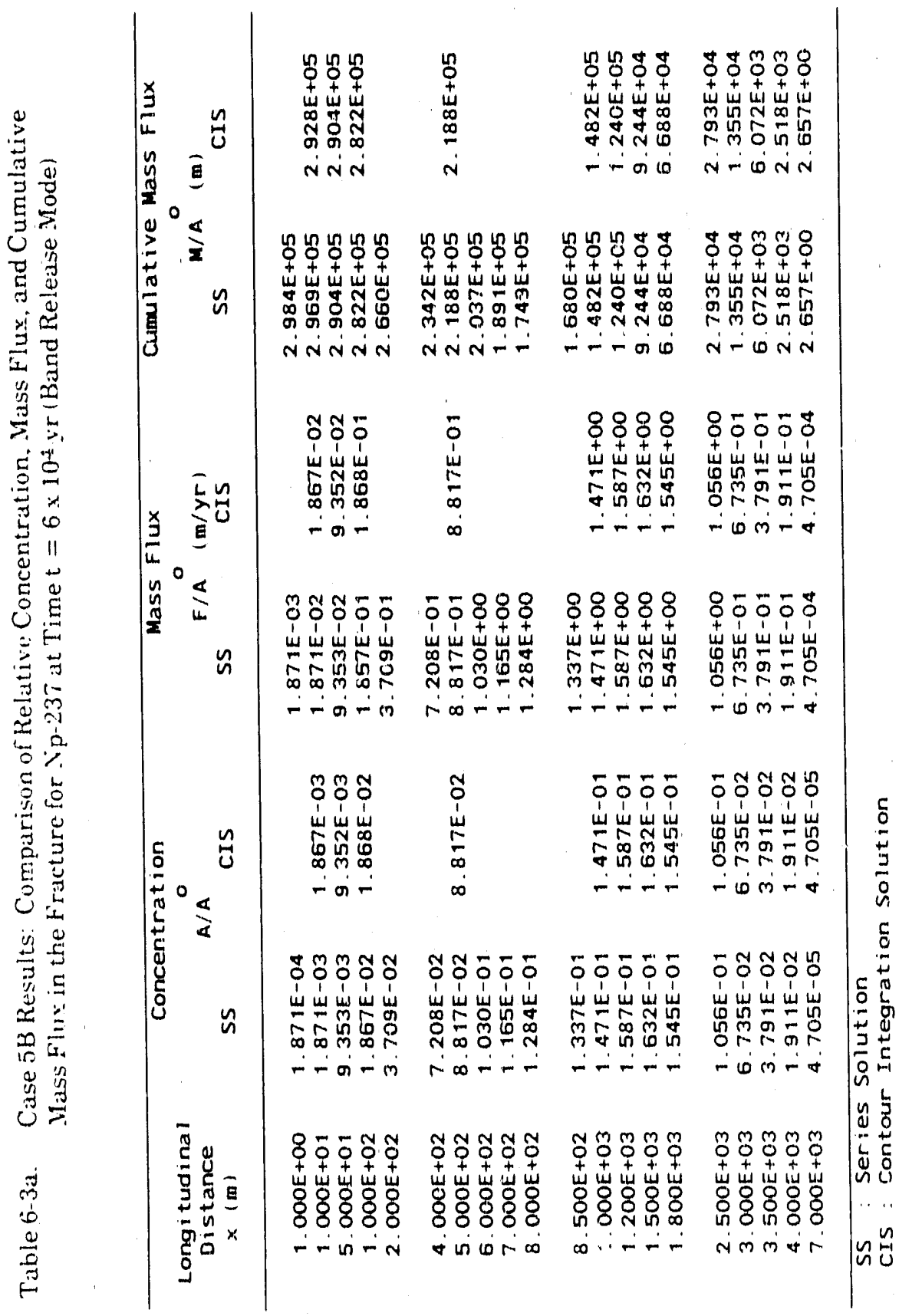




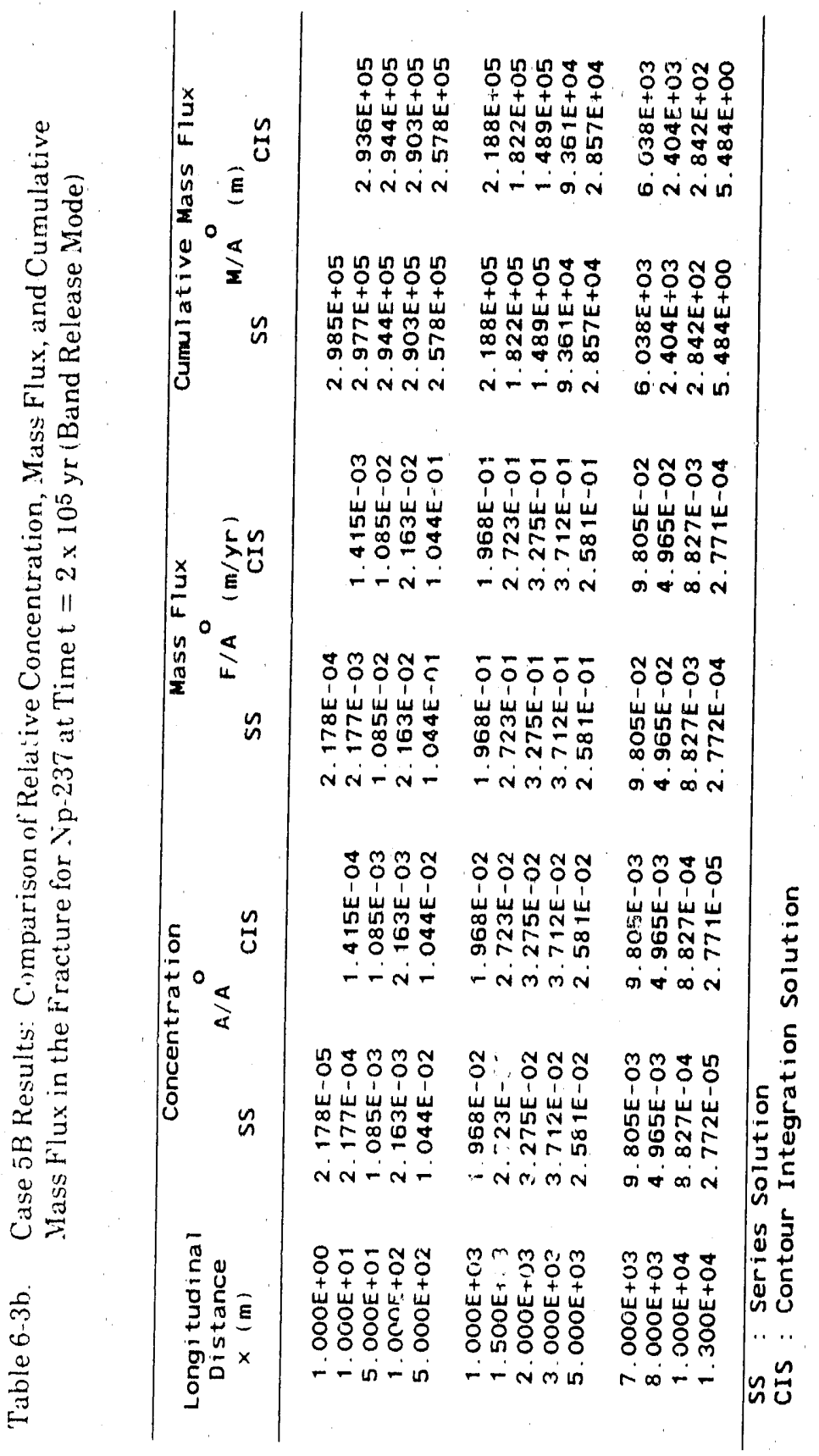




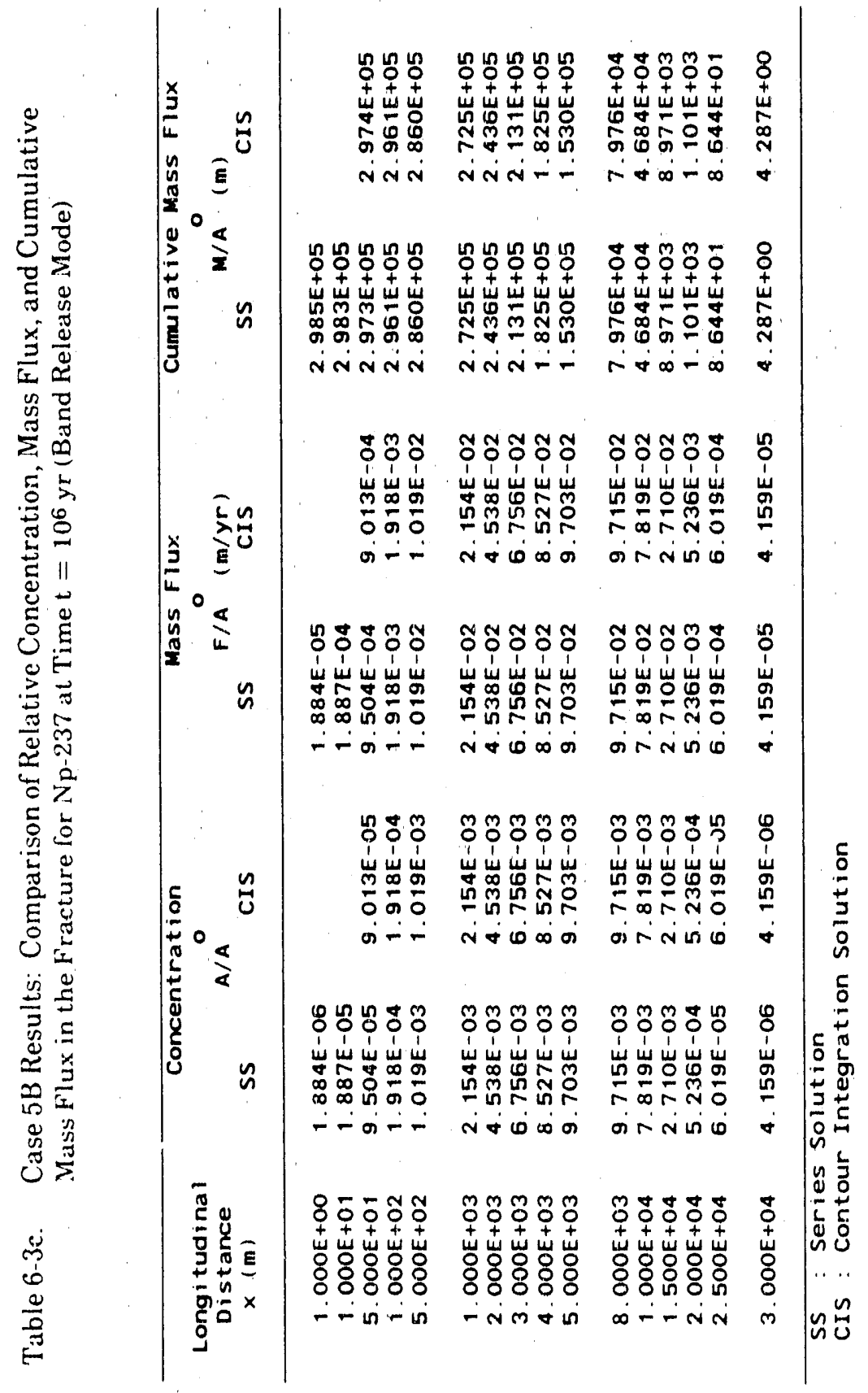




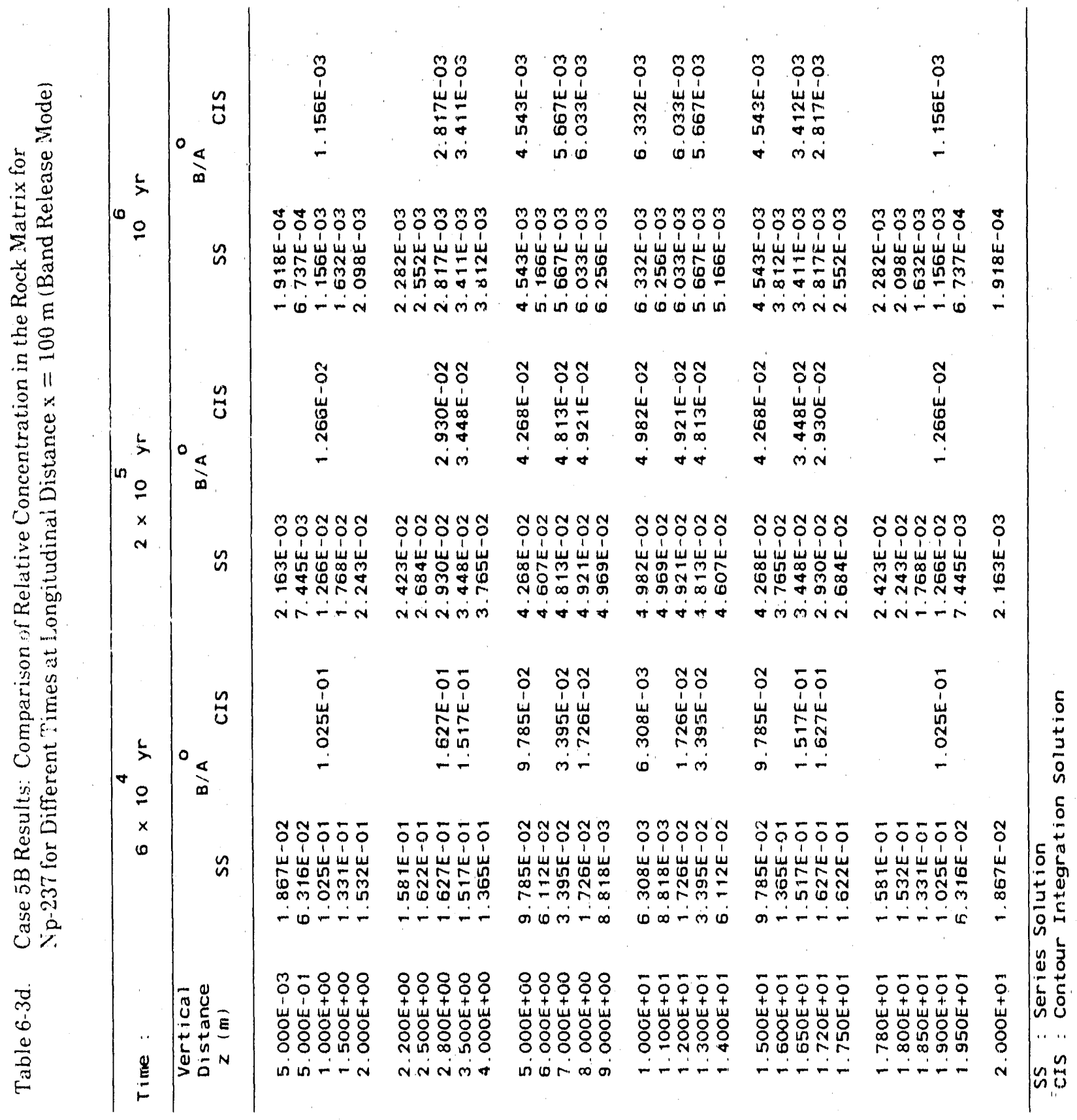


Table 6-4. Input Parameters for Case 6

\begin{tabular}{|c|c|}
\hline Species & $\mathrm{Np}-237$ \\
\hline $\begin{array}{l}\text { Initial Concentration } \mathrm{A}^{0} \\
\text { (arbitrary unit of activity/L } 3 \text { ) }\end{array}$ & 1 \\
\hline Type of Release Mode & $\begin{array}{l}\text { Case 6A: Step } \\
\text { Case 6B: Band }\end{array}$ \\
\hline Boundary Condition & Infinite Plane Source \\
\hline $\mathrm{x}$ & $500.0 \mathrm{~m}$ \\
\hline y & $0.0 \mathrm{~m}$ \\
\hline $\mathrm{z}$ & $0.3 \mathrm{~m}$ \\
\hline d. & $\infty$ \\
\hline u & $10.0 \mathrm{~m} / \mathrm{yr}$ \\
\hline$v$ & $0.0 \mathrm{~m} / \mathrm{yr}$ \\
\hline$D_{x x}$ & $0,10,100,1000 \mathrm{~m}^{2} / \mathrm{yr}$ \\
\hline $\mathrm{D}_{\mathrm{yy}}$ & $0.0 \mathrm{~m}^{2} / \mathrm{yr}$ \\
\hline$D_{y x}$ & $0.0 \mathrm{~m}^{2} / \mathrm{yr}$ \\
\hline $\mathrm{D}_{\mathrm{p}}$ & $0.01 \mathrm{~m}^{2} / \mathrm{yr}$ \\
\hline I & $0.3 \mathrm{~m}$ \\
\hline $\mathrm{T}_{1 / 2}$ & $2.14 \times 10^{6} \mathrm{yr}$ \\
\hline $\mathrm{T}_{\mathrm{L}}$ & $1 \times 10^{4} \mathrm{yr}$ \\
\hline b & $0.005 \mathrm{~m}$ \\
\hline$\phi$ & $10^{-2}$ \\
\hline $\mathrm{R}$ & 1 \\
\hline $\mathrm{R}^{\prime}$ & 100 \\
\hline
\end{tabular}



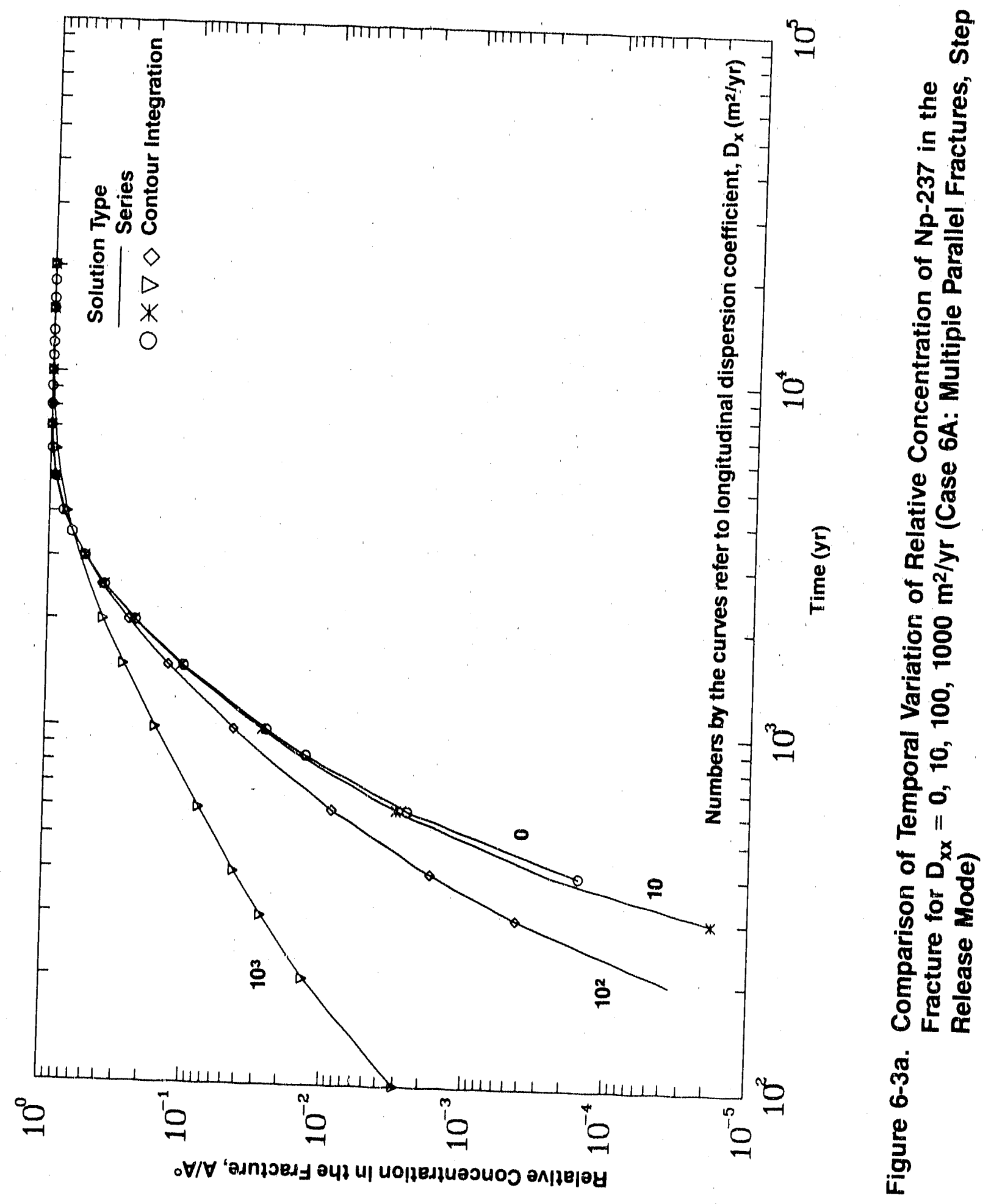

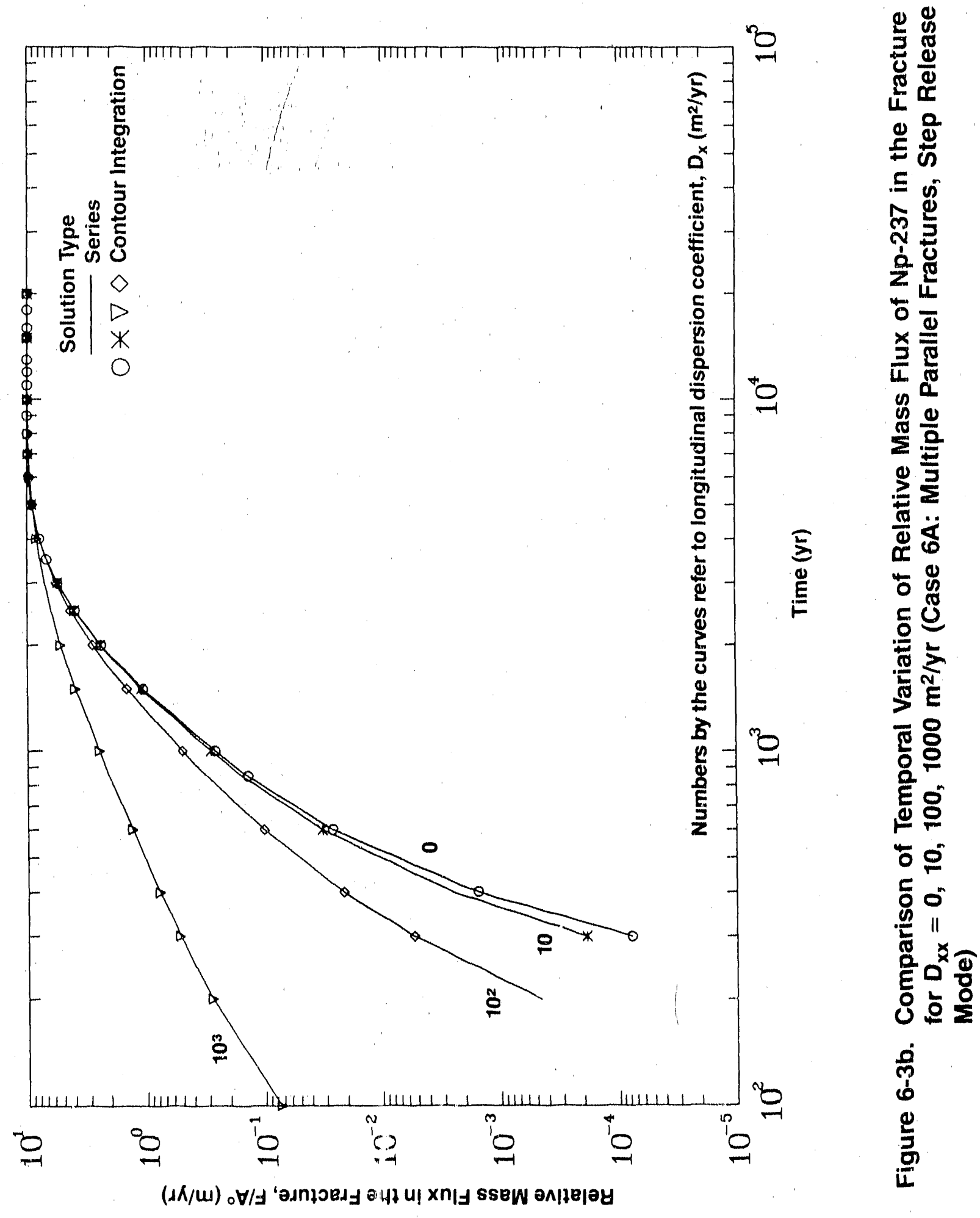


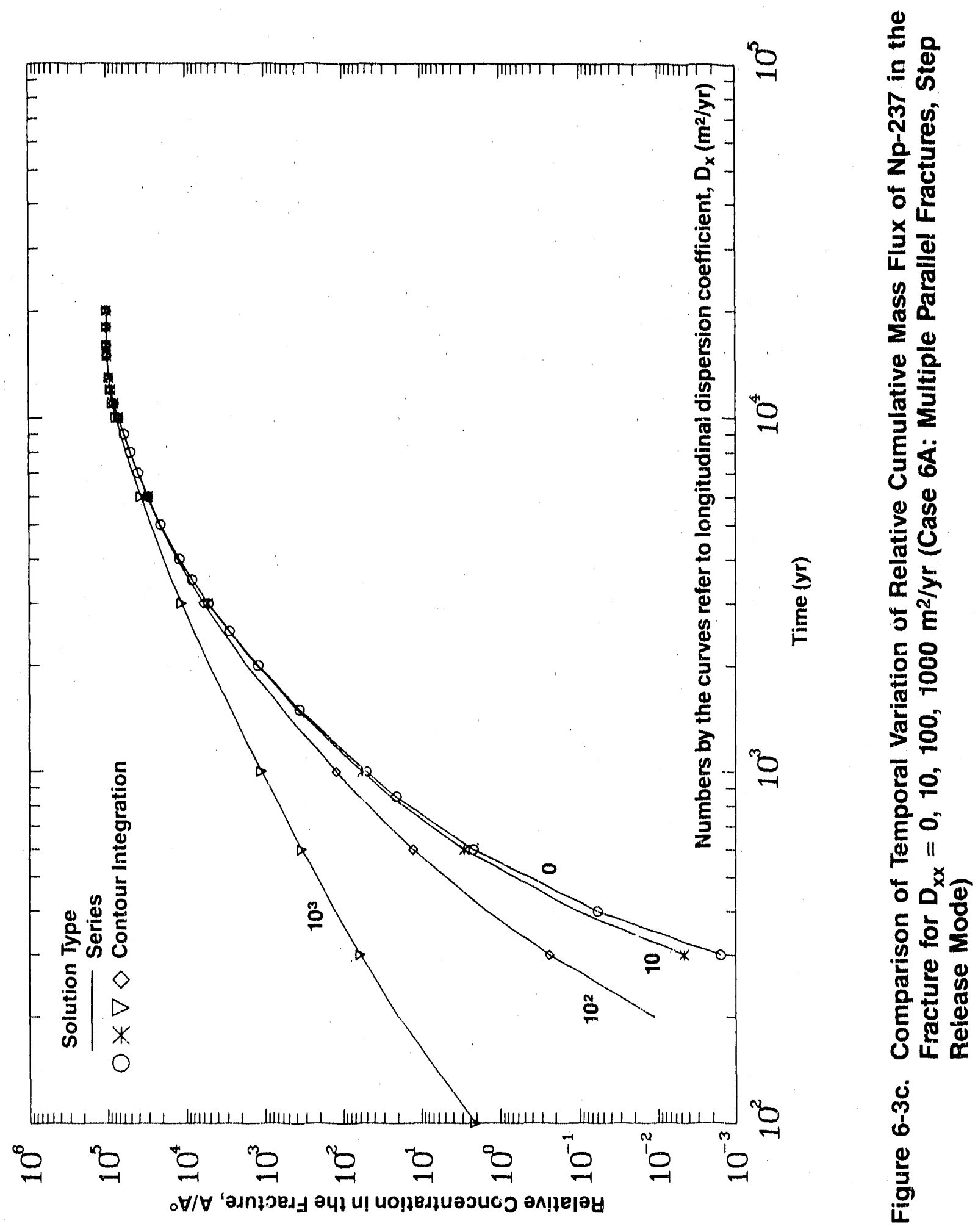




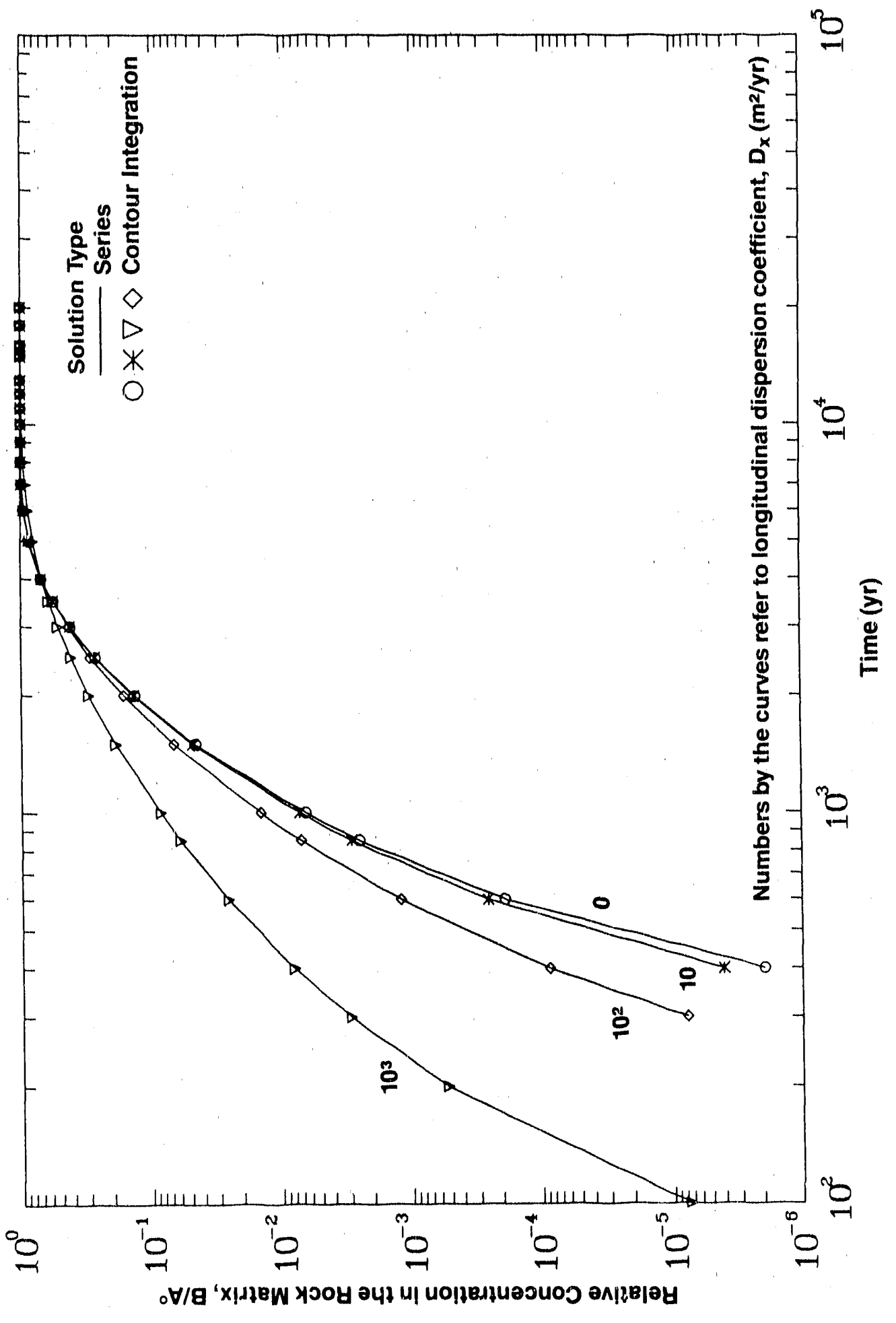

당

뜸

올

ชิ

之o d

$\leftarrow \mathcal{U}$

든 는

ह

동ㅇㅇㅇ

응

ㅇํㅇㅇㅡ

용

ब0

व $\|$

$5 \times$

ᄃ $0 \sum$

은

동

$>$ m

둥요

슨

등

\&응

ᄂ

ธ능

禹些

ำ

员要

ஜุ

co

ํํㄴ 


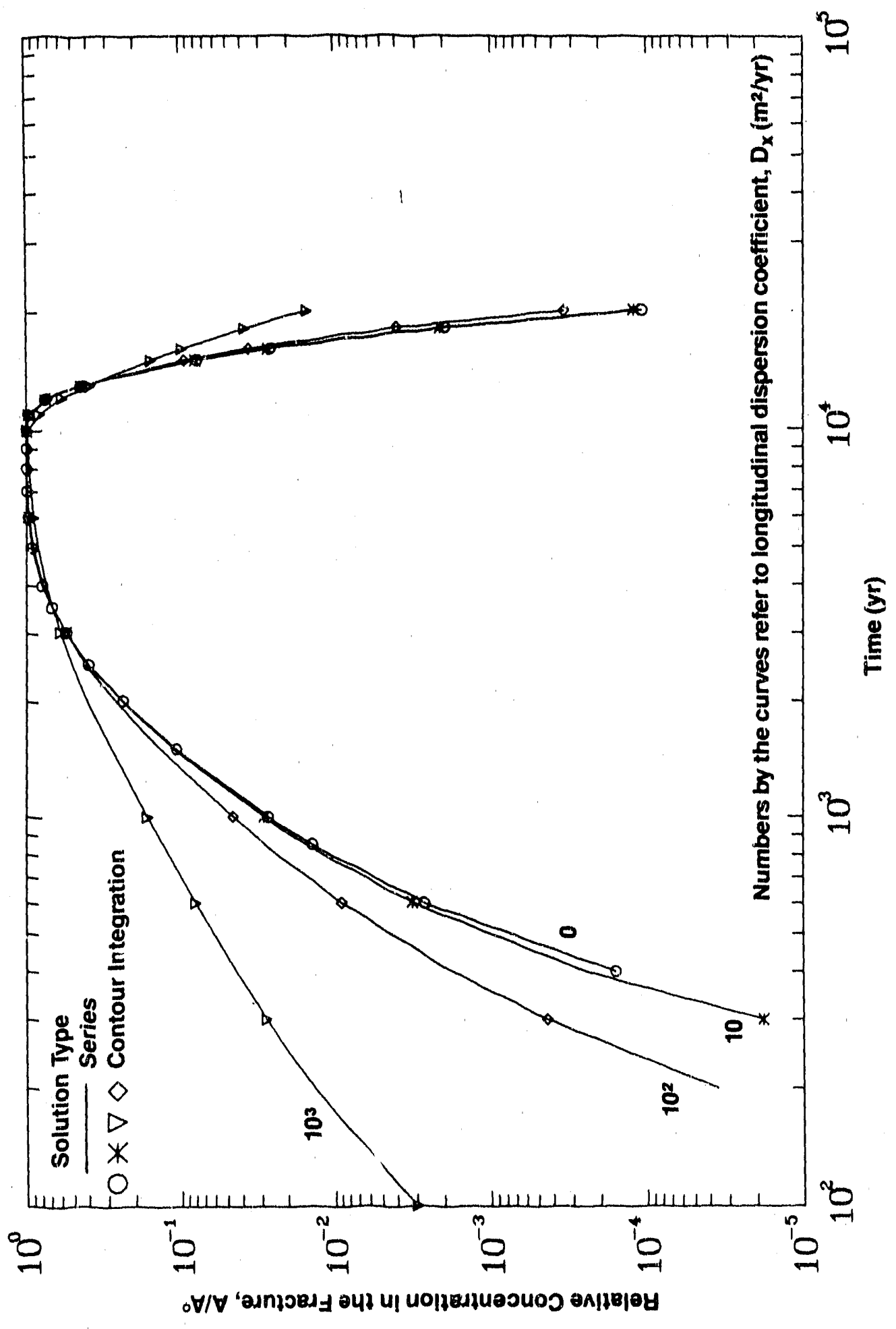

오ํ

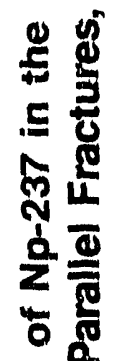

5

응

놀

¿

ठ்

ن

$\$$

สี

文

을

등용

등

동

뜽

음

むII

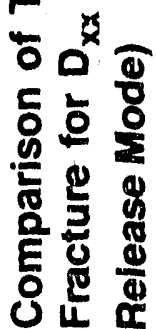

$\frac{1}{6}$

$\frac{2}{5}$ 


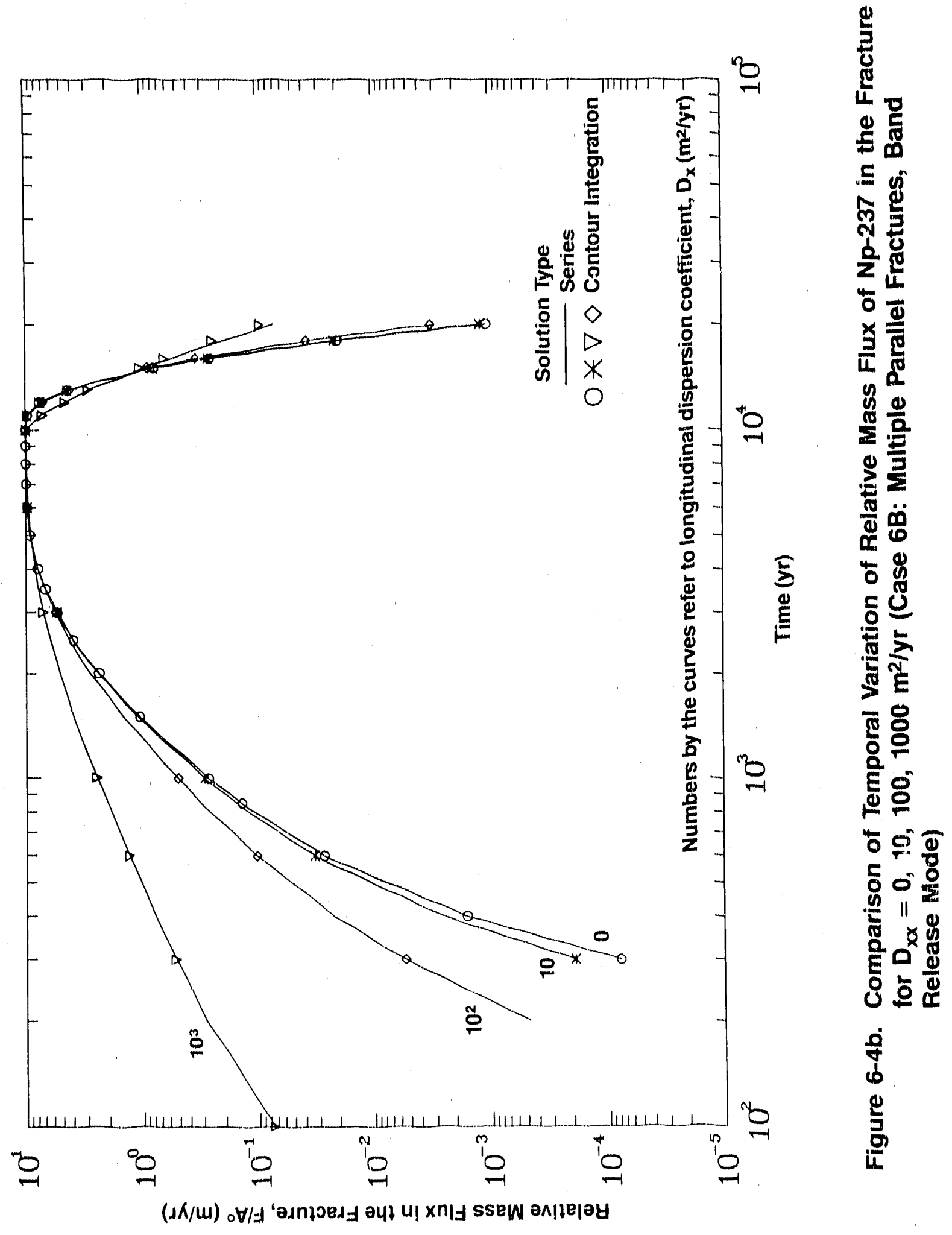




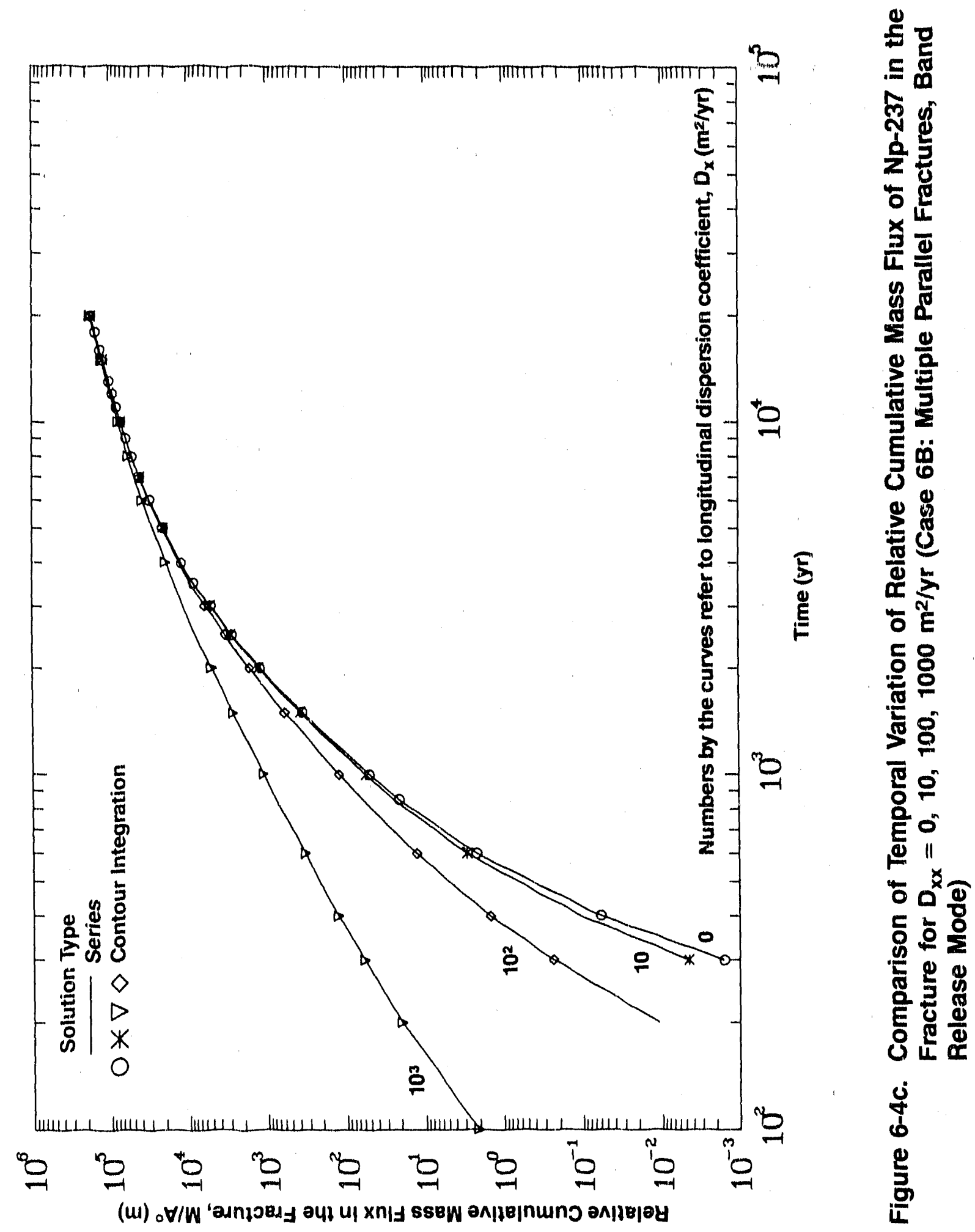




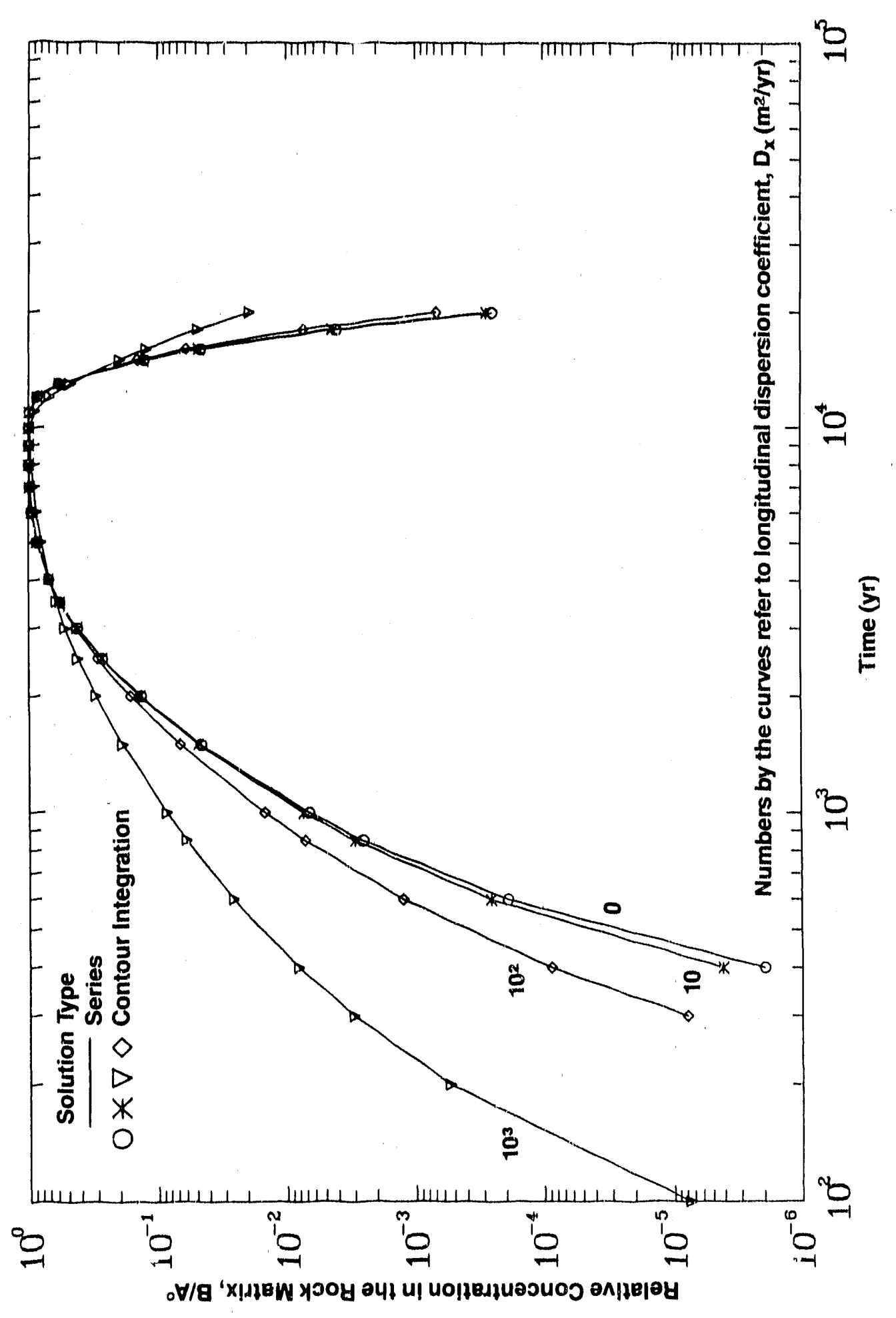

to

$\ddot{\theta}$

กั

르용

28

은

동

है

둥

으

论 용

$\sum^{\infty}$

중

ó

11

일

을 옹

통

$>$ m

ल 0

일

요

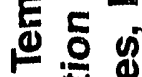

$\leftarrow$ 苗

더 항

드닌 象 究

을돈

它究

ఫ̛ं

욘 


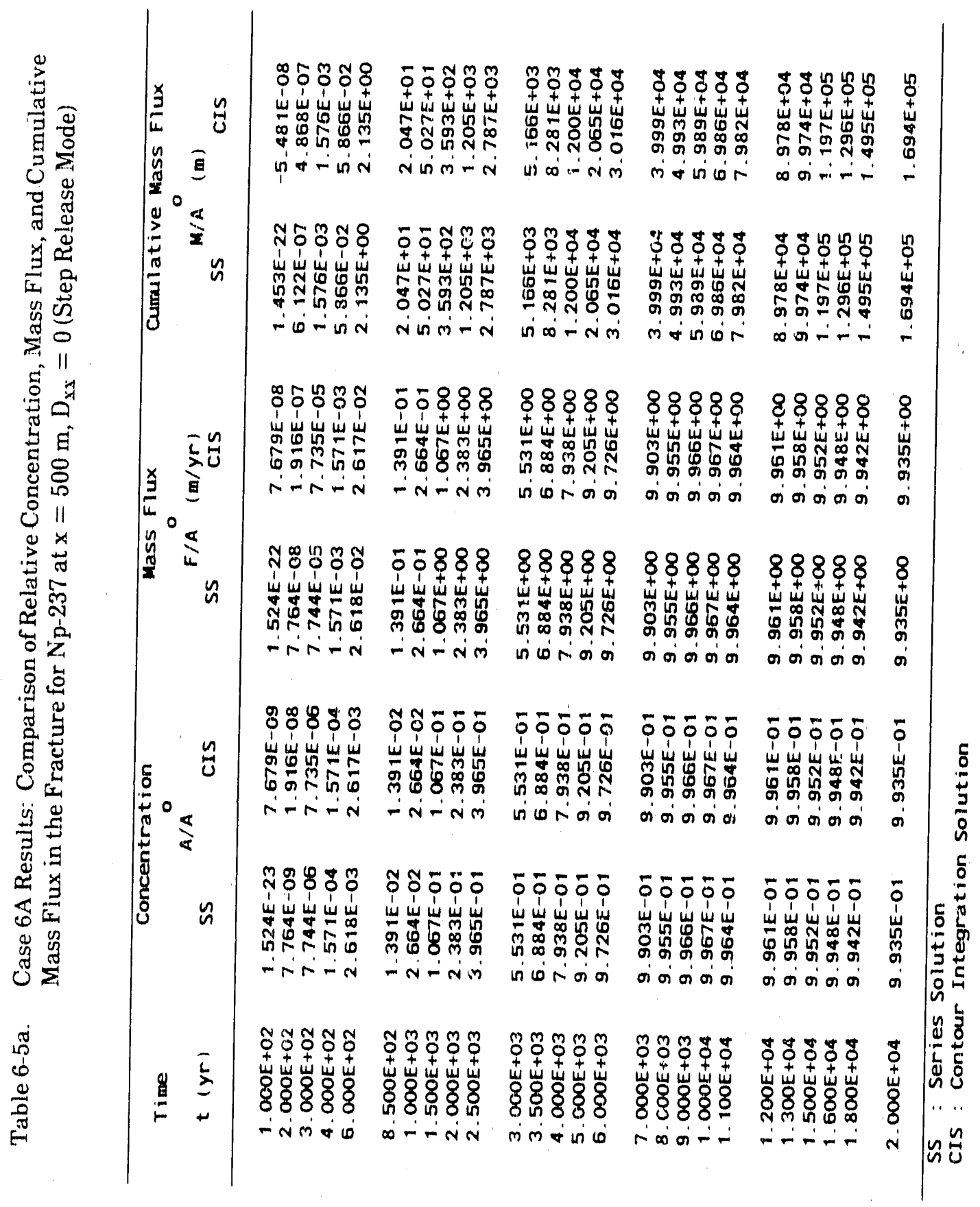




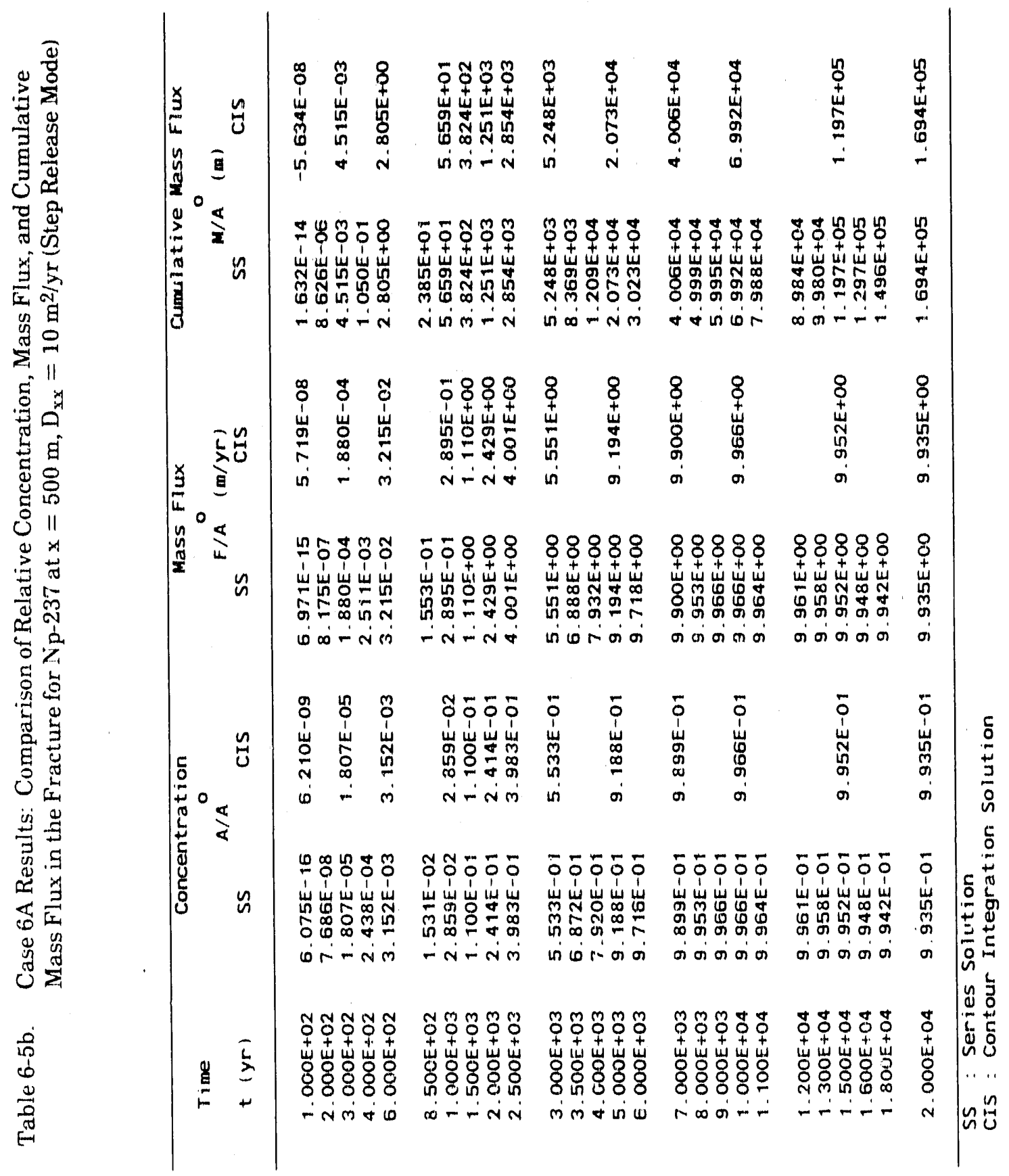




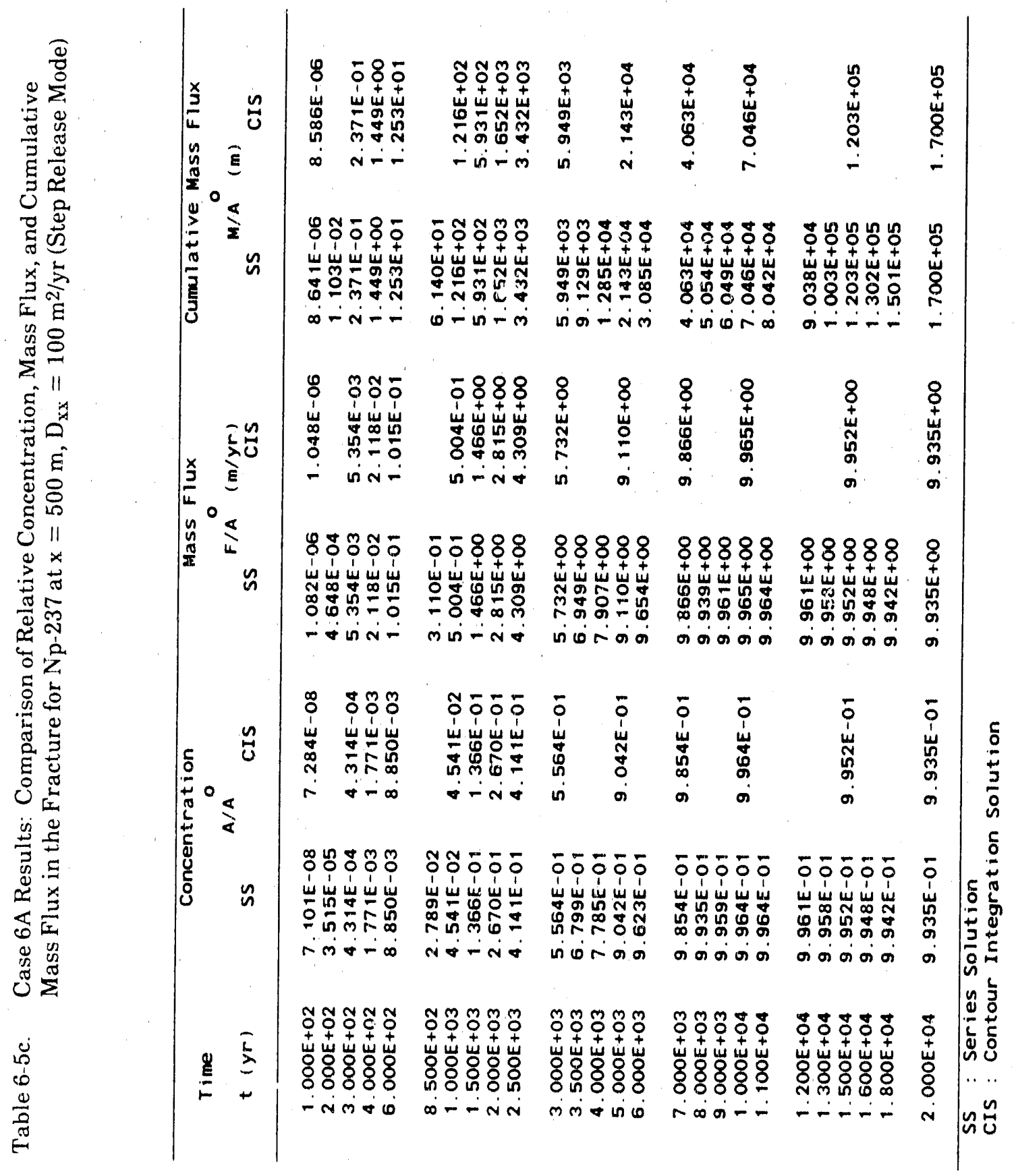




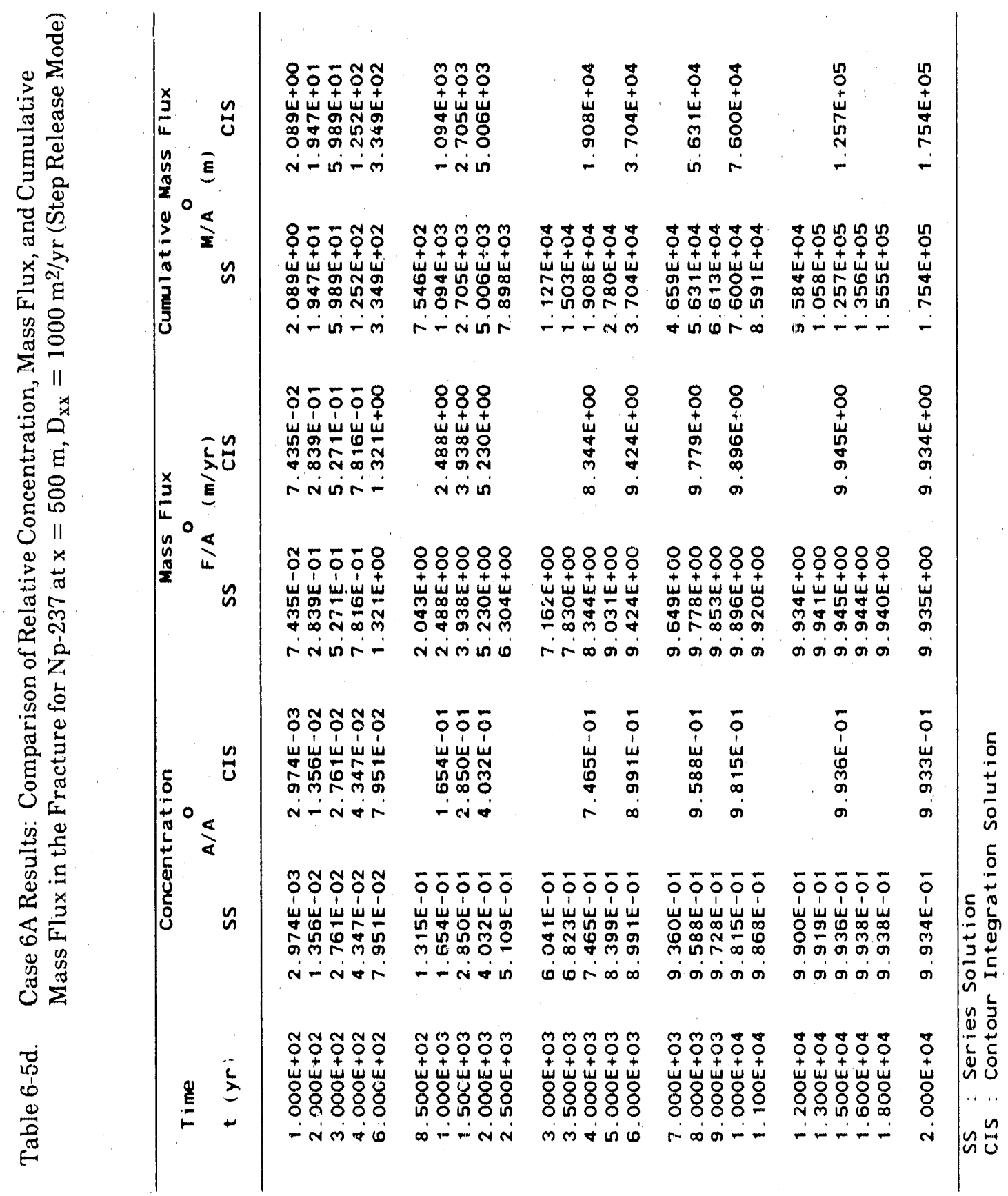




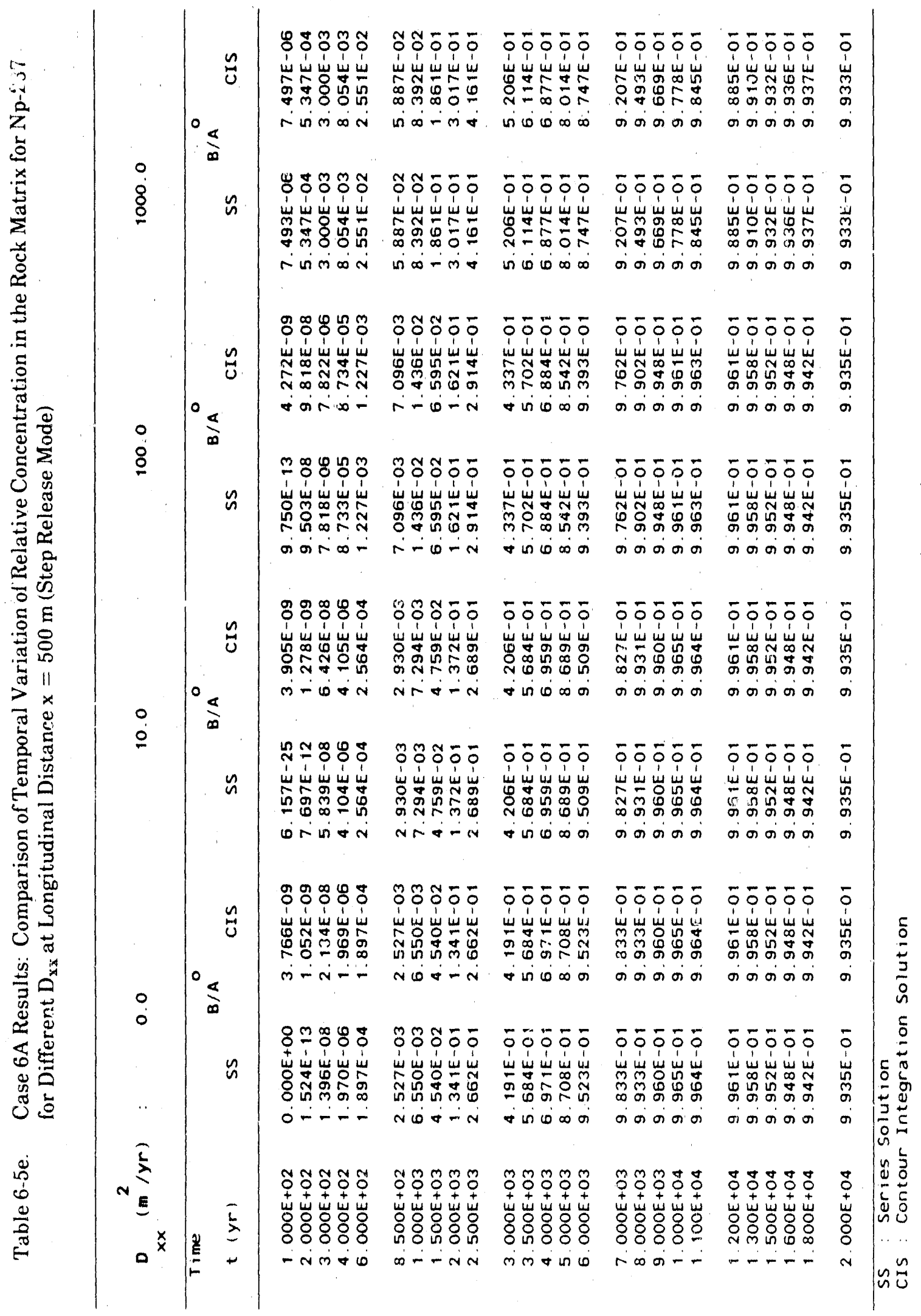




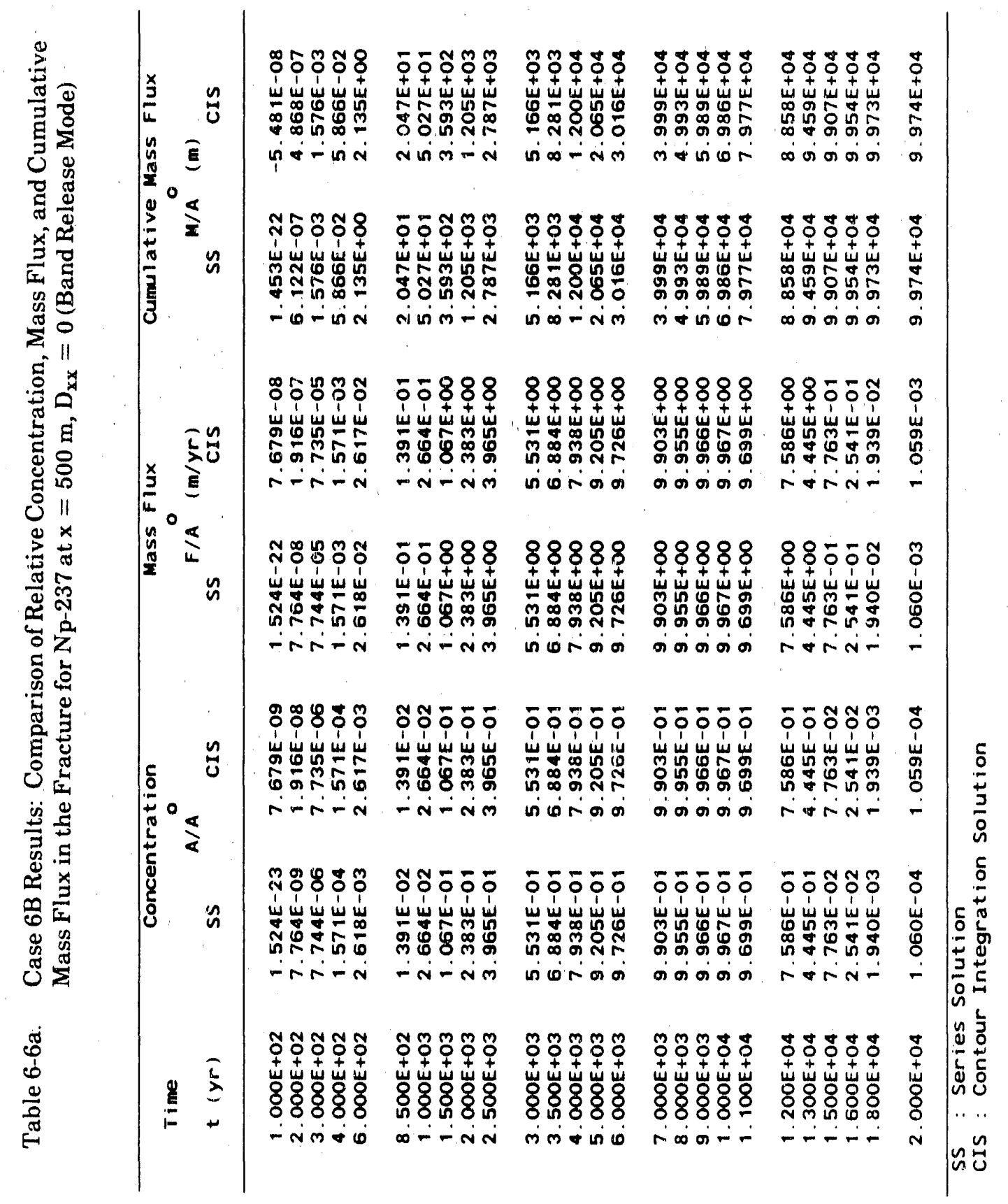




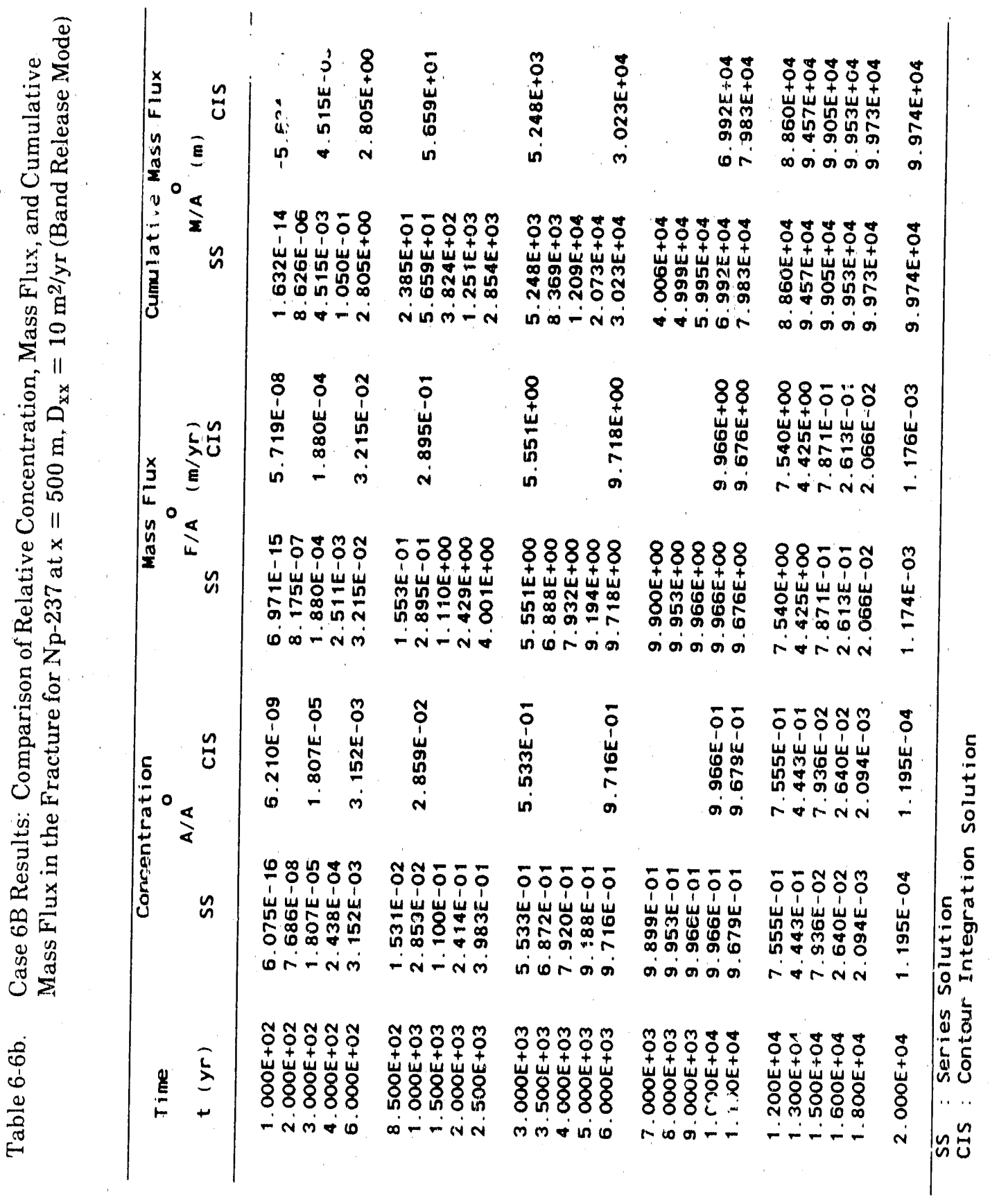




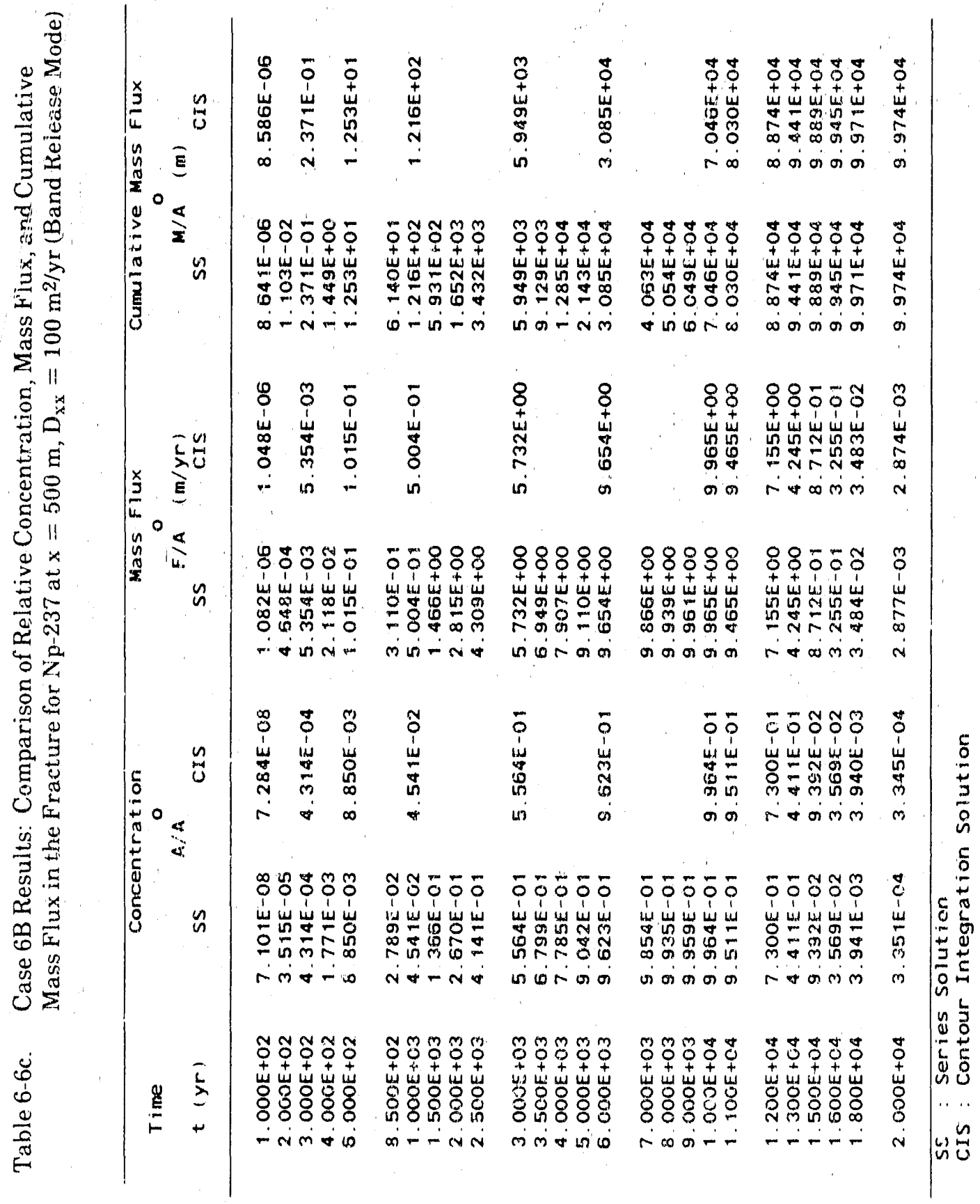




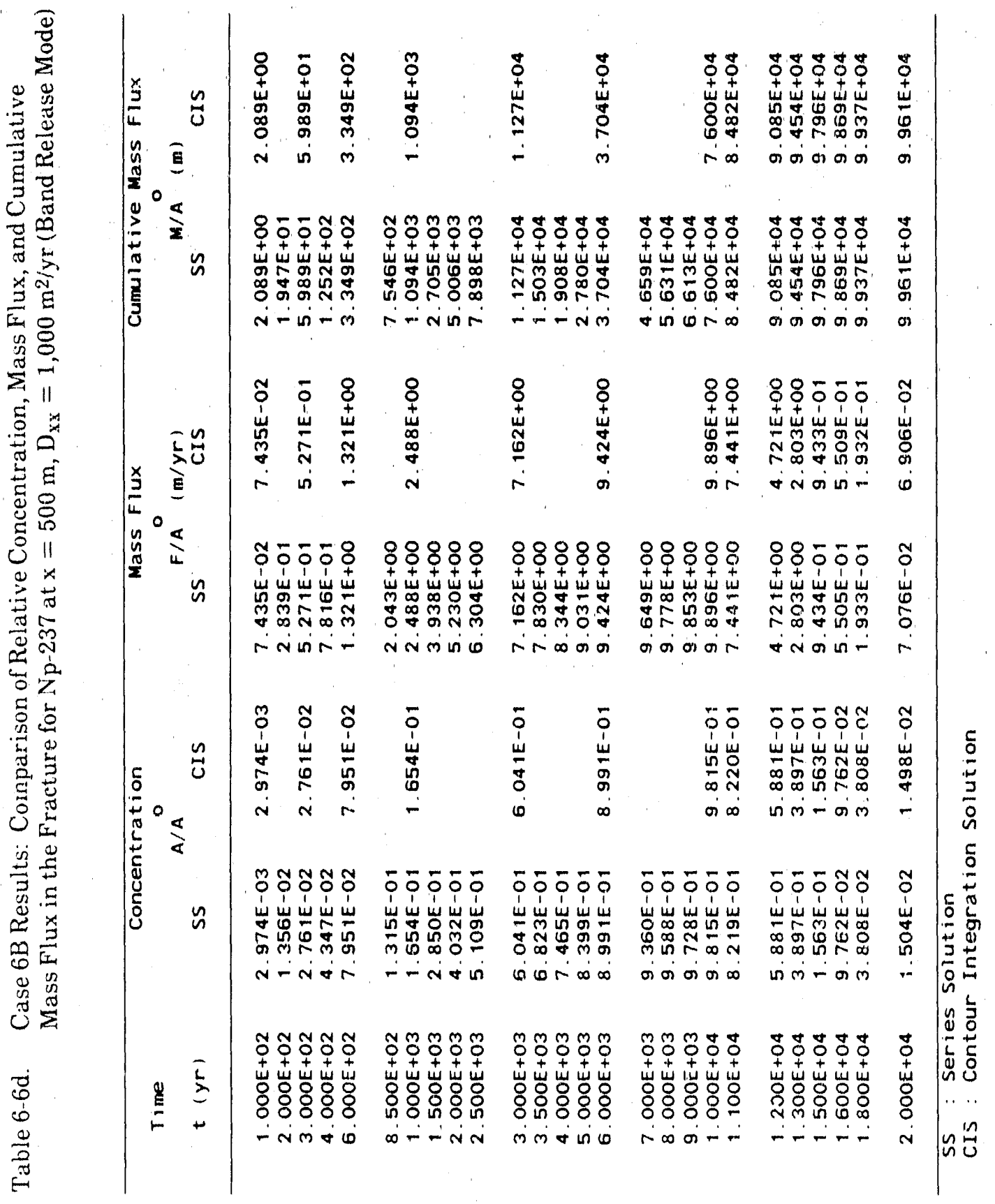




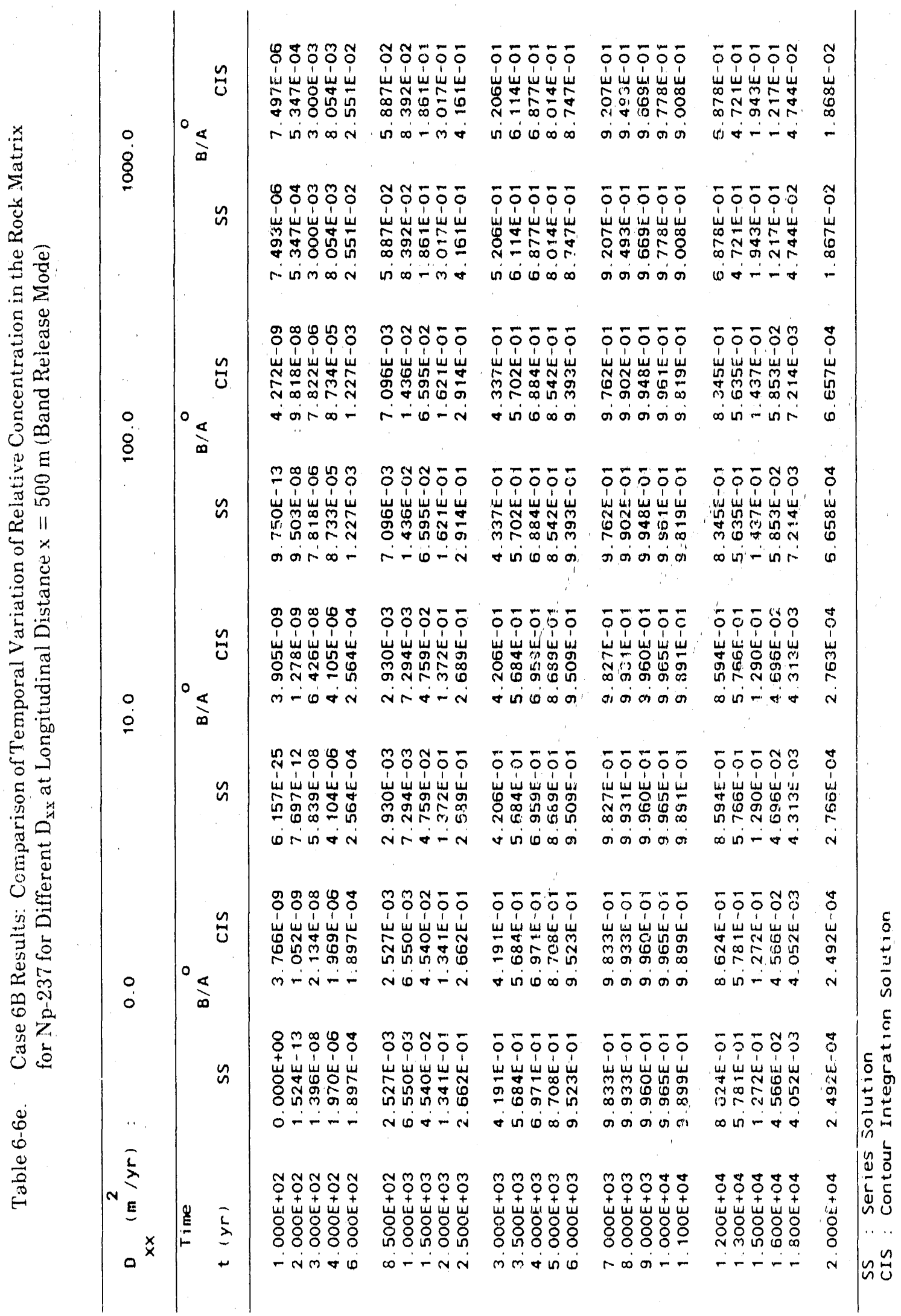




\subsection{DISCUSSION OF CASE 7: TWO-DIMENSIONAL TRANSPORT OF TC-99 IN FRACTURE AND ROCK MATRIX}

The results reported in this section illustrate the application of the series solution to a twodimensional problem dealing with the migration of TC-99 in a system of parallel fractures, where the concentration distribution at inlet is simulated by a set of three finite line sources and subject to a step release mode. In this instance, fluid flow is assumed to be in a direction normal to the upstream boundary; longitudinal dispersion effects are ignored. Concentration, mass flux, and cumulative mass flux in the fracture, as well as the concentration in the rock matrix, are computed at observation points located along lines downstream from the upstream boundary and parallel to it. A list of the innut parameters referred to this problem is reported in Table 6-7.

The simulation time for all the investigated cases corresponds to $5 \times 10^{4}$ years. Figures $6-5 \mathrm{a}$, $6-5 b, 6-5 c$, and $6-5 d$ show the relative concentration, mass flux, mass flux vector, and cumulative mass flux profiles at various distances. Corresponding tabulated results are given in Tables 6-8a, 6-8b, 6-8c, and 6-8d. Note that the concentration gradient in the transverse direction of the fracture, which is relatively important at short axial distances from the source, becomes smaller with increasing distance. As far as the lateral extent of the plume is concerned, the magnitude is greater at large distances from the source. This is a logical consequence of the large effective dispersion time which, in this instance, is proportional to the distance $x$ and inversely proportional to the velocity $u$. Similar conclusions may be drawn for the mass flux and cumulative mass flux results.

Figures 6-5e, 6-5f, and 6-5g show the relative concentration profiles in the rock matrix at elevations of $0.1 \mathrm{~m}, 0.5 \mathrm{~m}$, and $1.0 \mathrm{~m}$. Tabulated results are given in Tables $6-8 \mathrm{e}, 6-8 \mathrm{f}$, and $6-8 \mathrm{~g}$. The migration mechanism of T'-99 in the rock matrix downstream from the source which is solely due to the diffusive effects is proportional to the concentration gradient prevailing at the fracture walls and the effective diffusive time given by $t_{\mathrm{eff}}=\mathrm{t} . . \mathrm{x} / \mathrm{u}$. T'his suggests that either at short distances $\mathrm{x}$ from the source or for large velocities, the effective diffusive time is likely to enhance the migration process to the rock matrix. 
Table 6-7. Input, Parameters Used in Simulation of 'T'c-99 in Fracture and Rock Matrix for Case 7

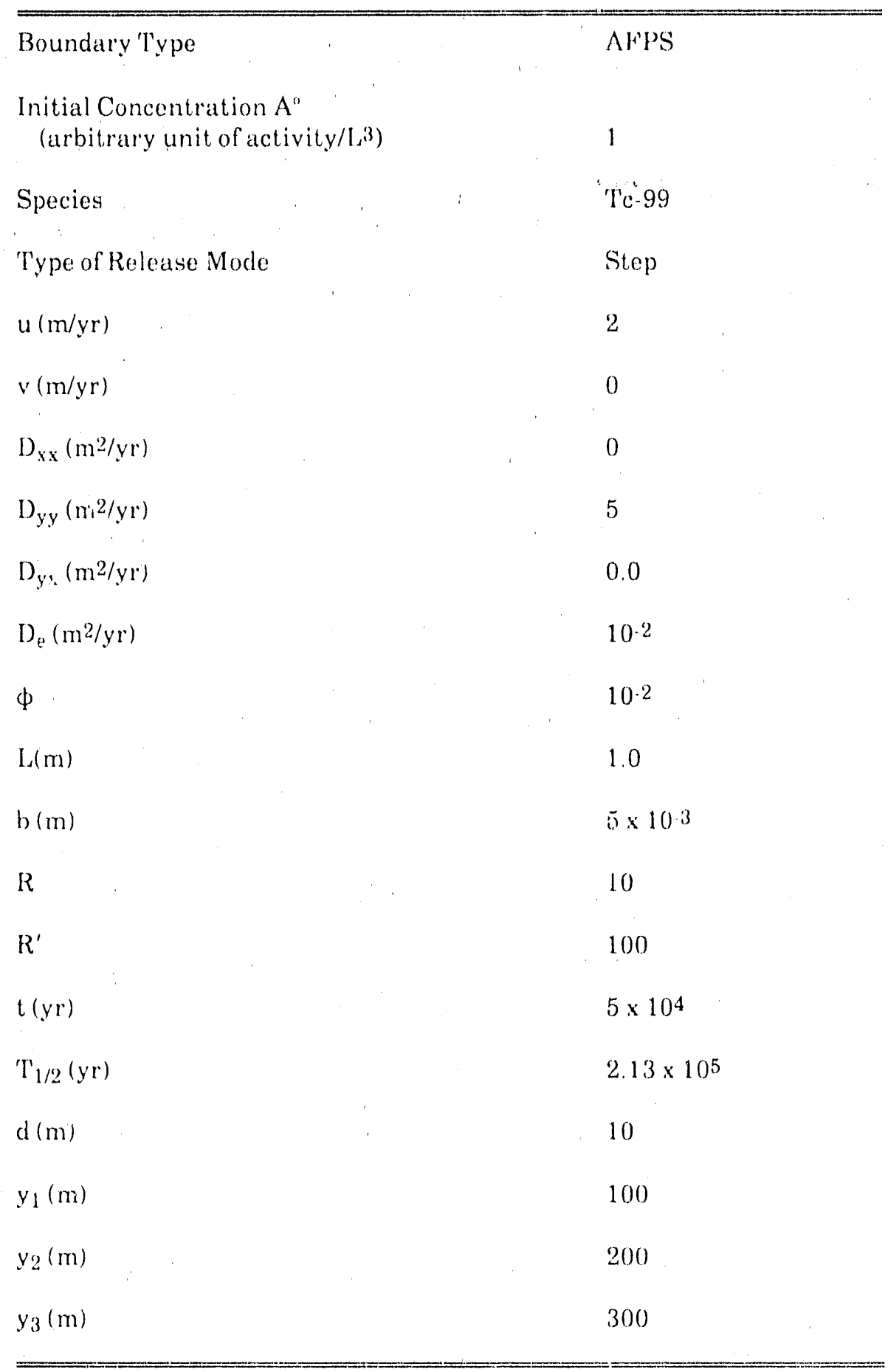




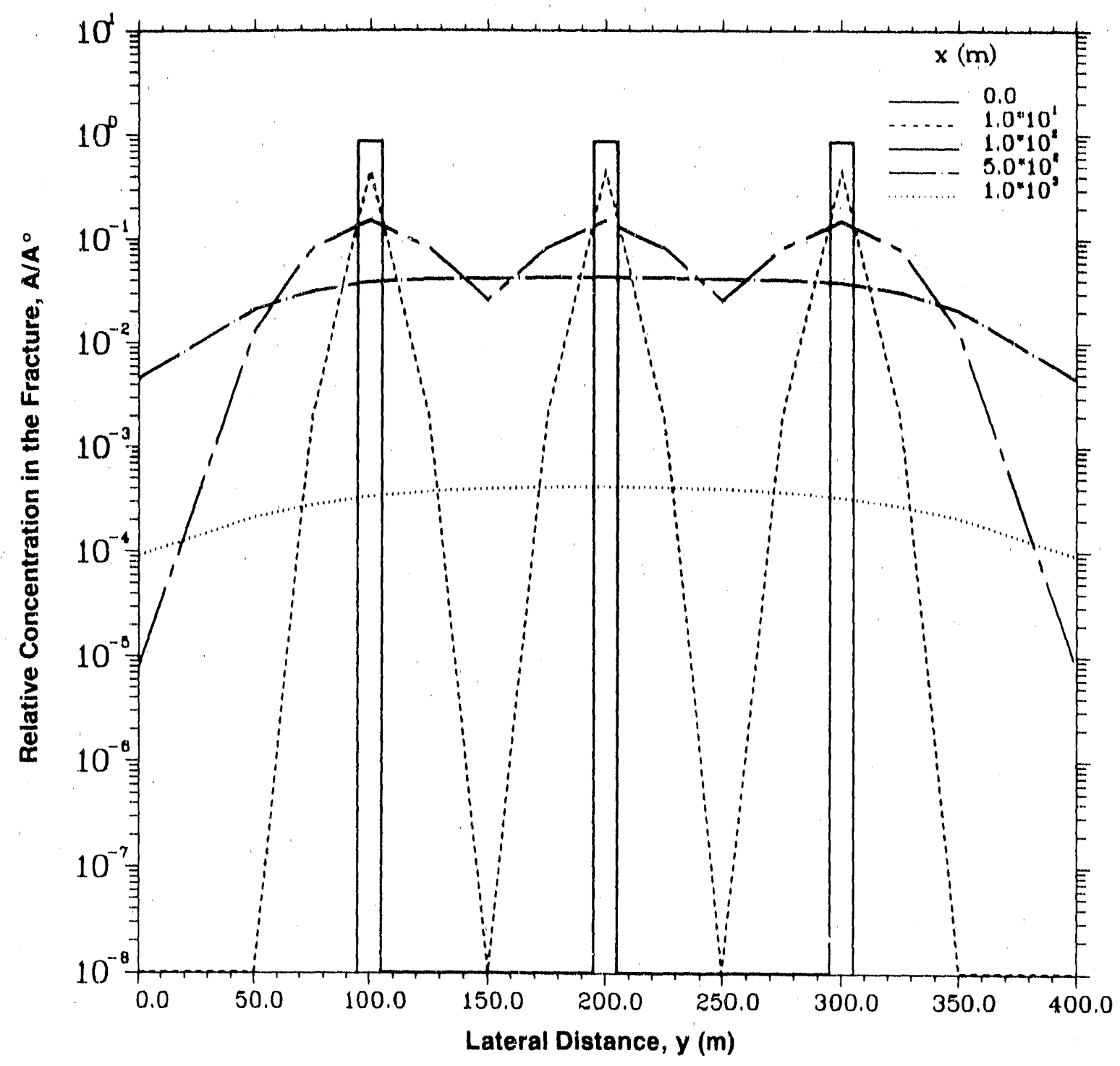

Figure 6-5a. Relative Concentration Profiles for Tc-99 in the Fracture at $z=0 \mathrm{~m}$ and $\mathrm{t}=5 \times 10^{4} \mathrm{yr}$ (Case 7: Multiple Patch Source) 


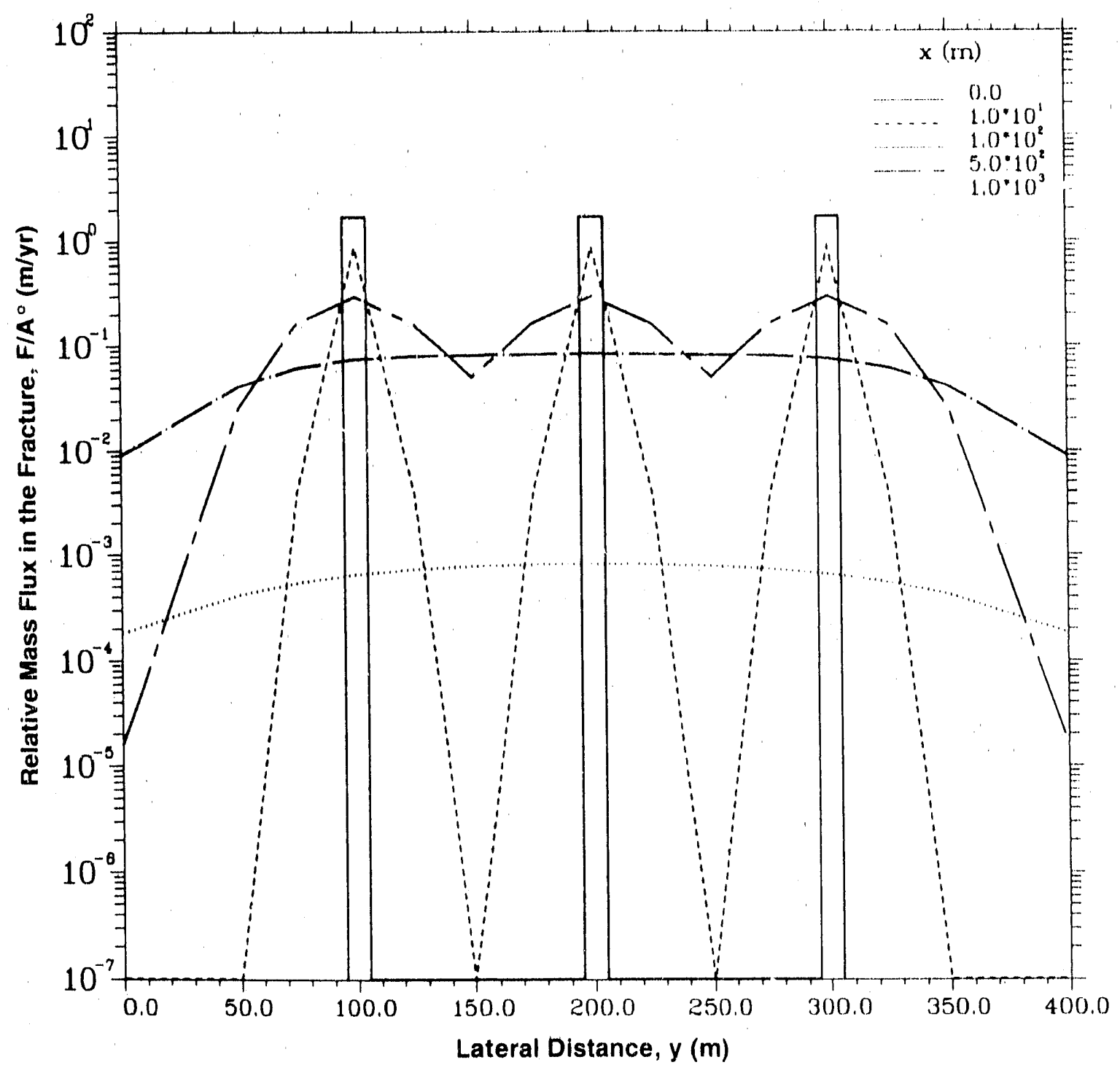

Figure 6-5b. Relative Mass Flux Profiles for Tc-99 in the Fracture at $z=0 \mathrm{mi}_{\mathrm{i}}$ and $t=5 \times 10^{4} \mathrm{yr}$ (Case 7: Multiple Patch Source) 


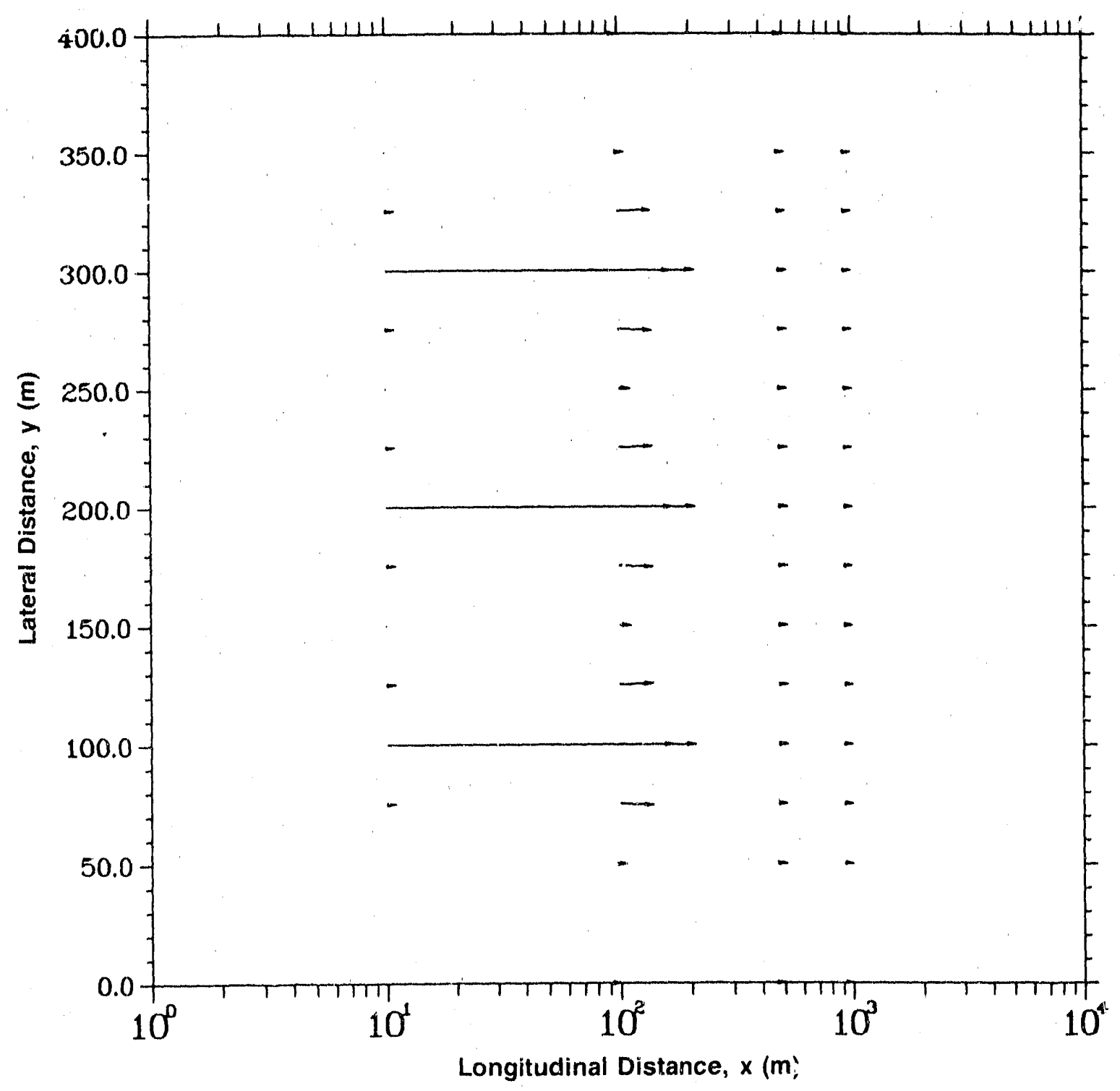

Figure 6-5c. Mass Flux Vector of Tc-99 at Discrete Points in the Fracture at $\mathrm{z}=0 \mathrm{~m}$ and $\mathrm{t}=5 \times 10^{4}$ (Case 7: Multiple Patch Source) 


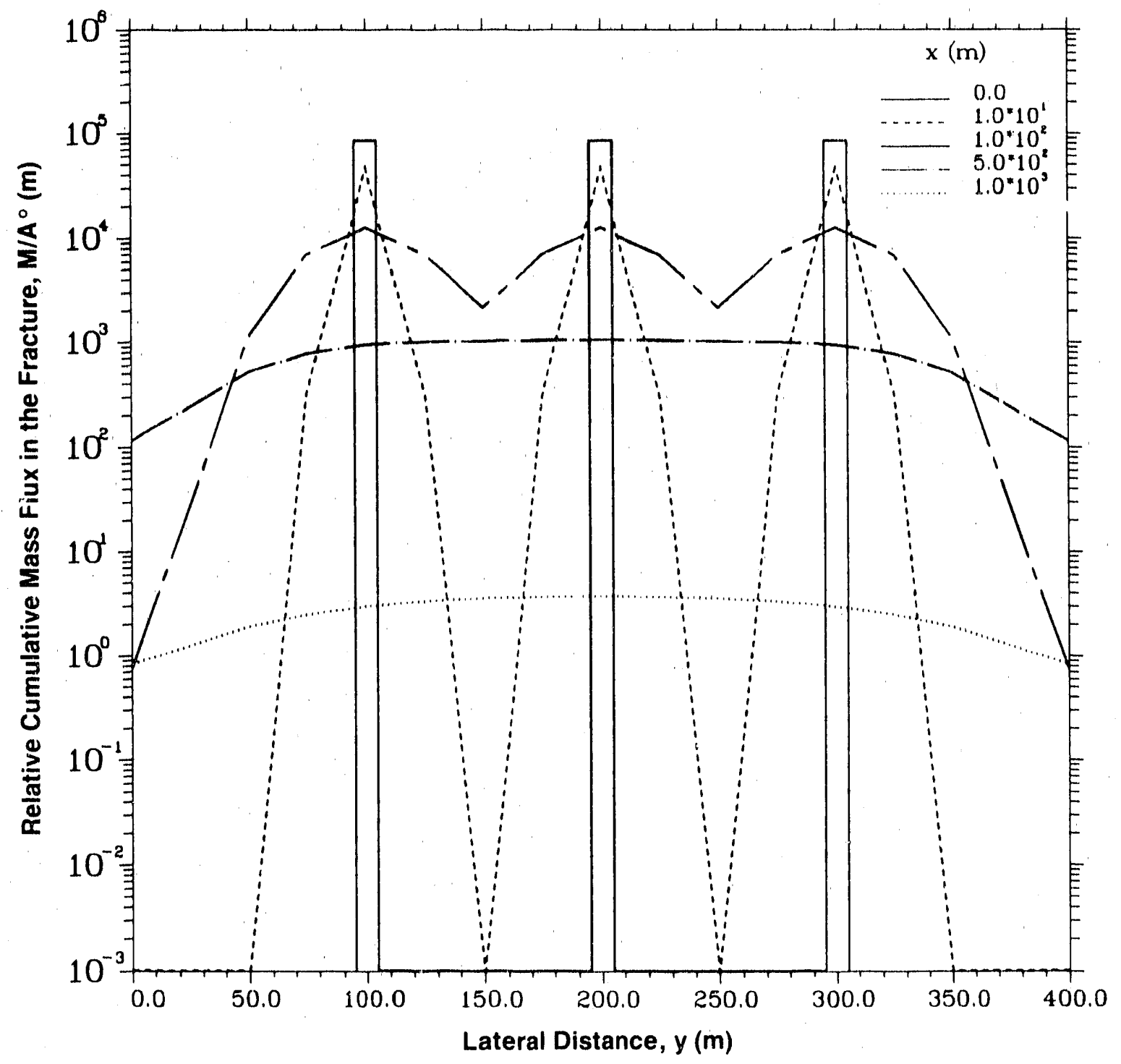

Figure 6-5d. Relative Cumulative Mass Flux Profiles for Tc-99 in the Fracture at $\mathrm{z}=0 \mathrm{~m}$ and $\mathrm{t}=5 \times 10^{4} \mathrm{yr}$ (Case 7: Multiple Patch Source) 

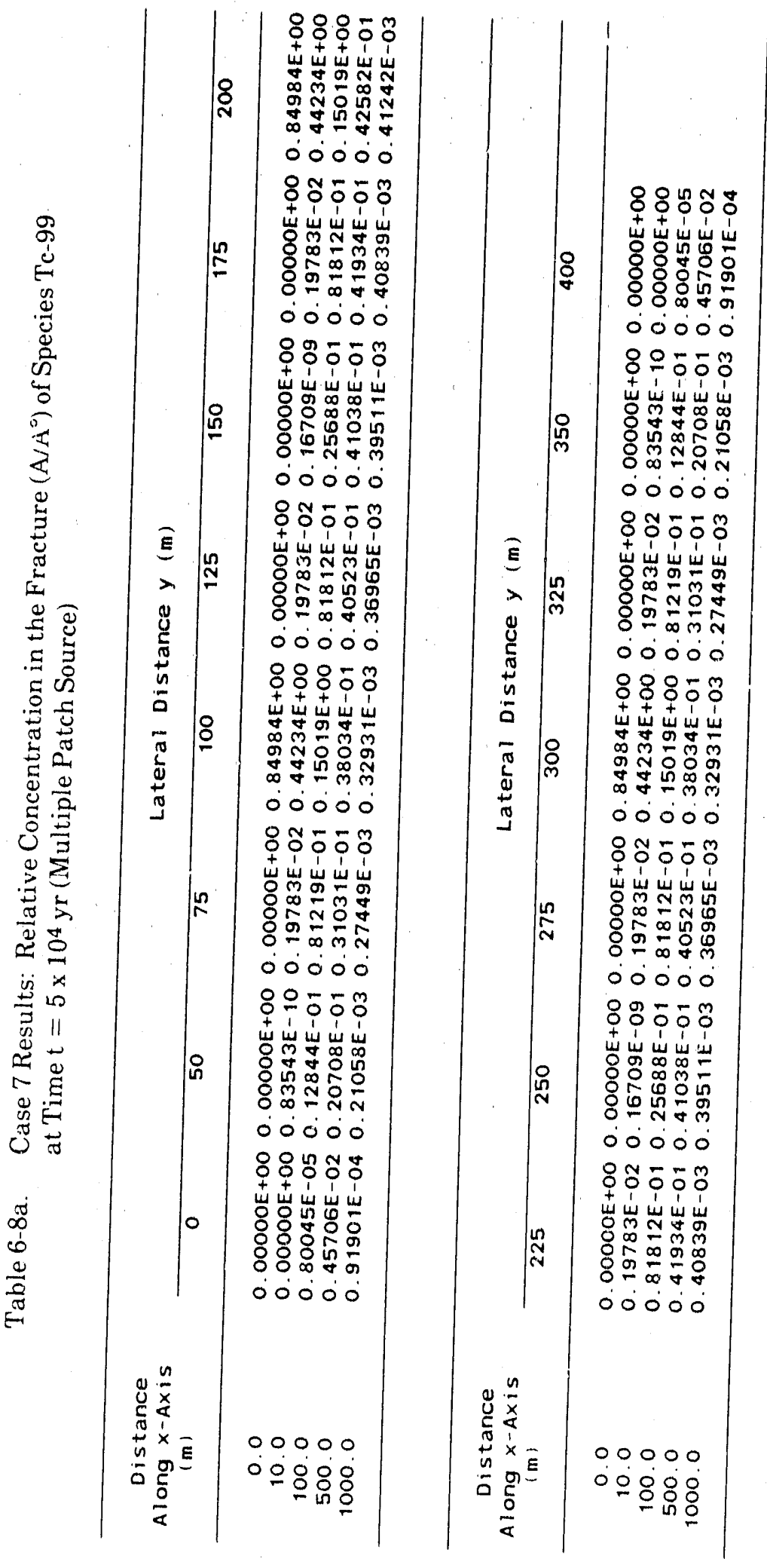

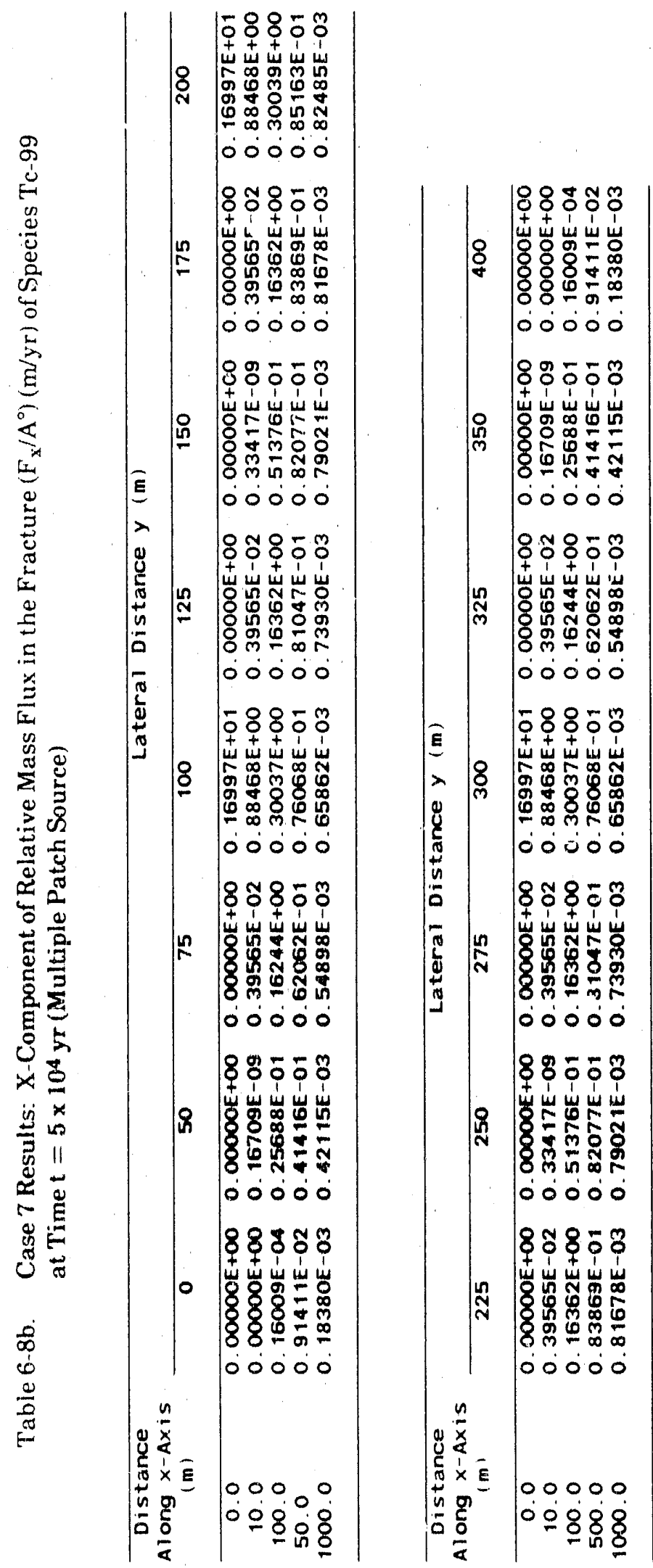

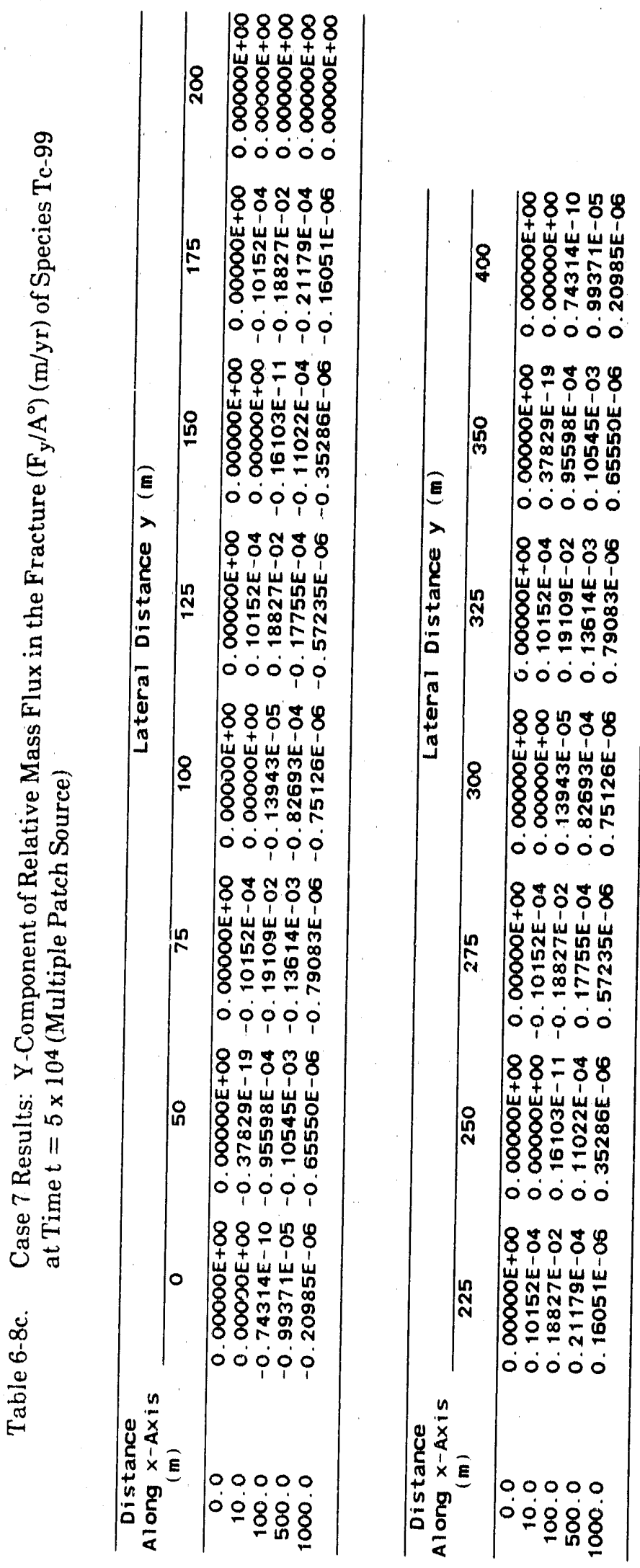


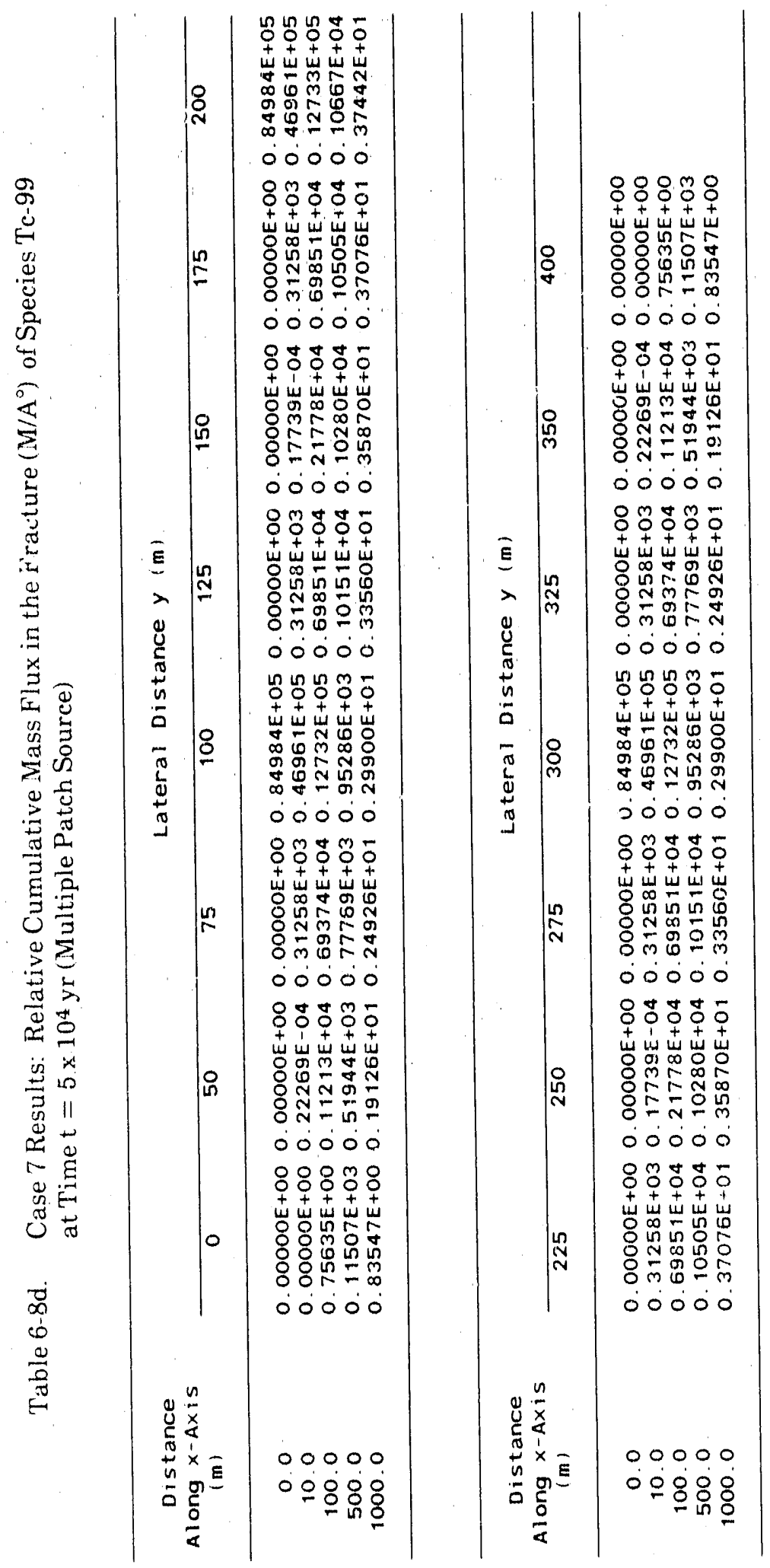




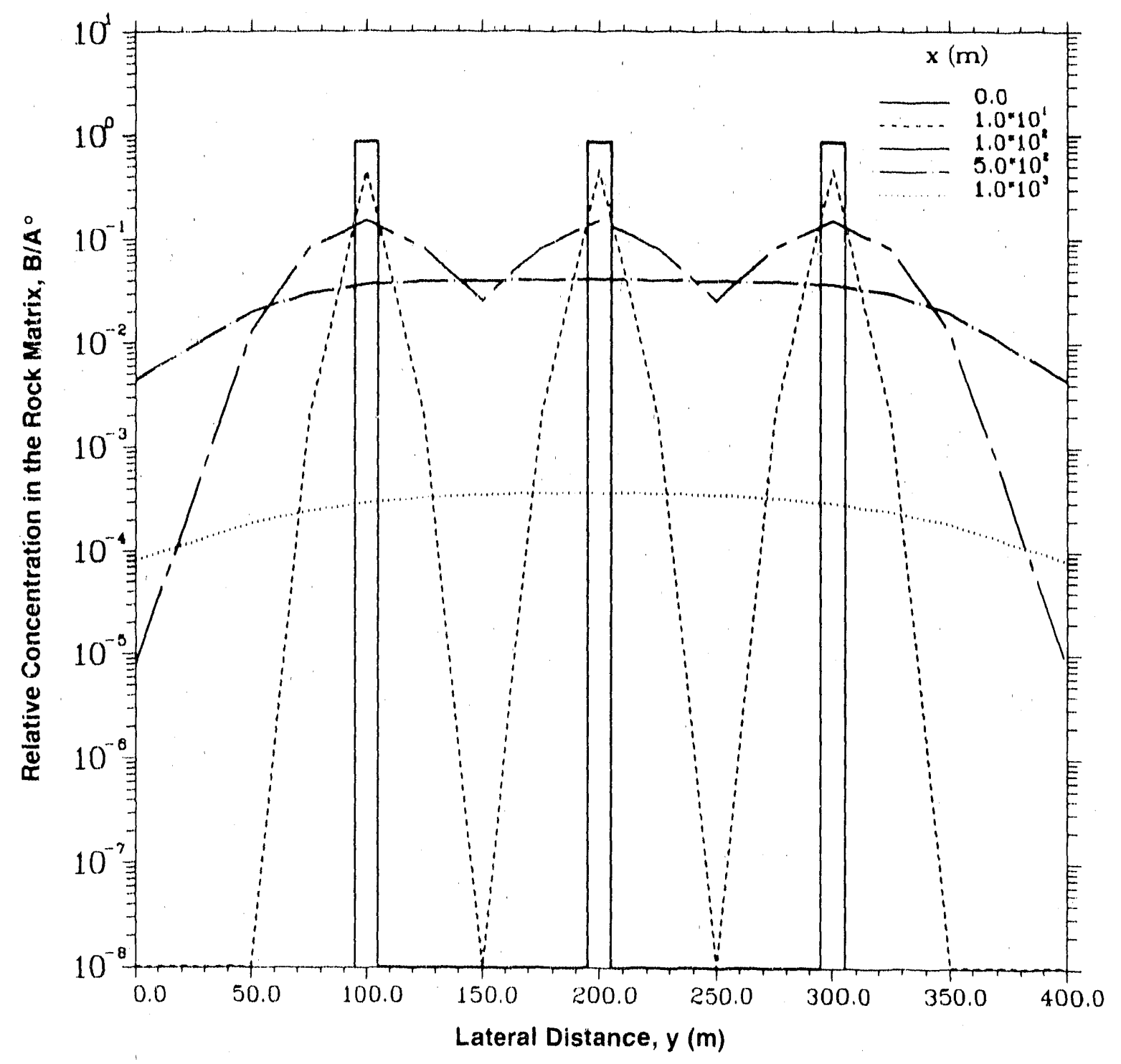

Figure 6-5e. Relative Concentration Profiles for Tc-99 in the Rock Matrix at $z=0.1 \mathrm{~m}$ and $\mathrm{t}=5 \times 10^{4} \mathrm{yr}$ (Case 7: Multiple Patch Source) 


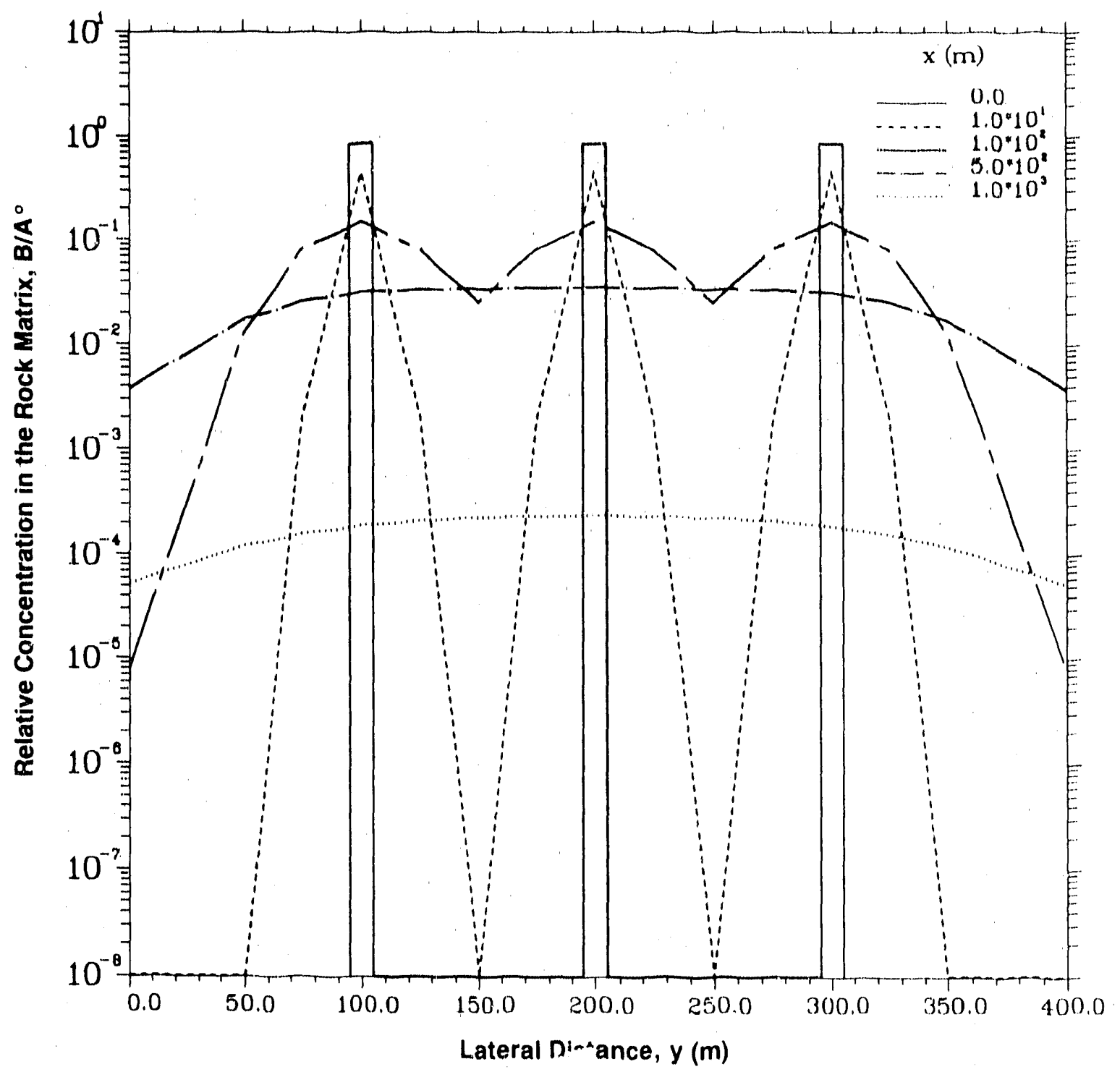

Figure 6-5f. Relative Concentration Profiles for Tc-99 in the Rock Matrix at $z=0.5 \mathrm{~m}$ and $\mathrm{t}=5 \times 10^{4} \mathrm{yr}$ (Case 7: Multiple Patch Source) 


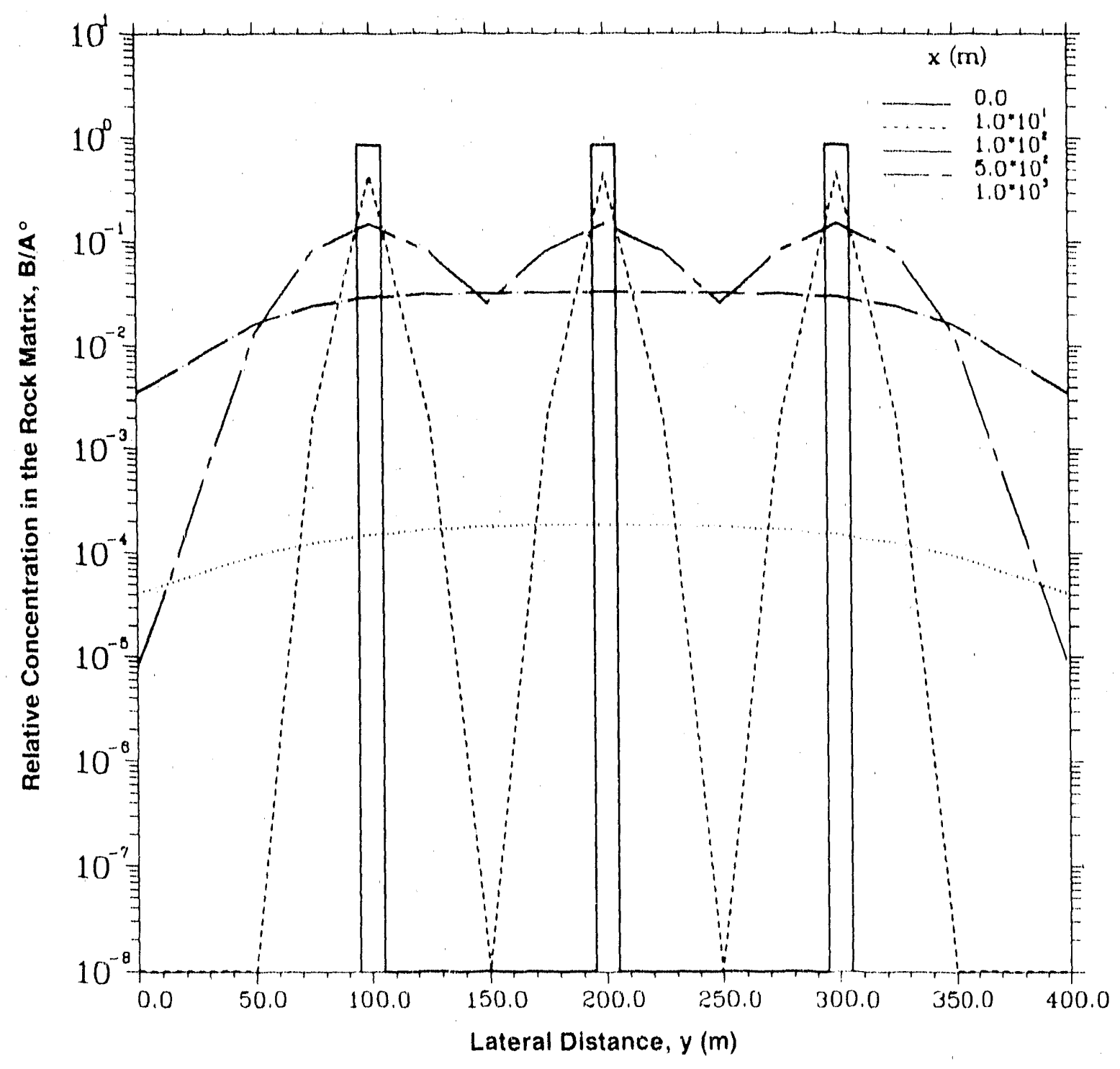

Figure 6.5g. Relative Concentration Profiles for TC-99 in the Rock Matrix at $z=1.0 \mathrm{~m}$ and $\mathrm{t}=5 \times 10^{4} \mathrm{yr}$ (Case 7: Multiple Patch Source) 


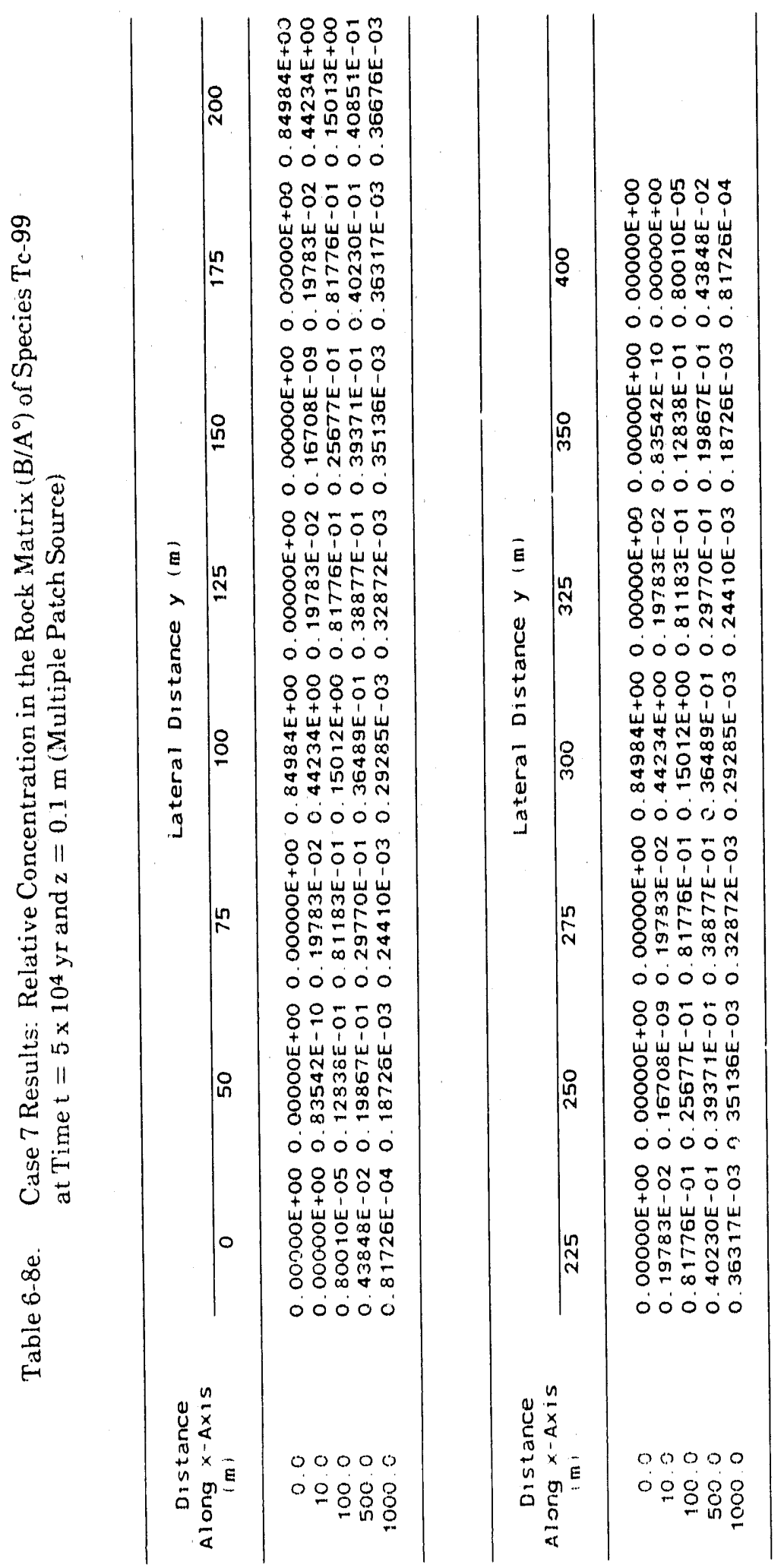



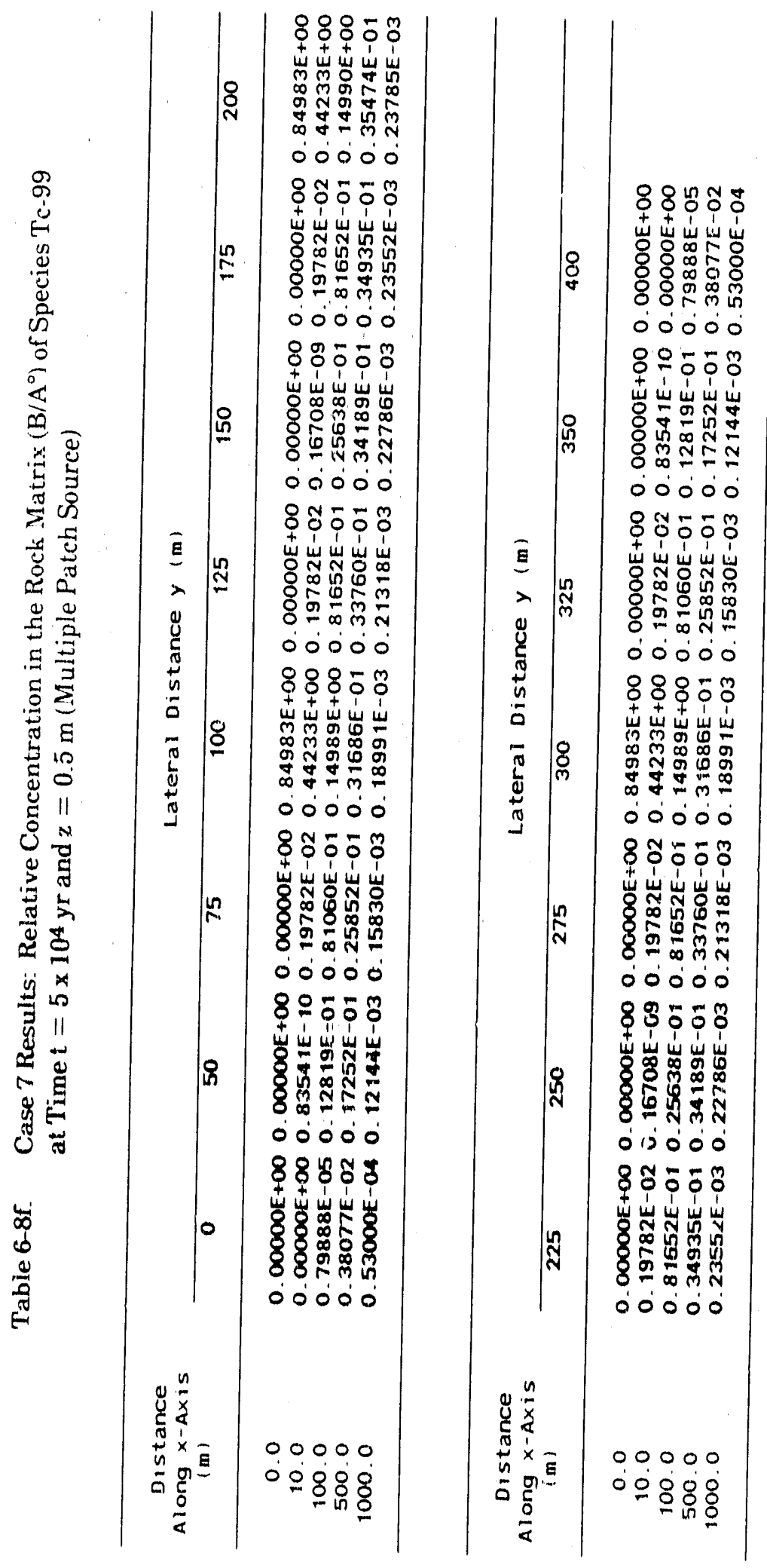


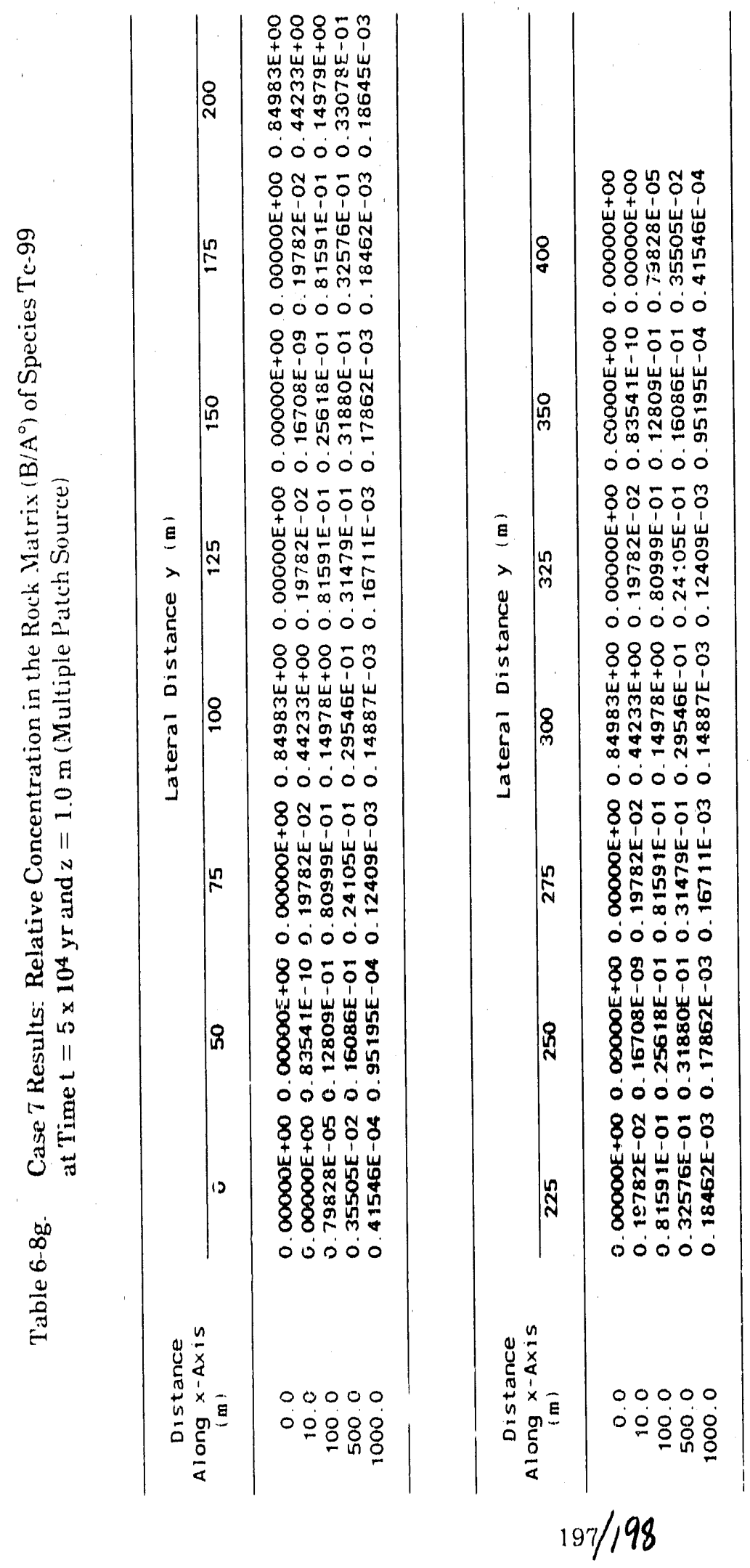




\subsection{SUMMARY AND CONCLUSIONS}

Analytical solutions have been derived for predicting the two-dimensional transport of a radionuclide with no precursor in a single planar fracture as well as a system of parallel fractures coupled with the one-dimensional diffusive transport in the rock matrix. The solution for the mass and cumulative mass flux in the fracture and the longitudinal dispersion-free form of these solutions have also been investigated.

The solutions related to the fracture are designed for an unbounded medium (semi-infinite in the axial direction and infinite in the lateral direction); solutions related to the rock matrix consider a semi-infinite rnedium for the case of single fracture and a finite domain for the multiple fracture case. The initial concentration in both the fracture and the rock is assumed to be zero. The gesmetry and concentrations of the waste form at the source correspond to a finite patch (or multiple patch) or a Gaussian distributed source subject to decay in all cases. Furthermore, the radionuclide release modes considered in this study focus on the step and band release modes.

'Two sets of solutions for the multiple parallel fracture case were derived; one based on a series approximation and the other based on contour integration are ideally suited to cope with small and large Fourier numbers, respectively. In particular, the new solution for the multiple parallel fracture case related to the rock matrix improved considerably the viability of its numerical evaluation by way of bypassing the restrictions inherent to a convolution-based solution.

An efficient transformation technique of the integration interval encountered in these solutions was derived, guaranteeing maximum stability and convergence. The Gauss-Legendre quadrature scheme was adopted to perform the integration. Note that in the multiple parallel fracture case, an efficient; iterative quadrature scheme was devised to take care of the oscillatory nature of the integrand encountered in the solution based on contour integration.

In the case of the single fracture, the reported solutions were verified by means of a vailable one. and two-dimensional analytical solutions; in the multiple parallel fracture case, the verification process was accomplished after comparing the results yielded by the two newly developed solutions, thas providing reasonable confidence to prospective users in utilizing then for verifying numerical codes.

Although overlooking longitudinal dispersion effects may lead to slightly conservative predictions both in terms of the maximum concentration in the system and the local concentration of a nuclide, yet the enhancement of the computational viability of the reported solutions in such a case cannot be underestimated. The need for a quadrature scheme is eliminated, except for the solution based on contour integration. These solutions also may be conveniently used for assessing the longterm geohydrochemical performance of a high-level nuclear waste repository located in fractured geologic media subjected to a water intrusion scenario. 


\subsection{RWFHENCES}

Abramowitz, M., and I. A. Stegun, 1972. I Gandbook of Mathematical Functions, Dover Publications, Inc., Now York, NY.

Ahn, J., P. L. Chambré, and 'I' H. Pigford, 1985. Nuclide Migration 'Through a Planar Fissure 'th Matrix Diffusion, LBL-19249, Lawrence Berkeley Laboratory and Department of Nuclear Er is is: ing, University of California, Berkeley, $\mathrm{C} \wedge$.

Ahn, J., P. L. Chambré, and 'T. H. Pigford, 1986. Radionuclide Migration 'Through Fractured Rock: Effects of Multiple Fractures and T'wo-Member Decay Chains, Earth Sciences Division, Lawrence Berkeley Laboratory and Department of Nuclear Engineering, University of California, Berkeloy, CA.

Babcock, R. E., I). W. Green, and R. II. Perry, 1966. "Longitudinal Dispersion Mechanisms in Packed Beds," A.I.Ch.E. Journal, Vol. 12, Vo. 5, p. 922.

Barker, J. A., 1982. "Laplace Transform Solutions for Solute'Transport in F'issured Aquifers," Advanced Water Resources, Vol. 5, No, 2, pp. $98-104$.

Bear, J., 1972. Dynamics of Fluid in Porous Media, American Flsevier Publishing Co., New York, NY.

Carnahan, B., H. A. Luther, and J. (). Wilkes, 1969 Applied Numerical Methods, John Wiley and Sons, Inc., New York, NY.

Carslaw, H. S., and J. C. Jaegor, 1958. Conduction of Lleat in Solids, 2nd ed., Clarendon Press, Oxford, UK.

Chambré, P. L., 'T' H. Pigford, A. Fujita, 'T. Kanki, A Kobayashi, H. Lung, D. 'T'ing, Y. Sato, and S. J. Zavoshy, 1982. Analytical Performance Models for Geologic Repositories Vol. II, LBL-14842, Lawrence Berkeley Laboratory, Lniversity of California, Berkeley, CA.

Chen, C. S., 1986. "Solutions for Radionuclide Transport From an Injection Well into a Single Fracture in a Porous Formation," Water Resources Research, Vol. 22, No. 4, pp. 508-518.

Cody, W. J., 1969. "Rational Chebyshev Approximation for the Error Functions," Mathematics of Computation, Vol. 23, No. 107, pp. 631-6337.

Davis, G. B., and C. I). Johnston, 1984. "Comment on 'Contaminant 'Transport in Fractured Porous Media: Analytical Solutions for a System of Parallel Fractures," Water Resources Research, Vol. 20, No.9, pp. $1321-1322$.

Foglia, M., F. Iwamcto, M. Ilarada, P. L. Chambre, and T'. I. I'igford, 1979. "The Superposition Equation for the Band Release of Decaying Radionuclides Through Sorbing Media," UCB-NE-3335, University of California at Berkeley, A.VS'Transactions, Volume 33, pp. 384.386.

Gradshteyn, I. S., and I. M. Ryzhik, 1980 Table of Integrals, Series, and Products, Academic Press, New York, NY, p. 1160.

Grisak, G. E'., and J. F' Pickens, 1981 "An Analyticai Solution for Solute T'ransport Through Fracture Media with Matrix Diffusion," Journal of Iydrologe, Vol. 52, pp. 47-57. 
Gureghian, A.B., 1987. Analytical Solutions for Multidimensional Transport of a Four-Member Radionuclide Decay Chain in Ground Water, BMI/OCRD-25; Office of Crystalline Repository Development, Battelle Memorial Institute, Columbus, OH, p. 162.

Hodgkinson, D. P., and P. R. Maul, 1985. One-Dimensional Modelling of Radionuclide Migration Through Permeable and Fractured Rock of Arbitrary Length Decay Chains Using Numerical Inversion of Laplace Transforms, AERE-11889, AERE-Harwell, Oxfordshire, UK, p. 36.

Kanki, T., A. Fujita, P. L. Chambre, and T. H. Pigford, 1981. Transport of Radionuclides Through Fractured Media, UCB-NE-4009, Lawrence Berkeley Laboratory, University of California, Earth Sciences Division, Berkeley, CA.

Moreno, L., and A. Rasmuson, 1986. "Contaminant Transport Through a Fractured Porous Rock: Impact of the Inlet Boundary Condition on the Concentration Profile in the Rock Matrix," Water Resources Research, Vol. 22, No. 12, pp. 1728-1730.

Neretnieks, I., 1980. "Diffusion in the Rock Matrix: An Important Factor in Radionuclide Retardation?" Journal of Geophysical Research, Vol. 85, pp. 4379-4397.

Neretnieks, I., T. Eriksen, and P. Tahtinen, 1982. "Tracer Movement in a Single Fissure in Granitic Rock: Some Experimental Results and Their Interpretation," Water Resources Research, Vol. 18, No. 4, pp. 849-858.

Rasmuson, A., and I. Neretnieks, 1980. "Exact Solution of a Model for Diffusion in Particles and Longitudinal Dispersion in Packed Beds," A.I.Ch.E. Journal, Vol. 26, pp. 686-690.

Rasmuson, A., and I. Neretiiteks, 1981. "Migration of Radionuclides in Fissured Rock: The Influence of Micropore Diffusion and Longitudinal Dispersion," Journal of Geophysical Research, Vol. 86, pp. 3749-3758.

Rasmuson, A., and I. Neretnieks, 1986. "Radionuclide Transport in Fast Channels in Crystalline Rock," Water Resources Research, Vol. 22, pp. 1247-1256.

Rasmuson, A., 1984. "Migration of Radionuclides in Fissured Rock: Analytical Solutions for the Case of Constant Source Strength," Water Resources Research, Vol. 20, No. 10, pp. 1435-1442.

Rickert, P. G., R. G. Strickert, and M. G. Seitz, 1979. Nuclide Migration in Fractured Porous Rock, American Chemical Society, pp. 167-197.

Rosen, A. B., 1952. "Kinetics of a Fixed Bed System for Solid Diffusion into Spherical Particles," Journal of Chemical Physics, Vol. 20, p. 387.

Skopp, J., and A. W. Warrick, 1974. "A Two-Phase Model for the Miscible Displacement of Reactive Solutes in Soils," Soil Science Society of America Proceedings, Vol. 38, No. 4, pp. 545-550.

Sneddon, L. N., 1951. Fourier Transforms, McGraw-Hill Book Co., New York, NY.

Stroud, A. H., and D. Secrest, 1966. Gaussian Quadrature Formulas, Prentice-Hall, Inc., Englewood Cliffs, NJ.

Sudicky, E. A., and E. O. Frind, 1982. "Contaminant Transport in Fractured Porous Media: Analytical Solution for a System of Parallel Fractures," Water Resources Research, Vol. 18, No. 6, pp. 1634-1642. 
Sudicky, E. A., and E. O. Frind, 1984. "Contaminant Transport in Fractured Porous Media: Analytical Solution for a Two-Member Decay Chain in a Single Fracture," Water Resources Research, Vol. 20, No. 7, pp. 1021-1029.

Tang, D. H., E. O. Frind, and E. A. Sudicky, 1981. "Contaminant Transport in Fractured Porous Media: Analytical Solution for a Single Fracture," Water Resources Research, Vol. 17, No. 3, pp. 555-565.

Van Genuchten, M. T., D. H. Tang, and R. Guennelon, 1984. "Some Exact Solutions for Solute Transport Through Soils Containing Large Cylindrical Macropores," Water Resources Research, Vol. 20, pp. 335-346. 


\section{APPENDIX A}

\section{THEOREMS, LAPLACE TRANSFORMS, AND DERIVATIVES}

In this appendix, a selected number of theorems, inverse Laplace transforms, and derivatives is reported.

\section{A. 1 THEOREMS}

The operations for the Laplace transformation reported in Chapters 1 to 4 require, in some cases, the use of the following theorems.

A.1.1 Translation

$$
L^{-1}\left[e^{-b s} f(s)\right]=F(t-b) U(t-b), b>0
$$

where $U(t)$ is the Heaviside unit step function defined as

$$
U(t)=\begin{aligned}
& 0, t<0 \\
& 1, t>0
\end{aligned}
$$

A.1.2 Linear Transformation

$$
\left.\mathrm{L}^{-1}[\mathrm{ff} \mathrm{s}-\mathrm{a})\right]=\mathrm{e}^{\mathrm{at}} \mathrm{F}(\mathrm{t})
$$

A.1.3 Differentiation

$$
\begin{gathered}
L^{-1} s f(s)-F(+0)=F^{\prime}(t) \\
L^{-1} s^{n} f(s)-L^{-1} s^{n-1} F(+0)-L^{-1} s^{n-2} F^{\prime}(+0)-\ldots-F^{(n-1)}(+0)=F^{(n)}(t)
\end{gathered}
$$

A.1.4 Convolution or Faltung

$$
L^{-1}\left[f_{1}(s) \cdot f_{2}(s)\right]=\int_{0}^{t} F_{1}(t-\tau) F_{2}(\tau)=F_{1}^{*} F_{2}
$$


$f(s)$

$$
\begin{array}{ll}
\frac{e^{-a \sqrt{s}}}{s} & =\operatorname{erfc}\left(\frac{a}{2 \sqrt{t}}\right) \\
\frac{e^{-a \sqrt{s}}}{\sqrt{s}} & =\frac{1}{\sqrt{n t}} \exp \left(-\frac{a^{2}}{4 t}\right) \\
e^{-a \sqrt{s}} & =\frac{a}{2 \sqrt{n t^{3}}} \exp \left(-\frac{a^{2}}{4 t}\right) \\
\frac{1}{s^{n}, n>0} & =\frac{t^{n-1}}{\Gamma(n)} \\
\frac{1}{s-i c} \cosh \left(b s^{1 / 2}\right) \operatorname{sech}\left(a s^{1 / 2}\right) & =e^{i c t} \cosh \left[b(i c)^{1 / 2}\right] \operatorname{sech}\left[a(i c)^{1 / 2}\right] \\
a>b>0 & -2 n \sum_{n=0}^{\infty}(-1)^{n}(n+1 / 2)\left[(n+1 / 2)^{2} n^{2}+i c a^{2}\right]^{-1} \\
& \cdot \cos (n+1 / 2) n b / a] \exp \left[-(n+1 / 2)^{2} n^{2} t / a\right]
\end{array}
$$

\section{A. 3 LAPLACE INVERSION OF $\mathrm{s}^{\mathrm{n}+1 / 2}$}

Because the inverse Laplace transform of $s^{n+1 / 2}$ for positive values of $n$ is not reported in standard tables, the derivation of this may be useful to the reader. The gamma function (see Abramowitz and Stegun, 1972) defined as

$$
\Gamma(z)=\int_{0}^{\infty} t^{z-1} e^{-t} d t
$$

where $\mathrm{z}$ is the complex variable, is single valued and analytic over the entire complex plane with the exception of negative integers. 
For positive values of the real part of $z$ (i.e., $x$ ) Equation A.3-1 becomes

$$
\Gamma(x)=\int_{0}^{\infty} t^{x-1} e^{-t} d t
$$

and the characteristic equation is given by

$$
\Gamma(x+1)=x \Gamma(x)
$$

It may be easily shown that

$$
\Gamma(-x)=\frac{\Gamma(1-x)}{(-x)}, x \neq 0,1,2, \ldots
$$

The Laplace transform of $t-n-3 / 2$ may be written as

$$
L\left\{t^{-n-3 / 2}\right\}=\int_{0}^{\infty} e^{-s t} t^{-1 n-3 / 2} d t
$$

Substitution of $\mathrm{s}=\mathrm{u} / \mathrm{t}$ yields

$$
L\left\{t^{-n-3 / 2}\right\}=\frac{1}{s^{-n-1 / 2}} \int_{0}^{\infty} u^{-n-3 / 2} e^{-u} d u .
$$

Hence, from Equation A.3-2, we have

$$
L^{-1} S^{n+1 / 2}=\frac{t^{-n-3 / 2}}{\Gamma(-n-1 / 2)}
$$

Using the relation given by Equation A.3-4 and with the knowledge of $\Gamma(1 / 2)=\sqrt{\mathrm{II}}$, we may derive $\Gamma(-n-1 / 2)$ through a recurrence formula. Thus it follows for $\mathrm{n}=0$

$$
\Gamma\left(-\frac{1}{2}\right)=-2 \Gamma\left(\frac{1}{2}\right)=-2 \sqrt{I 1}
$$

$\mathrm{n}=1$

$$
\Gamma\left(-\frac{3}{2}\right)=-\left(\frac{2}{3}\right) \Gamma\left(-\frac{1}{2}\right)=(-1)^{2}\left(\frac{2}{3}\right)(2) \sqrt{\mathrm{II}}=\frac{4}{3} \sqrt{\mathrm{II}}
$$


$\mathrm{n}=2$

$$
\Gamma\left(-\frac{5}{2}\right)=-\left(\frac{2}{5}\right) \Gamma\left(-\frac{3}{2}\right)=(-1)^{3}\left(\frac{2}{5}\right)\left(\frac{2}{3}\right)(2) \sqrt{11}=-\frac{8}{15} \sqrt{11}
$$

$\mathrm{n}=\mathrm{p}$

$$
\Gamma\left(-p-\frac{1}{2}\right)=(-1)^{p+1}\left(\frac{2}{2 p+1}\right)\left(\frac{2}{2 p-1}\right) \ldots\left(\frac{2}{5}\right)\left(\frac{2}{3}\right)(2) \sqrt{11}
$$

The above expressions may also be written as

$$
\Gamma\left(-p-\frac{1}{2}\right)=(-1)^{p+1} \sqrt{11} \prod_{i=0}^{11}\left(\frac{2}{1+2 i}\right) \text {. }
$$

Hence Equation A.3-7 becomes

$$
L^{-1} S^{n+1 / 2}(-1)^{n+1}=\frac{t^{-n-3 / 2}}{\sqrt{11}} \prod_{i=0}^{n}\left(\frac{1+2 i}{2}\right), n=0,1,2,3, \ldots
$$

\section{A.4 $\mathrm{N}^{\text {th }}$ DERIVATIVE OF ERROR FUNCIION}

The Nth derivative of the error function (see Abramowitz and Stegun, 1972) is given by

$$
\frac{\mathrm{d}^{\mathrm{n}+1}}{\mathrm{~d} \mathrm{z}^{\mathrm{n}+1}}\{\operatorname{erf}(\mathrm{z})\}=(-1)^{\mathrm{n}} \frac{2}{\sqrt{\mathrm{II}}} H_{11}(z) \mathrm{e}^{-\mathrm{z}^{2}}, \mathrm{n}=0,1,2,3, \ldots
$$

where $H_{\mathrm{n}}$ are the Hermite polynomials. A list of the first six polynomials is given horeafter.

$$
\begin{aligned}
& H_{0}=1 \\
& H_{1}(z)=2 z \\
& H_{2}(z)=4 z^{2}-2 \\
& H_{3}(z)=8 z^{3}-12 z \\
& H_{4}(z)=16 z^{4}-48 z^{2}+12 \\
& H_{5}(z)=32 z^{5}-160 z^{3}+120 z \\
& H_{6}(z)=64 z^{6}-480 z^{4}+720 z^{2}-120
\end{aligned}
$$


The recurrence relation (see Schiff, 1950) is given by

$$
H_{\mathrm{n}+1}(\mathrm{z})=2 \mathrm{z} H_{\mathrm{n}}(\mathrm{z})-2 \mathrm{n} H_{\mathrm{n}-1}(\mathrm{z}), \mathrm{n}>0
$$

\section{$\underline{\text { References }}$}

Abramowitz, M., and I. A. Stegun, 1972. Handbook of Mathematical Functions, Dover Publications, Inc., New York, NY.

Schiff, L. I., 1950. Quantum Mechanics, McGraw-Hill, New York, NY. 


\section{APPENDIX B}

\section{QUADRATURE}

The various solutions presented in this report require for tho most part the evaluation of integrals. An exception is made in the case of the longitudinal dispersion-free solution associated with the single fracture case (Chapter 3) and the series-based solution for the parallel fracture case (Chapter 4). The integrals associated with the general solution of Equations 2-10 and 2-11 which emerge from the consideration of longitudinal dispersion effects or result from the numerical inversion of the Laplace transform show some similarity with respect to their limits $(0, \infty)$. However, because of the distinct nature of their respective integrands the techniques used to approximate the integration over finite subintervals are quite different. Because of the remarkable convergence properties of the Gaussian integration formulas (see Stroud and Secrest, 1966), the Gauss-Legendre quadrature scheme has been adopted in this work.

\section{B.1 TRANSFORMATION FOR INFINITE INTEGRAL ASSOCIA'TED WITH 'THE PRESENCE OF LONGITUDINAL DISPERSION}

The integral of interest has the following form

$$
I=\int_{0}^{\infty} f(x) d x
$$

when the dependent variable of the integrand corresponds in our case to o (see Equations 3.42, 3-44, 3-58, and 4-4). Hence by virtue of the properties inherent to the Heaviside function (see Equations 2-21), the lower limit, say $o_{\min }$, must meet the following criterion

$$
t \geq R_{X}
$$

Substitution for $\mathrm{X}$ given by Equation 3-22d. The potential lower limit may then be written as

$$
1_{\text {min }}=\frac{x}{2}\left(\frac{R}{D_{x x} t}\right)^{1 / 2}
$$

The choice of the upper and lower limits of integration are also dictated by the condition that the maximum absolute value of the exponential argument appearing in Equation 3-22a written as

$$
\Psi(\mathrm{x}, 0)=\frac{2}{\sqrt{\mathrm{II}}} \exp \left|-\left(0-\frac{Y}{0}\right)^{2}\right|
$$


with

$$
y=\frac{u x}{4 D_{x x}}
$$

should always be less than or equal to the one allowed by the computer, say $A R G$. Hence equating the latter with the argument of the exponential form in Equation B.1-4, we obtain

$$
\sigma^{4}-(A R G+2 y) o^{2}+y^{2}=0
$$

where the roots of the above equation are given by

$$
\begin{gathered}
0_{\text {max }}^{2}=\frac{\left(A R G+2 \gamma^{2}\right)+\left|(A R G+2 \gamma)^{2}-4 \gamma^{2}\right|^{1 / 2}}{2} \\
2^{0_{\text {min }}^{2}}=\frac{(A R G+2 \gamma)-\left|(A R G+2 \gamma)^{2}-4 \gamma^{2}\right|^{1 / 2}}{2} .
\end{gathered}
$$

Note that both roots are positive. The potential values for the integration limits given by Equations B.1.7 and B.1.8 are now used to extract suitable upper (oUL) and lower limits $\left(O_{L L}\right)$. 'The integration domain is split over two finite intervals, i.e., $\left|\sigma_{L L}, \sigma_{I N}\right|$ and $\mid \sigma_{I N}$, oUL $\mid$, where $\sigma_{I N}$ will correspond to the value of $o$ in Equation B.1-6 when function $\psi(x, \sigma)$ (see Equation 3-22a) is a maximum;

$$
\sigma_{I N}=Y^{1 / 2}, \sigma_{L L}<Y^{1 / 2}<o_{U L}
$$

If the above condition is not satisfied, then

$$
\sigma_{I N}=\frac{1}{2}\left(o_{L L}+\sigma_{U L}\right), Y^{1 / 2}<o_{L L_{1}} \text { or } Y^{1 / 2}>\sigma_{U L}
$$

where

$$
\begin{aligned}
& \sigma_{L L}=\operatorname{MAX} l_{1} \sigma_{\min } \cdot 2^{\sigma} \sigma_{\min } l \\
& \sigma_{U L}=\operatorname{MAX} l_{1} \sigma_{\min }, \sigma_{\max } l
\end{aligned}
$$

Results yiclded by this method proved to be very satisfactory, however, at the expense of an additional computational effort. 


\section{B.2 PARALLFL FRAC'TURE CASE}

For the sake of simplicity, the discussion presented in this section ls focused on the longitudinal dispersion-free form of the transport equation given by Equation 2"10. However, it may easily be extended to the general form of the transport equation.

'The varlous integrands $\mathrm{Cr}(\eta, \mathrm{t})$ associated with the solution of the parallol fracture case resulting from the the numerical inversion of the Laplace transform by means of contour Integration may be looked upon as one corresponding to the product of two functions $g_{1}(\eta)$ and $g_{2}(\eta, t)$ written as

$$
G=g_{1}(n) \cdot g_{2}(n, t)
$$

where

$$
\begin{aligned}
& g_{1}(\eta)=\exp \left(\beta_{r}\right) / \eta \text { (Fracture, Mass Flux, and Cumulative Mass Flux) } \\
& \qquad g_{1}(\eta)=\sum_{n=1}^{2} \sum_{n=1}^{2} \frac{\exp \left(\bar{\beta}_{r}\right)}{\delta_{1} \eta} \text { (Rock Matrix) }
\end{aligned}
$$

and

$$
\begin{gathered}
\left.g_{i} \eta, t\right)=\sin \left(\bar{y}^{\prime} e^{\prime}+\sin \left(v-\bar{y}^{\prime} e^{\prime}\right. \text { (Fracture, Mass Flux) }\right. \\
g_{2}(\eta, t)=\sin \left(\bar{y}^{\prime} e^{\prime}\right)+\sin \left(v-\bar{y}^{\prime}{ }_{e}\right) \text { (Rock Matrix) } \\
g_{2}(r, t)=\sum_{k=1}^{2} I_{k} \text { (Cumulative Mass Flux) }
\end{gathered}
$$

where $I_{1}$ and $I_{2}$ are given by Equations 5-30c and 5-31b.

Reforring to Equations B.2-2 and B.2-3, these correspond to sots of smooth, exponentially decaying and quasi-sinusoidal functions, respectively, which generate rapidly oscillatory integrands (i.e., one with numerous local maxima and minima), however which decay over the range of integration. Figures B-1, B-2, and B-3 show some typical representative curves for $g_{1}(\eta)$ and $g_{2}(\eta, l)$ and the integrand $G$ obtained for three different values of the variable $x$, all cther parameters being kept. constant. 

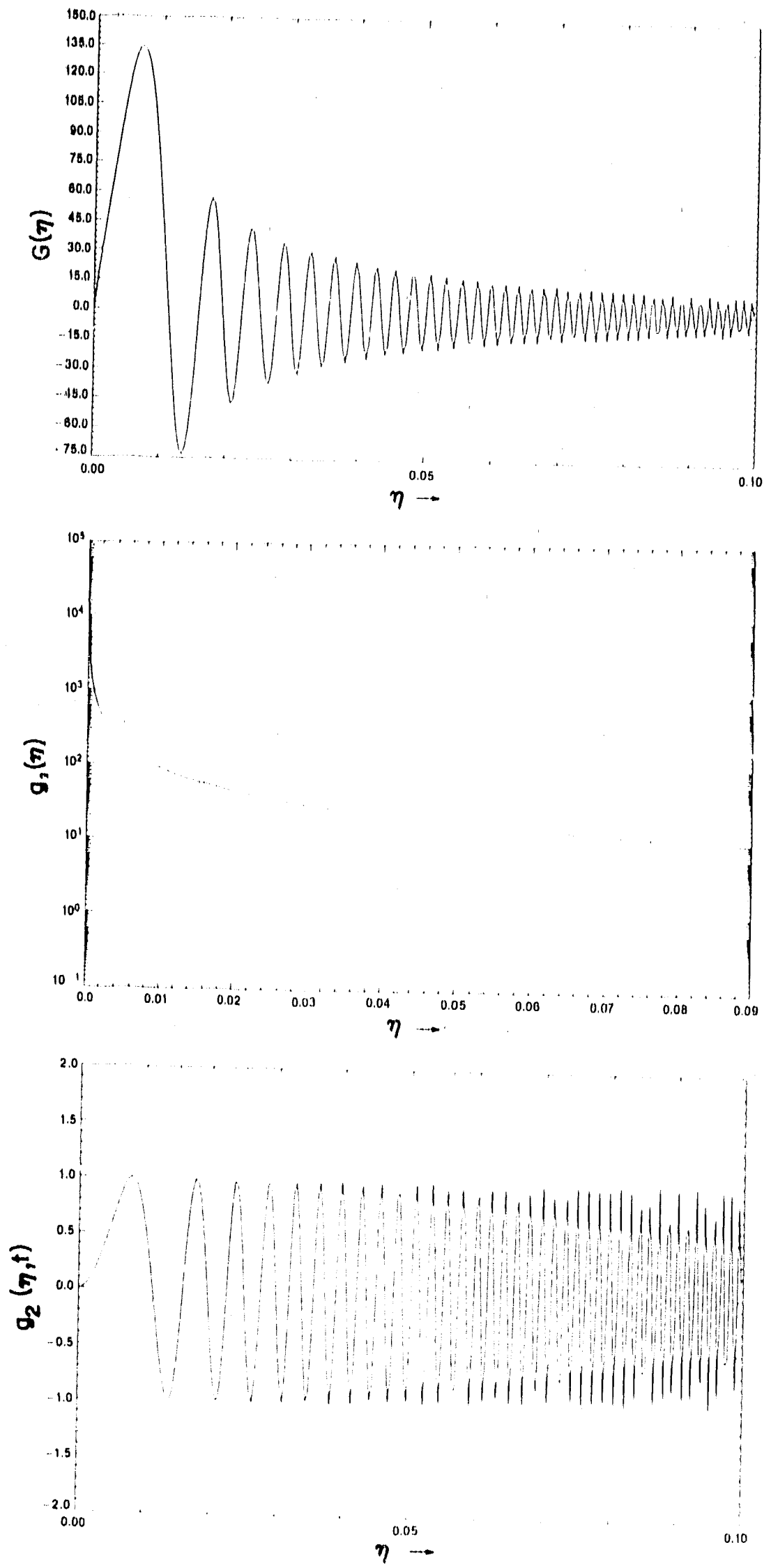

Figure B-1. Variations of Function $G(\eta), g_{1}(\eta)$, and $g_{2}(\eta, t)$ for $x=1 \mathrm{~m}$ 

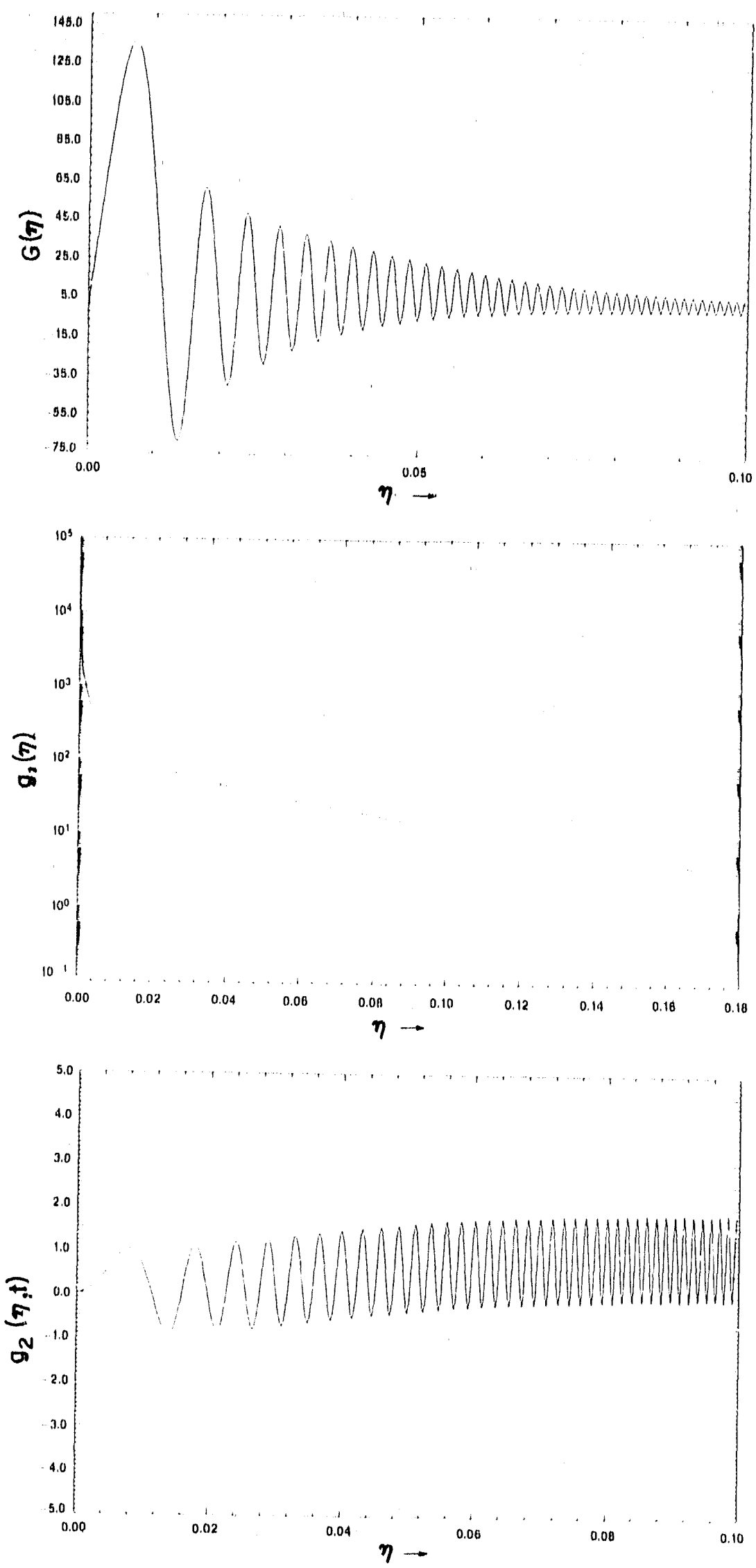

Figure B-2. Variations of Function $G(\eta), g_{1}(\eta)$, and $g_{2}(\eta, t)$ for $x=100 \mathrm{~m}$ 

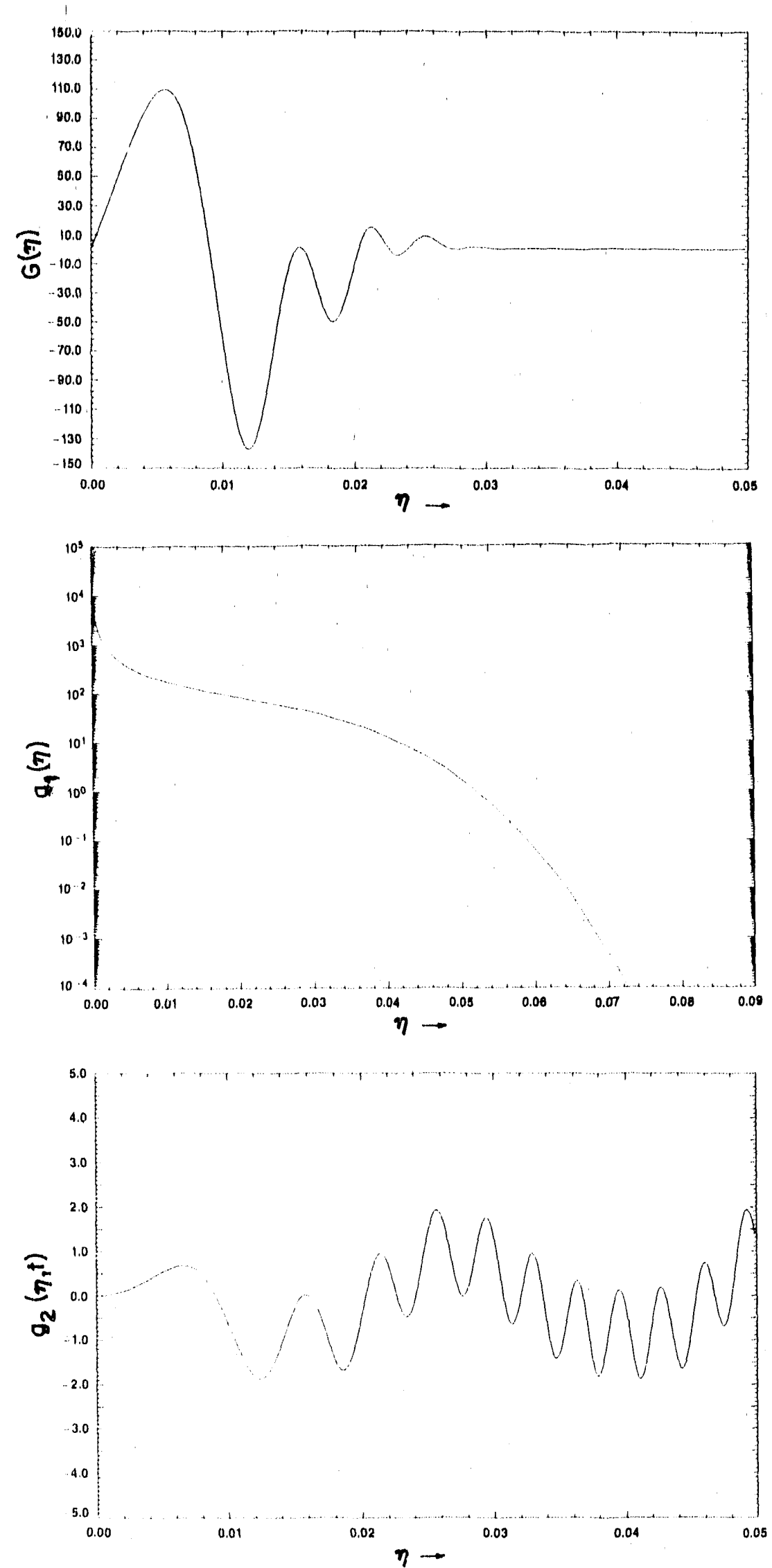

Figure B-3. Variations of Function $G(\eta), g_{1}(\eta)$, and $g_{2}(\eta, t)$ for $x=10,000 m$ 
Table B-1. Parametors Used to Estimate $\mathrm{Cr}(n)$, $g_{1}(\eta)$, and $g_{2}(\eta, t)$

\begin{tabular}{ll}
\hline $\mathrm{x}$ & $1,100,10^{4} \mathrm{~m}$ \\
$\mathrm{~L}$ & $0.32 \mathrm{~m}$ \\
$\mathrm{~b}$ & $0.005 \mathrm{~m}$ \\
$\mathrm{u}$ & $10 \mathrm{~m} / \mathrm{yr}$ \\
$\mathrm{v}$ & $0 \mathrm{~m} / \mathrm{yr}$ \\
$\mathrm{D}_{\mathrm{xx}}$ & $0 \mathrm{~m}^{2} / \mathrm{yr}$ \\
$\mathrm{D}_{\mathrm{yy}}$ & $0 \mathrm{~m}^{2} / \mathrm{yr}$ \\
$\mathrm{D}_{\theta}$ & $0.01 \mathrm{~m}^{2} / \mathrm{yr}$ \\
$\mathrm{R}$ & 1.0 \\
$\mathrm{R}^{\prime}$ & 100.0 \\
$\phi$ & 0.01 \\
$\mathrm{t}$ & $5 \times 10^{4} \mathrm{yr}$ \\
\hline
\end{tabular}




\section{Range of Integration}

Reduction of the infinite interval to a finite interval became mandatory because an initial attempt to evaluate the integral using a Gauss-Legendre quadrature scheme failed to produce acceptable results. A potential upper limit $\left(\eta_{U L}\right)$ for the range of integration is computed in our case after equating $g_{1}(\eta)$ to a small number (i.e., EPS)* and using the Newton-Raphson iteration formula. Subsequently, the segment $\left[0, \eta_{L}\right]$ is subdivided into $n$ unequal intervals (i.e., $\left.\left[0, \eta_{1}\right],\left[\eta_{1}, \eta_{2}\right], \ldots\left[\eta_{n-1}, \eta_{1 \mathrm{~s}}\right]\right)$ where the upper limit of each of these is computed using the following relation:

$$
\eta_{i}=\eta_{U L} a b^{i-1}, i=1,2,3, \ldots n
$$

with $b=\exp -[\ln (a) / n]$ and $a=0.02$. This yields geometrically increasing intervals which would allow a highly accurate evaluation of the integrals in the region close to the origin using a modest number of integration points. Their contributions to the anticipated result may be quite significant under some circumstances. In order to optimize the convergence of the integral, a search for a tentative reduction of the integration domain is carried out after performing a quadrature which uses 60 integration points for each interval. Subsequently the contributions of successive intervals are summed up beginning from the last (i.e., nth) and, in the event the absolute ratio of this to the value of the integral is less than $1 . E-06, \eta_{n-1}$ is then substituted for $\eta_{U L}$, where i denotes the current value of the summation index.

Because of the oscillatory nature of the aforementioned integrand, a composite iterative GaussLegendre quadrature scheme was adopted with $\left(\eta_{-i 1}, \eta_{i}\right)$ split initially into $m=2$ subintervals and increased by a factor of $1.5(\mathrm{~m} \geq=1000)$ or $1.2(\mathrm{~m}>1000)$ at subsequent iterations, using at all times 20 Gaussian points. Note that care is taken to round off the value of $m$ to the nearest integer whenever required. The convergence test is initiated at the end of the second iteration (see below). The selection of the initial value for $m$ for subsequent intervals is taken to correspond to the one registered at the step of the iteration process prior to the last marking the convergence of the preceding interval. The maximum allowed value for $m$ in the FRACFLO code corresponds to 750; when past this mark, iteration can no longer be performed. Note that in the case of the longitudinal dispersion free form of the transport equation the integration range is split into 25 intervals; however, due to the severe execution time constraint imposed by the solution of the general form of the transport equation, a maximum of 12 intervals was adopted in such an instance. In addition, the iterative quadrature scheme was

* EPS $=10^{-6}$ except in the case of the fracture, where it follows that for

$$
\begin{array}{r}
.01<\varepsilon / 2 \sqrt{t-R_{X}}<.1, \text { EPS }=0.01 \\
\varepsilon / 2 \sqrt{t-R_{X}}<.01, \text { EPS }=0.02
\end{array}
$$


applied only when longitudinal dispersive effects are neglected. However, in the general case an adequate match with results yielded by the series solution was registered using 60 quadrature points for each subinterval.

The convergence criterion may be summarized as follows:

$$
\begin{gathered}
\mid\left(G_{i}\right)_{n} I=1 . E-15 \\
\left|\left(G_{i}\right)_{n}-\left(G_{i}\right)_{n-1}\right|=1 . E-04 \text { (Absolute Error) } \\
\left|\frac{\left(G_{i}\right)_{n}-\left(G_{i}\right)_{n-1}}{\left(G_{i}\right)_{n}}\right|=1 . E-03 \text { (Relative Error) }
\end{gathered}
$$

where subscripts $\mathrm{i}$ and $\mathrm{n}$ refer to a typical integral and the iteration index, respectively. Note that for a particular integral, convergence is said to have been reached when either Equation B.2-5 or Equations B.2-6a and B.2-6b are satisfied. Convergence is normally witnessed at the end of the second iteration. Exceptions to this norm occur particularly when the integrand displays a high frequency of oscillation and its amplitude decreases very slowly with $\eta$. With the contribution of successive intervals summed up during the progress of the quadrature operation, a subsequent convergence test based on a criterion adopted for the series solution (see Equations 4-91 and 4-92) is performed past the 20th interval. This allows a further optimization of computer execution time.

Since the magnitude of parameter $\varepsilon$ appearing in the expression of the exponential argument $b_{r}$ in Equation B.2-1 (see also Equation 5-4a) controls the magnitude of the integration domain, and since parameter $t$ controls the frequency of oscillations, numerical experiments such as the one reported in Table B-2 indicate that for a constant value of the Fourier number, the magnitude of the dimensionless number $\varepsilon / 2 \sqrt{t-R_{X}}$, which encompasses the two parameters of interest has a critical bearing on the convergence properties of the present quadrature scheme. It may be added that for a constant value of $\varepsilon / 2 \sqrt{t-R_{X}}$, convergence is almost independent of the Fourier number. Note for example that when 2,500 quadrature points are the minimum required to satisfy convergence in the case of the longitudinal dispersion free form of the transport equation, substantial increases are registered (i.e., 10,420 and 186,340 for $\mathrm{F}_{0}=10 ; 12,250$ and 168,320 for $\mathrm{F}_{0}=408$; and 10,120 and 169,420 for $F_{0}=1666$ when the value of $\varepsilon / 2 \sqrt{t-R_{X}}$ drops to 0.1 and 0.005 , respectively. 
Table B-2. Quadrature Points Required for Selected Range of Values of $F_{0}$ and $\varepsilon / 2 \sqrt{t-R_{X}}\left(D_{x x}=0\right)$

\begin{tabular}{clr}
\hline \multicolumn{1}{c}{ Fo $_{0}$} & $\varepsilon / 2 \sqrt{t-R_{X}}$ & \multicolumn{1}{c}{ Quadrature Points } \\
\hline 10 & 1.0 & 2,200 \\
10 & 0.1 & 10,420 \\
10 & 0.005 & 186,340 (not converged) \\
408 & 1.0 & 2,500 \\
408 & 0.1 & 12,250 \\
408 & 0.005 & 168,320 (not converged) \\
1,666 & 1.0 & 3,080 \\
1,666 & 0.1 & 10,120 \\
1,666 & 0.005 & 169,420 (not converged) \\
\hline
\end{tabular}

\section{B.3 GAUSS-LEGENDRE QUADRATURE}

In the Gauss-Legendre quadrature scheme, the numerical approximation to a typical integral $l$ is given by

$$
I \approx \sum_{i=1}^{n} w_{i} f\left(x_{i}\right)
$$

where $w_{i}$ are the weighting functions and $x_{i}$ are the integration points for an n-point Gaussian integration.

The evaluation of the integral may be described as follows. Consider the problem of evaluating

$$
I \approx \int_{a}^{b} f(x) d x
$$

By Gauss-Legendre quadrature, this is accomplished by making the change of variable from $\mathrm{x}$ to $\mathrm{z}$ given by

$$
\begin{gathered}
z=\frac{2 x-a-b}{b-a} \\
x=\frac{1}{2}[(b-a) z+b+a]
\end{gathered}
$$


which changes Equation B.3-2 to

$$
\int_{a}^{b} f(x) d x=\frac{(b-a)}{2} \int_{-1}^{1} g(z) d z
$$

with

$$
g(z)=f\left(\frac{1}{2}(b-a) z+\frac{1}{2}(a+b)\right)
$$

The value of the integral $f(x)$ in the interval -1 and +1 is given by Equation B.3-1. It can be shown that an n-point Gaussian integration can evaluate exactly the integral of a $2 n-1$ degree polynomial. Subroutine DGAUSS provides the user with values of roots of the Legendre polynomials as well as the corresponding weight factors for a number of integration points, i.e., 10, 20,60, 104, and 256. (See Stroud and Secrest (1966), and Carnahan et al. (1969).1

Generally, the solution is sensitive to the number of integration points selected for the particular problem.

When the segment $[a, b]$ is subdivided into $\mathrm{m} / 2$ intervals ( $m$ even), the integral is then approximated as

$$
\int_{a}^{b} f(x) d x \approx \frac{(b-a)}{m} \sum_{j=0}^{(m / 2)-1} f\left[a+\frac{(b-a)}{m}[1+z+2 j]\right]
$$

In the case of a double integral, Equation B.3-1 becomes

$$
I \approx \sum_{j=1}^{m} w_{j} \sum_{i=1}^{m} v_{i j} f\left(x_{i}, y_{i j}\right)
$$

where the double subscripts on the right reflect the fact that the abscissas and weights of the m-point rule must be adjusted for each value of $j$ of the $n$-point rule. Note that the identity given by Equation B.3-8 is an mn-point rule for $I$.

\section{$\underline{\text { References }}$}

Carnahan, B., H. A. Luther, and J. O. Wilkes, 1969. Applied Numerical Methods, John Wiley and Sons, Inc., New York, NY.

Stroud, A. H., and D. Secrest, 1966. Gaussian Quadrature Formulas, Prentice-Hall, Inc, Englewood Cliffs, $\mathrm{NJ}$. 
Let the two functions $u$ and $v$ be defined as

$$
\begin{aligned}
& u=t^{p} \\
& v=e^{a / t}
\end{aligned}
$$

where a and $\mathrm{p}$ are constants.

The $n$th derivative of $u$ with respect to $t$ may be written as

$$
\frac{d^{n} u}{d t^{n}}=t^{(p-n)} \prod_{i=1}^{n}(p-i+1)
$$

and the $\mathrm{n}^{\text {th }}$ derivative of $\mathrm{v}$ with respect to $t$ (see Gradshteyn and Ryzhik, 1980, p. 19) is given by

$$
\begin{aligned}
\frac{d^{n}}{d t^{n}}\left(e^{a / t}\right) & =(-1)^{n} \frac{1}{t^{n}} e^{a / t} \mid\left(\frac{a}{t}\right)^{n}+(n-1)\left(\frac{n}{1}\right)\left(\frac{a}{t}\right)^{n-1}+(n-1)(n-2)\left(\frac{n}{2}\right)\left(\frac{a}{t}\right)^{n-2} \\
& +(n-1)(n-2)(n-3)\left(\frac{n}{3}\right)\left(\frac{a}{t}\right)^{n-3}+\ldots \mid
\end{aligned}
$$

or symbolically,

$$
\frac{d^{n}}{d t^{n}}\left(e^{a / t}\right)=(-1)^{n} \frac{1}{t^{n}} e^{a / t}\left|\sum_{m=1}^{n} \prod_{i=1}^{m-1}(n-i)\left(\begin{array}{l}
n \\
m-1
\end{array}\right)\left(\frac{a}{t}\right)^{n-m+1}\right|
$$

Using Leibnitz's theorem for differentiation of a product (Abramowitz and Stegun, 1972, p. 12) given by

$$
\frac{d^{n}(u v)}{d t^{n}}=\frac{d^{n} u^{v}}{d t^{n}}+\left(\begin{array}{l}
n \\
1
\end{array}\right) \frac{d^{n-1} u}{d t^{n-1}} \frac{d v}{d t}+\left(\begin{array}{l}
n \\
2
\end{array}\right) \frac{d^{n-2} u}{d t^{n-2}} \frac{d^{2} v}{d t^{2}}+\ldots+\left(\begin{array}{l}
n \\
r
\end{array}\right) \frac{d^{n-r} u}{d t^{n-r}} \frac{d^{r} v}{d t^{r}}+\ldots+u \frac{d^{n} v}{d t^{n}}
$$

and substitution of Equations C-1, C-2, C-3, and C-4 in the above equation yields

$$
\frac{d^{n}\left(t^{p} e^{a / t}\right)}{d t^{n}}=t^{p-n} e^{a / t} \sum_{r=0}^{n}\left(\begin{array}{l}
n \\
r
\end{array}\right) \prod_{i=1}^{n-r}(p-i+1)(-1)^{r} \sum_{m=1}^{r} \prod_{j=1}^{m-1}(r-j)(\underset{m-1}{r})\left(\frac{a}{t}\right)^{r-m+1}
$$




\section{$\underline{\text { References }}$}

Abramowitz, M., and I. A. Stegun, 1972. Handbook of Mathematical Functions, Dover Publications, Inc., New York, NY.

Gradshteyn, I. S., and M. Ryzhik, 1980. Table of Integrals, Series, and Products, Academic Press, New York, NY, 1160.pp. 


\section{APPENDIX D}

\section{A COMPLEXX DEFINITE IN'TEGRAL}

The following provides a proof of the incegral relation

$$
I(t)=\int_{0}^{\infty} \exp \left(-t^{2}-\frac{z^{2}}{t^{2}}\right) d t=\frac{\sqrt{\pi}}{2} \exp (-2 z)
$$

when $\mathrm{z}$ is a complex quantity written as:

$$
\mathrm{z}=(\mathrm{c}+\mathrm{id})^{2}
$$

Noting that the function under the integral sign in Equation D- 1 is an even function, substitution of $z$ given by Equation D-2, yields

$$
I=\int_{0}^{\infty} \exp \left(-t^{2}-\frac{c}{t^{2}}\right) \exp \left(\frac{-i d}{t^{2}}\right) d t
$$

Using Euler's formula written as:

$$
e^{i \theta}=\cos \theta+i \sin \theta
$$

Equation D-3 becomes:

$$
I=I_{1}+I_{2}
$$

where

$$
\begin{gathered}
I_{1}=\int_{0}^{\infty} \exp \left(-t^{2}-\frac{c}{t^{2}}\right) \cos \left(\frac{d}{t^{2}}\right) d t \\
I_{2}=-i \int_{0}^{\infty} \exp \left(-t^{2}-\frac{c}{t^{2}}\right) \sin \left(\frac{d}{t^{2}}\right) d t
\end{gathered}
$$


Recognizing the following integrals (see Gradshtoyn and Ryahik, 1980, p. 486)

$$
\begin{aligned}
& \quad \int_{0}^{\infty} \operatorname{oxp}\left|-\left(p^{2} x^{2}+\frac{q^{2}}{x^{2}}\right)\right| \cos \left(a^{2} x^{2}+\frac{b^{2}}{x^{2}}\right) d x \\
& =\frac{\sqrt{11}}{2 r} \exp (-2 r \operatorname{ros}(A+B)) \cos (A+2 r \sin (A+B)) \text { for } a^{2}+p^{2}>0
\end{aligned}
$$

and

$$
\begin{aligned}
& \quad \int_{0}^{\infty} \exp \left|-\left(p^{2} x^{2}+\frac{q^{2}}{x^{2}}\right)\right| \sin \left(a^{2} x^{2}+\frac{b^{2}}{x^{2}}\right) d x \\
& =\frac{\sqrt{11}}{2 r} \exp (-2 \operatorname{rscos}(A+B)) \sin (A+2 \operatorname{rssin}(A+B)) \text { for } a^{2}+p^{2}>0
\end{aligned}
$$

where

$$
\begin{aligned}
& r=\left(a^{4}+p^{4}\right)^{4} \\
& s=\left(b^{4}+q^{4}\right)^{3} \\
& A=\frac{1}{2} \operatorname{arctg} \frac{a^{2}}{p^{2}} \\
& B=\frac{1}{2} \operatorname{arctg} \frac{b^{2}}{q^{2}}
\end{aligned}
$$

the following relations are satisfied

$$
\begin{array}{llll}
\mathrm{p}=1 & \mathrm{r}=1 & \mathrm{q}^{2}=\mathrm{c} & \mathrm{s}=\left(\mathrm{d}^{2}+\mathrm{c}^{2}\right)^{2} \\
\mathrm{a}=0 & \Lambda=0 & \mathrm{~b}^{2}=\mathrm{d} & B=\frac{1}{2} \operatorname{arctg} \frac{\mathrm{d}}{\mathrm{c}}
\end{array}
$$

Then $I_{1}$ and $I_{2}$ are rewritten as

$$
I_{1}=\frac{\sqrt{\mathrm{II}}}{2} \exp \left(-2\left(\mathrm{~d}^{2}+\mathrm{c}^{2}\right)^{\frac{1}{4}} \cos \left(\frac{1}{2} \operatorname{arctg} \frac{d}{c}\right)\right) \cos \left(2\left(d^{2}+\mathrm{c}^{2}\right)^{3} \sin \left(\frac{1}{2} \operatorname{arctg} \frac{d}{c}\right)\right)
$$




$$
I_{2}=1 \frac{\sqrt{n}}{2} \exp \left(-2\left(d^{2}+c^{2}\right)^{\frac{1}{2}} \cos \left(\frac{1}{2} \operatorname{arctg} \frac{d}{c}\right)\right) \sin \left(2\left(d^{2}+c^{2}\right)^{\frac{1}{4}} \sin \left(\frac{1}{2} \operatorname{arctg} \frac{d}{c}\right)\right)
$$

Hence,

$$
\left.I=\frac{\sqrt{n}}{2} \exp (-x)|\cos y-i \sin y|=\frac{\sqrt{n}}{2} \exp \mid-(x+i y)\right]
$$

where

$$
x=2\left(d^{2}+c^{2}\right)^{\frac{1}{2}} \cos \left(\frac{1}{2} \operatorname{arctg} \frac{d}{c}\right)
$$

and

$$
y=2\left(d^{2}+c^{2}\right)^{\frac{1}{d}} \sin \left(\frac{1}{2} \operatorname{arctg} \frac{d}{c}\right)
$$

Let

$$
\operatorname{arctg} \frac{d}{c}=2 \theta
$$

Using

$$
\begin{gathered}
\cos \theta=\frac{1}{\sqrt{2}}(\cos 20+1)^{\frac{1}{2}} \\
\cos \left(\frac{1}{2} \operatorname{arctg} \frac{d}{c}\right)=\cos \theta=\left|\frac{c+\left(c^{2}+d^{2}\right)}{2\left(c^{2}+d^{2}\right)}\right|^{\frac{1}{2}} \\
\sin \left(\frac{1}{2} \operatorname{arctg} \frac{d}{c}\right)=\sin \theta=\left|\frac{-c+\left(c^{2}+d^{2}\right)}{2\left(c^{2}+d^{2}\right)}\right|^{\frac{1}{2}}
\end{gathered}
$$

Therefore, $x$ and $y$ given by Equations D-14 and D- 15 become:

$$
\begin{gathered}
x=\sqrt{2}\left(c+\left(c^{2}+d^{2}\right)^{\frac{1}{2}}\right)^{\frac{1}{2}} \\
y=\sqrt{2}\left(-c+\left(c^{2}+d^{2}\right)^{\frac{1}{2}}\right)^{\frac{1}{2}} .
\end{gathered}
$$


Then I can be expressed as:

$$
1=\frac{\sqrt{11}}{2} \exp \left|-2\left(\left(\frac{c+\left(c^{2}+d^{2}\right)^{2}}{2}\right)^{1}+1\left(\frac{-c+\left(c^{2}+d^{2}\right)^{1}}{2}\right)\right)\right| .
$$

Noting that the argument of the exponential function corrosponds to the sefunto root of the complex quantity $(c+i d)$ given by Wquation D-2 (see Dwight, 1961, p. 17), honco the above ofuation cun be written:

$$
1=\frac{\sqrt{11}}{2} \exp \left(-2|c+i d|^{\frac{1}{2}}\right)
$$

und the required rosult is estublishod.

\section{References}

Dwight, II, B., 1961. Table of Integrals and Other Mathomatical Dala, Fourth Edition, 'The Macmillan Company, New York, NY, $336 \mathrm{pp}$.

Gradshteyn, I. S., and I. M. Ryzhik, 1980. 'Tahle of Integrals, Series, and Products, Acudomic Press, New York, NY, 1160 pp. 


\section{APPLNDIXE}

\section{NOTATIONS}

Terms
$a_{L} \quad$ longitudinal dispersivity
a $\quad$ lateral dispersivity
A concontration in the fracture
$\mathrm{A}^{\circ} \quad$ initial concontration of the species
b half tho fracturo aperturo width
B concentration in tho rock matrix
d width of the finite line source at the origin
D hydrodynamic dispersion tonsor
$D_{d} \quad$ molecular diffusion of nuclide in water
$D_{\theta} \quad$ effective diffusivity in the rock matrix
$\mathrm{D}_{\mathrm{p}} \quad$ porediffusivity
$D_{x x}, D_{y y}$
$D_{x y}$
coefficients of hydrodynamic dispersion tensor in the fracturo
Fo Fourler number for rock matrix
$\mathrm{F}_{\mathrm{x}} \quad$ mass flux in $\mathrm{x}$-direction
Fy mass flux in $y$-direction
J diffusive rate of nuclide at surface of fracture per unit area of fracture surface
$\mathrm{K}_{\mathrm{f}} \quad$ sorption distribution coefficient in the fracture
$\mathrm{K}_{\mathrm{r}} \quad$ sorption distribution coefficient in the rock matrix
L half the fracture spacing
Q rate of production or removal of solute due to radioactive decay in the fracturo
$Q^{\prime} \quad$ rate of production or removal of solute due to radioactive decay in the rock matrix
$\mathrm{R} \quad$ rotardation factor in the fracture
$\mathrm{R}^{\prime} \quad$ retardation factor in the rock matrix
S concentration in the adsorbed phase in the fracture 


\begin{tabular}{|c|c|}
\hline $\mathbf{S}^{\prime}$ & concentration in tho adsorbod phase in the rock matrix \\
\hline $\mathrm{t}$ & lime \\
\hline $\mathrm{T}$ & loaching tlmo \\
\hline $\mathrm{T}_{1 / 2}$ & hulf-lif'o \\
\hline$u, v$ & $x$ and $y$ components of the fluid velocity vector in the fracture \\
\hline V & avorago fluid volocity voctor in the fracture \\
\hline$x, y$ & position vactors in the fracture \\
\hline$y_{0}$ & $y$ coordinate of the center of the Gaussian source \\
\hline$y_{1}$ & $y$ coordinate of the conter of a typical finite patch source \\
\hline $\mathrm{z}$ & position vector in the rock matrix \\
\hline$\Gamma$ & Gamma function \\
\hline$\delta_{d}$ & constrictivity for diffusion \\
\hline$\delta_{i j}$ & Kronecker delta \\
\hline$\lambda$ & first-order rato constant for decay \\
\hline$\sigma_{y}$ & standard deviation of Gaussian source at the origin \\
\hline $\mathrm{Pr}$ & rock donsity \\
\hline i & tortuosity \\
\hline$\phi$ & rock porosity \\
\hline$\phi r$ & volumetric fraction of the solid phase in the rock $\mathrm{r}$ \\
\hline
\end{tabular}

Abbreviated

Forms

$$
\begin{aligned}
& a_{1}=\frac{a_{y}^{2}+2 p^{2}}{4 p^{2} a_{y}^{2}} \\
& a_{2}=-\frac{(y-g) v_{y}^{2}+2 y_{0} p^{2}}{4 p^{2} o_{y}^{2}} \\
& a_{3}=\frac{(y-g)^{2} o_{y}^{2}+2 y_{0}^{2} p^{2}}{4 p^{2} o_{y}^{2}}
\end{aligned}
$$


Abbroviated

Forms.

$$
\begin{aligned}
& c_{f}=\frac{\Phi}{b}\left(R^{\prime} D_{p}\right)^{1 / 2} \\
& \mathrm{c}_{\mathrm{r}}=\left(\mathrm{R}^{\prime} / \mathrm{D}_{\mathrm{p}}\right)^{1 / 2} \\
& F_{0}=\frac{D_{p}(t-R x)}{R^{\prime}(L-b)^{2}} ; D_{x x}>0 ; x \text { becomes } x^{\prime} \text { for } D_{x x}=0 \\
& \bar{F}_{1}=u-2 D_{x x} a_{1}\left(a-a_{1} x\right) ; F_{y}=0 \\
& \mathrm{~F}_{1}^{*}=\mathrm{uE}_{\Omega} ; \mathrm{F}_{\mathrm{y}} \neq 0 \\
& \mathrm{~F}_{1}^{*}=\mathrm{u} ; \mathrm{F}_{\mathrm{y}}=0 \\
& { }_{x} F_{1}=u E_{\Omega}-D_{x x}\left[2 a_{1}\left(\sigma-a_{1} x\right) E_{\Omega}+E_{\Omega}^{x}\right]-D_{x y} E_{\Omega}^{y} ; F_{y} \neq 0 \\
& { }_{y} F_{1}=v E_{\Omega}-D_{y x}\left[2 a_{1}\left(\sigma-a_{1} x\right) E_{\Omega}+E_{\Omega}^{x}\right]-D_{y y} E_{\Omega}^{y} ; F_{y} \neq 0 \\
& i_{2}{ }^{\prime}=\frac{\bar{\beta} c_{p} D_{i x}}{\sqrt{\pi}} E_{\Omega} ; i=x, y ; F_{y} \neq 0 \\
& \bar{x}_{2}=\frac{\bar{\beta} c_{f} D}{\sqrt{\pi}} ; F_{y}=0 \\
& \mathrm{~F}_{2}^{*}=\mathrm{D}_{\mathrm{ix}} \mathrm{E}_{\Omega} \bar{\beta} ; \mathrm{i}=\mathrm{x}, \mathrm{y} \\
& \mathrm{E}_{3}^{\prime}=\left|\left(u \mathrm{E}_{\Omega}\right)^{2}+\left(\mathrm{vE}_{\Omega}-\mathrm{D}_{\mathrm{yy}} \mathrm{E}_{\Omega}^{\mathrm{y}}\right)^{2}\right|^{1 / 2} ; \mathrm{D}_{\mathrm{xx}}=\mathrm{D}_{\mathrm{yx}}=0 \\
& g=\left(v-u \frac{D_{y x}}{D_{x x}}\right) x+\left(\frac{D_{y x}}{D_{x x}}\right) x \\
& p=\left(\left(D_{y y}-\frac{D_{y x}^{2}}{D_{x x}}\right) x\right)^{1 / 2} \\
& r_{a}=-R(s+\lambda)-c_{f}(s+\lambda)^{1 / 2} \\
& r_{b}=-c_{r}(s+\lambda)^{1 / 2}
\end{aligned}
$$




$$
\begin{aligned}
& \text { Abbrevlated } \\
& \text { Forms } \\
& a_{1}=w / 4 D_{x x^{\sigma}} \\
& \beta=\left(\frac{R^{\prime}}{D_{n}}\right)^{1 / 2}(L-b) \\
& \bar{\beta}=x / 2 D_{x x} \sigma^{2} ; D_{x x}>0 \\
& \vec{\beta}=\frac{1}{u} ; D_{x x}=0 \\
& \beta_{r}=-\frac{\varepsilon \eta}{2}\left[\frac{\sinh (\beta \eta)-\sin (\beta \eta)}{\cosh (\beta \eta)+\cos (\beta \eta)}\right] \\
& \bar{\beta}_{r}=\beta_{r}+(-1)^{m+1} \frac{\beta \eta}{2}+(-1)^{11+1} \frac{\mu \eta}{2} \\
& \bar{\beta}_{\ell}=\frac{\eta^{2} \tau}{2}-y_{\ell} \\
& \beta_{e}=\frac{\eta^{2} \tau}{2}-\bar{y}_{\ell} \\
& Y_{\ell}=\frac{\varepsilon \eta}{2}\left[\frac{\sinh (\beta \eta)+\sin (\beta \eta)}{\cosh (\beta \eta)+\cos (\beta \eta)}\right] \\
& \bar{y}_{\ell}=Y_{\ell}+(-1)^{m+1} \frac{\beta \eta}{2}-(-1)^{n+1} \frac{\mu \eta}{2} \\
& \Gamma_{\delta}=(-1)^{\mathrm{n}} \frac{4}{(2 \mathrm{n}+1) \pi} \cos (\delta \mu) \\
& \delta=\frac{(2 n+1) n}{2 \beta} \\
& \varepsilon=c_{\mathrm{f}} \mathrm{X} \\
& \varepsilon^{\prime}=c_{f} x^{\prime} ; D_{x x}=0 \\
& \bar{\varepsilon}=\frac{c_{f} X}{2}
\end{aligned}
$$


Abbreviated

Forms

$$
\begin{aligned}
& =\frac{c_{\mathrm{f}} \mathrm{X}^{\prime}}{2} ; \mathrm{D}_{\mathrm{xx}}=0 \\
& \zeta_{\ell}=Y_{\ell} / \varepsilon \\
& \zeta_{r}=\beta_{r} / \varepsilon \\
& \mu=\left(\frac{R^{\prime}}{D_{p}}\right)^{1 / 2}(L-z) \\
& v=\frac{\eta^{2}}{2}\left(t-\frac{R x^{2}}{4 D_{x x} \sigma^{2}}\right) \\
& v^{\prime}=v\left(x^{\prime}\right)=\frac{\eta^{2}}{2}\left(t-\frac{R x}{u}\right) \\
& v_{1}=v\left(\eta_{1}\right)=\frac{\eta^{2}}{2}\left(t-R_{1} \eta_{1}\right) \\
& \bar{\xi}_{k}=k \beta+\bar{\varepsilon} \\
& \overline{\bar{\xi}}_{k}=k \beta+\bar{\varepsilon} \\
& \mathrm{X}=\frac{\mathrm{x}^{2}}{4 \mathrm{D}_{\mathrm{xx}} \mathrm{o}^{2}} ; \mathrm{D}_{\mathrm{xx}}>0 \\
& x^{\prime}=\frac{x}{u} ; D_{x x}=0
\end{aligned}
$$




\section{APPENDIX F}

\section{MODEL PARAMETERS}

CENT

DENSR

DIFF

DIFFR

DIMENS(I,J)

Location of center of source 1 along y axis (IPATCH $=1$ )

Rock matrix bulk density $\left(M / L^{3}\right)$ (used if IDIS'T $=1$ )

Molecular diffusion of species in water $\left(\mathrm{L}^{2 / \mathrm{T}}\right)$ (used if IDISP $=1$ )

Pore diffusivity $\left(\mathrm{L}^{2 / \mathrm{T}}\right)$

Dimensions used in the problem; each must be $\leq 12$ characters in length $\operatorname{DIMENS}(1, \mathrm{~J})=$ species name

$$
\begin{aligned}
& (2, J)=\text { time (year) } \\
& (3, J)=\text { length (meter) } \\
& (4, J)=\mathrm{L} / \Gamma \text { (meter/year) } \\
& (5, J)=\mathrm{L}^{2} / \mathrm{T}\left(\mathrm{m}^{2} / \text { year }\right) \\
& (6, J)=\text { mass/volume }(\mathrm{g} / \mathrm{cc}) \\
& (7, J)=\text { volume/mass }(\mathrm{cc} / \mathrm{g}) \\
& (8, J)=1 / \text { time }(1 . / \text { year }) \\
& (9, J)=\text { activity }(\mathrm{Ci})
\end{aligned}
$$

DISPX

Longitudinal dispersivity/dispersion in the $\mathrm{x}$ direction (see IDISP)

DISPY Lateral dispersivity/dispersion in the $y$ direction (see IDISP)

EXMAX $++\quad$ Largest allowed magnitude for exponential arguments

FDIST Fracture separation distance ( $L)$ (used if IMULT = 1)

HALFL Half-life of species (T)

$\begin{array}{ll}\text { IBAND } & =0 \text { Step release at source } \\ & =1 \text { Band release at source } \\ \text { ICONCF } & =0 \text { Do not calculate fracture concentrations } \\ & =1 \text { Do calculate fracture concentrations } \\ \text { ICONCR } & =0 \text { Do not calculate rock concentrations } \\ & =1 \text { Do calculate rock concentrations } \\ & =0 \text { Do not calculate cumulative mass flux } \\ \text { ICUMF } & =1 \text { Do calculate cumulative mass flux } \\ & =0 \text { DISPX, DISPY correspond to dispersion coefficients } \\ \text { IDISP } & =1 \text { DISPX, DISPY correspond to dispersivities } \\ & =0 \text { RETARD_F, RETARD_R correspond to retardation factors } \\ \text { IDIST } & =1 \text { RETARD_F, RETARD_R correspond to distribution coefficients }\end{array}$


IFLUX $\quad=0$ Do not calculate instantaneous mass flux

$=1$ Do calculate instantaneous mass flux

IGAUSL $\quad=0$ Interval of integration constant

$=1$ Integration limits divided into INTERV intervals

IGRAPH $\quad=0$ Graphics output disabled

$=1$ Graphics output enabled--formatted graphics data written to unit 30

IMULT $\quad=0$ Single fracture plane (infinite diffusion field)

$=1$ Multiple fracture planes (finite diffusion field) series solution

$=2$ Multiple fracture planes (finite diffusion field) contour integration solution

INTERV Number of subintervals $x 2$ for Gauss-Legendre integration (i.e., $\geq 4$ ) (used if IGAUSL $=1$ )

IPATCH $=0$ Boundary condition corresponds to a Gaussian distributed source

$=1$ Boundary condition corresponds to a finite patch source

MSG1 $\leq 72$ characters, first line of graphics output

MSG2 $\quad \leq 72$ characters, second line of graphics output

NMAX Number of Gaussian points for Gauss-Legendre quadrature (it can only have the value of $4,10,20,60,104$, or 256 )

NRUNMAX Number of data sets to be run

NT $\quad \leq 50$, number of time values to be evaluated

NUMBS Number of patch sources (IPATCH = 1)

NX $\quad \leq 50$, number of positions to be evaluated in $\mathrm{x}$ direction

NY $\quad \leq 50$, number of positions to be evaluated in y direction

$\mathrm{NZ} \quad \leq 50$, number of positions to be evaluated in $\mathrm{z}$ direction

PATCH Width of finite source (i.e., IPATCH $=1)(\mathrm{L})$

POROSR Average porosity in rock matrix (L// $\left.3 / \mathrm{L}^{3}\right)$

REFX(I) $\quad x$-position in space (L)

$\operatorname{REFY}(\mathrm{I}) \quad y$-position in space $\left(L_{1}\right)$

REFZ(I) $\quad$ z-position in space (L)

RETARD_F_Retardation factor/distribution coefficient in the fracture (see IDIST)

RETARD_R Retardation factor/distribution coefficient in the rock (see IDIST)

SPACING Distance between consecutive waste packages (IPATCH $=1$ ) 
STD

Standard deviation $($ IPATCH $=0)$

THICK

Fracture thickness (L)

TIME(I)

$\mathrm{T}$-position in time $(\mathrm{T})$

TIML

Leach time $(\mathrm{T})$ (used if IBAND = 1)

TITLE

2 lines, $\leq 80$ characters per line, title of data set

TORT

Tortuosity $(\mathrm{L} / \mathrm{L})($ used if IDIST $=1)$

VELX

Average apparent velocity in the $\mathrm{x}$-direction $(\mathrm{L} / \mathrm{T})$

VELY

Average apparent velocity in the $y$-direction $(\mathrm{L} / \mathrm{T})$

Y0

Location of the center of Gaussian source (IPATCH $=0$ )

$++$

Computer dependent. 

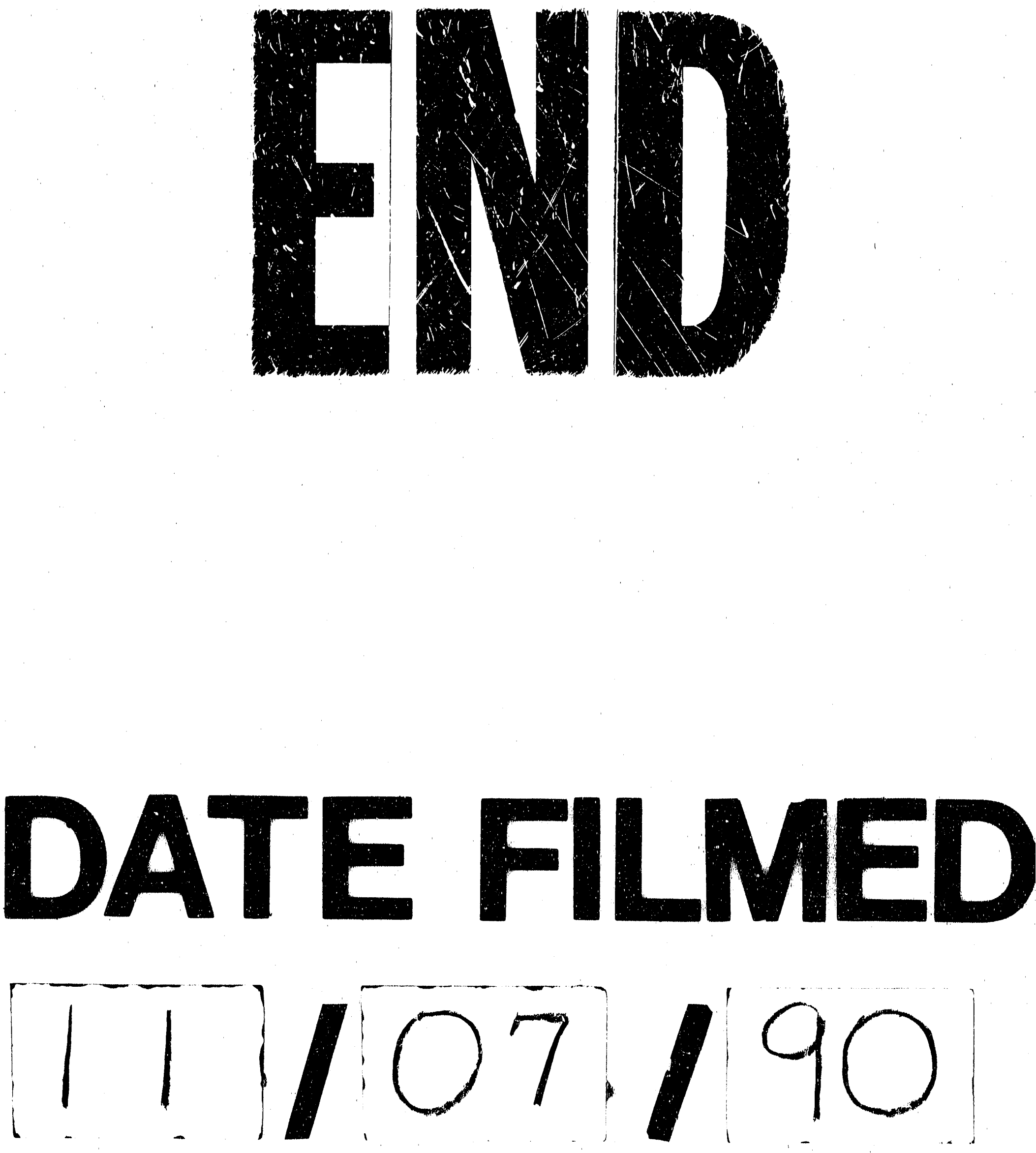
